\title{
Um Sistema de Gerenciamento de Workflow para Gestão de Documentos
}

\author{
Donizete Carlos Bruzarosco
}

Orientador: Prof. Dr. Paulo Cesar Masiero

Dissertação apresentada ao Instituto de Ciências Matemáticas e de Computação da Universidade de São Paulo, como parte dos requisitos para a obtenção do título de Mestre em Ciências - Área de Ciências de Computação e Matemática Computacional.

USP - São Carlos

Agosto de 1998 
A paz é fruto da caridade, da compreensão, da concórdia. Saibamos compreender, tolerar, desculpar... mesmo quando pensarmos que a razão está a nosso favor.

Tecla Merlo 


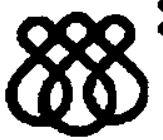

ICMC - USP

\section{AGRADECIMENTOS}

À Deus, pela luz e pela força para vencer os obstáculos.

Ao professor Paulo C. Masiero, pela oportunidade, orientação e ensinamentos.

À minha mãe Antonieta, pela educação que me proporcionou.

A minha esposa Sandra, pelo apoio e carinho.

Ao meu filho Andrei, pelos períodos de minha ausencia do seu convivio e pelo seu sorriso que sempre me motiva a lutar.

Aos professores Itana e Álvaro, do DIN - UEM, pela confiança e orientação.

Aos professores do ICMC - USP, pelos conhecimentos transmitidos.

Aos funcionários do ICMC - USP, pelo atendimento solícito.

À Universidade Estadual de Maringá e a CAPES, pelo apoio financeiro.

Ao grupo do projeto GDOC, em especial ao Willie, Janaina e Hamilton, pelo convívio e pelo intercâmbio técnico.

Aos meus amigos Alessando A. Santana e Sonia, pelas conversas agradáveis.

À todos que direta ou indiretamente colaboraram no desenvolvimento deste trabalho 
88

ICMC - USP

\section{Índice Analítico}

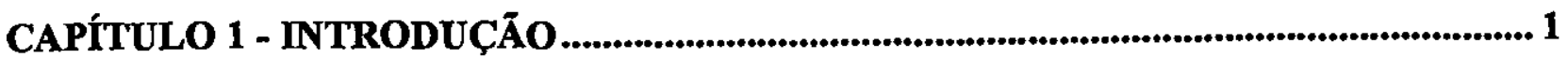

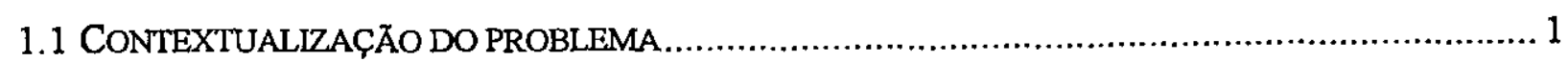

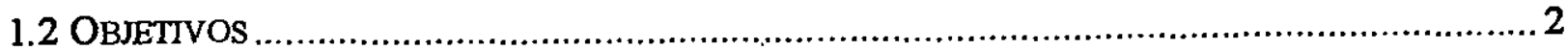

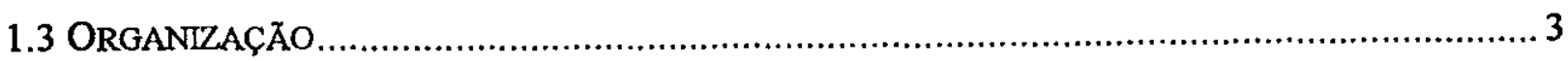

CAPÍTULO 2 - WORKFLOW E SEU GERENCIAMENTO ..................................................... 4

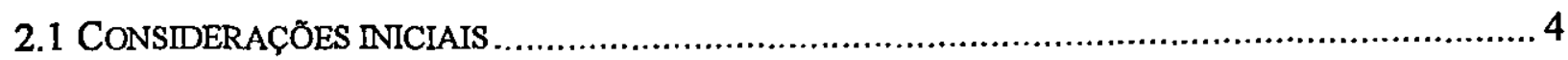

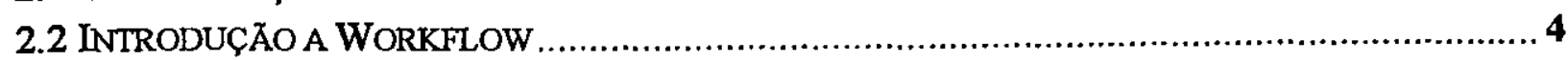

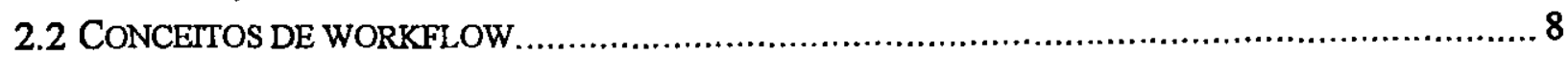

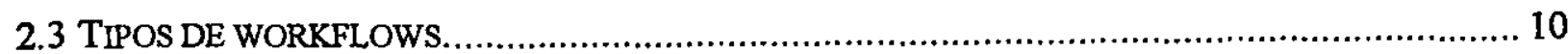

2.3.1 Caracterização de workflow conforme requisitos de implementação e automação.. 15

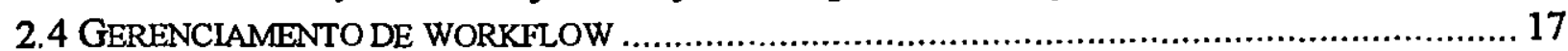

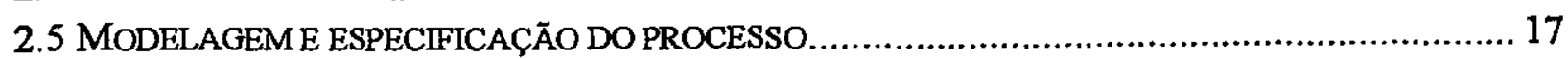

2.5.1 Métodos para modelagem do processo ............................................................... 18

2.6 TÉCNICAS E MODELOS CONCEITUAIS PARA MODELAGEM DE WORKFLOW ...........................22

2.6.1 Rede de controle de informaçäo (ICN) ................................................................ 22

2.6.2 Associação de gerenciamento de workflow (WFMC) ............................................. 25

2.6.3 Um método para análise de workflow .................................................................... 31

2.6.4 Modelagem conceitual de workflow ........................................................................ 34

2.6.5 Business Process Implementation - Building Workflow Systems............................ 37

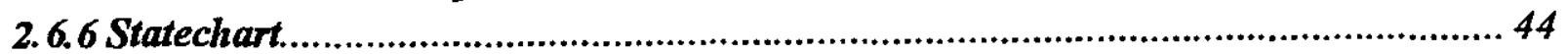

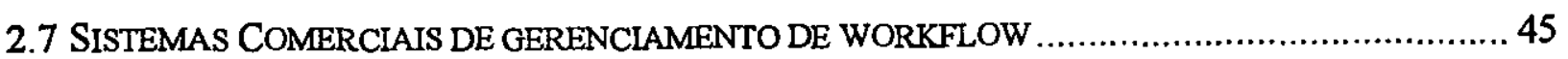

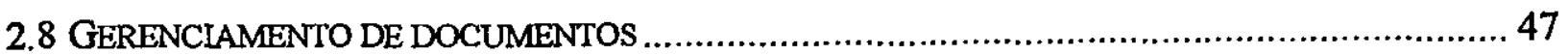

2.8.1 ISO 9000 para documentos ................................................................................4 48

2.9 EXEMPLOS DE SISTEMAS GERENCIADORES DE WORKFLOW E DE DOCUMENTOS ...................49

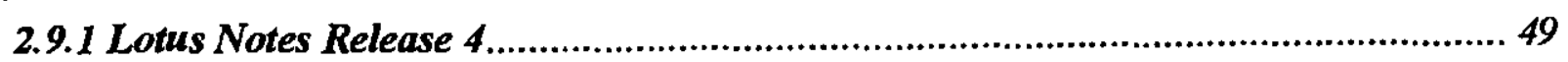

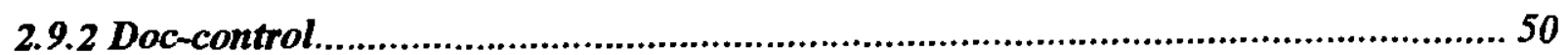

2.9.3 Process Builder- Analyst Edition........................................................................ 51

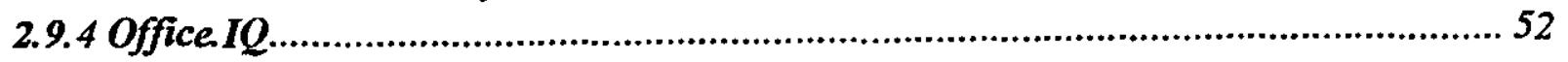

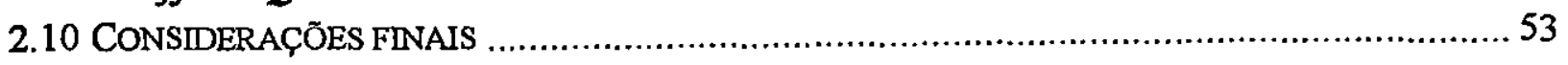


CAPITULO 3 - MODELO CONCEITUAL DE UM SISTEMA DE WORKFLOW PARA

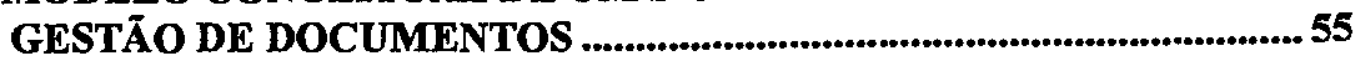

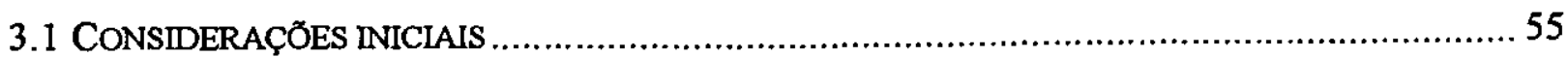

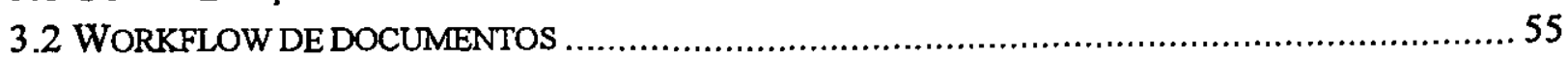

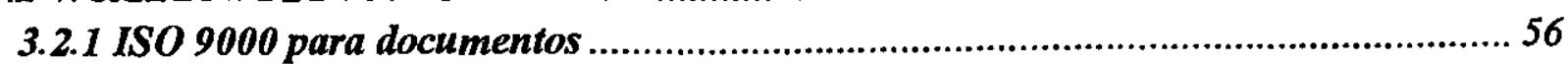

3.3 A ABORDAGEM DO SISTEMA DE WORKFLOW PARA GESTÃO DE DOCUMENTOS ............. 57

3.3.1 Workflow genérico e independente do módulo de autoria de documentos............... 57

3.3.2 Dados armazenados em um banco de dados relacional ........................................ 58

3.3.3 Reusabilidade de atividades $e$ especificação de ação automatica ............................ 58

3.3.4 Facilidade de especificação de workflow............................................................. 58

3.3.5 Interface homem-máquina padronizada ......................................................... 59

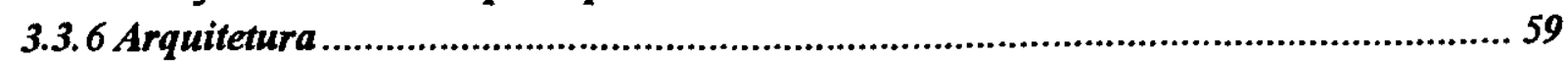

3.3.7 Portabilidade do sistema................................................................................. 59

3.3.8 Niveis de abstração de documentos .................................................................. 59

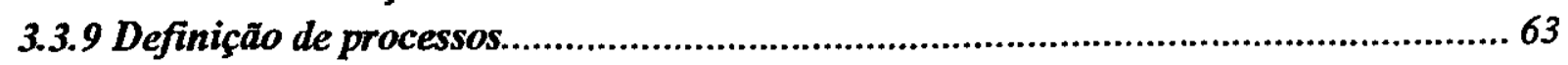

3.3.10 Atendimento das exigências ISO 9000 .........................................................6. 64

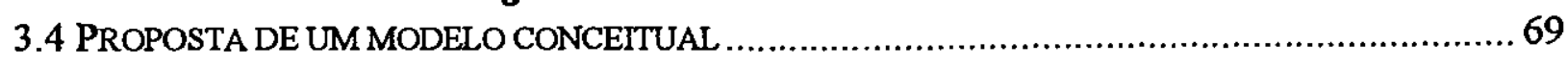

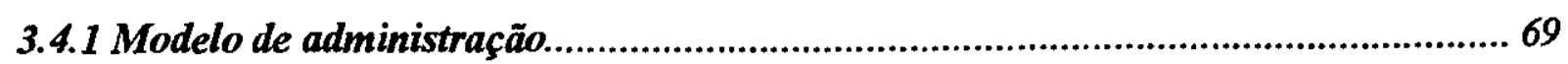

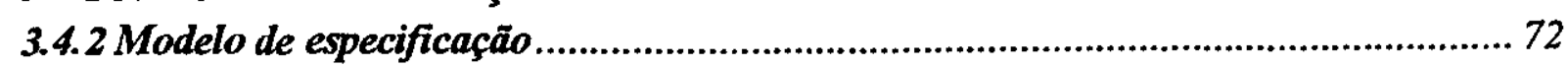

3.4.3 Modelo de instâncias de workflow................................................................... 73

3.5 LINGUAGENS PARA ESPECIFICAÇÃO DE WORKFLOW ................................................ 73

3.5.1 Linguagem de Roteamento de Atividades (LiRA).......................................... 73

3.5.2 Linguagem de Definição de Ação (LiDA) ...................................................... 81

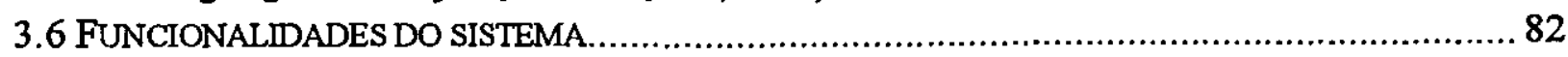

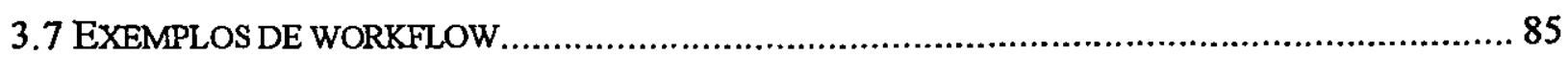

3.7.1 Workflow para criar tipo de documento .............................................................. 85

3.7.2 Workflow de uso para o tipo de documento de abertura de conta no sistema ......... 88

3.8 CONSIDERAÇõES FINAIS ............................................................................... 90

CAPÍTULO 4 - PROTÓTTPO DO SISTEMA DE WORKFLOW....................................91

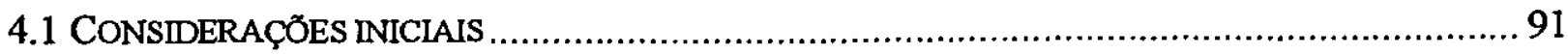

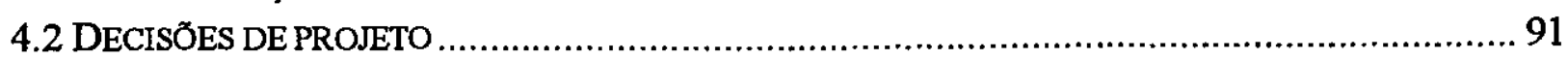

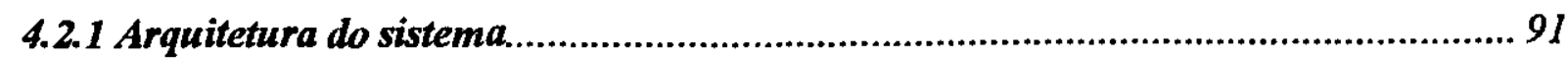

4.2.2 Linguagen' de programação................................................................... 93

4.2.3 Arquitetura interna do sistema .................................................................. 93

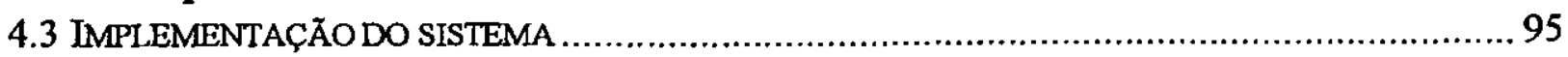

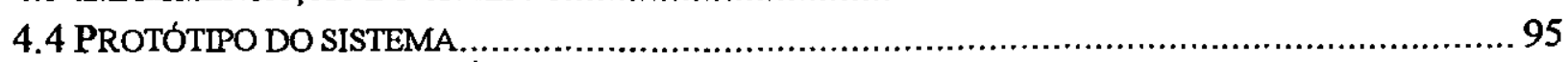

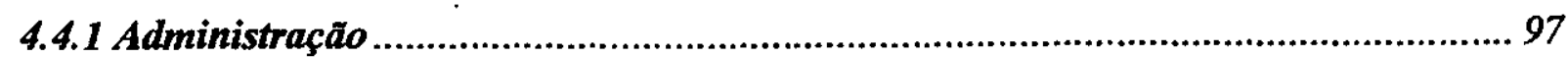

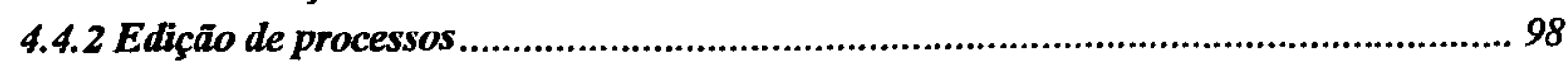

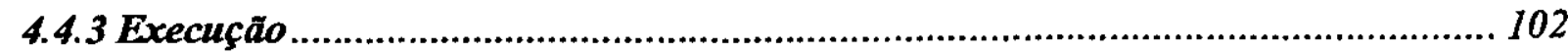

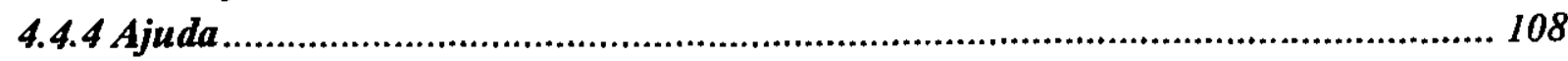

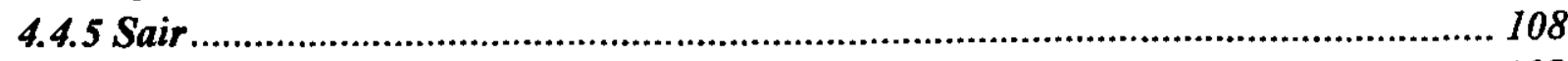

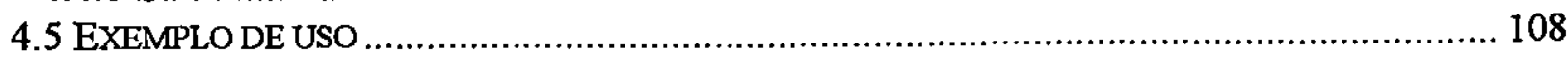


4.5.1 Especificaçäo de workflow.......................................................................... 109

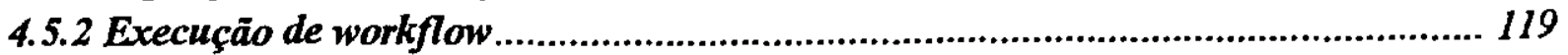

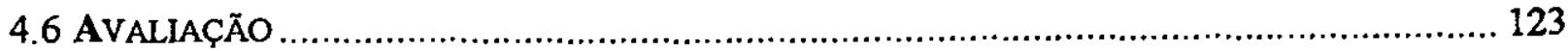

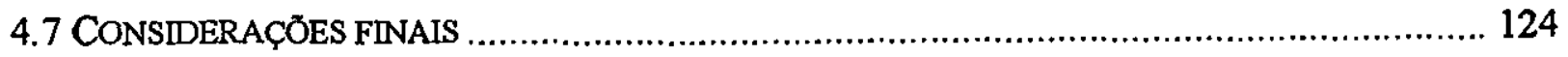

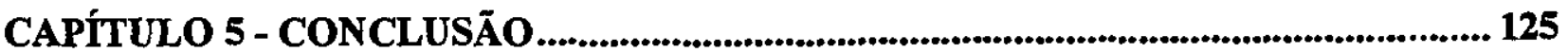

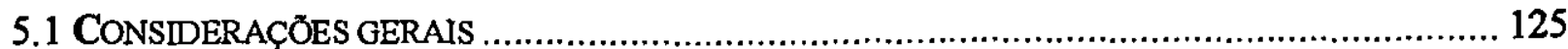

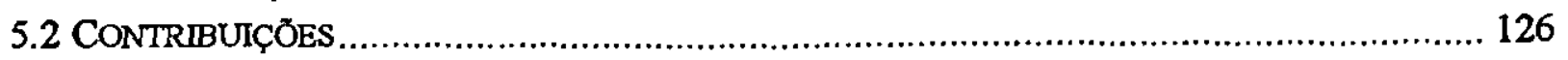

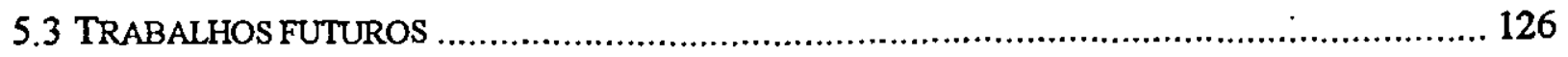

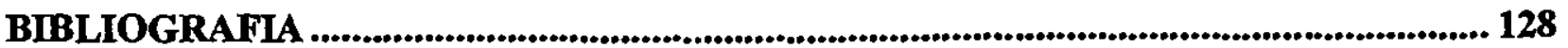

APÊNDICE A - ESPECIFTCAÇĀO DA GRAMÁTICA DA LINGUAGEM DE DEFINIÇÄO DE AÇÃO (LIDA) ....................................................... 132

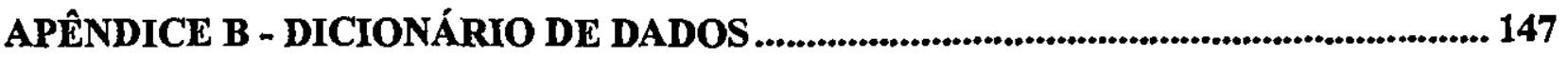

APÊNDICE C - IMPLEMENTAÇÃO RELACIONAL DO MODELO DE OBJETOS ... 172 APÊNDICE D - SITUAÇÃO FINAL DAS TABELAS APÓS SMMULAÇĀO DO SISTEMA ............................................................................................. 176 


\section{Índice de figuras}

Figura 2.1 Workflow de telecomunicação............................................................ 9

Figura 2.2 Workflow ad hoc de revisão de artigos ............................................. 12

Figura 2.3 Workflow administrativo para revisão de artigos.................................. 12

Figura 2.4 Workflow do processo de consulta médica........................................... 13

Figura 2.5 Caracterização de workflow conforme a imprensa comercial...................... 15

Figura 2.6 Questões de gerenciamento do workflow............................................ 17

Figura 2.7 Conversa pelo modelo de ação.............................................................. 19

Figura 2.8 Workflow para pedido de materiais...................................................... 19

Figura 2.9 Workflow para pedido de materiais..................................................... 20

Figura 2.10 Arquitetura conceitual do workflow.................................................. 23

Figura 2.11 Exemplo de modelagem com a ICN, do cálculo do I.R.......................... 24

Figura 2.12 Construtores gráficos da ICN.......................................................... 24

Figura 2.14 Relacionamentos entre a terminologia básica....................................... 26

Figura 2.15 Modelo de referência de workflow....................................................... 27

Figura 2.16 Meta-modelo de definição de processo básico........................................ 29

Figura 2.17 Construtores Gráficos WfMC....................................................... 30

Figura 2.18 Modelo conceitual de workflow......................................................... 31

Figura 2.19 Exemplo de procedimento de reclamação........................................... 33

Figura 2.20 Exemplo de workflow para alistamento militar........................................ 36

Figura 2.21 Simbologia gráfica para representar um workflow................................. 37

Figura 2.22 Diagrama de contexto para um sistema de workflow de escritório.............. 37

Figura 2.23 Exemplo de modelo de dados.......................................................... 40

Figura 2.24 Um modelo de interações de negócio..................................................... 43

Figura 2.25 Exemplo de modelagem com statechart, do cálculo do I.R...................... 44

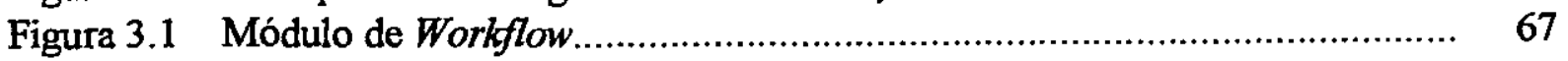

Figura 3.2 Módulo de Documentos................................................................. 68

Figura 3.3 Módulo de eespecificação.............................................................. 70

Figura 3.4 Módulo de execução de workflow..................................................... 71

Figura 3.5 Exemplo de representação gráfica de uma atividade item de trabalho.......... 74

Figura 3.6 Exemplo de representação gráfica de uma conexão direta.......................... 75

Figura 3.7 Exemplo de representação gráfica de um and-split................................ 76

Figura 3.8 Exemplo de representação gráfica de um and-join................................. 76

Figura 3.9 Exemplo de representação gráfica de um or-split................................ 77

Figura 3.10 Exemplo de representação gráfica de um or-join................................... 78

Figura 3.11 Exemplo de representação gráfica de uma iteração.................................. 79 
Figura 3.12 Exemplo de representação gráfica com terminadores.

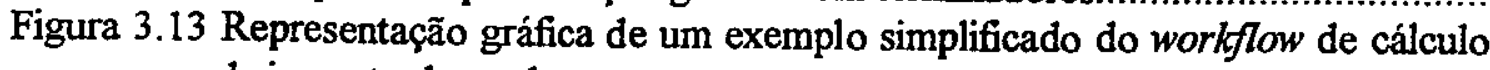
de imposto de renda.

Figura 3.14 Modelo de referência da WfMC ......................................................... 83

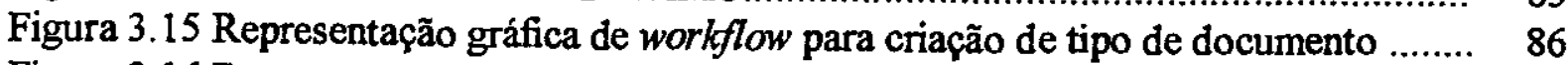

Figura 3.16 Representação gráfica do workflow de uso do tipo de documento de solicitação de abertura de conta.

Figura 4.1 Arquitetura do sistema.

Arquitetura interma do

Figura 4.2 Arquitetura interna do sistema....................................................... 94

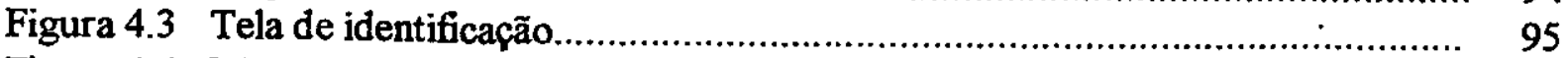

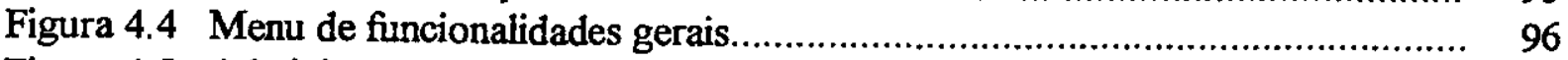

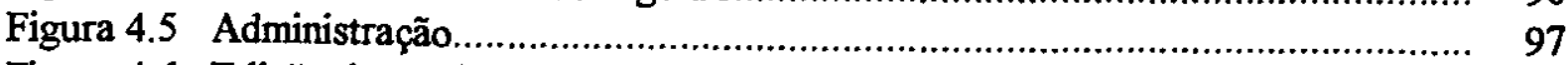

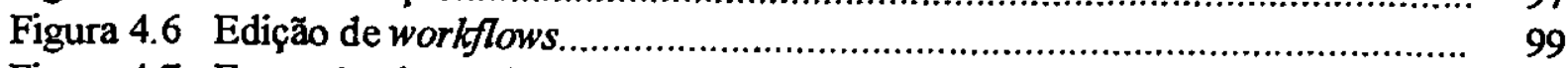

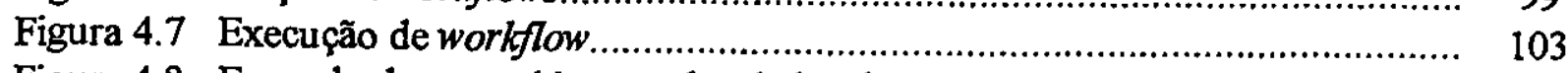

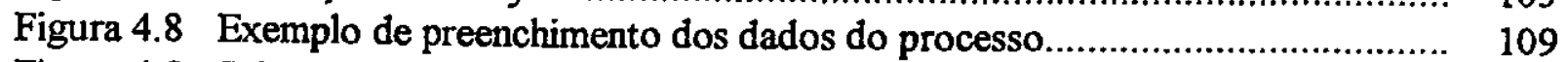

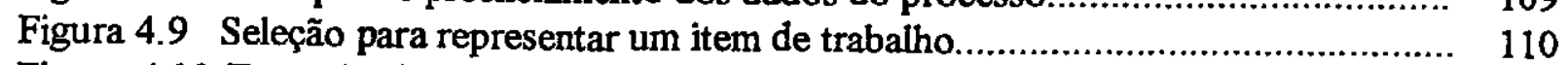

Figura 4.10 Exemplo de janela com informação de dados do item de trabalho "iniciar formulário".

110

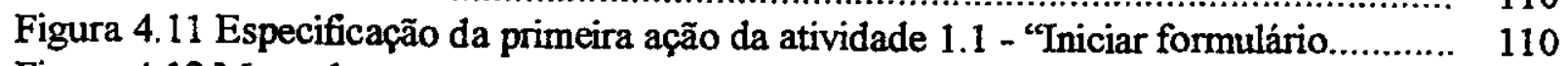

Figura 4.12 Menu de manutenção de variável..................................................... 111

Figura 4.13 Declaração da variável "observação" .................................................. 111

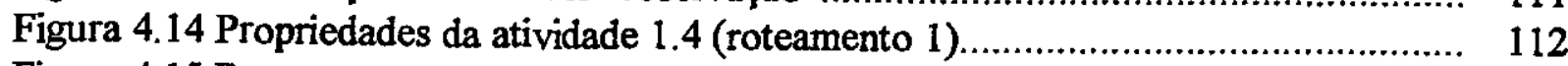

Figura 4.15 Representação gráfica do workflow para criar um tipo de documento............ 113

Figura 4.16 Janela com as propriedade do processo................................................. 114

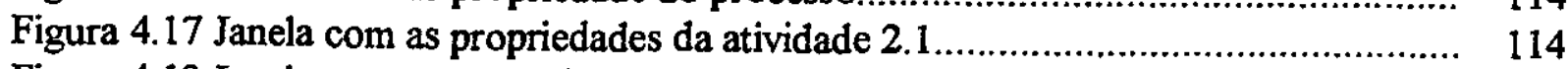

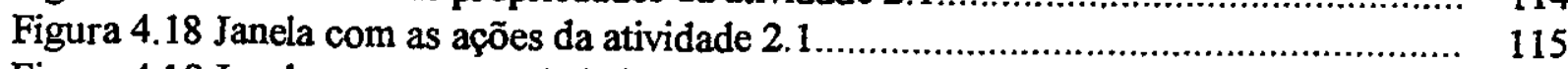

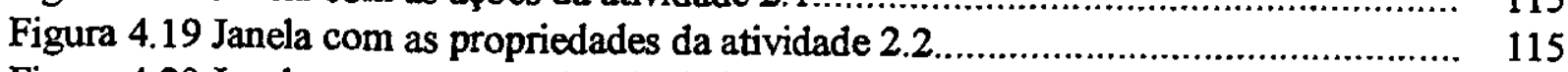

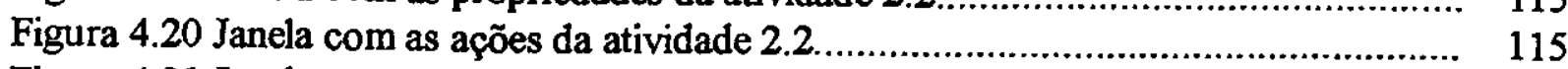

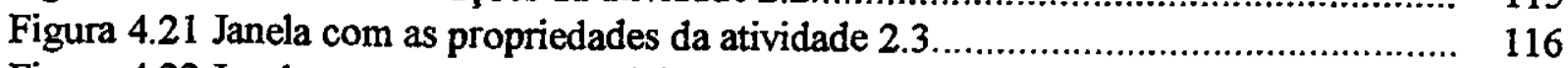

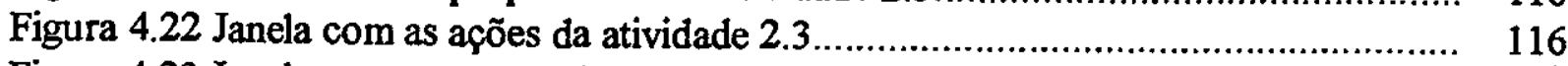

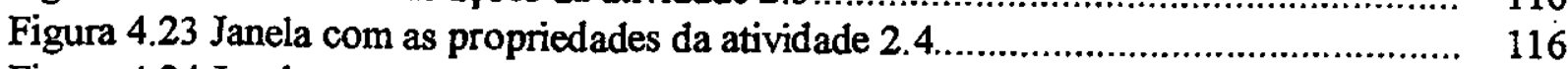

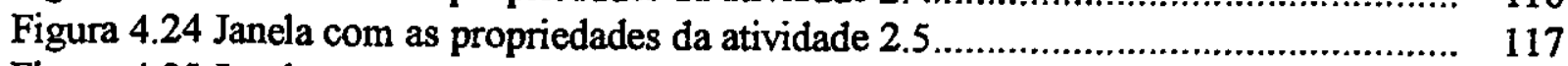

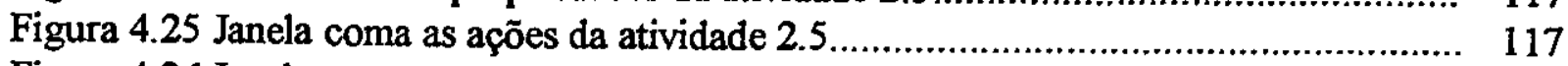

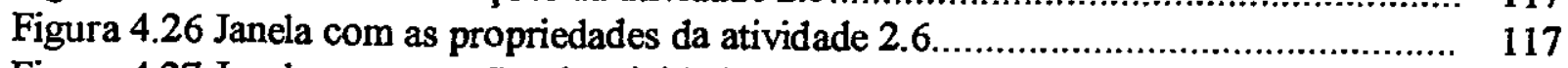

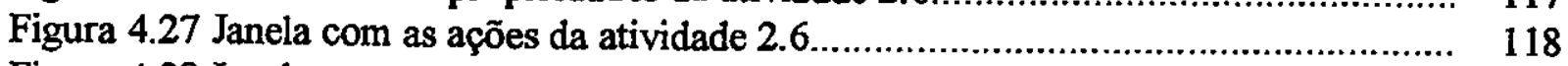

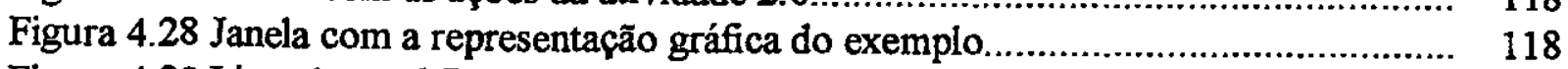

Figura 4.29 Lista de workflows para execução....................................................... 119

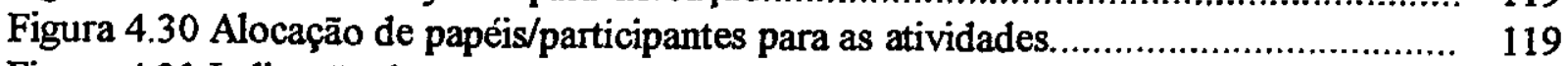

Figura 4.31 Indicação de um participante para um item de trabalho.................................. 120

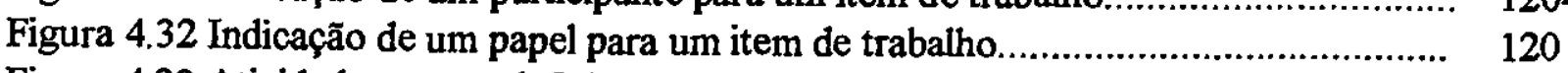

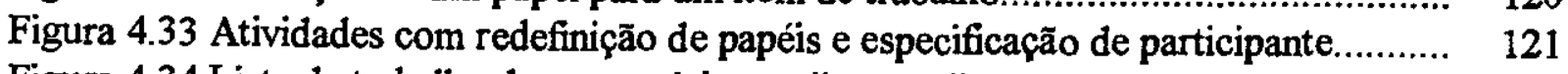

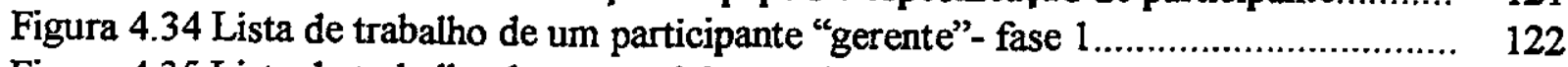

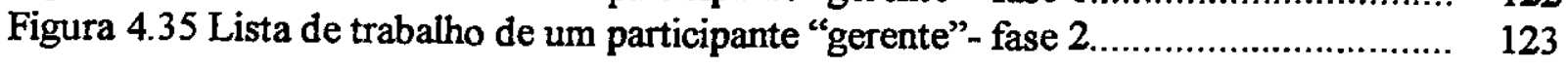




\section{Índice de tabelas}

Tabela 3.1 Níveis de abstração de documentos e sua manipulação 
ICMC - USP

\section{RESUMO}

Um Sistema de Gerenciamento de Workflow para apoiar a gestão de documentos, em especial daqueles controlados por sistemas de qualidade baseados nas normas da série ISO-9000, é proposto. O sistema desenvolvido, que é parte do projeto GDOC (Gestão de Documentos), incorpora características dos sistemas de workflow do tipo ad hoc e administrativo, estando também em conformidade com o modelo de referência proposto pela organização padronizadora "Workflow Management Coalition". O sistema tem arquitetura cliente-servidor e executa em ambiente operacional Windows $95 / \mathrm{NT}$. Sua interface pode ser visualizada por qualquer browser da web. Uma extensa revisão bibliográfica sobre aplicações, conceitos, tipos e produtos comerciais existentes, relacionados com workflow, é apresentada. Apresenta-se também a especificação conceitual do sistema e os resultados de uma simulação de exemplos reais de especificação e execução de workflow, os quais são validados pelo protótipo. Com isso, este trabalho mostra a potencialidade da tecnologia de workflow e do protótipo construído para auxílio às soluções de problemas enfrentados pelas organizações em um mercado globalizado. 
ICMC - USP

\section{ABSTRACT}

A Workflow Management System to support the administration of documents, especially of those controlled by quality systems based on the norms of the series ISO-9000, is proposed. The developed system, that it is part of the project GDOC, incorporates characteristics of workflow systems of the types ad hoc and administrative, being also in conformity with the reference model proposed by the standardization organization Workflow Management Coalition. The system has architecture client-server and executes in the operational environment Windows $95 / \mathrm{NT}$. Its interface can be visualized by any browser of the web. An extensive bibliographical revision about applications, concepts, types and existent commercial products, related with workflow, is presented. It is also presented the conceptual specification of the system and the results of a simulation of real examples of specification and workflow execution, which are validated by the prototype. With that, this work exhibits the potentiality of the workflow technology and of the prototype built to support the solution of the problems faced by organizations in a global market. 


\section{Capítulo 1}

ICMC - USP

\section{Introdução}

\subsection{Contextualização do problema}

A globalização da economia eleva o nível de concorrência entre as empresas sob todos os aspectos, exigindo constante redução de custos, melhora da qualidade de produtos, racionalização de processos e desenvolvimento rápido de novos produtos e serviços, assim como o aperfeiçoamento de recursos humanos e técnicos. A qualidade é um aspecto fundamental para que as empresas possam vencer nesse mercado competitivo. Exemplo disso é a exigência do certificado ISO-9000 (aplicação das normas da série ISO-9000 na organização, as quais representam modelos de garantia de qualidade, certificando os produtos e serviços).

Muitas organizações possuem grandes dificuldades com a coordenação de seu trabalho, em que procedimentos descritos em papel não são atualizados, compartilhados e usados na prática; o trabalho fica emperrado na mesa das pessoas por muito tempo; a responsabilidade por tarefas não é clara e é gasto muito esforço em ações corretivas devido a erros de procedimentos.

É de vital importância para o desempenho das tarefas organizacionais usar procedimentos de gestão de documentos que facilitem o controle da geração, do fluxo, das versões, das restrições de uso, das revisões e das desativações de documentos. $\mathrm{O}$ compartilhamento simultâneo, a rapidez na recuperação e a redução do volume e do fluxo de documentos também impacta significativamente o desempenho.

Para obter êxito, as empresas devem constantemente revisar e otimizar o modo de realizar seu negócio, bem como mudar os sistemas de informação e aplicações existentes para dar suporte ao processo de negócio. A tecnologia de workflow facilita essa tarefa, fornecendo métodos e software que proporcionam meios rápidos de (re)projeto e (re)implementação de processos e que auxiliam na solução dos problemas citados. 
As tecnologias de automação de escritório, gerenciamento de base de dados, correio eletrônico, gerenciamento de documento, gerenciamento de processo de software, modelagem do processo de negócio e modelagem de empresa são consideradas como as "ancestrais conceituais" do gerenciamento de workflow [Jab96]. A tecnologia de gerenciamento de workflow introduz uma qualidade nova ao agregar pessoas, organização e processos como uma unidade. Gerenciamento de workflow é geral e genérico, suportando diversas áreas de aplicação. Sistemas de gerenciamento de workflow são usados para: interações assíncronas distribuídas, as quais estejam fortemente relacionadas a sistemas de coordenação, sistemas de informação cooperativo e sistemas administrativos.

\subsection{Objetivos}

O sistema de workflow para gestão de documentos faz parte do projeto GDOC (Gestão de Documentos), que é multiinstitucional e cujo objetivo é a construção de um sistema gestor de hiperdocumentos envolvendo aquisição, autoria e fluxo de documentos (workflow), bem como a disponibilização destes na internet, a ser comercializado pela empresa Polo de Software de Curitiba e destinado primária-, mas não exclusivamente, a aplicações industriais no controle e armazenamento de documentos, levando em conta também o proposto a este respeito nas normas das séries ISO-9000. Os participantes e as respectivas áreas de trabalho no projeto são: ICMC USP, pesquisa e desenvolvimento de um protótipo de gerenciamento de workflow; UFRGS, pesquisa e desenvolvimento de um protótipo de autoria de hiperdocumento; PUC - Pr, pesquisa e desenvolvimento de um protótipo de aquisição de documentos; CEFET -Pr, pesquisa de workflow e criação de uma nova versão do sistema "DOC-CONTROL", comercializado atualmente pela empresa Polo de Software, que é o parceiro industrial envolvido no projeto.

Este trabalho discute a tecnologia envolvida com workflow na gestão de documentos e apresenta a arquitetura e o modelo conceitual de um sistema de workflow para gestão de documentos. O sistema envolve um módulo de autoria de documentos que está fora do escopo desse trabalho e um módulo de workflow, objeto desse trabalho. A integração entre esses módulos se dá de forma ad hoc ou através de API's (Aplication Programing Interface). Embora a ênfase do workflow aqui seja para gestão de documentos, este módulo é desenvolvido de forma genérica podendo ser utilizado em outras aplicações. 
Os aspectos mais importantes abordados neste trabalho são a arquitetura distribuida, o gerenciador de workflows, composto por um módulo especificador e um ambiente de execução de workflows, o armazenamento dos dados em uma base relacional e o suporte às exigências ISO9001, seção 4.5. Ë um sistema projetado para ser usado em uma rede local baseada no conjunto de protocolos da internet, denominada de intranet. Os usuários utilizam as funcionalidades do sistema por intermédio de um browser da $W E B$. Outros aspectos de destaque do sistema são a utilização de uma linguagem de representação gráfica estendida dos componentes gráficos apresentados pela Workflow Management Coalition (WfMC) e de uma linguagem de definição de açס̃es, estendida do SQL (Structured Query Language) para especificação de pré-condições ações e expressão de roteamento de atividades.

\subsection{Organização}

Este trabalho está organizado em 5 capítulos e 4 apêndices, cujo conteúdo é descrito a seguir.

Este capitulo é introdutório e descreve a contextualização do problema e os objetivos a serem atingidos. 0 capítulo 2 faz uma revisão bibliográfica sobre workflow e seu gerenciamento, conceituando-os, bem como descrevendo técnicas de modelagem e modelos de workflow. Comenta as principais caracteristicas de sistemas comerciais de gerenciamento de workflow, os recursos do gerenciamento de documentos e a norma ISO-9001, seção 4.5, bem como os recursos de alguns sistemas gerenciadores de workflows e documentos existentes no mercado. No capítulo 3, são descritas as principais características e requisitos do sistema desenvolvido e como o sistema pretende atender às exigências ISO-9001, seção 4.5. Também é proposto um modelo conceitual do sistema e são definidas duas linguagens para especificação de workflow: LIRA e LIDA, além de listar as funcionalidades e exemplificar aplicações de workflows com o sistema. O capítulo 4 detalha as decisões de projeto e mostra como as funcionalidades do sistema são oferecidas aos usuários por intermédio de sua interface, bem como descreve exemplos de uso de especificação e execução de workflows utilizando o protótipo. 


\section{Workflow e seu Gerenciamento}

\subsection{Considerações iniciais}

Existem várias definições para workflow e muitos métodos para o desenvolvimento de sistemas gerenciadores de workflow, os quais geralmente possuem características de aplicação para certos domínios. Os sistemas gerenciadores de workflow utilizam plataformas diferentes de acordo com sua área de aplicação.

Este capítulo enfoca os tipos de workflow aplicados à área comercial, que é o domínio desse trabalho. Neste caṕtulo, inicialmente na seção 2.2 são apresentadas definições de workflow, na seção 2.3 os tipos de workflows destacados pela imprensa comercial e na seção 2.4 um modelo de gerenciamento de workflow. Posteriormente, nas seções 2.5 e 2.6 revisa algumas técnicas e modelos conceituais para modelagem de workflow, na seção 2.7 as características de sistemas comerciais de gerenciamento de workflow e na seção 2.8 os recursos para gerenciamento de documentos e as normas ISO 9000 para documentos. Finalmente, na seção 2.9 mostra alguns exemplos de sistemas gerenciadores de workflow e de documentos existentes no mercado, comentando seus principais recursos.

\subsection{Introdução a Workflow}

O conceito de workflow foi desenvolvido da noção de processo em manufatura e no escritório. Tais processos existem desde o inicio da industrialização e são produtos de pesquisas para aumentar a eficiência, concentrando-se nos aspectos de rotina das atividades de trabalho. Eles, tipicamente, separam atividades de trabalho em tarefas bem definidas, papéis, regras e 
procedimentos, os quais regulam a maioria do trabalho na manufatura e no escritório. Inicialmente, os processos eram realizados inteiramente por seres humanos, pela manipulação de objetos físicos. Com a introdução da tecnologia da informação, os processos nos locais de trabalho foram parcialmente ou totalmente automatizados por sistemas de informação, por exemplo, programas de computador executando tarefas e fazendo cumprir regras que foram previamente implementadas por pessoas.

Os processos em uma organização são categorizados em: processos de materiais, processos de informação e processos de negócio'. O escopo de um processo de material reúne componentes físicos e entrega de produtos físicos. Isto é, os processos de materiais especificarn tarefas humanas que estão enraizadas no mundo físico. Tais tarefas incluem movimentar, armazenar, transformar, medir e reunir objetos físicos. Os processos de informação compõem-se de tarefas automatizadas (por exemplo, tarefas executadas por programas) e tarefas parcialmente automatizadas (por exemplo, tarefas executadas por seres humanos interagindo com computadores), que criam, processam, gerenciam e fornecem informação. Tipicamente, um processo de informação está enraizado em uma estnutura da organização e/ou no ambiente existente de sistemas de informação. As tecnologias de base de dados, processamento de transação e sistemas distribuídos proporcionam a infra-estrutura básica de apoio aos processos de informação. Os processos de negócio são descrições centradas no mercado das atividades da organização, implementadas como processos de materiais e/ou informação. Isto é, um processo de negócio é criado para cumprir um contrato de negócio ou para satisfazer a uma necessidade especíica do cliente. Assim, a noção de processo de negócio é conceitualmente de mais alto nível do que a noção de processo de informação ou material.

Quando uma empresa modela seu negócio em termos de processos de negócio, ela pode fazer reengenharia em cada processo para racionalizá-lo ou adaptá-lo a novas necessidades. A motivação para se fazer o reprojeto do processo de negócio inclui aumento da satisfação do cliente, melhora da eficiência das operações de negócio, aumento da qualidade dos produtos, redução dos custos e estudo de novos desafios e oportunidades para o negócio, mudando os serviços existentes ou introduzindo serviços novos. Reengenharia do processo de negócio envolve explicitamente reconsideração e reprojeto do processo de negócio. Ele é desenvolvido

\footnotetext{
${ }^{1}$ Medina-Mora, R., Wong, H. e Flores, P. - The Action Workflow Approach to Workflow Management Citado em [Geo95].
} 
antes que sistemas de informação e computadores sejam usados para automação destes processos. Reengenharia do processo de informação é uma atividade complementar da reengenharia do processo de negócio. Ela determina como usar sistemas de informação legados e novos e como usar computadores para automatizar a reengenharia do processo de negócio. As duas atividades podem ser executadas iterativamente para prover feedback mútuo. Enquanto o reprojeto do processo de negócio pode explicitamente tratar questões de satisfação de clientes, a reengenharia do processo de informação pode tratar questōes de eficiência e custos de sistemas de informação e aproveitamento dos avanços tecnológicos.

Workflow é um conceito fortemente relacionado com a reengenharia e automação de negócios e processos de informação em uma organização. Um workflow pode descrever as tarefas do processo de negócio em um nível conceitual necessário para entendê-lo, avaliá-lo e reprojetálo. Por outro lado, um workflow pode capturar tarefas do processo de informação em um nivel que descreva os requisitos do processo para a funcionalidade do sistema de informação e habilidades humanas. A distinção entre essas duas perspectivas de workflow nem sempre é feita e algumas vezes esse termo é usado para descrever um deles ou ambos, com perspectivas dos sistemas de informação e de negócio.

Gerenciamento de workflow (WFM) é uma tecnologia de apoio à reengenharia dos processos de informação e de negócio, que envolve:

1. Definir workflows, por exemplo, descrever aqueles aspectos de um processo que sejam relevantes para controlar e coordenar a execução de suas tarefas (e possivelmente as habilidades de indivíduos ou de sistemas de informação requeridas para executar cada tarefa), e

2. Prover um rápido (re)projeto e (re)implementação dos processos, conforme as necessidades do negócio e das mudanças dos sistemas de informação.

Para efetivamente dar apoio ao gerenciamento de workflow, as organizaçōes devem evoluir seu ambiente de computação existente para um novo ambiente distribuído que:

- seja orientado a componentes para, por exemplo, apoiar a integração e interoperabilidade entre componentes fracamente acoplados correspondendo a sistemas heterogêneos, autônomos, e/ou distribuído (HAD), herdados e novos,

- apóie aplicações de workflow com implementações de processos de negócios ou informações, acessando múltiplos sistemas $\mathrm{HAD}$, 
- assegure a corretitude e confiabilidade das aplicações na ocorrência de concorrência e falhas, e

- apoie a evolução, substituição e adição de aplicações de workflow e de sistemas componentes, quando processos são reprojetados.

Muitos sistemas comerciais dão apoio ao gerenciamento de workflow, tal como o software de WFM da Genesis, que automatiza o processo de negócio dirigido a documento ${ }^{2}$. Alguns dos produtos iniciais eram extensões do gerenciamento de software e de imagens de documentos ${ }^{3}$. Uma estimativa da rápida expansão do tamanho do mercado, de menos de \$100 milhões em 1991, para em tomo de $\$ 2.5$ bilhões em $1996^{4}$, atraiu um interesse significativo de companhias de software, gerando uma grande quantidade de novos produtos para WFM. Atualmente, sistemas de WFM comerciais para automação de escritórios dão apoio ao gerenciamento de documentos, imagens, e/ou coordenação humana, colaboraçã่o e co-decisão. Embora muitos desses sistemas de WFM reunam alguns dos requisitos acima, eles permitem uma interoperabilidade limitada (em termos dos tipos de sistemas HAD que eles integram e tarefas que eles apoiam), não podem assegurar corretitude e confiabilidade das aplicações em situações de concorrência e falhas e possuem problemas de desempenho e escalabilidade. Portanto, os sistemas de WFM atuais não comportam efetivamente aplicações de workflow em grandes empresas [Geo95].

Para solucionar os problemas citados acima em relação a sistemas de WFM, as tecnologias de gerenciamento de objetos distribuídos e gerenciamento de transação customizada (CTM), devem ser combinadas com os recursos existentes dos sistemas WFM comerciais. $O$ gerenciamento de objetos distribuídos $(\mathrm{DOM})^{5}{ }^{6}$ apoia a interoperabilidade e integração de sistemas HAD e aplicações que implementam os processos de negócio ou de informação. Um DOM permite aos sistemas de WFM tratar substituição, migração e evolução de sistemas HAD, ou mudanças na sua funcionalidade e dados. Adicionalmente o DOM provê um modelo de objetos que facilita gerenciar complexidade pelo uso de abstração, herança e polimorfismo. Outras abordagens de computação distribuída que atualmente oferecem menor nível de

\footnotetext{
${ }^{2}$ Smith, T. - The Future of Work flow Software. Citado em [Ge095].

${ }^{3}$ Black, D. - Workflow Software: A Layman's Handbook, Part 1. Citado em [Geo95].

${ }^{4}$ McCready, S. - There is more than one kind of Work-flow Software. Citado em [Geo95].

${ }^{5}$ Manola, F., Heiler, S., Georgakopoulos, D. - Distributed Object Management. Citado em [Geo95].

${ }^{6}$ OMG. - Object Transaction Service. Citado em [Ge095].
} 
interoperabilidade do que o DOM podem também ser úteis para prover interoperabilidade para um WFM. O gerenciamento de transação customizada assegura a corretitude e confiabilidade das aplicações, implementando processos de negócio ou de informação, enquanto permite a funcionalidade que cada processo particular requer (por exemplo, isolamento, coordenação ou colaboração entre tarefas). O CTM também trata de mudanças nos requisitos de corretitude e confiabilidade do processo e das garantias de corretitude e confiabilidade providas pelos sistemas $\mathrm{HAD}$.

\subsection{Conceitos de workflow}

Há pouco acordo sobre o que seja um workflow e quais características um sistema de gerenciamento de workflow deve ter. O termo workflow pode ser usado por pessoas para se referir ao processo de negócio, especificação de um processo, software que implementa e automatiza um processo, ou software que simplesmente dá apoio à coordenação e colaboração de pessoas que implementam um processo. Há ainda várias definições de workflow, provenientes dos vendedores de software que produzem produtos de workflow.

Rusinkiewicz, em [Rus94], define workflow, como atividades envolvendo a execução coordenada de múltiplas tarefas executadas por entidades de processamento diferentes. Uma tarefa define algum trabalho a ser feito e pode ser especificada de várias maneiras, incluindo descrição textual em um arquivo ou em uma mensagem de correio eletrônico, um formulário ou um programa de computador. A entidade de processamento que executa as tarefas pode ser uma pessoa ou um sistema de software (por exemplo, um carteiro, um programa de aplicação ou um sistema gerenciador de base de dados). Especificação de um workflow envolve descrever aqueles aspectos das tarefas que o constitui (e as entidades de processamento que as executa) que são relevantes para controlar e coordenar sua execução. Também é necessária a especificação dos relacionamentos (por exemplo, dependências) entre tarefas e seus requisitos de execução. Estes podem ser especificados usando uma variedade de paradigmas (por exemplo, regras, restrições ou programas). Essas definições citadas não deixam claro o relacionamento entre os termos usados pelas pessoas.

Georgakopoulos, em [Geo95], define workflow como uma coleção de tarefas organizadas para concluir algum processo de negócio (por exemplo, processo de pedido de compra por 
telefone, solicitação de serviço telefônico, processamento de pedido de seguro). Uma tarefa pode ser executada por um ou mais sistemas de softwares, um ou vários seres humanos, ou por uma combinação destes. Tarefas humanas incluem interação intensa com computadores (por exemplo, para digitar comandos de entrada) ou esporádica (por exemplo, somente o controle do progresso da tarefa). Exemplos de tarefas são a atualização de um arquivo ou base de dados, a geração ou envio de uma conta, a instalação de um cabo, etc. Para uma coleção de tarefas, um workflow define a ordem de execução das tarefas ou as condições sob as quais as tarefas devem ser executadas, sincronização de tarefas e fluxo de informação (fluxo de dados).

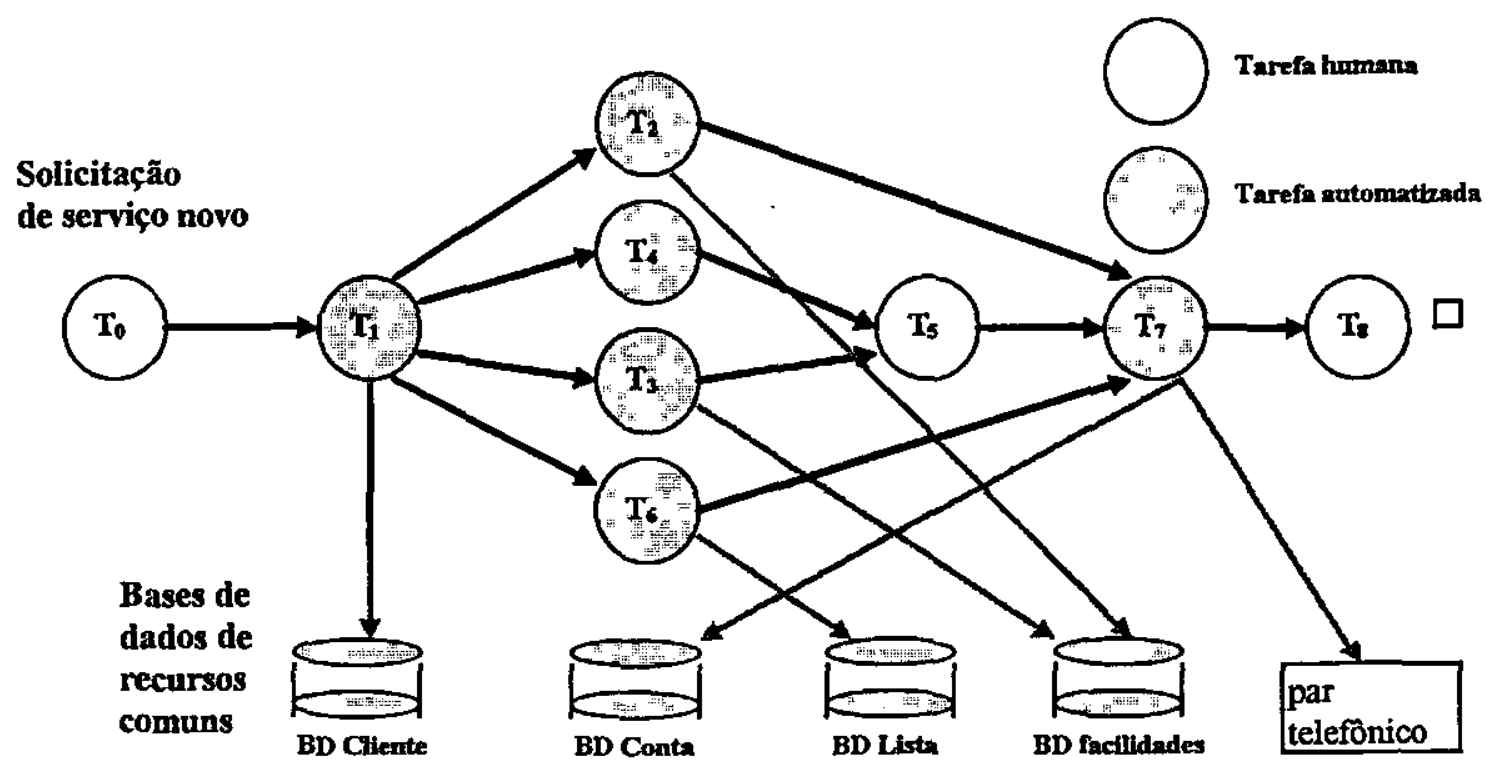

Figura 2.1 Workflow de telecomunicação

A figura 2.1 apresenta um workflow de telecomunicação, o qual requer acessos a uma base de dados compartilhada. O workflow de solicitação de serviço novo modela o processo de solicitação de serviço telefônico para um novo cliente. O workflow inicia quando um cliente da companhia telefônica solicita instalação de serviço telefônico. A tarefa $T_{0}$ envolve a informação a respeito do cliente coletada pelo operador. Quando são coletados os dados necessários do cliente, a tarefa $T_{1}$ é executada para verificar se a informação fornecida pelo cliente é precisa e cria um registro da ordem de serviço. Na finalização da tarefa $T_{1}$, as tarefas $T_{2}, T_{3}$ e $T_{4}$ são iniciadas para executar três atividades. $\mathrm{O}$ objetivo de uma atividade solicitada é construir o circuito local de um cliente, para o par telefônico de telefone apropriado e alocar equipamento para conectar o circuito. Somente uma destas três tarefas iniciadas deveria ser executada, pois 
todas resultarão em um circuito completado, isto é, um conjunto de linhas e equipamentos que conectam o cliente à rede telefônica (este requisito não é representado na figura 2.1). A tarefa $\mathrm{T}_{2}$ tenta prover uma conexão usando facilidades existentes, tais como linhas e pares telefônicos das centrais. Se a tarefa $T_{2}$ for bem sucedida, o custo da solicitação é baixo, isto é, a conexão solicitada pode ser estabelecida alocando recursos existentes. Contudo, a finalização com sucesso dessa tarefa pode não ser possível se as facilidades não estiverem disponíveis. As tarefas $\mathrm{T}_{3}$ e $\mathrm{T}_{4}$ possuem os mesmos objetivos que a tarefa $T_{2}$, mas envolvem caminhos diferentes para instalações fisicas de novas facilidades. A tarefa $T_{s}$ requer trabalho manual para instalação dos recursos. A tarefa humana T5 é iniciada pelas instruções de instalação providas pelos engenheiros (por exemplo, via terminal) e é completada quando os engenheiros fornecem os dados necessários para a finalização do trabalho. A tarefa $\mathrm{T}_{6}$ envolve mudanças na lista telefônica, enquanto a tarefa $\mathrm{T}_{7}$ atualiza a central telefônica do telefone para ativar o serviço e então gerar uma conta. Finalmente, a tarefa $T_{8}$ envolve um operador humano que telefona ao cliente para informar-lhe do estabelecimento do serviço solicitado e verificar se o serviço provido atende ao pedido do cliente. Alem das tarefas envolvidas, o workflow define as seguintes dependências: (i) a tarefa $T_{1}$ inicia após a finalização da tarefa $T_{0}$, (ii) as tarefas $T_{2}, T_{3}, T_{4}$ e $T_{6}$ podem ser executadas concorrentemente após a tarefa $T_{1}$ ser completada, (iii) a tarefa $T_{5}$ deve iniciar após a finalização das tarefas $T_{3}$ e $T_{4}$, (iv) $T_{7}$ é executada após a finalização de $T_{2}, T_{5}$, e $T_{6}$ e (v) $T_{8}$ inicia após a tarefa $\mathrm{T}_{7}$ completar.

\subsection{Tipos de workflows}

Várias organizações produziram sistemas de gerenciamento de workflow (WFMS) com recursos para especificar e executar workflows, envolvendo seres humanos e sistemas HAD'.

As publicações comerciais normalmente fazem distinção entre três tipos de workflow: ad hoc, administrativo e de produção. Esses tipos de workflow normalmente abrangem:

- repetitividade e previsibilidade de tarefas e fluxos de trabalhos,

- como o workflow é iniciado e controlado, por exemplo, de controle humano para automatizado, e

${ }^{7}$ McCarthy, D. e Sarin, S. - Workflow and Transactions in Inconcert. Citado em [Ge095]. 
- requisitos para funcionalidade do WFMS.

Workflows ad hoc executam processos de escritório, tais como documentação de produto ou propostas de vendas, onde não há um conjunto padrão para passar a informação entre pessoas $^{89}$. Tarefas de workflow ad hoc tipicamente envolvem coordenação, colaboração ou codecisão humana ${ }^{10}$. Assim, a ordem e a coordenação das tarefas em um workflow ad hoc não são automatizadas e sim controladas por seres humanos. Além do mais, decisõès sobre a ordem das tarefas e sobre coordenação são tomadas durante a execução do workflow. Workflows ad hoc tipicamente envolvem grupos pequenos de profissionais para execução de atividades de curta duração, as quais requerem uma solução rápida de workflow, por exemplo, apoio ao processo de preparação do programa de uma conferência profissional.

Os sistemas de gerenciamento de workflow, para apoiarem workflow ad hoc, devem prover funcionalidade para facilitar a coordenação, colaboração e co-decisão humana. A funcionalidade para controlar a ordem das tarefas geralmente não é apoiada por tais WFMSs. Usuários de um workflow ad hoc necessitam acessar o WFMS para determinar que o trabalho foi completado. WFMSs ad hoc não são missão crítica para o negócio da organização, isto é, o fracasso periódico desses workflows não interfere significativamente com o processo geral de negócio. A infra-estrutura tecnológica atualmente usada pelos WFMSs vai desde o correio eletrônico até sistemas de conferência e agendas em grupo. Os WFMSs ad hoc normalmente utilizam uma base de dados (proprietária) para armazenar informação compartilhada (por exemplo, documentos, tais como formulários de revisão de conferência ou artigos). Os WFMSs que apoiam workflow ad hoc também são chamados de groupware.

A figura 2.2 ilustra um workflow ad hoc simplificado, envolvendo o processo de revisão de artigos para uma conferência. O processo de revisão seleciona revisores e distribui os artigos aos revisores selecionados; os revisores selecionados executam as revisð̄es e colaboram na produção de um documento de revisão conjunto; e, finalmente, as revisões são enviadas aos autores. Esse é um workflow ad hoc porque ele envolve: (i) negociação para selecionar os revisores e (ii) colaboração entre os revisores na produção de uma revisão conjunta. Além do mais, revisões adicionais de artigos podem não ser executadas pelos mesmos revisores.

\footnotetext{
${ }^{8}$ Black, D. - Workflow Software: A Layman's Handbook, Partl. Citado em [Geo95].

${ }^{9}$ Korzeniowski, P. - Workflow Software Automates Processes. Citado em [Geo95].

${ }^{10}$ Schael, T. e Zeller, B. - Design Principles for Cooperative Office Support Systems in Distributed Process Management. Citado em [Ge095].
} 


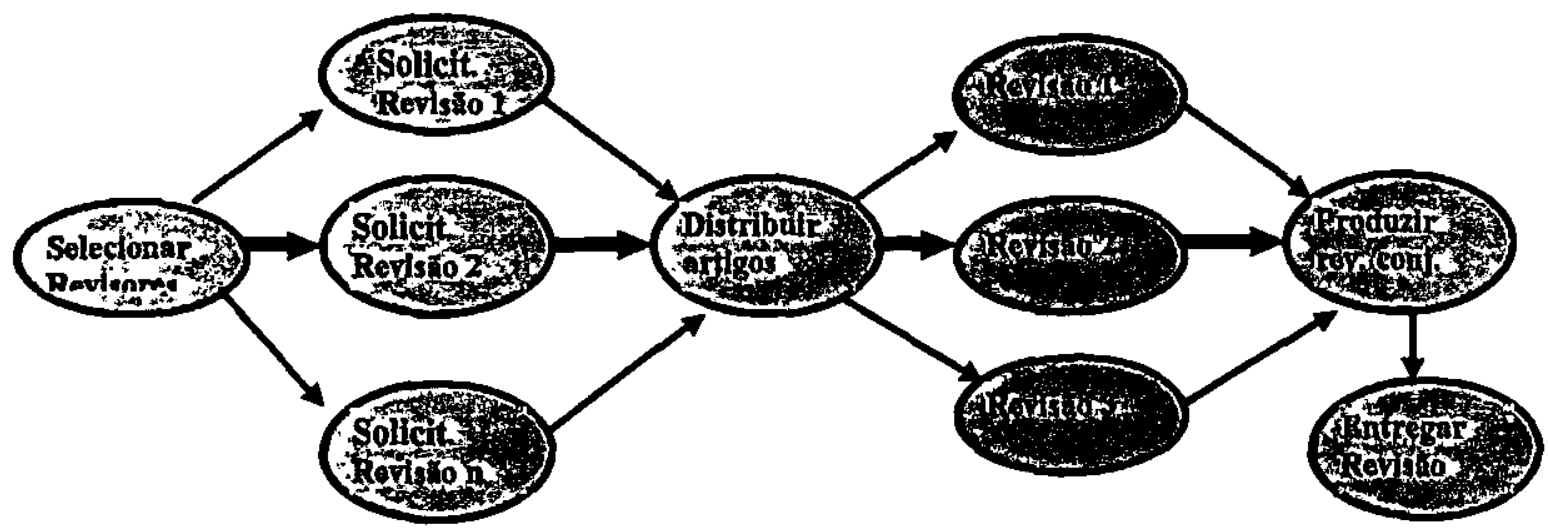

Figura 2.2 Workflow ad hoc de revisão de artigos

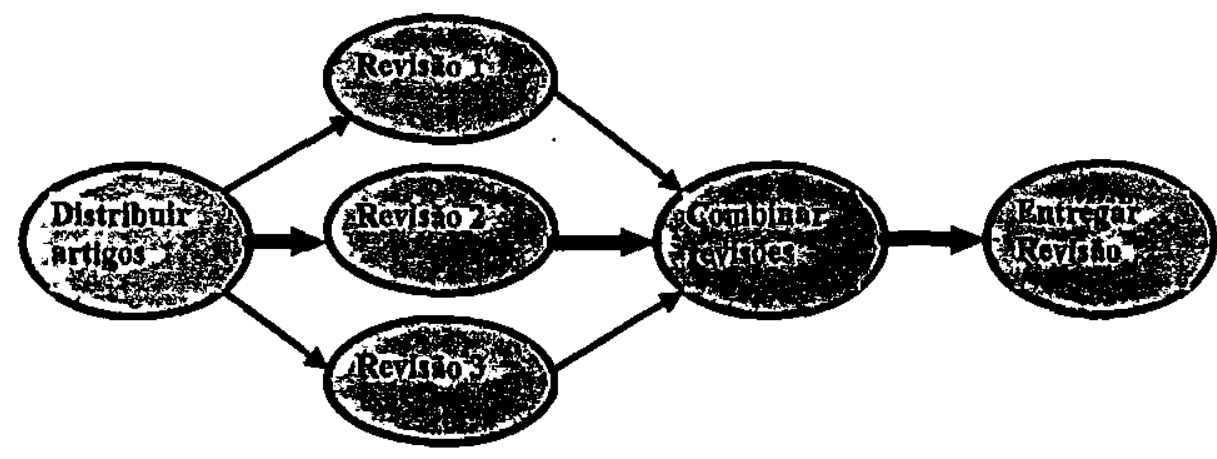

Figura 2.3 Workflow administrativo para revisão de artigos

Workflow administrativo envolve processos repetitivos e previsíveis com regras de coordenação de tarefa simples, tais como rotear um relatório de despesas ou solicitação de viagem por intermédio de um processo de autorização. A ordem e a coordenação de tarefas em workflows administrativos podem ser automatizadas. Um WFMS que apóia workflow administrativo trata do roteamento de informação simples e funções de aprovação de documentos, tais como aquelas encontradas em planejamento de viagens e solicitações de compras. Workflows administrativos não abrangem um processo de informação complexo e não requerem acesso a sistemas de informação múltiplos usados no. apoio à produção e/ou serviços a clientes. Os WFMSs administrativos geralmente não atuam na missão crítica do negócio. A infra-estrutura tecnológica que eles atualmente usam é tipicamente baseada em correio eletrônico.

Considerando novamente o processo de revisão de artigos, agora assumindo que os revisores são conhecidos no progresso do processo (por exemplo, os mesmos revisores são usados para as revisões de todos os artigos) e que eles não colaboram na produção de uma 
revisão conjunta. Ao invés, eles produzem revisões individuais que são consideradas pelo editor (por exemplo, o presidente da comissão de programa), que toma a decisão final. Sob essas suposições o workflow de revisão de artigos torna-se um workflow administrativo, tal como representado na figura 2.3 .

Em um workflow administrativo os usuários são ativamente impelidos a executar suas tarefas. Contudo, revisores usando um workflow ad hoc necessitaram acessar o WFMS para determinar que o trabalho foi finalizado e revisores usando um WFMS administrativo podem receber email com instruções de revisões junto com o artigo a ser revisado e um formulário para os comentários das revisões. Quando o formulário for completado, ele é automaticamente roteado ao presidente do comitê do programa e essa pessoa é alertada quando todas as revisões forem completadas.

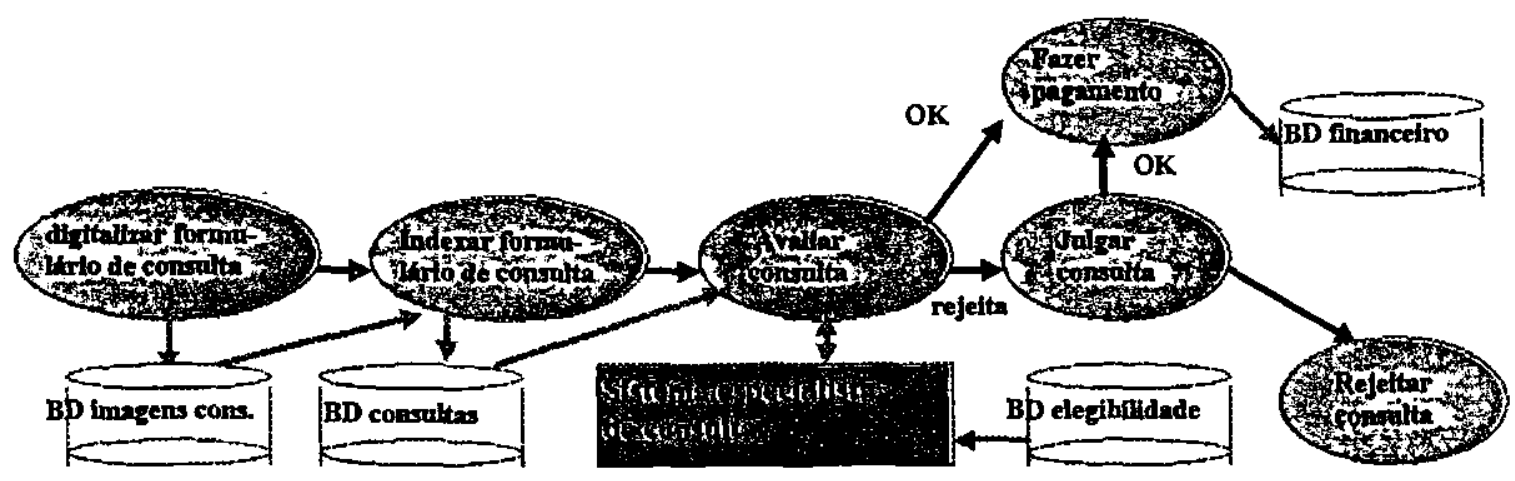

Figura 2.4 Workflow do processo de consulta médica

Workflows de produção envolvem processos de negócio repetitivos e previsíveis, tais como aplicaçōes de empréstimo ou pedidos de seguro. Diferentemente dos workflows administrativo, os workflows de produção normalmente abrangem um processo de informação complexo, envolvendo acesso a múltiplos sistemas de informação. A ordem e coordenação das tarefas nesses workflows podem ser automatizadas. Contudo, a automação de workflows de produção é complicada devido: (i) à complexidade do processo de informação, e (ii) ao acesso a sistemas de informação múltiplos para executar o trabalho e recuperar dados para tomadas de decisōes (workflows administrativos são dependentes de seres humanos para a maioria das decisões e trabalhos executados). Um WFMS que apóia workflow de produção fornece recursos para definir dependências de tarefas e controle de execução de tarefas ou com pouca ou nenhuma intervenção humana. Um WFMS de produção é freqüentemente usado diretamente em atividades 
de missão crítica para o negócio da empresa e deve tratar a integração e interoperabilidade de sistemas de informação HAD.

No workflow de consulta médica mostrado na figura 2.4 um formulário de consulta é primeiro digitalizado e armazenado como objeto na base de dados. Então a consulta é indexada em uma base de dados relacional e essa informação é subseqüentemente analisada pela tarefa automatizada "avaliar consulta". A tarefa é executada por um sistema especialista que usa uma base de dados para determinar se o pagamento deveria ser feito. Se a consulta for rejeitada, um representante discute a consulta com o cliente, que ou concorda em fazer um pagamento ou rejeita a consulta. Se o pagamento for feito, a tarefa "fazer pagamento" acessa a base de dados financeira e registra o pagamento. As diferenças significativas entre este workflow de produção e os workflows ad hoc e administrativos são: (i) a interação de sistemas de informação com o processo de negócio, e (ii) o uso de executores de tarefas (não humanos) automatizados.

O relacionamento entre os tipos de workflow ad hoc, administrativo e de produção é ilustrado na figura 2.5 usando o grau de estruturação das tarefas versus seu nível de complexidade.

Um Workflow com pouca estrutura pode envolver um caminho linear de tarefas a ser seguido; um workflow altamente estruturado pode envolver um grafo da organização das tarefas, no qual algumas tarefas podem ser executadas em paralelo ou múltiplas tarefas devem ser completadas antes que outras possam começar. A complexidade pode ser determinada pelos tipos de regras de coordenação/colaboração ou restrições aplicadas na execução das tarefas. Por exemplo, um aspecto de complexidade poderia ser o requisito de que uma tarefa começasse a execução somente após um conjunto de eventos ter ocorrido. A complexidade também é refletida pelos tipos de sistemas HAD que devem estar integrados para produzir uma implementação da tarefa, por exemplo, aplicações de escritório, sistemas de gerenciamento de bases de dados, ou sistemas de informação legados.

Outros tipos de workflow têm recentemente aparecido na imprensa comercial [Als94, Fry94]. Alsop, em [Als94] divide workflows: de apoio a grupo de trabalho ad hoc, de automação de tarefa, de fluxo de documentos e de automação de processo. Frye, em [Fry94], divide workflows em três categorias: centrado no correio, centrado no documento e centrado no processo. Essas caracterizações não separam semânticas de workflow do WFMS comercial que os apóia da infra-estrutura tecnológica que eles estão usando atualmente. Além disso, tais 
caracterizações de workflow pela imprensa comercial geralmente não distinguem entre workflows de produção, acessando um pequeno número de sistemas de informação homogêneos e workflows altamente automatizados, acessando muitos sistemas de informação HAD compartilhados. Por exemplo, workflows nos domínios de controle e comando militar ou de telecomunicações. Tais workflows não são discutidos ou caracterizados pela imprensa comercial. Aplicando o framework de complexidade versus estrutura da figura 2.5 , esses workflows possuem requisitos com maior estrutura e complexidade do que aqueles encontrados nos workflows de produção. Considerando que workflows nos domínios de comando e controle militar ou telecomunicações envolvem sistemas HAD com maior heterogeneidade (por exemplo, controle de hardware de centrais de telecomunicações) e maior demanda por execução com corretitude e confiabilidade (por exemplo, aplicações militares em que vidas humanas dependem da integridade dos dados) seus requisitos de implementação e automação são maiores do que os de workflows de produção.

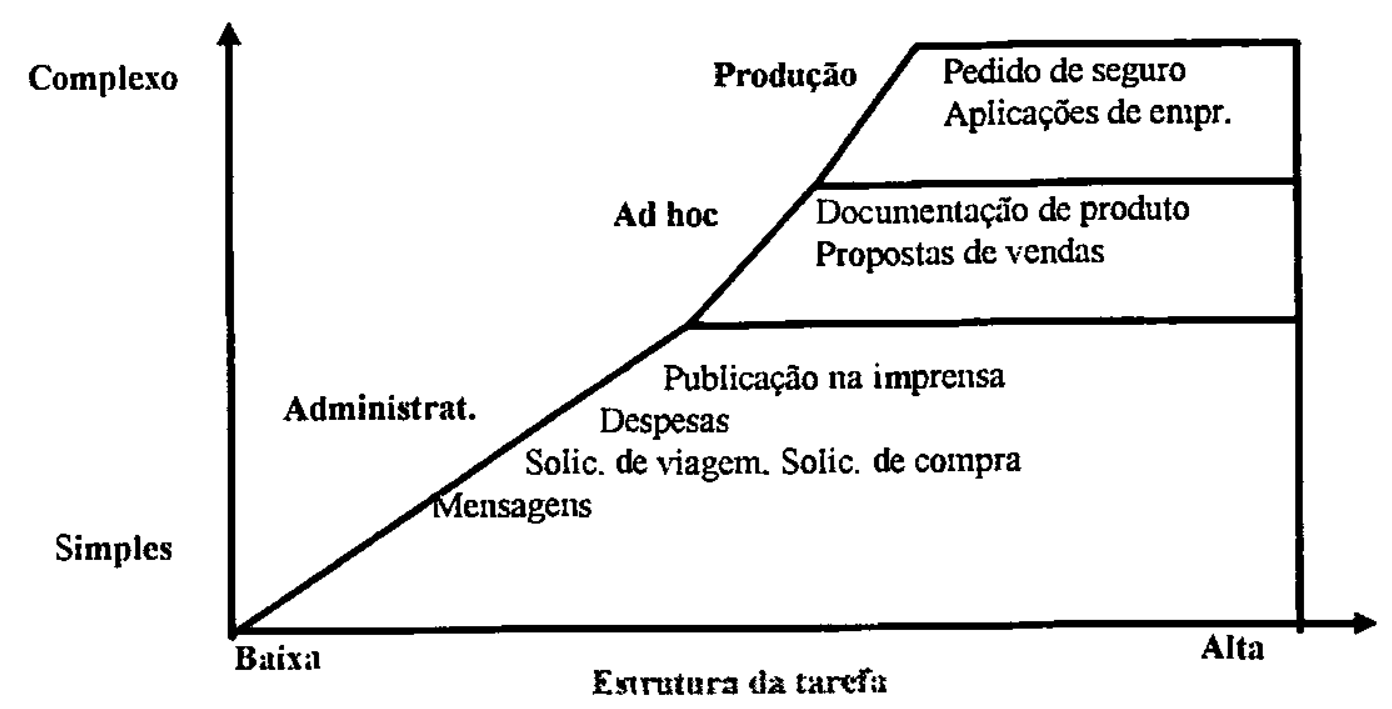

Figura 2.5 Caracterização de workflow conforme a imprensa comercial

\subsubsection{Caracterização de workflow conforme requisitos de implementação e automação}

O Workflow neste caso é caracterizado por uma classificação que vai de orientado a ser humano até orientado a sistema [Geo95]. Os workflows orientados a seres humanos envolvem 
colaborações humanas nas execuções e coordenações de tarefas. Os requisitos para os WFMSs neste ambiente envolvem o apoio à coordenação e colaboração humana e aumenta a produção humana. Seres humanos, contudo, devem assegurar a consistência de documentos e resultados do workflow. No outro extremo, workflows orientados a sistemas envolvem sistemas de computador que executam operações intensivas de computação e tarefas de software especializadas. Alem de serem altamente automatizados, workflows orientados a sistemas acessam sistemas de informação HAD. Enquanto implementações de workflows orientados a seres humanos normalmente controlam e coordenam tarefas humanas, implementações de workflows orientados a sistemas controlam e coordenam tarefas de software (normalmente com pouca ou nenhuma intervenção humana). Consequentemente, implementações de workflows orientadas a sistemas devem incluir softwares de controle de concorrência e técnicas de recuperação para assegurar consistência e confiabilidade. Isso não é requerido e não pode ser provido por WFMSs que apoiam workflows orientados a seres humanos. Workflows orientados a seres humanos têm processo semântico (por exemplo, capturar onde rotear um documento), mas não têm conhecimento real da semântica das informações processadas. Entretanto, em workflows orientados a seres humanos o WFMS deve assistir pessoas e não pode ser responsabilizado pela consistência de dados, visto que ele não tem informações semânticas. Por outro lado, workflows orientados a sistemas possuem mais conhecimento de informações semânticas (por exemplo, embutidas em várias aplicações envolvidas nos sistemas de informação que sincronizam aplicações para acessos compartilhados à base de dados). Portanto, o WFMS pode e deve ter mais responsabilidade na consistência das informações.

No workflow orientado a seres humanos, as principais questões tratadas são:

- interação homem-computador,

- casamento das habilidades humanas com os requisitos das tarefas,

- mudança da cultura de escritório, isto é, como pessoas necessitam ou preferem trabalhar.

No workflow orientado a sistemas, as questões tratadas são:

- casamento dos requisitos do processo de negócio com as funcionalidades e dados providos pelos sistemas de informação e/ou suas aplicações,

- interoperabilidade entre sistemas HAD, 
- encontrar tarefas de software apropriadas para executar tarefas do workflow,

- determinar software novos requeridos para automatizar o processo de negócio,

- assegurar corretitude e confiabilidade na execução do sistema.

\subsection{Gerenciamento de workflow}

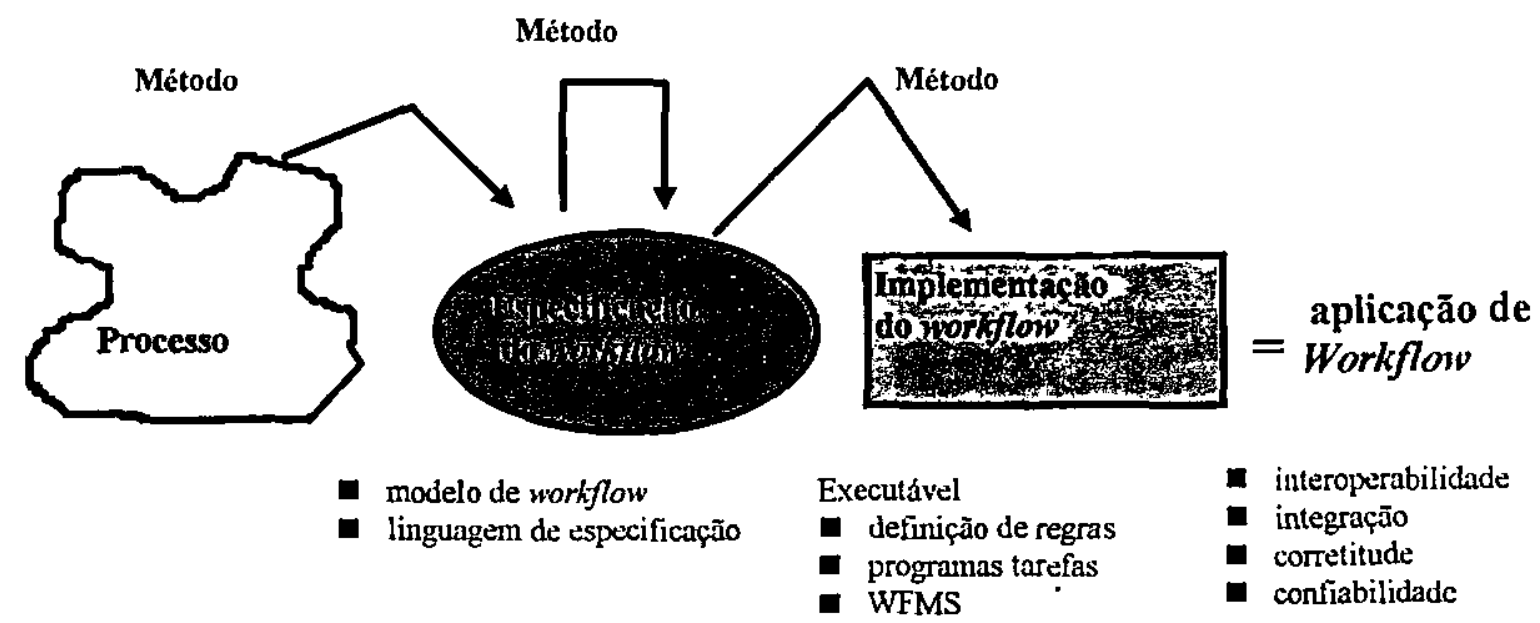

Figura 2.6 Questões de gerenciamento do workflow

O Gerenciamento de workflow envolve desde a modelagem do processo até a sincronização de atividades de sistemas de informação e de seres humanos que executam os processos. Em particular, o gerenciamento de um workflow, ilustrado na figura 2.6, inclui:

1. modelagem do processo e especificação de workflow: requer modelos de workflow e métodos para capturar um processo como uma especificação de workflow,

2. reengenharia do processo: requer métodos para otimizar os processos, e

3. implementação e automação de workflow: requer métodos/tecnologias para usar sistemas de informação e executores humanos para implementar, programar, executar e controlar as tarefas do workflow descritas pela especificação do workflow.

\subsection{Modelagem e especificação do processo}


Antes de modelar um processo, é preciso primeiro entendê-lo. Isso usualmente envolve entrevistas com pessoas e com especialistas do conhecimento sobre o processo. Métodos de entrevistas tais como aqueles usados para projeto de sistemas especialistas são apropriados para conduzir tais entrevistas. Quando for obtido conhecimento suficiente sobre o assunto, é feita a especificação do processo. Uma especificação de workflow captura uma abstração do processo. O nível de abstração do processo em uma especificação de workflow depende da intenção de uso da especificação do workflow. Por exemplo, uma especificação pode descrever um processo num nível conceitual mais alto, necessário para entender, avaliar e reprojetar o processo. Por outro lado, uma outra especificação de workflow pode descrever o mesmo processo em um nível de detalhe mais baixo, requerido para executar a implementação do workflow.

Para criar uma especificação, é necessário um modelo de workflow. Um modelo de workflow tipicamente inclui conceitos úteis para descrever os processos, suas tarefas, as dependências entre tarefas e os papéis requeridos (por exemplo, habilidades de indivíduos ou de sistemas de informação) que possam executar as tarefas especificadas. Uma especificação de workflow, tipicamente, é criada usando uma linguagem de especificação de workflow. Linguagens de especificação de workflow em um WFMS comercial usam regras, restrições e/ou construtores gráficos para descrever a ordem e a sincronização de tarefas em um workflow e atributos de tarefas para descrever as tarefas e os papéis para executá-las. Por exemplo, uma especificação de workflow gráfico pode ser similar ao ilustrado na figura 2.1 (possivelmente sem os recursos comuns das bases de dados, a menos que eles indiquem os papéis dos sistemas de informação e os seres humanos requeridos para implementar as tarefas especificadas). Um exemplo de especificação baseada em regra para o processo de provisionamento do serviço novo da figura 2.1 poderia ser: On $T_{1}$ completion Do start $T_{2}, T_{3}, T_{4}, T_{6}$. Esta regra captura o fato de que as tarefas $T 2, T_{3}, T_{4}$, e $T_{6}$ devem ser executadas após a finalização da tarefa $T_{1}$.

\subsubsection{Métodos para modelagem do processo}

Existem duas categorias básicas de métodos de modelagem do processo: baseada em comunicação e baseada em atividade ${ }^{11}$. Os métodos baseados em comunicação originam-se de

\footnotetext{
${ }^{11}$ Marshak, R. - Software to Support BPR - The value of Capturing Process Definitions. Citado em [Geo95].
} 
“Conversation for Action Model" de Winograd e Flores ${ }^{12}$ [Sch96]. Esses métodos assumem que o objetivo da reengenharia do processo de negócio é melhorar a satisfação do cliente. Eles dividem cada ação de um workflow em quatro fases baseadas na comunicação entre o cliente e um executor (ilustrado na figura 2.7):

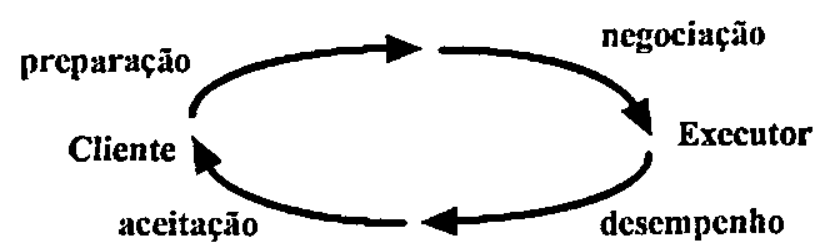

Figura 2.7 Conversa pelo modelo de ação

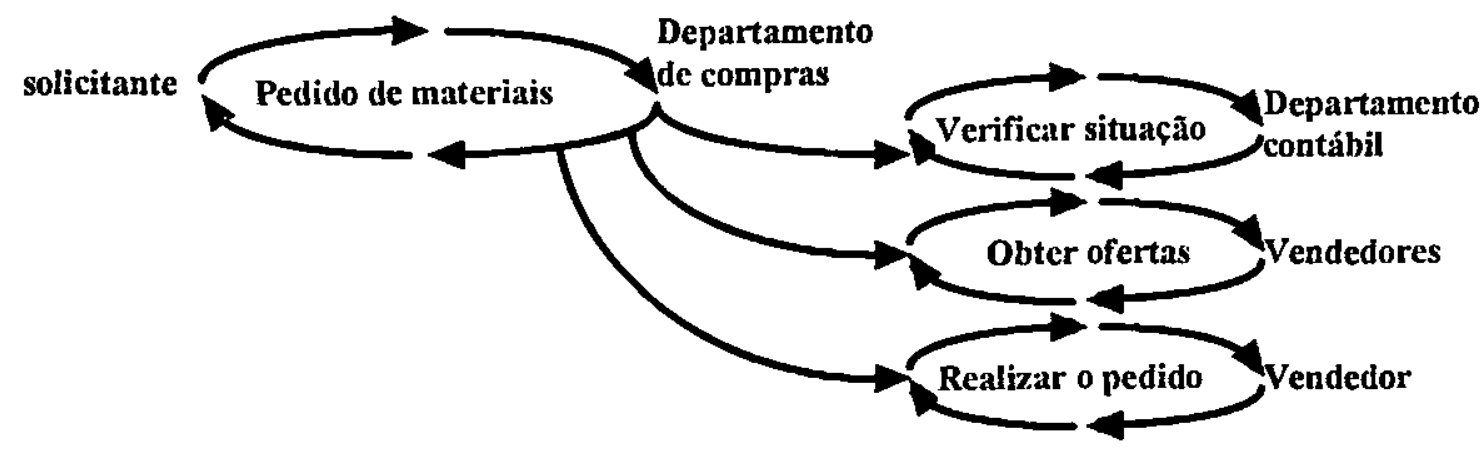

Figura 2.8 Workflow para pedido de materiais

1. preparação - um cliente solicita uma ação para ser executada ou um executor se oferece para fazer alguma ação,

2. negociação - cliente e executor concordam na ação a ser executada e definem os termos de satisfação,

3. desempenho - a ação é executada de acordo com os termos estabelecidos,

4. aceitação - o cliente relata a satisfação (ou insatisfação) com a ação.

Cada laço de execução do workflow entre um cliente e um executor pode ser acrescentado com outros laços de workflows, para completar um processo de negócio. O executor em um laço

${ }^{12}$ Winograd, T. e Flores, R. - Understanding Computers and Cognition. Citado em [Geo95]. 
de workflow pode ser o cliente de outro laço de workflow. O processo de negócio resultante revela uma rede social na qual um grupo de pessoas, preenchendo vários papéis, realiza esse processo de negócio.

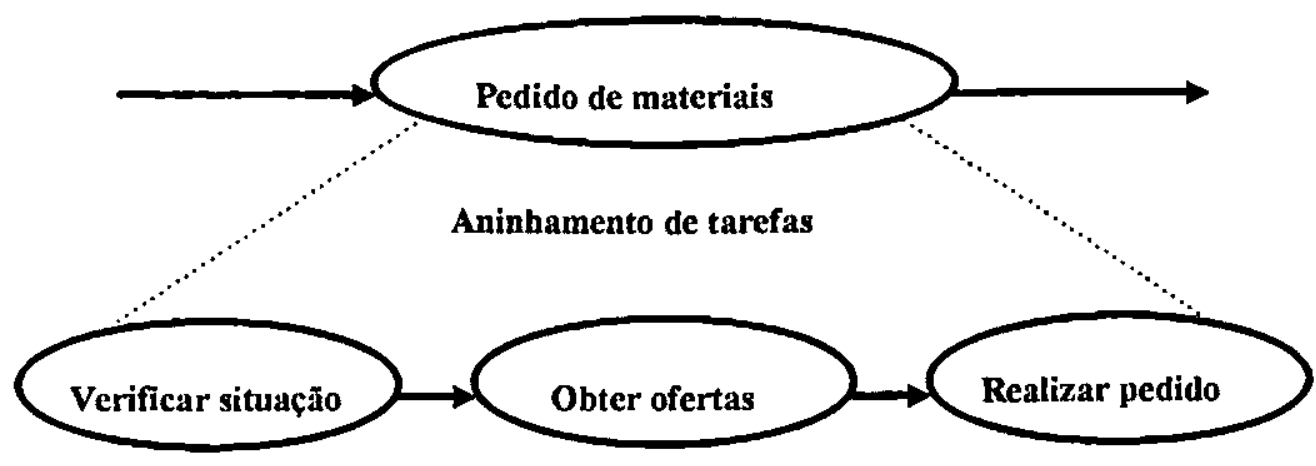

Figura 2.9 Workflow para pedido de materiais

O exemplo da figura 2.8 ilustra um processo de negócio para pedido de materiais. O laço do workflow principal (pedido de materiais) requer vários laços de workflows secundários durante a fase de execução (verificar situação, obter ofertas, realizar o pedido). A partir de um pedido de materiais, o setor de compras solicita ao setor contábil verificar a situação do comprador e também contata vendedores para obter as ofertas, selecionando enfim um desses para realizar o pedido. O workflow é finalizado (isto é, o laço principal é fechado) quando o setor de compras relata ao solicitante que o material foi pedido. O executor no laço principal é o cliente nos laços secundários. As especificações de workflow usando este método não indicam quais atividades podem ocorrer em paralelo ou se há ações condicionais ou alternativas. Considerando que a ênfase deste método é no cliente e que existem processos de negócios em que a ênfase no cliente pode ser superficial, por exemplo, se os objetivos forem minimizar custos de sistemas de informação ou reduzir desperdícios de materiais nos processos, este método não é apropriado para modelar processos do negócio com objetivos diferentes do que a satisfação do cliente. Uma outra limitação é que este método, por si só, não apoia o desenvolvimento de implementações de workflows a partir de especificações.

O sistema de gerenciamento de workflow "Action Workflow Analyst"13 14, da Action Tecnologies é baseado no modelo de Winograd/Flores, assim como a ferramenta "Business Transformation Management' da Business Transaction Design ${ }^{15}$.

\footnotetext{
${ }^{13}$ Medina-Mora, R., Wong, H. e Flores, P. - The Action Workflow Approach to Workflow Management.. Citado em [Geo95].
} 
Métodos baseados em atividades enfocam a modelagem do trabalho ao invés da modelagem de compromissos entre seres humanos. Por exemplo, considere o workflow representado na figura 2.9, no qual o processo "pedido de materiais" é composto por várias tarefas. As flechas indicam a natureza seqüencial desse mapa do processo. Note que "pedido de materiais" pode já ser uma tarefa em outro workflow, e que tarefas podem aninhar-se arbitrariamente em profundidade. Diferente dos métodos baseados em comunicação, métodos baseados em atividade não modelam a satisfação do cliente como objetivo do processo. Muitos WFMSs comerciais fornecem modelos de workflows baseados em atividades. Por exemplo, no modelo de workflow fornecido por InConcert ${ }^{16}$, workflows (referidos como jobs) consistem de tarefas. Cada tarefa pode conter subtarefas. Cada tarefa possui dependências de outras tarefas no mesmo nível e tem um papel assinalado que é por procuração um ser humano ou programa que executa a tarefa. O Método GTE's $R A P I D^{17}$ é também baseado em atividade e ele provê dois modelos de workflows: um modelo de alto nível para executar análise conceitual do processo de negócio e um modelo de baixo nível para descrição do processo de informação correspondente. No modelo de workflow de alto nível, workflows (referidos como mapas do processo) contêm tarefas (referidas como passos) necessárias para executar em um processo de negócio particular. Esses passos podem ser parcialmente ou totalmente ordenados conforme a necessidade, para indicar execuções alternativas ou paralelas dos passos do processo de negócio.

Os modelos de workflow baseados em comunicação e em atividade podem ser combinados quando os objetivos da reengenharia do processo são compatíveis com ambos os modelos (por exemplo, satisfazendo clientes e minimizando tarefas e papéis humanos). Por exemplo, o modelo de workflow usado para os workflows de telecomunicações na figura 2.1 pode ser visto como baseado em comunicação e em atividades.

Métodos orientados a objetos, tais como aqueles propostos por Rumbaugh e outros ${ }^{18} \mathrm{e}$ Jacobson $^{19}$, podem ser úteis na definição de especificaçōes de workflow (e derivação de

\footnotetext{
${ }^{14}$ Action Technologies Inc. - Action Workflow System product literature. Citado em [Ge095].

${ }^{15}$ Marshak, R. "Software to Support BPR - The value of Capturing Process Definitions. Citado em [Ge095].

${ }^{16}$ McCarthy, D. e Sarin, S. - Workflow and Transactions in InConcert. Citado em [Geo95].

${ }^{17}$ Eckerson, W. - Case Study: The Role of IS in Reengineening. Citado em [Ge095].

${ }^{18}$ Rumbaugh, J. e outros - Object-Oriented Modeling and Design. Citado em[Geo95].
} 
implementações). Por exemplo, Jacobson descreve como (i) identificar objetos que correspondem a "atores" (isto é, papéis de workflow), (ii) identificar as dependências entre aqueles objetos, (iii) usar técnicas de objetos tais como herança para organizar especificações de objetos, e (iv) descrever "casos de uso", os quais são uma seqüência de tarefas necessárias para completar algum processo do negócio. Casos de uso também podem incluir "cursos alternativos" os quais descrevem como manusear condições excepcionais. Contudo, orientação a objeto não fornece apoio explícito (de modelo de workflow) para modelagem do processo.

Algumas ferramentas de modelagem de processo do negócio comercial usam conceitos e técnicas orientadas a objetos para representar e implementar processos. Por exemplo, InConcer $t^{20}$ e ObjectFlow $^{21}$ combinam orientação a objeto com o método baseado em atividade.

\subsection{Técnicas e modelos conceituais para modelagem de workflow}

A seguir são descritas algumas técnicas e modelos conceituais utilizados para modelagem de sistemas de workflow:

\subsubsection{Rede de controle de informação (ICN)}

A ICN [El193] é descrita como uma variante de alto nível das Redes de Petri, em cuja derivação foram adicionadas primitivas de fluxo de controle e simplificação da semântica para que o modelo se tornasse intuitivo e útil para projetistas de procedimentos de escritório. Representa fluxo de controle e de dados; relações indicam quais atividades se aplicam para quais procedimentos; quais atividades precedem quais atividades e quais repositórios de dados são entradas ou saídas para quais atividades. Tem sido aplicado na industria ${ }^{22}$ e em pesquisas

\footnotetext{
${ }^{19}$ Jacobson, I. - Object-Oriented. Software Engineering - A Use Case Driven Approach. Citado em [Geo95].

${ }^{20}$ McCarthy, D. e Sarin, S. - Workflow and Transactions in InConcert.. Citado em [Ge095].

${ }^{21}$ Hsu, M. e Kielssner, C. - ObjectFlow: Towards a Process Management Infrastructure. Citado em [Ge095].

${ }^{22}$ Bull S. - FlowPath Functionai Specfication. Citado em [EII93]
} 
universitárias $^{23}$ e tem-se mostrado eficiente na modelagem de procedimentos de escritório, para análises matemáticas (possui definição formal) e para simulações. Fornece mecanismo para tratar exceção, comunicação informal, programação dinâmica, notificação e avisos.

A figura 2.10 apresenta a arquitetura conceitual da ICN, representada em um diagrama de entidade-relacionamento cujos componentes são definidos a seguir:

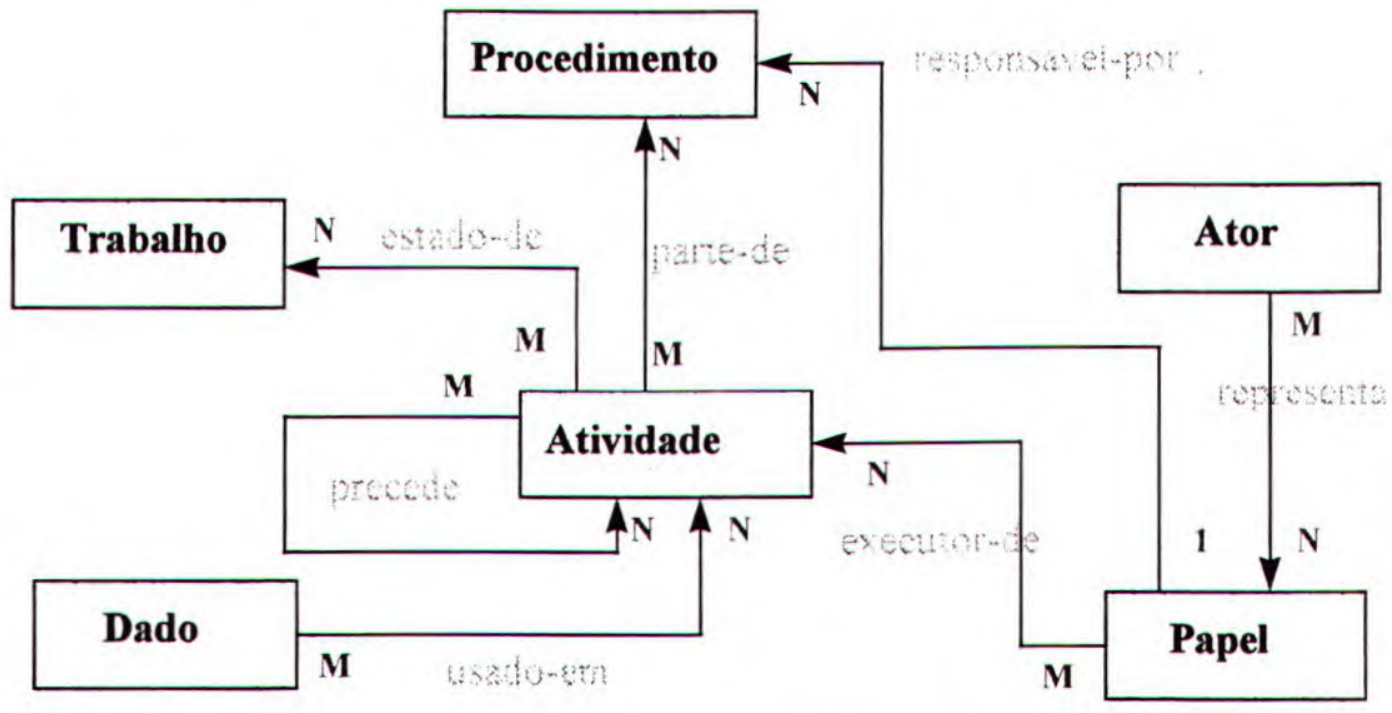

Figura 2.10 Arquitetura conceitual do workflow

- procedimento: é um conjunto pré-definido de passos de trabalho e o ordenamento parcial desses passos. Um passo de trabalho consiste de um cabeçalho (identificação, precedência, etc.) e um corpo (o trabalho a ser feito),

- atividade: uma atividade é o corpo de um passo de trabalho de um procedimento. Uma atividade pode ser composta, isto é, conter um outro procedimento ou ser uma atividade elementar,

- trabalho: é o controle de execução particular de um procedimento (um caso de trabalho),

- papel: é uma designação para um ator ou grupo de atores, os quais são a base para controle de acesso e execução,

- ator: é uma pessoa, programa ou entidade que possui as habilidades para preencher os papéis.

${ }^{23}$ Durnas, P. - La Methode. Citado em [El|93]. 


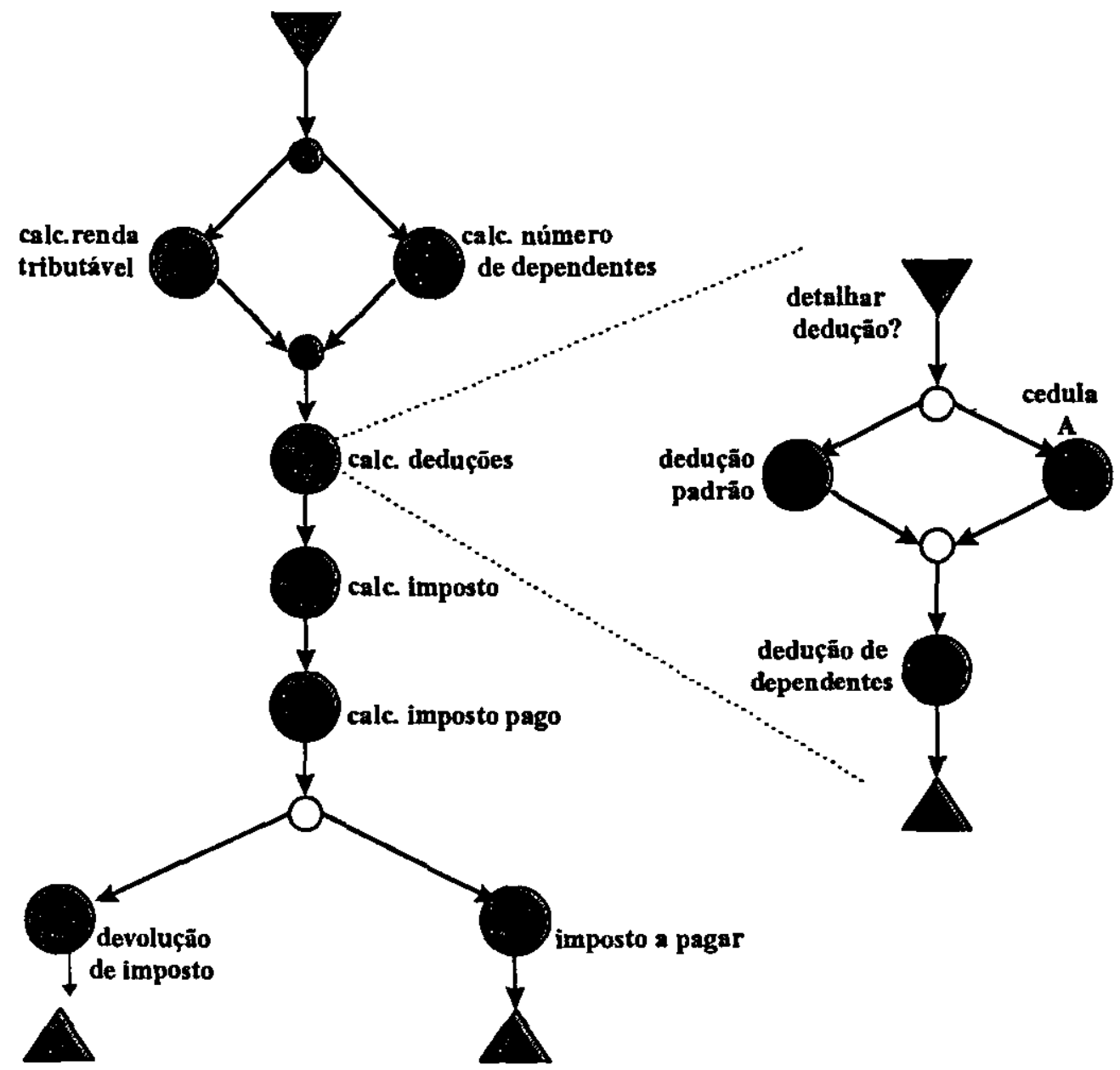

Figura 2.11 Exemplo de modelagem com a ICN, do cálculo do I.R.

Terminador (inicio/fim)

Círculo grande $=$ atividades

Nó de controle de fluxo or

Nó de controle de fluxo and

Arco para interconectar instâncias dos nós

Nó repositório

Figura 2.12 Construtores gráficos da ICN 
$\mathrm{O}$ modelo apóia relações de precedência conjuntiva e disjuntiva entre as atividades. $\mathrm{O}$ trabalho mostra a qualquer instante o estado das atividades executadas por ele. A entidade “dado" se refere aos dados de aplicações que são acessados durante a execução de atividades.

Na figura 2.11 é apresentado um exemplo de modelagem do cálculo do imposto de renda e na figura 2.12 os construtores gráficos da ICN. Na figura 2.11 destaca-se a execução de atividades concorrentes (as atividades calc.renda tributável e calc.número de dependentes) e a representação de refinamento de atividade como apresentada pela atividade calc.deduções.

\subsubsection{Associação de gerenciamento de workflow (WFMC)}

A Associação de Gerenciamento de Workflow [Wfm96a][Law97], fundada em 1993, é uma organização internacional sem fins lucrativos de vendedores, usuários e analistas de workflow. A missão da associação é promover o uso de workflow pelo estabelecimento de padrões para terminologia de software, interoperabilidade e conectividade entre produtos de workflow. A associação propõe um framework para o estabelecimento desses padrões, o qual é composto por cinco categorias de padrões de comunicação e interoperabilidade que permitirão a produtos de workflow coexistirem e interoperarem num mesmo ambiente de usuário. $\mathrm{O}$ trabalho desenvolvido pela WFMC gerou os seguintes resultados:

\section{Glossário}

Desenvolvimento de terminologia padrão para workflow.

A figura 2.14 apresenta os relacionamentos entre a terminologia básica constante no glossário do workflow [Wfm96b], as quais são definidas abaixo:

- Processo de negócio: é um conjunto de um ou mais procedimentos ou atividades ligadas, os quais coletivamente realizam um objetivo ou meta política do negócio, geralmente dentro do contexto de uma estrutura organizacional, definindo papéis funcionais e relacionamentos.

- Processo: é a representação de um processo de negócio de maneira que apoie a manipulação automatizada, tais como modelagem ou execução por um sistema de gerenciamento de workflow. O processo consiste de uma rede de atividades e seus relacionamentos, possuindo 
critério para seu inicio e fim e contendo informações sobre atividades individuais, tais como: participantes, aplicações e dados associados.

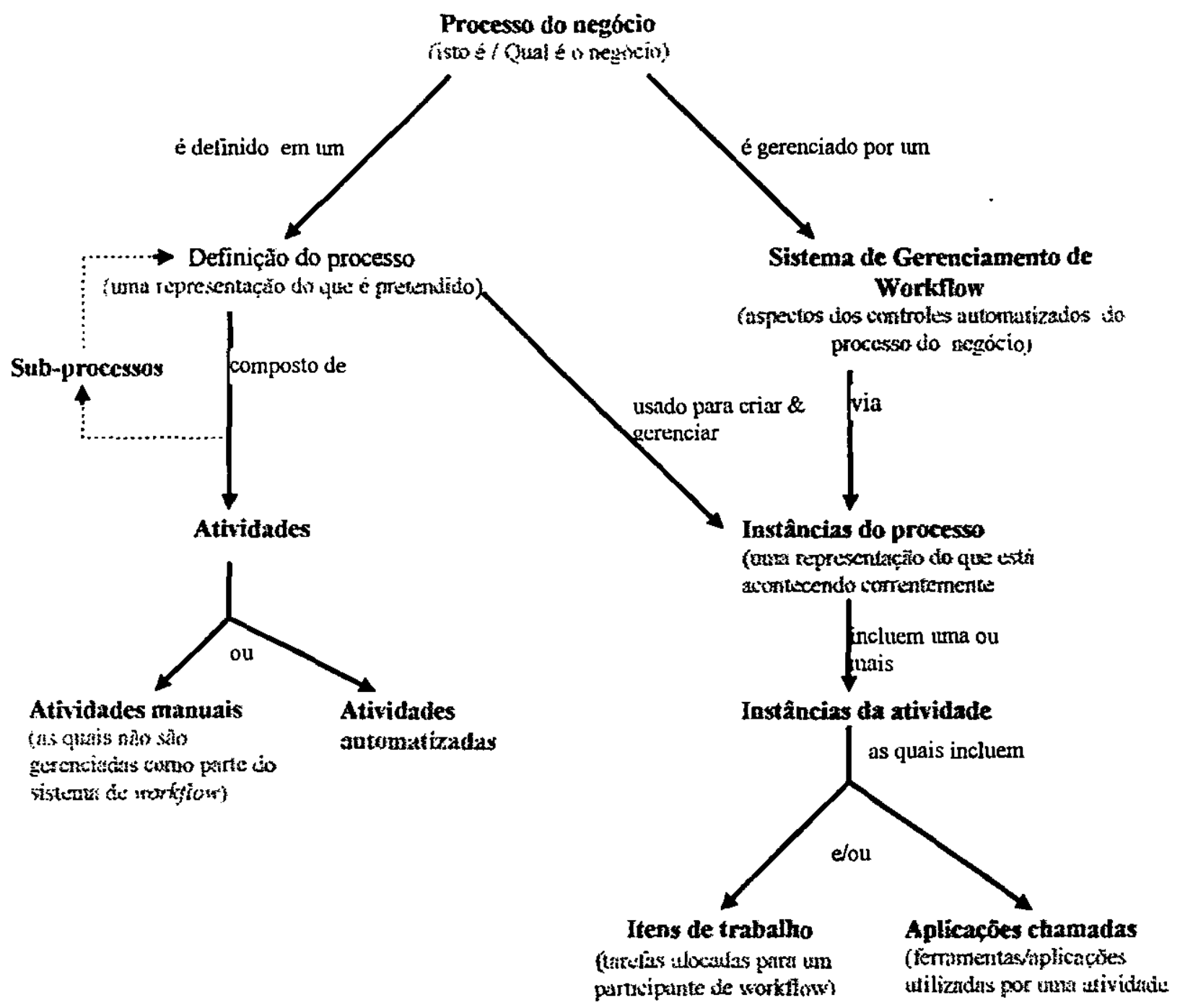

Figura 2.14 Relacionamentos entre a terminologia básica

- Atividade: é a descrição de uma parte do trabalho que é um passo lógico em um processo. Uma atividade pode ser manual (sem apoio de automação computadorizada) ou uma atividade de workflow automatizada (executada em um computador). Um atividade de workflow requer recursos humanos e/ou de máquina para apoiar a execução de um processo; no caso da requisição de recurso humano por uma atividade é alocado um participante de workflow.

- Sistema de Gerenciamento de workflow: é um sistema que define, cria e gerência a execução de workflows por meio de software, executando-os em uma ou mais máquinas de workflow, a 
qual possui habilidade para interpretar a definição do processo, para interagir com os participantes do workflow e para invocar quando necessário ferramentas e aplicações.

- Instância de processo: é a representação de uma execução particular de um processo.

- Instância de atividade: é a representação de uma atividade na execução de um processo (instância de processo).

- Item de trabalho: é a representação do trabalho a ser executado (por um participante de workflow) no contexto de uma atividade, em uma instância de processo.

\section{Modelo de referência}

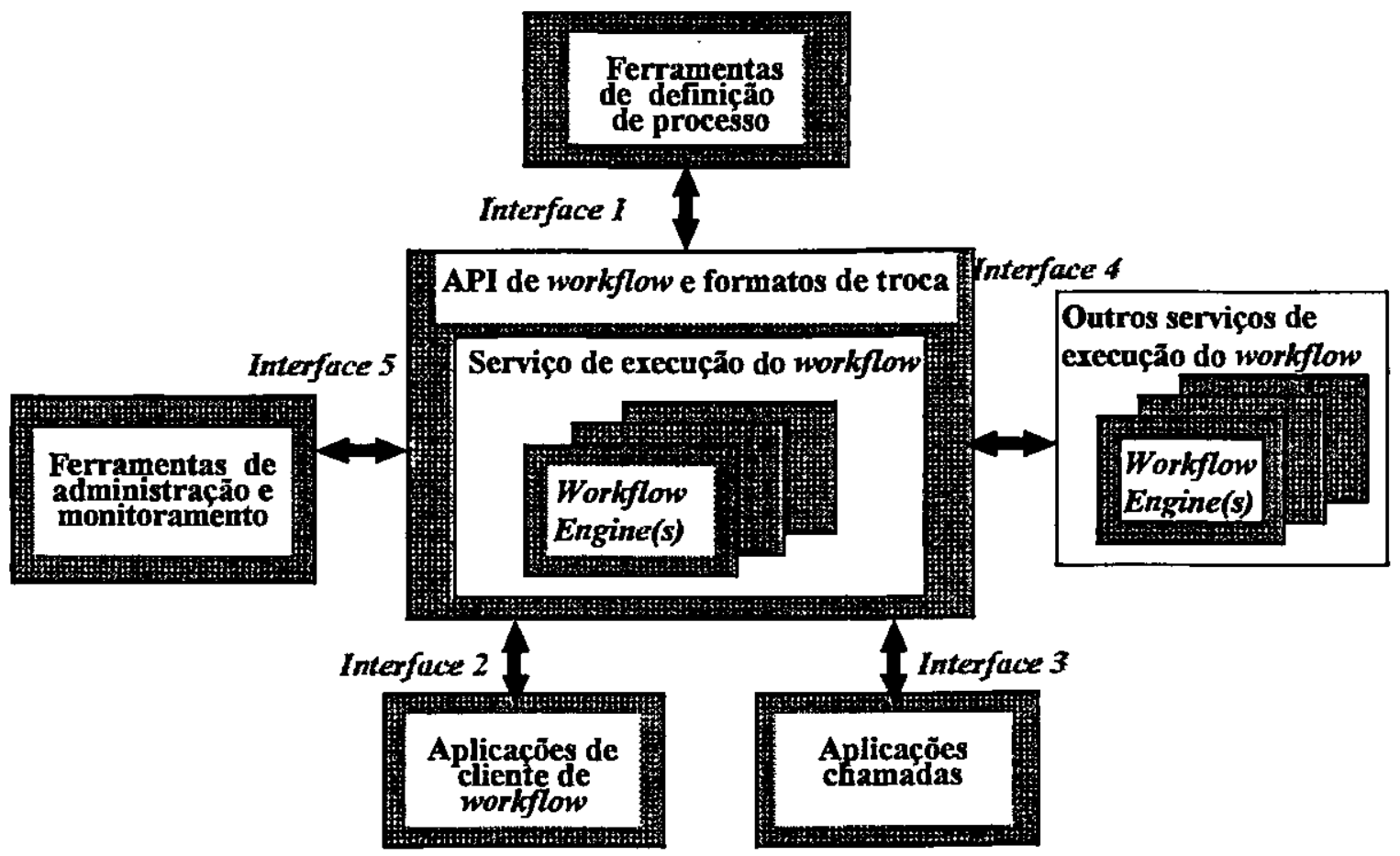

Figura 2.15 Modelo de referência de workflow

O modelo de referência [Wfm95] apresentado na figura 2.15 fornece o framework arquitetural geral para o trabalho da WFMC. Ele identifica as interfaces cobrindo cinco áreas (conforme figura 2.15) de funcionalidade entre o sistema de gerenciamento de workflow e seu ambiente, as quais habilitam produtos a interoperarem e que são descritas abaixo:

- a importação e exportação das definições do processo, por intermédio da definição de uma interface padrão entre a ferramenta de definição de processo e a máquina de workflow.(interface 1), 
- interação com as aplicações clientes e o software que manuseia a lista de trabalho, por meio da definição de padrões para a máquina de workflow manter os itens de trabalho que o workflow cliente apresenta aos participantes.(interface 2),

- a chamada de ferramentas de software ou de aplicações, por meio da definição de uma interface padrão que permita a uma máquina de workflow fazer chamada a uma variedade de aplicações (interface 3),

- interoperabilidade entre diferentes sistemas de gerenciamento de workflow, pela definição de uma variedade de modelos de interoperabilidade e seus correspondentes padrões aplicáveis (interface 4),

- funções para administração e monitoramento, por meio da definição de funções de monitoramento e controle (interface 5).

Para permitir a interoperabilidade entre diversos produtos de workflow foram projetadas a WAPI - Workflow Aplication Program Interface e formatos padrão para troca de dados. WAPI pode ser considerada como sendo um conjunto de primitivas pelas quais os serviços do sistema de workflow podem ser acessados e que regulam as interações entre o software de controle de workflow e outros componentes de sistemas.

- serviço de execução de workflow fornece um ambiente de execução no qual a ativação e instanciação de um processo ocorrem, utilizando uma ou mais máquinas de gerenciamento de workflow, responsável pela parte de interpretação e ativação, ou também pela definição do processo e interação com recursos externos necessários para executar as atividades.

\section{Meta-Modelo básico}

A WfMC desenvolveu um meta-modelo para a definição de processo, o qual identifica um conjunto básico de tipos de objetos apropriados para um nível inicial, para a troca de definições de processos relativamente simples. Define também atributos para esses tipos de objetos, os quais 
podem sofrer extensões conforme necessidade do desenvolvedor. Os tipos de objetos do metamodelo e que constam na figura 2.16 são:

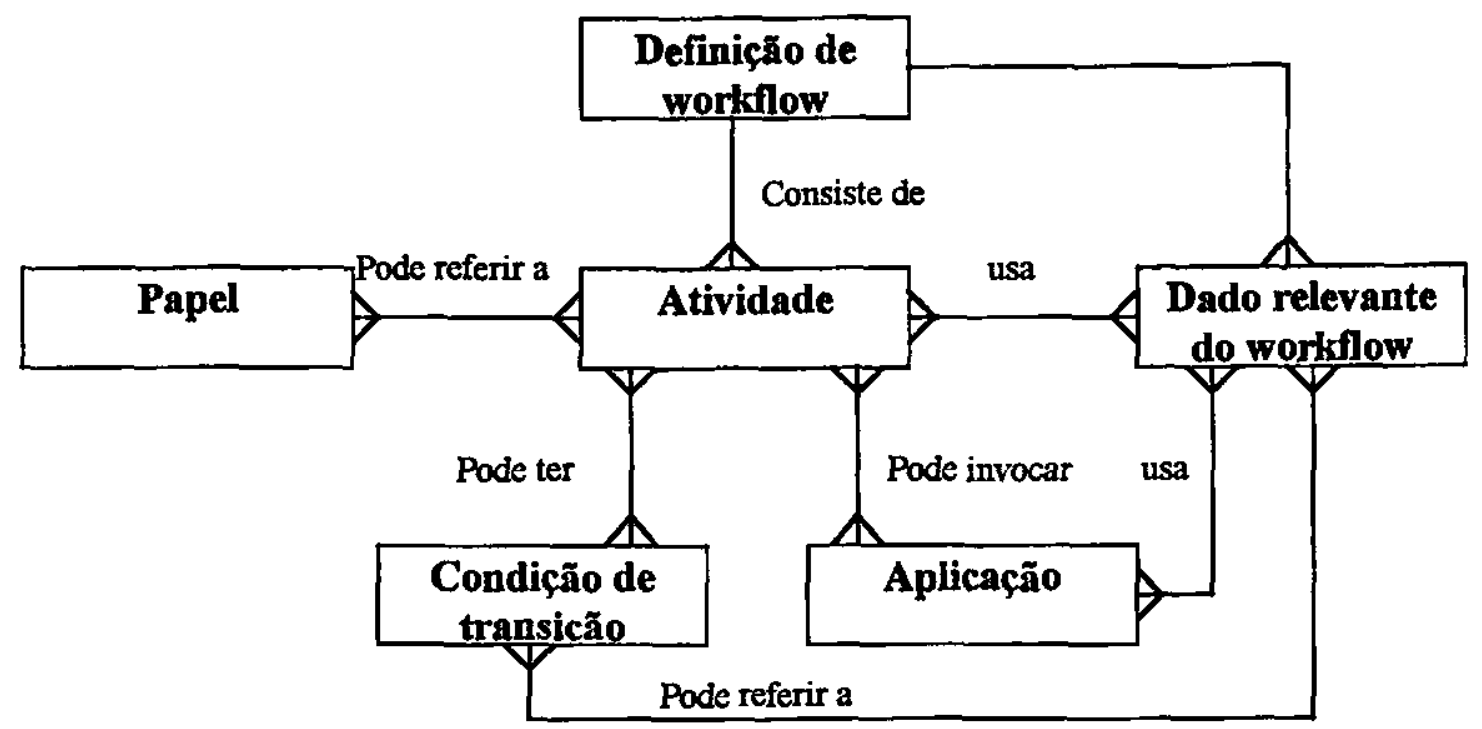

Figura 2.16 Meta-modelo de definição de processo básico

- Definição de workflow: sinônimo de processo.

- Papel: define o contexto do qual o usuário participa em um processo particular ou atividade. O papel geralmente abrange conceitos organizacionais tais como, estrutura e relacionamentos, responsabilidade ou autoridade e também no que se refere a habilidades.

- Dado relevante do workflow: são dados que são usados por um Sistema de Gerenciamento de Workflow para determinar as transições de estados de uma instância de workflow.

- Condição de transição: é uma expressão lógica que pode ser avaliada por uma máquina de workflow para decidir a seqüência de execução de atividade em um processo.

- Aplicação: são aplicações que podem ser invocadas por um sistema de gerenciamento de workflow para automatizar parcialmente ou completamente uma atividade, ou para dar apoio a um participante de workflow na execução de um item de trabalho.

\section{Definição de processo e construtores gráficos}

A WeMC especifica no seu glossário construtores gráficos para serem utilizados na representação gráfica de um workflow. Por meio deles pode-se representar: 


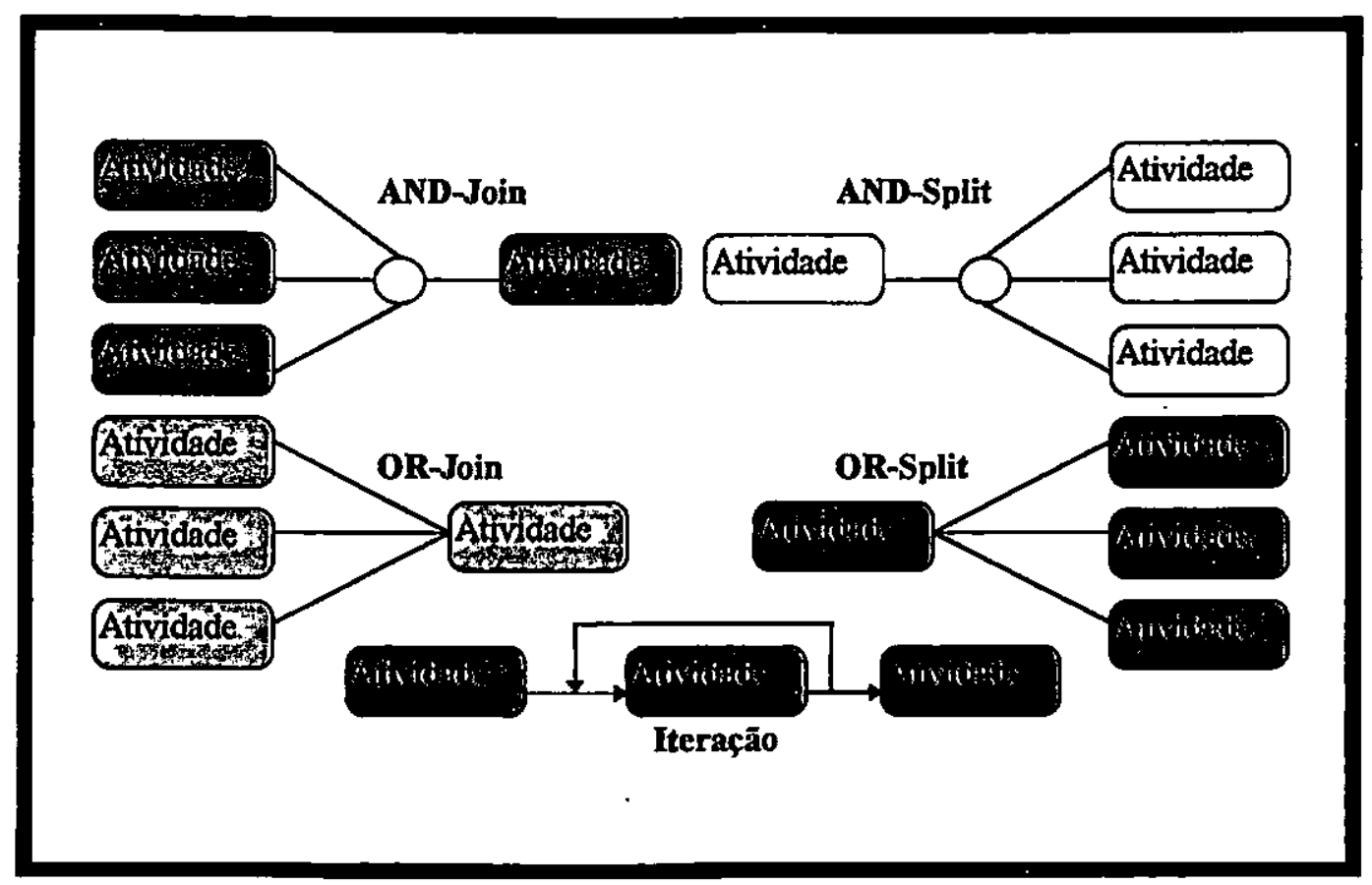

Figura 2.17 Construtores gráficos WfMC

- AND-Join: um ponto no workflow onde duas ou mais execuções de atividades em paralelo convergem em um fluxo comum simples de controle.

- AND-Split: um ponto em um workflow onde um fluxo simples de controle se divide em duas ou mais atividades em paralelo.

- OR-Join: um ponto no workflow em que dois ou mais ramos de atividades alternativos reconvergem para uma atividade comum simples como seu próximo passo.

- OR-Split: um ponto no workflow onde um fluxo simples de controle toma uma decisão sobre qual ramo seguir quando se encontra com múltiplos ramos alternativos.

- Iteração: um ciclo de atividade envolvendo execução repetitiva de uma ou mais atividades até que uma condição seja satisfeita.

Embora não haja especificação gráfica no glossário, uma definição de processo também pode conter:

- Subprocesso: um processo que é executado ou chamado de um outro processo (ou subprocesso) e que compõe um processo geral. 
- roteamento sequencial: um segmento de uma instância de processo em execução por um sistema de gerenciamento de workflow, no qual várias atividades são executadas em sequência em um fluxo simples de execução.

- bloco de atividade: um conjunto de atividades em uma definição de processo as quais compartilham uma ou mais propriedades comuns, que acarretam certas ações com efeito para o bloco como um todo.

\subsubsection{Um método para análise de workflow}

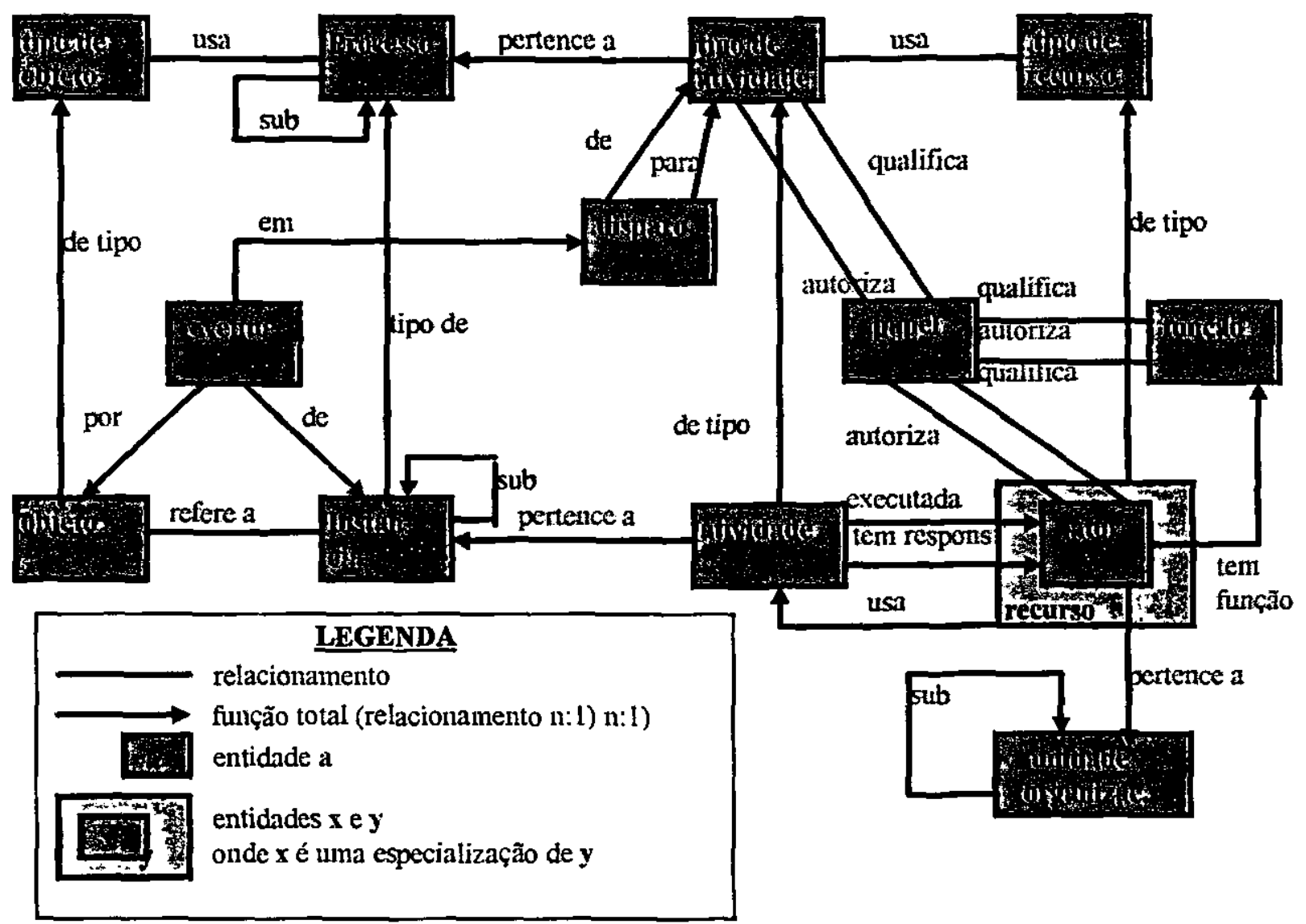

Figura 2.18 Modelo conceitual de workflow

O método trata questões que são específicas para gerenciamento de workflow [Jo095], embora ressaltado também a necessidade de informações sobre análise e projeto de sistemas de informação em geral, para implementar com sucesso workflows. A figura 2.18 apresenta o modelo conceitual de workflow associado a esse método. 
Um método para apoio ao gerenciamento de workflow auxilia na solução de problemas de coordenação do trabalho. Suas etapas de desenvolvimento compreendem:

1. Análise do problema

2. Soluções de projeto

3. Implementação

A análise do problema dá mais enfoque na organização do que na tecnologia e seu primeiro passo é modelar as atividades e como são disparadas. Após a análise do problema, soluções são projetadas e o documento de projeto deve conter informações sobre as metas de inovação, a situação pretendida após a inovação, a transição em direção à nova situação, de investimentos nos meios, treinamento e serviços com respectivas justificativas, conseqüências para o pessoal atingido, avaliação de riscos, infra-estrutura técnica e ferramentas, bem como assegurar o compromisso de gerenciamento, participação das partes envolvidas e envolvimento de especialistas no problema. A implementação da inovação é uma fase crítica porque as pessoas atingidas serão confrontadas com a nova maneira de trabalhar e a tecnologia para apoiá-la.

\section{Modelo de disparos}

Após a delimitação do escopo de um workflow, ele pode ser mapeado usando a técnica de modelagem por disparos, a qual adiciona o aspecto específico de workflow. Outros aspectos, tais como estrutura organizacional, estrutura de dados e fluxo de dados devem também ser modelados. Em análise de workflow é importante modelar a dinâmica do trabalho do processo, sendo que as noções centrais são disparo, atividade e papel. Para cada papel (por exemplo, cliente, gerente e representante) é definida uma entrada no modelo que conterá as atividades (representadas inicialmente por um retângulo) pelas quais o papel é responsável. Então, flechas ligam as atividades que representam uma relação de disparo, isto é, se uma atividade $\mathrm{Y}$ pode ser executada como conseqüência direta de um evento que ocorre em uma atividade $X$, então uma flecha liga $\mathrm{X}$ em direção a $\mathrm{Y}$. Uma maneira sistemática para desenvolver um modelo de disparo é:

- determinar quem é responsável (papéis);

- encontrar quais atividades são executadas sob a responsabilidade de um papel; e, 
- encontrar como cada atividade é disparada.

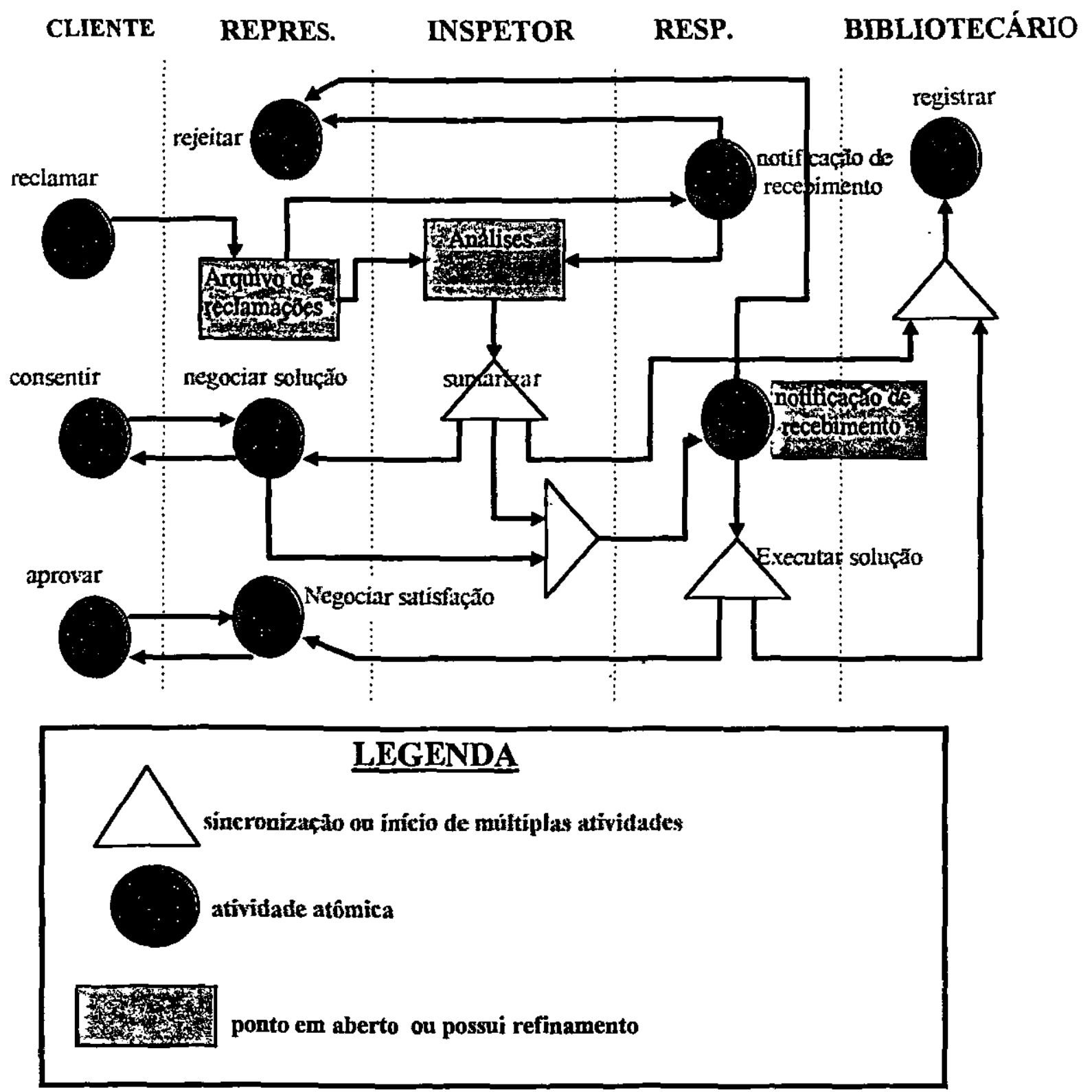

Figura 2.19 Exemplo de procedimento de reclamação

É possivel expandir uma atividade em um modelo novo de disparo, permitindo modelar em niveis diferentes de abstração. Após modelar um workflow em um modelo de disparo, muitos problemas e gargalos se tornam evidentes. No entanto, esse modelo inicial deve ser enriquecido com informações de cronometragem para definir precisamente quais ordens possíveis de eventos são permitidos. Cada retângulo deve ser substituído por um círculo, por um triângulo ou por uma construção de círculos e triângulos. Um círculo representa uma atividade atômica, significando 
que a atividade não será refinada; um triângulo representa um ponto de sincronização ou de início de múltiplas atividades. Um retângulo nesse modelo significa um ponto em aberto (aguardando dados adicionais) ou que este possui refinamento. O modelo de disparo serve como laboratório onde as mudanças na organização são tentadas. A figura 2.19 apresenta um exemplo de modelagem de disparo, de um procedimento de reclamação.

\subsubsection{Modelagem conceitual de workflow}

Esse modelo ressalta a necessidade de sistemas de gerenciamento de workflow serem mais integrados com a tecnologia de gerenciamento de dados [Cas95]. Para que isso ocorra é necessário melhorar e consolidar a especificação de workflows conceituais formalizando num único modelo seu comportamento interno (por exemplo, interação e cooperação entre tarefas), seu relacionamento com o ambiente (por exemplo, o assinalamento de tarefas para agentes) e o acesso a bases de dados externas. O modelo conceitual é uma base para se obter à convergência de workflows e bases de dados. A linguagem de descrição de workflow usada combina a especificação de workflows com acessos a bases de dados externas. Demonstra também como o modelo conceitual apresentado é mantido por meio de regras ativas em estruturas de dados de workflow específico.

O modelo conceitual se compõe de:

- Esquema de WF: é uma estrutura que descreve relações entre tarefas (WT) que são parte de um workflow e são descritas por meio de linguagens de descrição de workflow,

- Instância de WF (ou caso): é uma execução particular de um esquema,

- Linguagem de descrição de workflow: descreve as tarefas a serem executadas durante a execução de workflow e os mecanismos que são usados para sua ativação e finalização, em situações normais e excepcionais,

- Seção de definição: um esquema é composto por descrições de fluxos, supertarefas (ST) e tarefas, sendo que na especificação destes, inicia-se com definições de constantes, tipos, variáveis e funções, 
- Tarefas: são unidades de trabalho elementares que coletivamente realizam a meta do workflow. Elas possuem cinco características apresentadas na sua especificação, as quais são: o nome, sua descrição, pré-condições, ações e exceções,

- Conexões entre tarefas: descrevem as interações entre tarefas e estas podem ser feitas por uma conexão direta ou por meio de tarefas de roteamento (RT). Cada RT pode ser uma tarefa de separação (FT - fork task) (podendo ser total, não determinística, condicional e condicional com exclusão mútua) para início de execuções concorrentes ou uma tarefa de união (JT - join task), (podendo ser total, parcial e iterativa), para sincronização de tarefas após execução concorrente,

- Supertarefas: são úteis para agrupar várias tarefas relacionadas (introduzem noção de modularidade, definindo pré-condiçбes e exceçбes comuns a um conjunto de tarefas),

- Multitarefa: conjunto de tarefas que executam o mesmo serviço, em paralelo, por agentes diferentes,

- Agentes: são pessoas que são assinaladas para execução de tarefas, podendo também ser designadas como administradores do workflow.

A arquitetura do sistema de gerenciamento de workflow possui dois ambientes cooperativos, sendo um dedicado à coordenação do workflow e o outro dedicado à execução das tarefas. Existem tabelas para descrição de workflow, que podem ser independentes da aplicação e da aplicação específica. As regras ativas constituem as reações no núcleo do ambiente de execução (run time) e podem ser genéricas ou específicas. Pertencem ao paradigma EventoCondição-Ação e são disparadas por eventos específicos, incluindo uma condição declarativa e uma sequeência de ações procedimentais. Possui a seguinte sintaxe:

rule (rule-name) in group (group-name) - regras agrupadas por função

when (events) - lista de eventos

if (condition) - expressão boolena

then (action) - seqüencia de comandos.

Os componentes gráficos do modelo são apresentados na figura 2.21 e um exemplo utilizando o modelo é mostrado na figura 2.20 . 


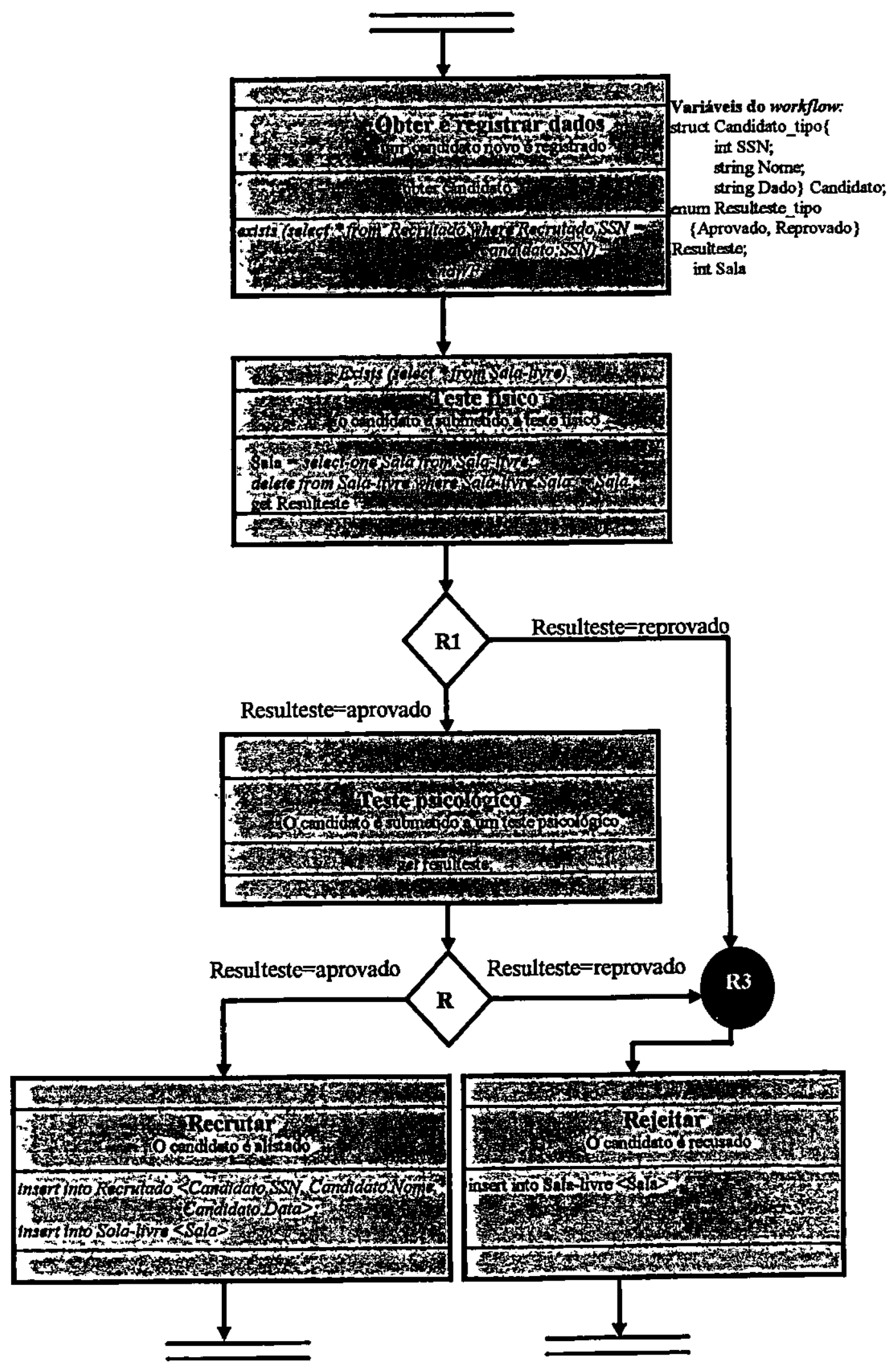

Figura 2.20 Exemplo de workflow para alistamento militar 


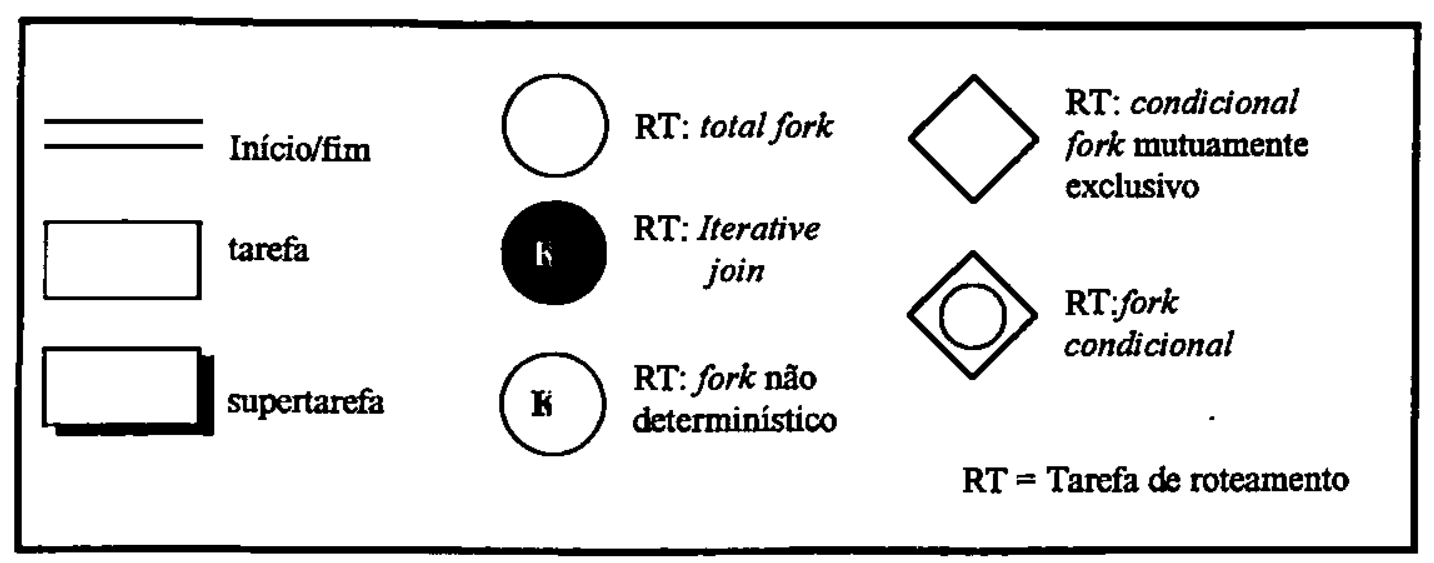

Figura 2.21 Simbologia gráfica para representar um workflow

\subsubsection{Business Process Implementation - Building Workflow Systems}

As técnicas deste método são de grande aplicabilidade, tais como: modelagem de processo e dados, o escalonamento de execução de programas e implementação utilizando um banco de dados subjacente. $O$ que o diferencia de outros métodos é o enfoque dado aos requisitos e à forma de desenvolvimento dos seus estágios [Jac97].

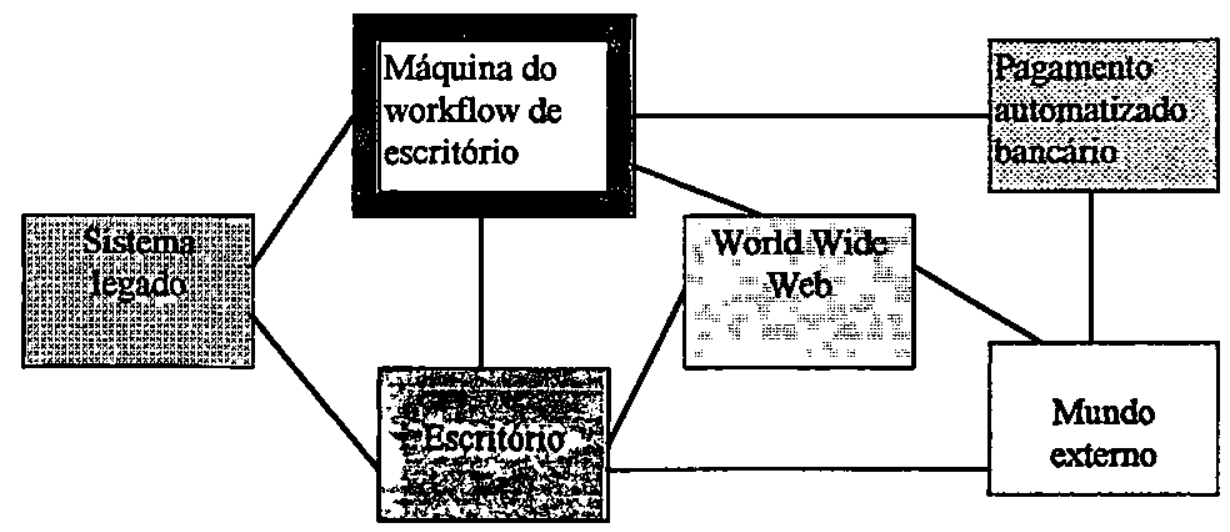

Figura 2.22 Diagrama de contexto para um sistema de workflow de escritório

Para entender a natureza e característica de um problema de desenvolvimento de sistema a primeira coisa a fazer é levantar o contexto do sistema. O contexto é composto pelas partes do mundo que afetam o sistema e são afetadas por ele (veja figura 2.22). Sistemas de workflow de 
escritório são encontrados em muitas áreas de administração e negócios, nos quais a função e finalidade central do sistema é dar apoio ao trabalho de pessoas de escritório que interagem com pessoas e organizações do mundo externo.

O retângulo duplo representa a máquina - isto é, o computador. O escritório é a parte do mundo cujo trabalho o sistema deve apoiar, sendo uma parte importante de qualquer empresa. As pessoas que trabalham no escritório, as quais são chamadas de usuários do sistema, possuem acesso direto à máquina e o trabalho do escritório é direcionado ao negócio da empresa, podendo ser chamado de negócio com pessoas e organizações do mundo externo. $\mathrm{O}$ negócio cobre sistemas que são usados em aplicações comerciais. A figura 2.22 mostra que pessoas e organizações no mundo externo não possuem contato direto com a máquina e seu contato é com as pessoas do escritório, com quem eles se comunicam tipicamente por telefone, conversações e carta, embora possa haver contato indireto pelo uso da WEB ou pela troca de dados eletrônicos. Um sistema legado é um sistema antigo existente na empresa, usado para manusear um aspecto do negócio que não está sendo manuseado pelo novo sistema e que possui um fluxo de dados diretamente com a máquina de workflow. O sistema legado possui também uma ligação direta com o escritório que é responsável por entradas de dados. A WEB permite aos clientes se comunicarem com a máquina de workflow, como por exemplo, o preenchimento de um formulário por meio de um "browser". O pagamento automatizado bancário representa um outro sistema de computador que transfere débitos e faz outras transações pertinentes, o qual também está ligado diretamente à máquina de workflow e ao mundo externo, talvez por uma rede de troca de dados eletrônicos (EDI).

Um dos beneficios do método é que ele fornece facilidades para atribuir a diferentes usuários, diferentes responsabilidades apropriadas às suas habilidades e aos seus trabalhos.

O negócio do escritório é principalmente conduzido pela interação entre usuários no escritório e pessoas e organizações do mundo externo (clientes, fornecedores, bancos, etc.). As interações refletem e servem a contratos e obrigações mútuas que surgem em qualquer relacionamento de negócio. Muitas obrigações passam por vários estágios e torna-se necessário armazenar uma quantidade considerável de informação sobre a história de obrigações e interações e a manter estas informações por longos períodos.

Embora se tenha discutido a atividade do negócio em termos de interações surgidas de contratos ou obrigações, o negócio é muito mais complexo e uma parte significativa do método é 
voltada para manusear essa maior complexidade. Pode-se capturar a essência desta maior complexidade na idéia de uma seqüência de interação, a qual consiste de um número de ações relacionadas aos usuários do escritório e às pessoas e organizações do mundo externo. Uma seqüência de interação é caracterizada pelo conjunto de eventos relacionados ocorrendo em alguma ordem pré-definida, sujeita a restrições que vêm da prudência comercial, da prática rotineira estabelecida do negócio (ex.: carência de tempo para alteração ou cancelamento da transação) e do próprio bom senso (ex.: um pedido não pode ser cancelado antes de ser emitido).

Um sistema de workflow de escritório é caracterizado pela riqueza de suas seqüências de interações e pela riqueza do relacionamento entre elas. O sistema deve permitir a interação dos usuários com o mundo externo, cujas informações nele armazenadas deve ser capazes de refletir fielmente como o mundo externo afeta o negócio. Também deve assegurar a ordem na qual as ações na seqüência de interações devem ocorrer.

Os requisitos do sistema discutidos impõem restrições na seqüência de ações de usuários no escritório, os quais devem ser ajustados às ordens prescritas da seqüência de interações, mas que ainda deixam uma liberdade considerável no sequenciamento e gerenciamento de todas as ações do escritório e ainda das ações de um simples usuário.

Um sistema de workflow de escritório tem como característica central proporcionar liberdade de escolha na forma de trabalho e organização do escritório. Por exemplo, existem escritórios em que um usuário trata todas as etapas de um tipo de trabalho e existem outros escritórios que possuem departamentos especializados para cada etapa de um tipo de trabalho e, portanto, existem usuários que somente tratam de uma etapa de um tipo de trabalho. Sendo assim, um sistema de workflow de escritório deve ser flexível na programação do trabalho, facilitando as mudanças. Ao mesmo tempo deve assegurar que as restrições impostas a cada seqüência de interação sejam respeitadas. Deve proporcionar às pessoas no escritório escolher padrões gerais de trabalho.

O método dá ênfase na fase de análise e especificação e assume que os requisitos do sistema estejam bem definidos na empresa, se preocupando com o entendimento da informação necessária para dar apoio ao negócio, registrando-a em modelos de processo e de dados.

O método pode ser estruturado em quatro fases de desenvolvimento: dados, processo, tarefas e workflow. Inicialmente necessita de informações do negócio para fazer o modelo de dados do mundo externo, que é desenvolvido a partir do reconhecimento das entidades que são 
significativas ao negócio. Posteriormente faz-se a descrição das seqüências de interações permissiveis entre o escritório e o mundo externo, gerando o modelo de processo, desenvolvido em termos de ciclos de vida, estágios dos ciclos de vida e tarefas. Em seguida, são definidos os detalhes das tarefas nos ciclos de vida e os pontos que exigem alguma ação no escritório, além da restrição de uso, definindo regras que controlam a natureza de cada tarefa, as partes do modelo de entidades que a tarefa usa e o que pode ou deve ser feito. Finalmente, pode-se determinar a estrutura do workflow que pode conter tarefas automáticas, que são programadas pela máquina, $\mathrm{e}$ tarefas manuais, que são selecionadas pelas ações dos usuários. Nesta fase se define a gerência das tarefas que são executadas automaticamente pela máquina ou oferecidas aos usuários como tarefas manuais, as quais podem ser escolhidas por eles.

\section{Fase de modelo de entidades}

Neste modelo, os dados representam partes e aspectos do mundo externo ao computador. Por exemplo: no mundo existe um cliente cuja identificação é 4567 , de nome João e com um pedido de número 1234. O modelo de dados é representado conforme abaixo:

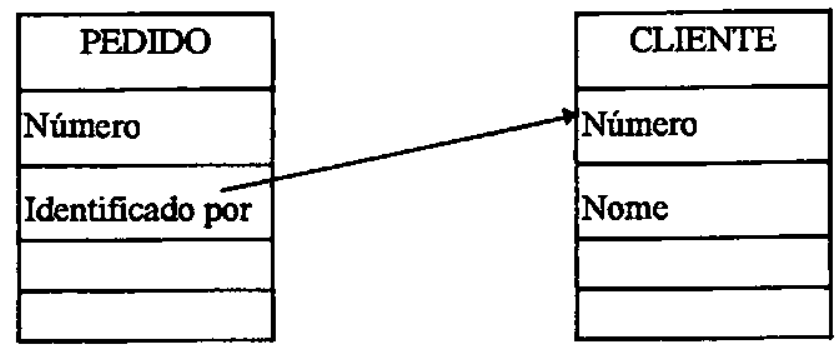

Figura 2.23 Exemplo de modelo de dados

Os retângulos são entidades e os relacionamentos aparecem no modelo como atributos de entidades (atributo "identificado por" na entidade "Pedido").

\section{Fase do modelo de interação do negócio}

O modelo de entidades é um modelo estático e descreve o estado em qualquer momento da base de dados quando nada está mudando, mas não descreve que mudanças são possíveis e em que ordem. Para isso, precisa-se de um modelo dinâmico que é o produto desta fase, a qual 
descreve as seqüências de interações permissíveis que podem ocorrer entre o escritório e o mundo externo.

As maiores e mais importantes seqüências de interações são associadas com entidades do modelo de dados, as quais são chamadas de ciclos de vida da entidade. Um ciclo de vida consiste de um número de estágios que ocorrem em uma ordem. Os estágios dos ciclos de vida de entidade associados com a entidade "CLIENTE" podem ser:

- Cadastro do cliente: entrar com as informações básicas do cliente em uma base de dados com a correspondente verificação.

- Avaliação do crédito: avaliar e cadastrar o crédito comercial do cliente.

- Cliente Ativo: cliente em operação.

- Cliente suspenso: cliente inativo.

Os estágios de um ciclo de vida de entidade associado com a entidade "PEDIDO" podem ser:

- Entrada do pedido: entrar com as informações básicas do pedido na base de dados.

- Verificação do crédito: verificar o crédito atual do cliente contra o valor do pedido.

- Verificação do estoque: achar e selecionar as mercadorias pedidas.

- Entrega do pedido: entregar o pedido para faturamento.

- Faturar o pedido: emitir nota fiscal do pedido.

Cada estágio de um ciclo de vida envolve um número de tarefas para ser executada pelo escritório. Por exemplo, o estágio avaliação do crédito pode envolver uma consulta à agência de avaliação de crédito comercial, espera pela resposta e avaliação da informação na resposta. Como a entidade progride pelo seu ciclo de vida, ela passa por um número sucessivo de estágios que é chamado de ciclo de vida de estágios associados, por exemplo, um cliente pode estar em um dos estágios: cadastro do cliente, avaliação do crédito, cliente ativo ou cliente supenso.

A técnica usada para descrever os relacionamentos entre ciclos de vida pretende obter o maior grau possível de paralelismo e identifica as dependências entre os ciclos de vida, o que significa identificar os pontos em um ciclo de vida em que se deve ser forçado a esperar pela ocorrência de um evento. Um estágio consiste de um número de tarefas a serem executadas, as 
quais podem ser executadas em paralelo. Uma tarefa pode ainda ter sua própria estrutura de seqüência de interação de subtarefas.

O método apoia as seguintes modificações para as estruturas de sequêencia simples de estágios:

- um ciclo de vida de entidades pode ser prematuramente terminado em algumas circunstâncias,

- um ciclo de vida de entidade pode retornar para um estágio inicial na ocorrência de certas falhas,

- em certas circunstâncias, um ciclo de vida pode avançar para um estágio mais avançado enquanto que algumas tarefas no estágio inicial ainda não foram completadas,

- uma tarefa simples pode ser explodida em várias subtarefas.

\section{Fase da definição das tarefas do negócio}

Nesta fase se descrevem os detalhes das tarefas e subtarefas individualmente, os quais são determinados pelos requisitos do negócio. Existem diferentes tipos de tarefas. Por exemplo, considere as seguintes tarefas:

- Cadastramento do cliente: nesta tarefa as informações sobre o novo cliente são digitadas no sistema.

- Verificar a validade da proposta: nesta tarefa uma proposta feita por um cliente é validada em relação às normas existentes.

- Recebimento de débito: nesta tarefa um débito direto por um sistema bancário automatizado é registrado na conta apropriada.

Obviamente existem tarefas de diferentes categorias adaptadas ao trabalho do escritório de diferentes formas. Cada tarefa usa alguma parte do modelo de dados e um conjunto de dados usados por uma tarefa possui uma entidade raiz, a qual é a entidade em cujo ciclo de vida a tarefa ocorre e que forma o ponto de inicio para a extração desse conjunto. A principal parte da definição de uma tarefa é composta principalmente por regras do negócio e uma regra pode especificar:

- um valor que deve ser alterado em um registro de entidade: por exemplo, o crédito disponivel do cliente deve ter reduzido o valor do pedido, 
- uma ação que deve ser executada: por exemplo, a geração de uma carta para ser enviada ao cliente.

\section{Fase de definição do workflow do escritório}

Num dado momento do escritório existem muitos ciclos de vida de tarefas em andamento e os usuários possuem muitas escolhas sobre o próximo passo a executar. O estágio de definição de workflow de escritório se preocupa em dar apoio aos usuários sobre a escolha do próximo passo a executar, mantendo um pool de tarefas disponíveis aos usuários sujeitas unicamente a restrições que podem ter sido explicitamente especificadas. A técnica de gerenciamento de workflow oferece a maior eficiência possivel, permitindo o máximo de paralelismo na execução das tarefas de cada ciclo de vida.

O diagrama da figura 2.24 mostra que cada definição de ciclo de vida é representada por uma entidade "ciclodevida" e que dependência entre dois ciclos de vida são representadas por uma entidade "dependência", a qual possui atributos para os ciclos de vida dependentes e o estágio pelo qual ele deve esperar e o ciclo de vida mestre e o estágio pelo qual o ciclo de vida dependente deve esperar. Cada estágio em um ciclo de vida é representado pela entidade "CVestágio" e cada tarefa em um estágio por uma entidade "tarefa". Uma entidade "tarefa" possui atributos que apontam para seu estágio de ciclo de vida e para o programa que implementa as regras aplicáveis. Quando é estabelecida a dependência entre dois ciclos de vida, a máquina de workflow assegura que a dependência é cumprida.



Figura 2.24 Um modelo de interações de negócio 


\subsubsection{Statechart}

Statechart [Har87] é uma técnica para especificação de sistemas reativos, ou seja, sistemas que devem reagir a estímulos externos e internos, normalmente em tempo restrito. Statecharts são uma extensão de máquinas de estado finito em que, além da noção de estados e transições, define-se hierarquia de estados, concorrência entre estados e propagação de eventos (possibilitando comunicação entre estados). Uma especificação baseada em statecharts enfoca 0 comportamento do sistema, que no caso dos sistemas reativos, é o requisito mais importante. A vantagem de utilizar statecharts para especificar esse tipo de sistema é que, ao contrário dos diagramas de estado, os statecharts possuem característica compacta, permitindo especificar comportamento complexo com diagramas concisos e claros.

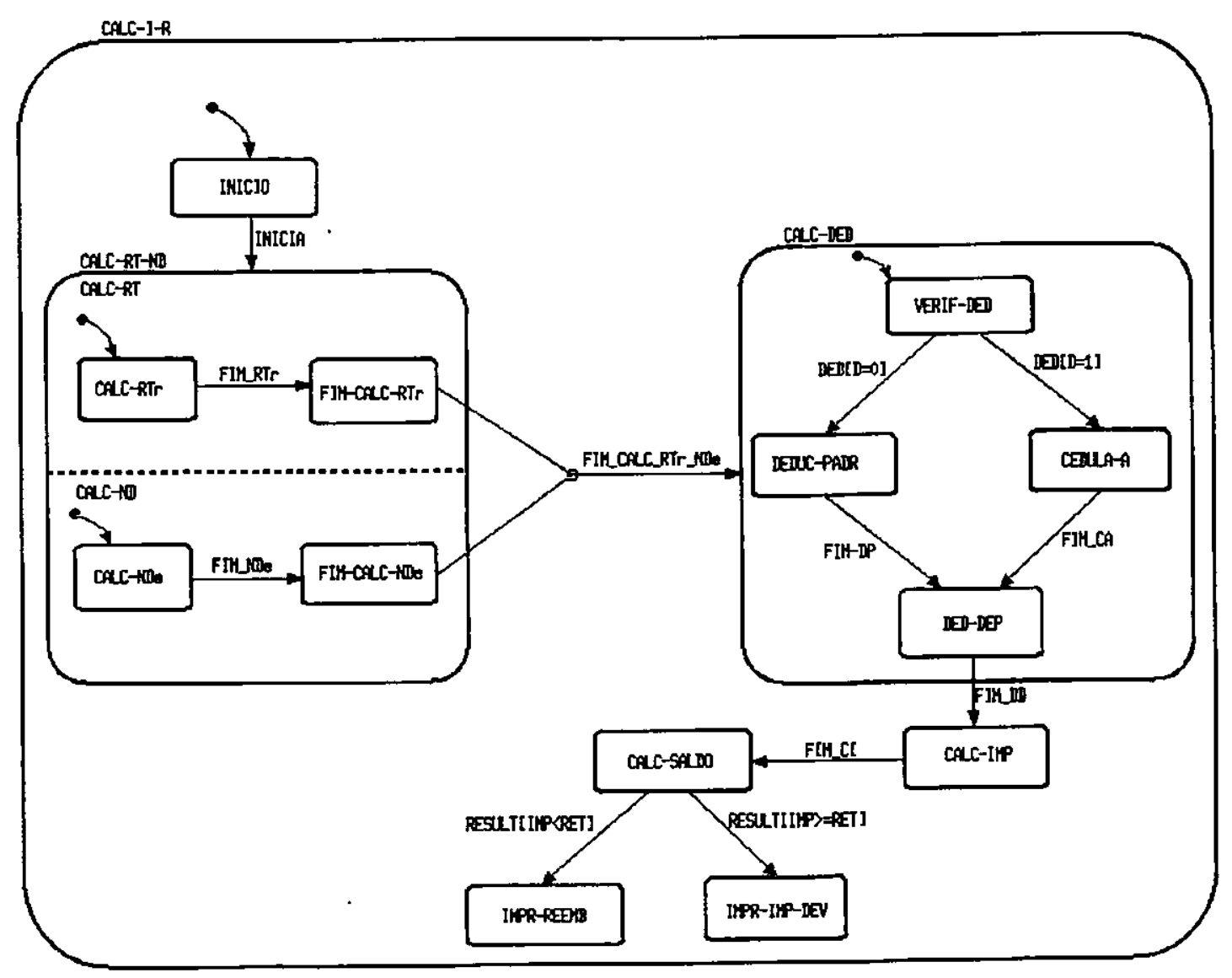

Figura 2.25 Exemplo de modelagem com statechart, do cálculo do I.R. 
A definição de statecharts é baseada em conjuntos de estados, transições, eventos primitivos, condições primitivas e variáveis. Usando esse conjunto de elementos básicos pode-se definir os seguintes conjuntos de elementos estendidos: eventos, condições, expressões, ações e rótulos, além dos inter-relacionamentos entre eles. $\mathrm{O}$ leitor mais profundamente interessado nesse assunto poderá encontrar em [Har87] toda a descrição do seu poderoso formalismo e semântica operacional, através do qual é possível elucidar todas as possíveis dúvidas a respeito da execução de uma especificação realizada com essa técnica.

Este formalismo pode ser estendido para a modelagem de um workflow, no qual os estados representam a execução de tarefas e as transições indicam o fluxo de controle (a ordem de execução das atividades). Statecharts possuem recursos para representar concorrência e sincronização de tarefas e poderiam ser usados como formalismo para definição de processo por um produto de workflow. A figura 2.25 mostra um exemplo simples de modelagem de um workflow por statechart, para o mesmo exemplo do processo de cálculo do imposto de renda.

Nesse exemplo são demonstrados alguns recursos do statecharts na modelagem do processo simplificado de cálculo do imposto de renda. Os retângulos arredondados correspondem às tarefas a serem executadas e estas podem ser decompostas em tarefas concorrentes (por exemplo, a tarefa CALC_RT_ND decomposta nas tarefas Calc_RT e CALC$\mathrm{ND}$, as quais serão executadas simultaneamente) ou seqüenciais (por exemplo, a tarefa CALC.DED decomposta nas tarefas VERIF-DED, DEDUC-PADR, CEDULA-A e DED-DEP, as quais serão executadas uma por vez). O fluxo de controle (a ordem de execução do workflow) é controlado pelas transições que são disparadas por eventos, sendo que estas possuem condições que permitem selecionar tarefas a serem executadas. Por exemplo, a transição DED utilizada em dois arcos a partir da tarefa VERIF-DED possui condição que permite selecionar de forma mutuamente exclusiva a execução das tarefas DEDUC-PADR e CEDULA-A. Uma sincronização de tarefas também é representada no exemplo, onde a tarefa CALC-DED somente iniciará execução após o término das tarefas CALC-RT e CALC-ND. 0 arco sem transição ligando apenas uma tarefa indica uma tarefa inicial padrão.

\subsection{Sistemas Comerciais de gerenciamento de workflow}

A maioria dos modelos de workflow apoia WFMSs que são baseados em atividades, e consiste de elementos similares, conforme abaixo: 
- workflows: um ordenamento parcial ou total de um conjunto de tarefas,

- tarefas: uma ordem parcial ou total de operações, descrições para ações humanas ou outras tarefas,

- objetos manipulados: documentos, registros de dados, imagens, telefones, máquinas de fax, impressoras, etc.,

- papéis: envolve conceitos de habilidades e responsabilidades dentro de uma organização requeridos para realizar uma tarefa particular,

- agentes: seres humanos ou sistemas de informação que desempenham papéis executam tarefas e interagem durante a execução do workflow.

Para prover níveis diferentes de abstrações, WFMSs normalmente permitem aninhamentos de tarefas. A definição de papéis em um workflow é particularmente benéfica quando uma tarefa pode ser executada por mais de um agente. O mapeamento de agentes para papéis ajuda a administrar mudanças na força de trabalho e no ambiente de computação e também pode facilitar o balanceamento dinâmico da carga de trabalho. Por exemplo, para o papel "aprovador da ordem de compra", um departamento de compra pode ter vários usuários (agentes humanos), que podem preencher esse papel. Se a carga de trabalho de um aprovador de ordem de compras estiver alta, o sistema pode automaticamente passar uma solicitação para um outro aprovador de compra.

A maioria dos WFMSs fornece linguagens gráficas para especificação de workflow. E muitos WFMSs também fornecem linguagens de especificações de workflow baseadas em regras ou restrições. Essas linguagens são de nivel mais alto do que as linguagens de programação padrão, tais como $\mathrm{C} \mathrm{e} \mathrm{C+H}$. Elas fornecem a especificação da seguinte maneira:

- estrutura da tarefa (fluxo de controle) e troca de informação entre tarefas (fluxo de dados) em um workflow, por exemplo, especificando quais tarefas podem ser executadas em paralelo, ou que uma tarefa necessita esperar por dados de outras tarefas,

- manuseio de exceção, por exemplo, especificar quais ações são necessárias se a tarefa falhar ou um workflow não puder ser completado,

- duração da tarefa, por exemplo, especificar o tempo de inicio e término de uma tarefa, e 
- atributos de prioridade, por exemplo, especificar prioridades para programação de tarefas.

Nas linguagens de especificação de workflow baseadas em restrições ou regras, a estrutura do workflow e do fluxo de dados é tipicamente especificada para definir regras ou restrições de roteamento. Roteamento é normalmente classificado como condicional, baseado em regra ou paralelo. Um exemplo de roteamento condicional é, "if item.cost $>1000$, then contact Manager". Roteamento baseado em regra é mais poderoso que roteamento condicional e pode envolver arbitrariamente regras complexas declaradas em uma linguagem baseada em regras. Roteamento paralelo permite que uma tarefa se ramifique em múltiplas outras e que possam executar em paralelo. Umaṣ poucas linguagens apoiam também explicitamente sincronização de tarefas. Alguns WFMSs usam uma especificação gráfica para automaticamente gerar código ou organizar as regras para uma implementação e execução do workflow. Alguns WFMSs comerciais possuem arquiteturas cliente-servidor aberta e interfaces de programação de aplicação completa (APIs), isto é, tudo que pode ser feito por meio da interface do usuário pode também ser feita via uma API.

\subsection{Gerenciamento de documentos}

Conforme discutido anteriormente, um sistema de gerenciamento de workflow incorpora muitas tecnologias, tal como o gerenciamento de documentos. Um sistema de gestão de documentos permite gerenciar uma faixa ampla de documentos eletrônicos, tais como documentos de qualquer formato, armazenados em qualquer local; documentos que sofrem alterações durante a sua vida útil e documentos que podem ser acessados facilmente, tanto dentro como fora da sua organização. Um sistema de gestão de documentos executa as seguintes funções, dentre outras: identificação de documentos; armazenamento e recuperação de documentos; rastreabilidade de documentos; gerenciamento do fluxo de trabalho e apresentação de documentos. São elementos de um sistema de gestão de documentos: a infra-estrutura, compreendendo o conjunto de computadores, estações de trabalho e servidores que estão interconectados às redes; as ferramentas de autoria, que auxiliam a criação de documentos; o fluxo de trabalho (workflow) definido como a coordenação de tarefas, dados e pessoas para tornar um processo mais eficiente, efetivo e adaptável a mudanças; o armazenamento de documentos; os 
serviços relacionados a mecanismos de controle de documentos, tais como controle da entrada e saida de documentos, da trilha de auditoria, do nível de proteção/segurança e da versão de documentos; e os serviços de apresentação e distribuição de documentos.

Tradicionalmente existem duas classes de gestão de documentos:

- o gerenciamento de imagens fixas de papel (estáticas);

- o gerenciamento de documentos editáveis (dinâmicos e que mudam).

\subsubsection{ISO 9000 para documentos}

Foi ressaltada ·anteriormente a importância da certificação ISO, a qual estabelece normas de qualidade, sendo essencial na aceitação de produtos e serviços pelo mercado. A norma ISO 9000 trata na sua seção 4.5 do controle de documentos, a qual normatiza que o fornecedor deve estabelecer e manter procedimentos documentados para controlar todos os documentos e dados (podendo estes estar em forma de cópia física, meios eletrônicos e outros) que digam respeito aos requisitos da norma, incluindo, na extensão aplicável, documentos de origem externa, tais como normas e desenhos do cliente.

Os documentos e dados devem ser analisados criticamente e aprovados quanto à sua adequação por pessoal autorizado, antes de sua emissão. Uma lista mestra ou procedimento equivalente de controle de documentos, identificando a situação da revisão atual dos documentos, deve ser estabelecida e estar prontamente disponível, a fim de evitar o uso de documentos não válidos e/ou obsoletos. As modificações em documentos e dados devem ser analisadas criticamente e aprovadas pelas mesmas funções/organizações que realizaram a análise crítica e aprovação original, salvo prescrição em contrário. Onde praticável, a natureza das modificações deve ser identificada no documento ou em anexos apropriados.

Adicionalmente, orienta que os documentos utilizados para transmissão de informações na empresa devem ser controlados, de maneira que cada pessoa tenha acesso às informações que necessita, no momento correto. Tendo em vista que as normas NBR ISO 9000/94 exigem grande esforço de documentação dos processos da empresa, deve-se atentar para que estes documentos tenham distribuição controlada, além de terem sido analisados e aprovados por pessoas capacitadas para tal, antes de sua emissão. 


\subsection{Exemplos de sistemas gerenciadores de workflow e de documentos}

Em seguida são apresentados e discutidos resumidamente alguns sistemas comerciais de gerenciamento de workflow e de documentos.

\subsubsection{Lotus Notes Release 4}

O produto Notes [Rei96], da Lotus, é uma plataforma cliente-servidor que habilita acessar, compartilhar e gerenciar informação em um ambiente de rede. Possibilita sua instalação em uma estação de trabalho rodando Windows 95 ou OS/2 de uma rede local (LAN). Possui uma base de dados integrada e uma arquitetura de comunicação. $O$ cliente Notes serve como uma interface de usuário de desktop simples para muitos tipos de aplicações de usuário final. Também fornece a infra-estrutura básica para coordenar, rastrear e gerenciar processos de negócio e compartilha dados em um ambiente distribuido, assim como possibilita ao usuário final receber trabalho. O sistema pode automatizar certos passos de trabalho e executar o roteamento deste para os próximos passos.

Alguns sistemas de gerenciamento de workflow, tais como 0 da Action Technologies/WorkManager, Workflow Inc./FlowMaker e Pavone /GroupFlow têm sido construidos sobre o Notes, os quais possuem um modelo de workflow próprio, mas são baseados na tecnologia do lotus Notes. O Notes tem um modelo de dados orientado a documento para compor documentos multimídia, sendo que uma aplicação Notes geralmente consiste de formulários, visões e documentos. Os documentos são armazenados na base de dados do Notes, as visões são usadas para listar os documentos e os formulários são as interfaces para editar os documentos. Os formulários podem conter fórmulas, macros e agentes. Os elementos do projeto Notes são armazenados junto com os documentos na sua base de dados. O Notes possui muitas características que facilitam gerenciar aplicações de workflow tais como, a definição de agentes, os quais disparam automaticamente na ocorrência de certos eventos e executam tarefas especificadas; o LotusScript, que é uma linguagem semelhante ao Visual Basic, orientada a objeto e pode ser usada para rotear e possivelmente implementar um passo de trabalho; o Notes OLE2, que possibilita a integração entre aplicações para desktop, sendo que a integração de workflow 
com aplicações existentes é uma propriedade importante de sistemas de gerenciamento de workflow e o livro de endereços do Notes, que pode ser usado para o modelo organizacional e que pode ser explorado para endereçar mensagens.

\subsubsection{Doc-control}

Doc-Control é um sistema de gestão de documentos desenvolvido pela empresa Polo de Software de Curitiba S.A. [Pol97], para ambientes gráficos, Windows-95 e DOS-Windows e que atende ao padrão internacional ISO 9001 para o controle de documentos. O sistema Doc-control organiza, controla e distribui documentos que tramitam diariamente nas organizações, em papel ou sob a forma de documentos eletrônicos. Mecanismos de controle são aplicados sobre documentos, tais como: controles de entrada, de saida, da trilha de auditoria, do nível de proteção/segurança e de versão. O sistema de software Doc-Control realiza o controle de documentações em uma empresa, mas não os manuseia fisicamente.

Fornece um manual aos usuários que os orienta nos passos básicos para a utilização do sistema, o qual é composto pelos módulos:

- cadastramento de tabelas: composto pelas tabelas de áreas da empresa, manipuladores de documentos, tipos de documentos, finalidade da distribuição de documentos, localização física dos documentos, tipos de mídia utilizados para armazenar documentos, lista de distribuição de documentos, projetos dos quais os documentos fazem parte, ciclos de distribuição de documentos e segurança de acesso a documentos.

- operações: permite o cadastramento dos documentos existentes numa organização, de documentos versus projetos, lista de desenhos, consulta de documentos sem projeto, vários tipos de relatórios (por exemplo, de documentos por projeto). Fornece também consulta de quem acessou o sistema e as respectivas operações realizadas. Possui funções de edição que movimentam dados entre aplicações e registros de cadastros de documentos (por exemplo, copiar, recortar e colar). Possibilita fazer a distribuição de documentos com os devidos controles, bem como consultas e relatórios referentes a esta (por exemplo, guia de remessa, histórico de distribuição e documentos por destinatário). E, finalmente, permite solicitação de documentos originais, de cópias e manutenção de revisão. 
Adicionalmente, o manual fornece um glossário de termos utilizados, descrição da interface do sistema, descrição de comandos de atalhos e de manipulação de janelas.

\subsubsection{Process Builder - Analyst Edition}

O Process Builder é uma ferramenta da Action Tecnologies [Act96], para projetar e analisar processos de negócio, que permite detectar gargalos e outras ineficiências. $\mathbf{O}$ usuário pode fazer simulação no seu desktop, evitando riscos de tentativas antes do desenvolvimento de uma solução. Este produto segue o método baseado em comunicação descrito anteriormente e possui duas versões: o Analyst Edition para analistas de negócio e o Developer Edition para desenvolvedores de aplicação. O sistema mínimo requerido é um PC com $16 \mathrm{MB}$ de $R A M$, com 8 MB de disco e sistema operacional Windows 95 ou Windows NT.

Os principais recursos oferecidos são:

- modelagem aberta do processo (descreve o processo em qualquer formato ou notação), a qual permite definir, analisar e melhorar continuamente o processo,

- gabaritos de acesso simples permitem ao analista de negócio um desenvolvimento rápido de modelagem de processo similar ou fornece modelagem pronta de alguns workflows específicos,

- framework centrado em pessoa define a satisfação do cliente como centro do processo de negócio,

- notificação automática por e-mail envia respostas e avisos,

- processamento de exceção habilita negociações e workflows ad-hoc e permite modelar processos de negócio do mundo real.

O editor gráfico possui alguns ícones, tais como o que representa um compromisso entre duas pessoas para executar uma tarefa, sendo que uma delas é o cliente e a outra é o executor. A modelagem aberta do processo permite que se criem os próprios objetos com suas propriedades, métodos e eventos, sendo possível integrar uma figura feita pelo software Flowchart. 0 recurso de link é usado para ligar os workflows baseado na seqüência em que ele é composto. Existem também icones de roteamento que iniciam tarefas de forma concorrente, de sincronização de tarefas, de tomada de decisão, de atualização da base de dados; etc. 
A representação gráfica do workflow pode ser exportada para os produtos da Microsoft, Power Point ou Word para uso em apresentações, para comunicação com o grupo envolvido epoder obter um feedback deste, possibilitando melhorar o processo.

\subsubsection{Office.IQ}

O Office.IQ, propriedade da empresa Portfólio Technologies Inc. [Port96], é uma aplicação de gerenciamento de documento distribuido e workflow baseado na plataforma Windows (Windows95 e Windows NT), que executa também em rede Novell. Seus recursos habilitam o usuário a executar as seguintes funções:

- Organizar a informação em desktops de forma customizada,

- Compartilhar somente os documentos desejáveis, restringindo acesso aos indivíduos conforme especificação,

- Rotear informação por rotas designadas ou via workflows ad-hoc, para especificar indivíduos ou grupos de qualquer lugar da rede empresarial,

Este produto possibilita administrar a certificação ISO9000, criar uma biblioteca de documentos permitindo recuperação rápida destes, controlar o acesso a documentos evitando modificações indesejadas, criar, rotear, rastear e manter a ordem de trabalho ou propostas de projeto, verificar o estado do processo de trabalho, distribuir documentos eletronicamente, recuperar documentos antigos, etc.

O Office.IQ permite personalizar o desktop por projeto ou responsabilidade. Também utiliza pastas para colecionar e organizar documentos conforme a necessidade do usuário. Envia e recebe informações (pastas e documentos eletrônicos) pelo recurso $\mathrm{In} / \mathrm{Out}$ Box, a qual apresenta as mensagens recebidas, podendo-se abri-las com um duplo click sobre elas. Possui um mecanismo para localizar rapidamente arquivos (search), que fornece os resultados da pesquisa em uma pasta. Uma forma de obter informações atualizadas é criar uma pasta com uma consulta (query) e ligá-la a uma nova pasta para os resultados, chamada de pasta inteligente, em que se pode executar um refresh (execução da consulta atualizando o conteúdo da pasta resultado) na pasta de resultado sempre que necessário. $\mathrm{O}$ acesso a documentos poderá ser controlado por meio de estabelecimento de privilégios, aos quais serão ligados usuários e documentos. Outro 
recurso disponivel é a definição e seleção de um workflow para indicar quem recebe uma informação e em que ordem. Isto é feito pelo editor gráfico de workflow, que permite representar a distribuição de cópias de documento em paralelo e sincronizar recebimentos múltiplos de um workflow, sendo que após esta definição de roteamento do workflow, seleciona-se o documento, arrasta-se e solta-se na In/Out Box e seleciona o workflow definido. É possivel visualizar graficamente a progressão do workflow (flecha azul indica rota completada e flecha vermelha rota não iniciada). Pode-se também indicar para ser notificado na ocorrência de um evento.

Além disso, o Office.IQ possui outros recursos, tal como, gerar gabaritos de documentos com formulários ou informações padrões, criando uma barra de gabaritos à direita da tela. Podese também forçar que o conteúdo de uma pasta herde o privilégio da pasta pai automaticamente. O Office.IQ oferece um conjunto de documentos pré-desenhados e de procedimentos para aplicações específicas de negócio.

\subsection{Considerações finais}

Neste capitulo foram apresentados vários conceitos e tipos de workflow, bem como as tecnologias envolvidas no gerenciamento de workflow. Foram também apresentadas algumas técnicas e métodos para modelagem e especificação de workflow, assim como os recursos de exemplos de sistemas de gerenciamento de workflow comerciais existentes no mercado.

Pôde-se verificar o estagio atual dessa tecnologia, bem como seus recursos potenciais a serem empregados em empresas, auxiliando significativamente na solução de problemas de um mercado globalizado. Apesar da existência de muitos produtos de workflow no mercado e essa tecnologia já ser explorada há algum tempo, nota-se que ela ainda pode evoluir muito, principalmente na questão de interoperabilidade entre produtos de fornecedores diferentes, permitindo que as organizações tenham ao seu dispor um leque de alternativas e possam optar por produtos que melhor atendam as suas necessidades em termos de recursos, custos e também de preferências, as quais possibilitariam mudanças sem grande impacto, isto é, mudanças parciais, como por exemplo, a troca da ferramenta de modelagem de workflow ou aquisição de outras contendo uma formalização diferente mais adequadas a determinadas áreas da empresa. Tais possibilidades aumentam a qualidade dos produtos e serviços, pois disponibilizam ferramentas apropriadas ao tipo de trabalho e melhor adaptadas ao perfil do usuário, melhorando a sua 
satisfação e produção. Em relação à gerência de documentos identificou-se a carência de ofertas pelo mercado de produtos que possuam recursos de autoria, armazenamento e visualização de documentos estruturados, integrado com workflow, que controlem seu ciclo de vida e também atendam às exigências das normas ISO-9000 para documentos; que seja portável para plataformas diferentes e possa ser manipulado por um browser na WEB, facilitando pelo oferecimento de uma interface padrão, alem de disponibilizar as informações na internet. 


\section{Capítulo 3}

ICMC - USP

\section{Modelo Conceitual de um Sistema de Workflow para Gestão de Documentos}

\subsection{Considerações iniciais}

O sistema de workflow para gestão de documentos proposto nesta dissertação tem por objetivo controlar o ciclo de vida de cada documento, bem como as tarefas que envolvem cada estagio desse ciclo, fornecendo apoio a empresas para atender às exigências da norma ISO-9001. Esse sistema é composto por dois módulos: um módulo de armazenamento de documentos, com capacidade de autoria, armazenamento e visualização de documentos (o qual está fora do escopo desse trabalho) e um módulo de workflow, que é composto por um componente de modelagem de workflow e um componente de execução de workflow. Tais módulos se complementam para atingir a meta do sistema.

Este capítulo inicialmente apresenta na seção 3.2 os recursos e os elementos de um sistema de gestão de documentos e a interpretação da ISO-9001, em sua seção 4.5. Em seguida, na seção 3.3 destaca as principais características da abordagem do sistema de workflow para gestão de documentos e na seção 3.4 representa o seu modelo de dados em três níveis inter-relacionados. Finalmente, na seção 3.5 define duas linguagens para especificação de workflow, na seção 3.6 lista as funcionalidades oferecidas pelo sistema e na seção 3.7 dá exemplos de especificação de workflow.

\subsection{Workflow de documentos}


Um sistema de gerenciamento de workflow incorpora muitas tecnologias, como por exemplo, o gerenciamento de documentos [Ge095]. Um sistema de gestão de documentos permite gerenciar uma faixa ampla de documentos eletrônicos, tais como documentos de qualquer formato, armazenados em qualquer local; documentos que sofrem alterações durante a sua vida útil $\mathrm{e}$ documentos que podem ser acessados facilmente, tanto dentro como fora da sua organização.

Um sistema de gestão de documentos executa as seguintes funções, dentre outras: identificação de documentos; armazenamento e recuperação de documentos; rastreamento de documentos; gerenciamento do fluxo de trabalho associado ao documento e apresentação de documentos.

São elementos de um sistema de gestão de documentos: a infra-estrutura, compreendendo o conjunto de computadores, estações de trabalho e servidores que estão interconectados às redes; as ferramentas de autoria, que auxiliam na criação de documentos; o fluxo de trabalho (workflow) definido como a coordenação de tarefas, dados e pessoas para tornar um processo mais eficiente, efetivo e adaptável a mudanças; o armazenamento de documentos; os serviços relacionados a mecanismos de controle de documentos, tais como: controle da entrada e saída de documentos, da trilha de auditoria, do nível de proteção/segurança e da versão de documentos; e os serviços de apresentação e distribuição de documentos.

Tradicionalmente existem duas classes de gestão de documentos:

- o gerenciamento de imagens fixas de papel (estáticas);

- o gerenciamento de documentos editáveis (dinâmicos).

\subsubsection{ISO 9000 para documentos}

É essencial para aceitação de produtos e serviços no mercado globalizado a certificação ISO, a qual estabelece normas de qualidade. A norma ISO 9001 trata na sua seção 4.5 do controle de documentos, exigindo que as empresas devem estabelecer e manter procedimentos documentados para controlar todos os documentos e dados (podendo estes estar em forma de cópia fisica, meios eletrônicos e outros) que digam respeito aos requisitos da ISO 9001, incluindo, na extensão aplicável, documentos de origem externa, tais como normas e desenhos do cliente. 
Os documentos e dados devem ser analisados criticamente e aprovados quanto a sua adequação por pessoal autorizado, antes de sua emissão. Uma lista mestra ou procedimento equivalente de controle de documentos, identificando a situação da revisão atual dos documentos, deve ser estabelecida e estar prontamente disponível, a fim de evitar o uso de documentos inválidos e/ou obsoletos. As modificações em documentos e dados devem ser analisadas criticamente e aprovadas pelas mesmas funções/organizações que realizaram a análise crítica e aprovação original, salvo prescrição em contrário. Quando for praticável, a natureza das modificações deve ser identificada no documento ou em anexos apropriados.

Adicionalmente, a ISO 9001 orienta que os documentos utilizados para transmissão de informações na empresa devem ser controlados, de maneira que cada pessoa tenha acesso às informações que necessita e no momento correto. Tendo em vista que as normas NBR ISO 9001/94 exigem grande esforço de documentação dos processos da empresa, deve-se atentar para que estes documentos tenham distribuição controlada, além de terem sido analisados e aprovados por pessoas capacitadas para tal, antes de sua emissão.

\subsection{A abordagem do sistema de workflow para gestão de documentos}

O sistema integra algumas características e requisitos (alguns definidos pelo projeto GDOC) que o diferenciam dos sistemas existentes no mercado apresentados no capítulo anterior e que são descritos a seguir.

\subsubsection{Workflow genérico e independente do módulo de autoria de documentos}

O módulo de workflow deve ser genérico, isto é, permitir ser usado na modelagem de processos com diferentes enfoques, tais como: processo de software, gerenciamento de configuração, processos de negócio e outros, bem como processos envolvendo o ciclo de vida de documentos e 
que é o objetivo desse trabalho. O sistema deve oferecer mecanismos para especificação de workflow de documentos que utilizam ferramentas de autoria diferentes, sendo, portanto independente delas, o que permite que o usuário selecione a ferramenta de autoria de documentos que melhor lhe convier, fornecendo flexibilidade ao usuário e possibilidade de aproveitamento dos recursos existentes na organização. A integração entre o workflow e as ferramentas de autoria de documento pode ser feita de forma ad hoc ou por API's (Aplication Programing Interface).

\subsubsection{Dados armazenados em um banco de dados relacional}

Todos os dados de especificação e execução de workflow devem ser armazenados em uma plataforma de banco de dados relacional compatibilizando-se com a maioria das aplicações de banco de dados do mercado, a qual é amplamente usada pelas empresas. A plataforma relacional oferece ainda a simplicidade de consulta e manipulação dos dados de workflow por intermédio de SQL (Structured Query Language), que é a linguagem mais usada de acesso à banco de dados relacionais.

\subsubsection{Reusabilidade de atividades e especificação de ação automatica}

O sistema deve oferecer a possibilidade de reuso das atividades especificadas, facilitando a tarefa de definição de workflow e com isso permitindo o estabelecimento de atividades padronizadas a serem usadas em diversos processos, facilitando o aprendizado do usuário executor e também incrementando a produtividade. Outro fator facilitador e de aumento de produtividade que deve ter é a especificação de ações automáticas, reduzindo parcialmente ou totalmente a intervenção humana nas suas execuções.

\subsubsection{Facilidade de especificação de workflow}

Deve oferecer simplicidade e facilidade na definição de processo combinado com recursos poderosos oferecidos por uma linguagem de roteamento de atividades, em conformidade com o padrão estabelecido pela WfMC e por uma linguagem de definição de ações. 


\subsubsection{Interface homem-máquina padronizada}

As funcionalidades do sistema devem ser disponibilizadas aos usuários por intermédio de um web browser, o qual é uma peça importante de software da internet, cuja popularização vem ocorrendo em um nivel exponencial. Portanto, facilitando o aprendizado da execução do sistema.

\subsubsection{Arquitetura}

Deve ter uma arquitetura distribuída, podendo ser executado sem mudanças em ambiente internet e intranet. Outra vantagem dessa característica é a facilidade de atualização, pois todas as instalações de software devem ser realizadas apenas no servidor da aplicação. A manutenção e gerência da base de dados também é facilitada, pois apenas uma instância do repositório é usada pelo sistema.

\subsubsection{Portabilidade do sistema}

O sistema deve ser portável, de forma que as suas funcionalidades possam ser executadas em múltiplas plataformas e serem oferecidas a partir de páginas HTML exibidas por um web browser.

\subsubsection{Niveis de abstração de documentos}

Documentos podem ser categorizados conceitualmente por características que os tomam similares. É fácil perceber informalmente a diferença entre um formulário e uma carta. Um tipo de documento possui um esquema pré-definido em relação à estrutura lógica e de apresentação a serem seguidas pelas instâncias desse documento. Em tempo de autoria os usuários completam somente o conteúdo do documento e de seus componentes. Exemplos de documentos que podem ser categorizados são: cartas, memorandos, oficios, atas, notas fiscais, recibos, requerimentos, etc. 
Tabela 3.1 - Níveis de abstração de documentos e sua manipulação

\begin{tabular}{|c|c|c|}
\hline Nivel Conceitual & Definição do workflow & Execução do workflow \\
\hline $\begin{array}{l}\text { Categoria de } \\
\text { documentos }\end{array}$ & $\begin{array}{l}\text { Workflow para manipulação de } \\
\text { tipos de documentos (por ex., } \\
\text { criar um formulário) }\end{array}$ & $\begin{array}{l}\text { Exemplos: } \\
\text { - carta } \\
\text { - formulário }\end{array}$ \\
\hline $\begin{array}{l}\text { Tipo de } \\
\text { Documento }\end{array}$ & $\begin{array}{l}\text { Workflow para manipular } \\
\text { instâncias de documento (por } \\
\text { ex., workflow que produz como } \\
\text { resultado um formulário } \\
\text { preenchido) }\end{array}$ & $\begin{array}{l}\text { Exemplo: } \\
\text { - formulário de abertura de } \\
\text { conta no sistema }\end{array}$ \\
\hline $\begin{array}{l}\text { Documento } \\
\text { (ou Instância de } \\
\text { documento) }\end{array}$ & & $\begin{array}{l}\text { Documento } \\
\text { Exemplo: } \\
\text { - formulário de abertura de } \\
\text { conta no sistema preenchido } \\
\text { por alguém }\end{array}$ \\
\hline
\end{tabular}

Legenda: $\longrightarrow$ "a execução do workflow produz"

A integração entre workflow e documento se dá pela definição de processos manipuladores de tipos de documento e de documentos, os quais podem ser criados, distribuídos, armazenados, etc. $\mathrm{O}$ relacionamento entre os diferentes níveis de documentos e workflow é mostrado na tabela 3.1.

Um documento que não se enquadra em um tipo é um documento de estilo livre, em que a estrutura lógica e de apresentação é definida pelo usuário em tempo de autoria [Gra97]. Exemplos de documentos que geralmente não são classificados em tipos são: relatórios, projetos, gráficos, avisos, publicações, modelagem gráfica, etc. 
Tabela 3.2 - Operações com tipos de documentos e documentos

\begin{tabular}{|l|c|}
\hline & Tipos de operaçöes \\
\hline Tipo de Documento & $\bullet$ criar \\
& $\bullet$ consolidar \\
& $\bullet$ consultar \\
& $\bullet$ modificar \\
\hline Documento & $\bullet$ desativar/ativar \\
& $\bullet$ excluir \\
\hline & $\bullet$ criar \\
& $\bullet$ distribuir \\
& $\bullet$ comitir cópias \\
& $\bullet$ baixar para arquivo morto \\
\hline
\end{tabular}

Existem tipos de documentos a partir dos quais poderão ser geradas várias instâncias de documentos, como por exemplo, um formulário de abertura de conta em um sistema computacional (por exemplo, o formulário de senha do ICMC), o qual será preenchido por diversos usuários, gerando diversas instâncias. $\mathrm{E}$ há outros cujo tipo gera apenas uma instância de documento, por exemplo, uma norma interna da empresa ou um documento de origem externa.

Em um ambiente organizacional, a criação de tipos de documentos padroniza a documentação e facilita a sua manipulação por processos administrativos, mas existem operações com características particulares exigindo a geração de documentos que não se adequam ao esquema pré-definido pelos tipos, sendo então criados documentos de estilos livres. Portanto, um mesmo documento poderá, dependendo do seu uso, ser categorizado em tipo ou não. Essa classificação dos documentos poderá também diferir de empresa para empresa, de acordo com a natureza do negócio. 
Deve-se notar que o workflow usa em sua definição os conceitos do documento um nível acima e sua execução manipula ou produz um documento no nível imediatamente inferior. As principais operações que podem ser executadas sobre um tipo de documento ou a um documento são mostradas na tabela 3.2 .

Criar um tipo de documento: significa executar um processo que define um tipo de documento. Posteriormente, um processo que define seu preenchimento pode gerar um documento.

Consolidar um tipo de documento: significa habilitar um tipo de documento para uso, não permitindo sua alteração ou exclusão.

Consultar um tipo de documento: significa visualizar um esquema pré-definido de estrutura lógica e de apresentação (por exemplo, visualizar um formulário não preenchido).

Modificar um tipo de documento: um tipo de documento após consolidado, isto é, depois de ter sido disponibilizado para uso, não pode ser alterado, devendo neste caso ser criada uma versão. Caso contrário, o tipo de documento pode sofrer as alterações necessárias e estas são realizadas por meio de um processo definido obedecendo às normas da organização.

Desativar/ativar um tipo de documento: quando se quer inibir o uso de um tipo de documento, este é desativado. Posteriormente o mesmo pode ser ativado, isto é, restabelece-se a permissão de uso.

Excluir um tipo de documento: somente é possível enquanto não for consolidado (disponibilizado para uso) pelo autor do documento ou administrador do sistema.

Criar um documento: significa executar um processo de uso previamente definido com esta finalidade, isto é, um processo que oriente, por exemplo, o preenchimento de um formulário (no caso de ser um documento categorizado em tipo) ou a criação de um documento de estilo livre e também o fluxo dessa operação na organização.

Modificar ou excluir um documento: não pode ser feito após o término da execução do processo de criação do documento por questões legais, operacionais ou administrativas. As modificações ou exclusões permitidas devem ser tratadas pelo processo de criação.

Distribuir um documento: após a criação de um documento, o mesmo pode ser distribuído às pessoas competentes que o manipularão. Isto é feito mediante a criação de processos que contêm 
atividades com ações sobre o documento. Pode-se também comunicar pessoas sobre a geração de documentos para que elas executem workflows.

Emitir cópias de documento: é executada a partir de um processo (previamente definido), exigindo autorização de um participante competente para a emissão da cópia e registrando a operação para futura auditoria.

Consultar um documento: mostra o conteúdo (atributos) de um documento, parcialmente ou na sua totalidade.

Baixar para arquivo morto: significa que todos os documentos com período de competência vencido podem ser transferidos para um meio de armazenamento mais barato e seguro, agilizando também as operações sobre os documentos ativos.

\subsubsection{Definição de processos}

Um processo representa um conjunto ordenado de_atividades (paralelas e/ou seriais), que são conectadas a fim de atingir uma meta comum [Wfing6b]. Muitas operaçóes envolvendo tipos de documentos ou documentos podem ser efetuadas por intermédio de processos. Esses processos são especificados conforme as necessidades do negócio. As operações possíveis com processos são:

Criar um processo: possibilita desenvolver um processo novo, especificar as suas atividades, a sequêencia de execução delas, bem como as respectivas propriedades.

Consultar um processo: permite ao usuário visualizar a especificação gráfica do processo e as propriedades geradas na criação.

Modificar um processo: esta operação permite alterar a especificação de um processo, sendo que sua execução somente pode ser efetuada antes do mesmo estar habilitado para execução por usuários. Após isso, as alterações devem ocorrer na forma de criação de versões para não provocar problemas operacionais de processos em execução e também garantir a integridade referencial entre a especificação e seu histórico de execução.

Excluir um processo: significa excluir fisicamente a especificação de um processo e só é permitida antes do mesmo estar habilitado para execução. 
Consolidar um processo: habilita-o para execução e impede a sua alteração ou exclusão.

Cancelar ou desativar um processo: altera o estado da situação de definição do processo, não permitindo que novas instâncias de execução do processo sejam geradas.

Habilitar a execução de um processo: restaura a sua possibilidade de execução (criação de instâncias do processo).

\subsubsection{Atendimento das exigências ISO 9000}

No item 3.2.1 deste capitulo foram relatadas exigências a serem cumpridas para obtenção da certificação ISO 9001, na sua seção 4.5. A seguir é apresentado como o sistema de gerenciamento de workflow para gestão de documentos pode contemplar essas exigências.

1. Manter procedimentos documentados para controlar todos os documentos (podendo estes estarem no formato de cópia fisica, meios eletrônicos e outros).

Todos os documentos recebidos e emitidos pela organização são armazenados no módulo de armazenamento de documentos. Todas as operações (procedimentos) sobre esses documentos são efetuadas por pessoas autorizadas, por intermédio de processos ou por funcionalidades oferecidas pelo sistema. Isso permite controlar e documentar eficazmente todos os documentos e suas operações. Por exemplo, para criar um documento o usuário autorizado executa um processo previamente definido, contendo as ações necessárias conforme as normas estabelecidas pela organização e registrando esse processo em um histórico.

2. Os documentos devem ser analisados criticamente e aprovados quanto a sua adequação por pessoal autorizado, antes da sua emissão.

No módulo de workflow são gerados processos de criação de documentos, definindo participantes que conferem e autorizam a emissão. A execução desses processos é restrita a pessoas 
autorizadas e documentos somente podem ser criados a partir de processos formais de workflow. Por exemplo, ainda citando o processo de criação de um documento, este contem atividades de conferência e autorização que são executadas por participantes qualificados pela organização, antes da emissão do documento, garantindo a aplicação deste item da norma.

3. A situação da revisão atual dos documentos deve ser estabelecida e estar prontamente disponível, a fim de evitar o uso de documentos inválidos e/ou obsoletos.

O tipo de documento usado na instanciação de documentos possui uma data de revisão gerada pela ferramenta com a qual o documento foi criado. Periodicamente pode ser executada uma funcionalidade do sistema que verifica as datas próximas de vencimento e caso alguma se enquadre nesta situação, é disparado um processo de revisão. A revisão pode ser feita também por iniciativa de algum participante, existindo um processo específico para tal. É emitido um aviso ao usuário para indicar que o tipo de documento está com data próxima de ser revisado ou para impedir a utilização de tipos de documentos com data de revisão vencida. Sempre que o tipo de documento exigir mudanças, é criada uma nova versão e se necessário desativada a versão obsoleta, impedindo seu uso, mas mantendo-se para fins de histórico.

Os documentos gerados são mantidos ativos (disponíveis on line para uso) por um período adequado à necessidade de cada organização e, após isso, são baixados para arquivo morto (em um meio de armazenamento barato) e mantidos por um período de tempo conforme legislação. Por exemplo, periodicamente uma funcionalidade do sistema pode ser executada para baixar ao arquivo morto documentos que não se enquadram no período de competência atual.

Os tipos de documentos, documentos e respectivos controles mencionados neste item ficam disponibilizados para uso em rede e, portanto, garantem o compartilhamento por todos os locais autorizados, onde são executadas operações essenciais para o funcionamento efetivo do Sistema de Qualidade.

4. As modificações em documentos devem ser analisadas criticamente e aprovadas pelas mesmas funções/organizações que realizaram a análise crítica e aprovação original. 
Esta situação é garantida pela definição de processos de alteração de tipo de documento que, como no item 2, qualificam pessoas para conferir e autorizar as modificações, além de restringir por autorizações a execução desses processos. As modificações e justificativas são registradas pela história dos processos e das atividades, permitindo a verificação destas por pessoas autorizadas. Para os documentos, somente são permitidas alterações durante o seu processo de geração.

5. Documentos utilizados para transmissão de informações na empresa devem ser controlados, de maneira que cada pessoa tenha acesso às informações que necessita $e$ no momento correto.

Este requisito é atendido pelo armazenamento dos documentos em uma base de dados disponivel em rede. Isso permite que nos diversos locais da empresa (conforme necessidade) existam estações que recuperem rapidamente os documentos com posição mais atualizada no momento desejado. São criadas restrições de acesso aos documentos, inclusive quanto ao seu conteúdo. Desta forma, as informações adequadas são mostradas, conforme a necessidade, às pessoas certas. Por exemplo, operações de consulta com conteúdo e níveis de sintetização diferenciados, oferecidas pelo sistema, conforme autorizações.

6. Os documentos devem ter distribuição controlada, além de terem sido analisados $e$ aprovados por pessoas capacitadas para tal, antes de sua emissão.

A distribuição ou emissão de cópias é efetuada por definição de processo com atividades que atinjam o resultado desejado e com restrições de execução. A operação é registrada para futuras verificações. Por exemplo, a definição de um processo cujas atividades comuniquem a participantes interessados a geração do documento e as operações a serem efetuadas com ele. Outro exemplo: um participante autorizado executando um processo (definido anteriormente) que permita selecionar um documento para cópia e exija autorização de participante qualificado para sua emissão. 


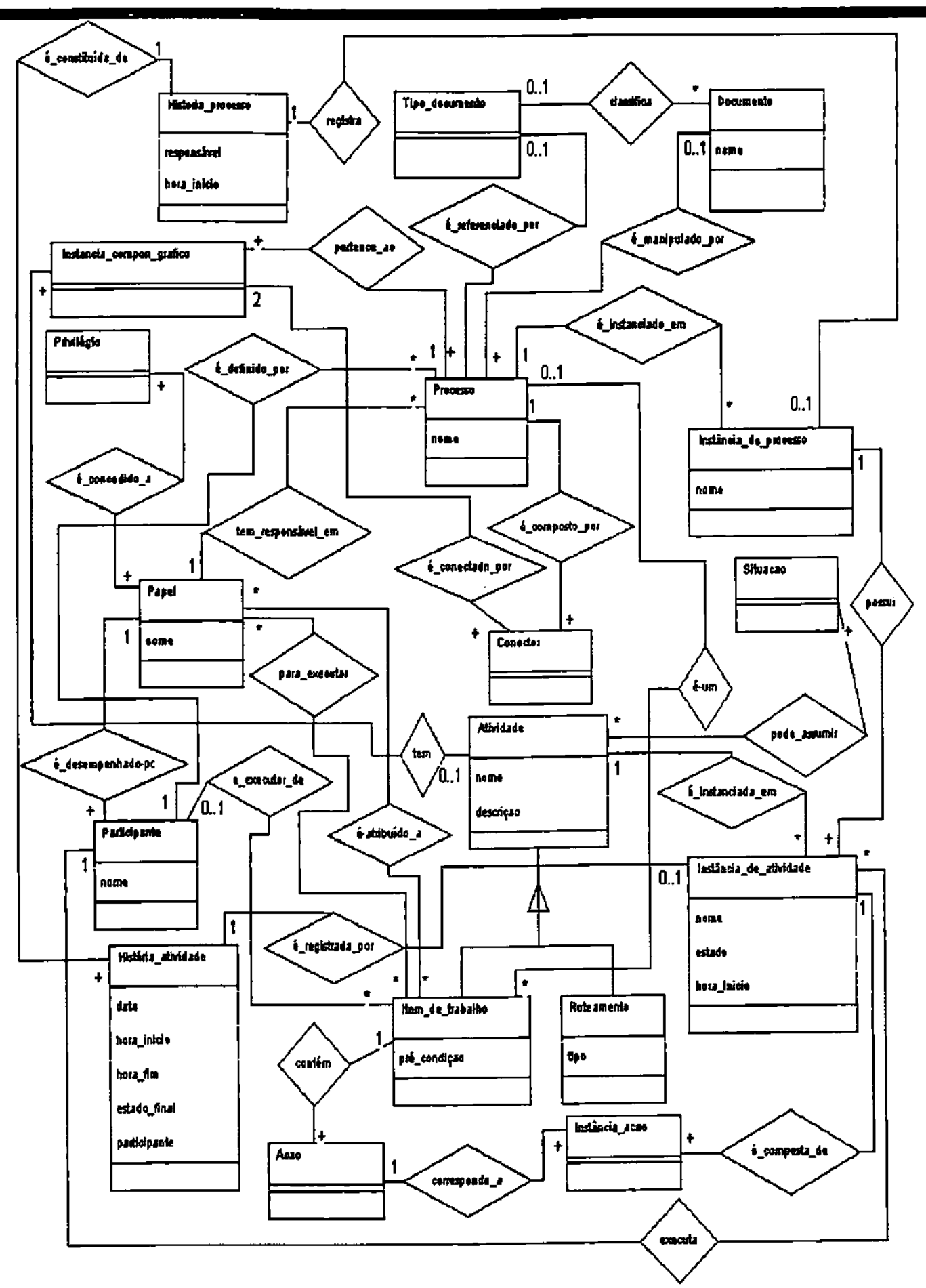

Figura 3.1 Módulo de Workflow 


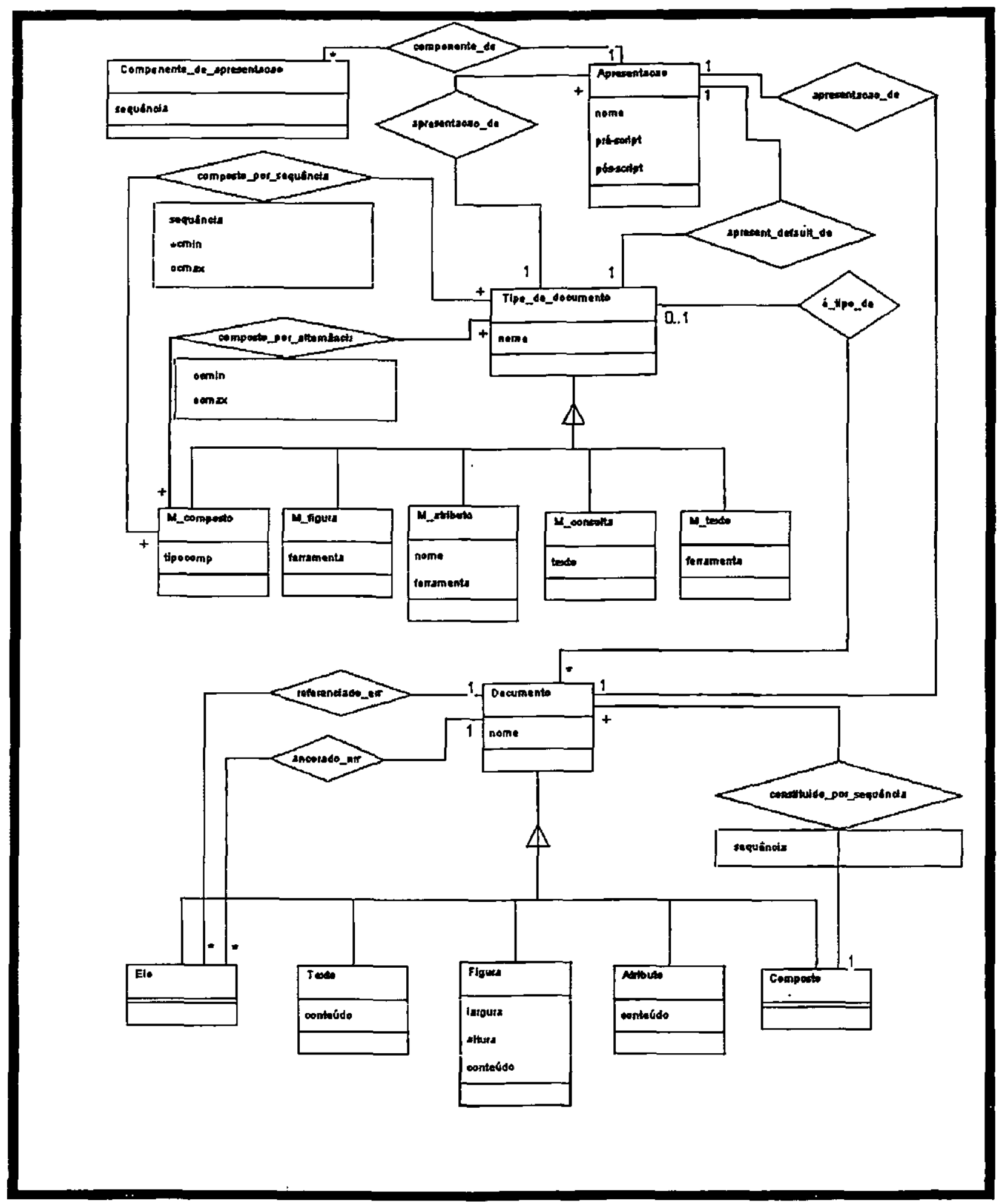

Figura 3.2 Módulo de Documentos 


\subsection{Proposta de um modelo conceitual}

O modelo de objetos resultante da modelagem do sistema usa a notação do método FUSION [Col94] e reflete os requisitos do sistema. A modelagem do sistema é composta de dois módulos: de workflow e de documentos [Bru97b], os quais estão representados graficamente pela figura 3.1 e 3.2 respectivamente. As classes de "Tipo_documento" e "Documento" representam o elo entre os dois módulos. O protótipo construído é multiinstitucional, sendo que o objeto deste trabalho atende aos requisitos do módulo de workflow, estando o módulo de documentos sob responsabilidade de outra instituição componente do projeto GDOC [Gra98].

O modelo de dados do workflow é composto por três partes inter-relacionadas:

- o modelo de administração, que compreende as classes que armazenam os dados essenciais para que o sistema se torne operacional,

- o modelo de especificação de workflow, que compreende as classes que contêm informações geradas pelo editor de processos, e

- o modelo de instâncias de workflow, formado pelas classes que armazenam informações referentes à execução de processos pela máquina de workflow.

\subsubsection{Modelo de administração}

Este modelo representa as informações iniciais do sistema necessárias aos demais modelos. As classes em verde da figura 3.3, do submódulo de especificação de workflow representam essas informações, as quais são descritas a seguir:

- Participante: contém informações de usuários autorizados a manipular as funcionalidades do sistema.

- Papel: envolve conceitos organizacionais tais como: autoridade, responsabilidade e habilidade, correspondendo às funções existentes em uma organização, como por exemplo: gerente, chefe de seção e auxiliar administrativo. 


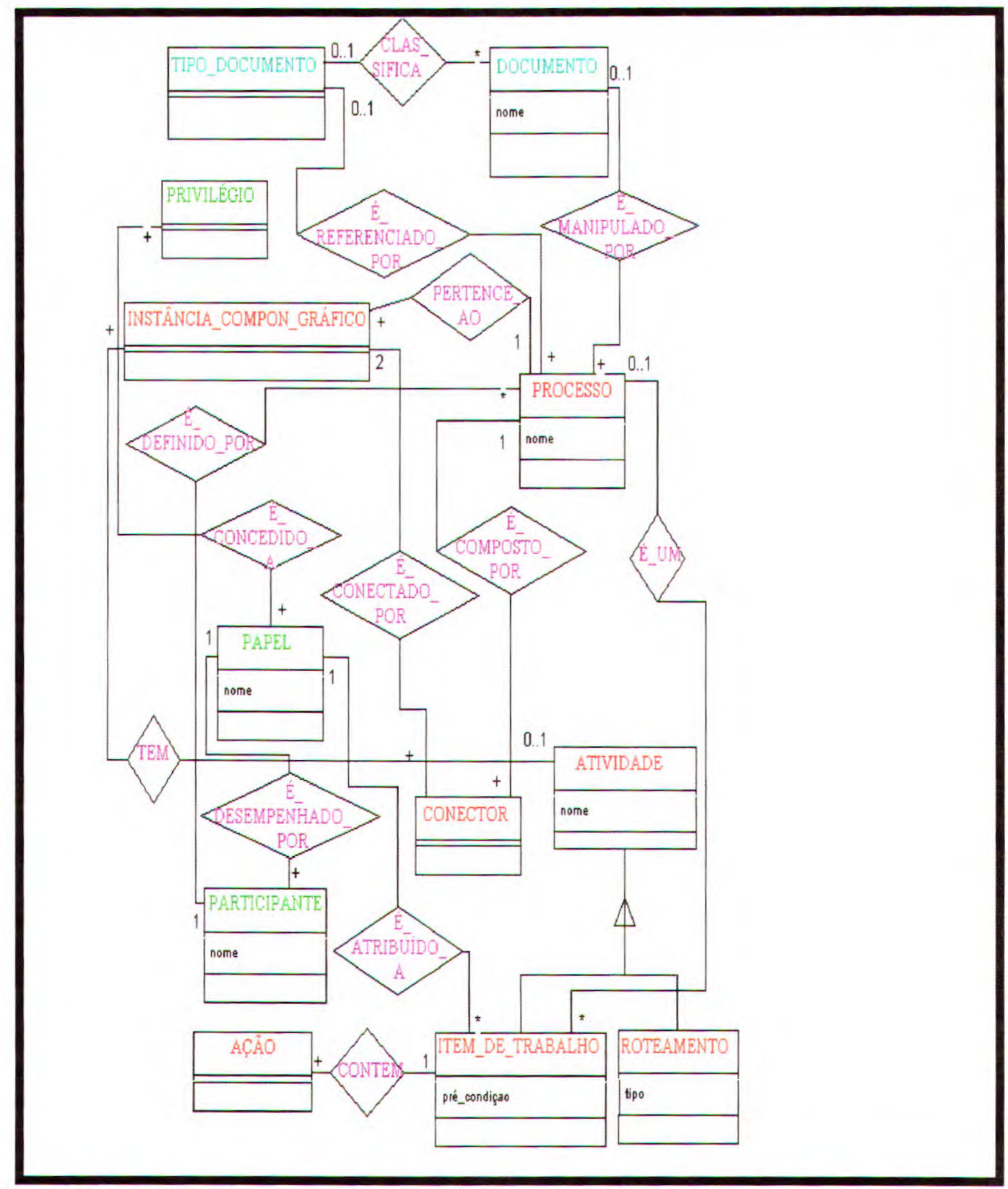

Figura 3.3 Módulo de especificação 


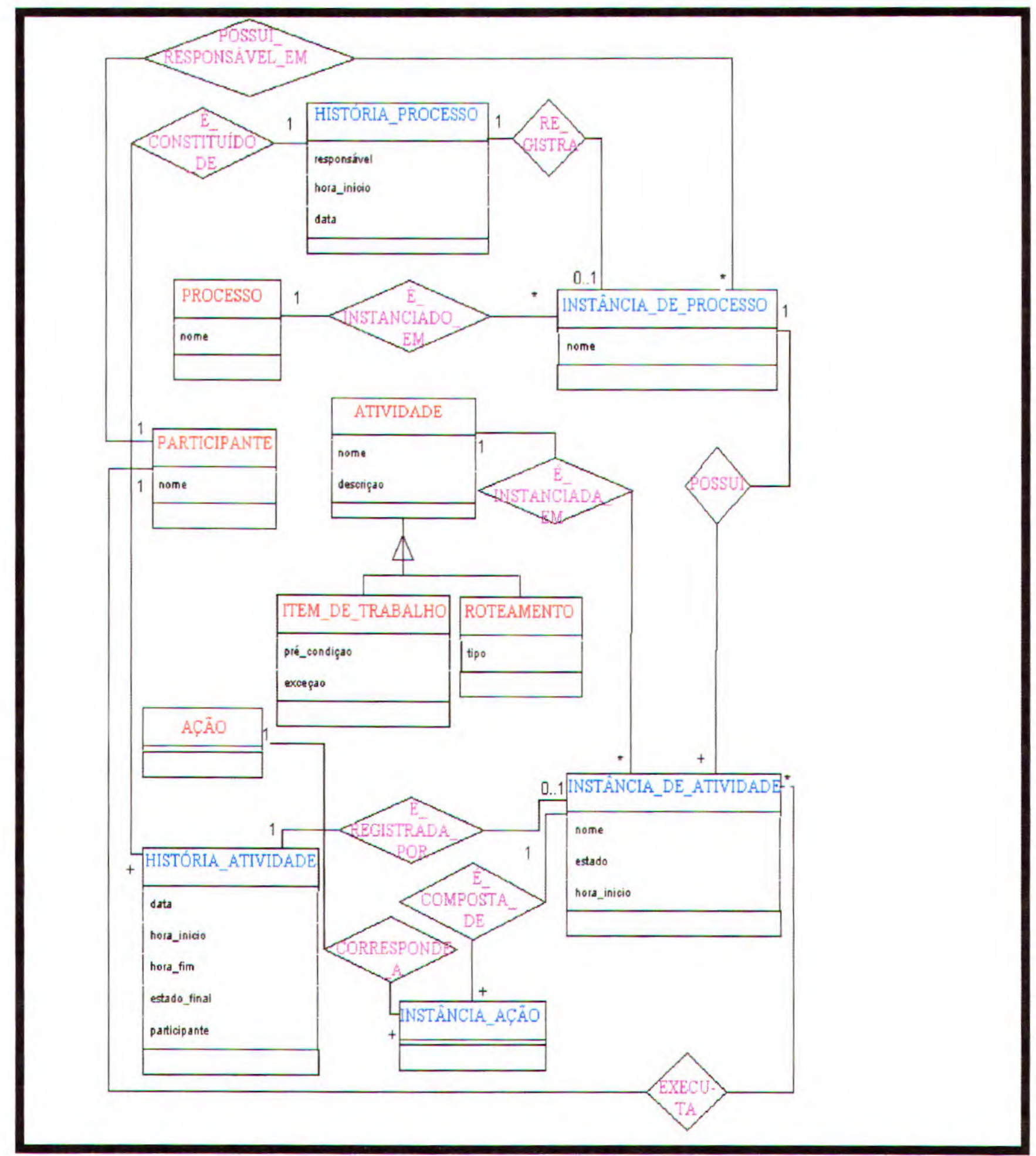

Figura 3.4 Módulo de execução de workflow 
- Privilégio: corresponde ds funcionalidades oferecidas pelo sistema e às identificações de workflows especificados.

Papéis são atribuídos a participantes e privilégios são atribuídos a papéis, gerando assim as autorizações de manipulação do sistema.

\subsubsection{Modelo de especificação}

Nesta parte são representadas as informações referentes à definição do processo pelo editor de workflow, as quais correspondem às classes em vermelho da figura 3.3, descritas a seguir:

- Processo: contém dados de sua identificação e informações gerais sobre o processo.

- Instância_compon_gráfico: contem as instâncias de componentes gráficos, de workflows especificados, com suas coordenadas em relação à área de desenho do editor.

- Conector: fornece informação referente a que workflow pertence uma instância de componente gráfico e a sua seqüência de execução.

- Atividade: mantém informações gerais sobre si e indica o seu tipo, que pode ser um item de trabalho ou de roteamento.

- Item_de_trabalho: um item de trabalho é um tipo de atividade que relaciona as ações a serem executadas por um participante e contém informações gerais a seu próprio respeito.

- Ação: define as ações que serão executadas em um workflow, podendo ser manual ou automática.

- Roteamento: esta classe contem regras de navegação de workflows, dentre as quais, a que permite execução em paralelo e sincronização de atividades.

As classes "tipo_documento" $\mathrm{e}$ "documento" em ciano representam o elo entre este módulo e o módulo de documentos. 


\subsubsection{Modelo de instâncias de workflow}

Este modelo representa as informações geradas na instanciação (execução) de workflows representadas pelas classes em azul na figura 3.4 , as quais são descritas a seguir.

- Instância_de_Processo: mantêm informações sobre a execução do workflow, tais como: data e hora de início e seu estado.

- Instância_de_Atividade: nesta classe são instanciadas as atividades dos processos em execução na ordem estabelecida na definição do processo, contendo informações tais como: estado, data e hora de início e participante executor.

- Instância_Ação: contém informações referentes à execução das ações de uma atividade do tipo item de trabalho, tais como: estado, data e hora de inicio, data e hora de finalização e a identificacão do participante que a cancelou ou suspendeu.

- História_Atividade: mantém informações referentes às atividades executadas para fins estatísticos e de auditoria.

- História_Processo: mantém informações a respeito dos workflows executados para fins estatísticos e de auditoria.

As classes em vermelho são o elo com o módulo de especificação de workflow.

\subsection{Linguagens para especificação de Workflow}

Como foi visto anteriormente, há a necessidade de se especificar processos formalmente para a manipulação de documentos. Para atender a esse requisito foram definidas duas linguagens: a Linguagem de Roteamento de Atividades (LIRA) e a Linguagem de Definição de Ações (LIDA).

\subsubsection{Linguagem de Roteamento de Atividades (LIRA)}


Aqui é definida informalmente a linguagem de roteamento de atividades, listando os seus componentes gráficos juntamente com suas propriedades [Bru97c]. É feita também uma comparação dessa linguagem com a desenvolvida pela Workflow Management Coalition (WFMC), mostrando as diferenças entre as mesmas.

\subsubsection{Atividade item de trabalho}

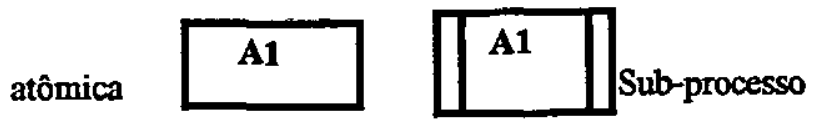

Figura 3.5 Exemplo de representação gráfica de uma atividade item de trabalho

Pode representar uma atividade atômica ou um subprocesso, conforme mostrado na figura 3.5. A atividade atômica contém as ações que deverão ser executadas para cumprir a meta, tais como, as atividades A1, A2, A4, A5, A6 e A7 do exemplo da figura 3.13. A atividade subprocesso é composta de atividades que poderão ser atômicas ou subprocessos representando níveis de abstração do workflow. A atividade A3 da figura 3.13 exemplifica uma atividade contendo um subprocesso.

A atividade do tipo item de trabalho pode ter uma expressão booleana no atributo de précondição que a habilita a iniciar a execução somente se o resultado for verdadeiro e nesse caso a instância da atividade passa para o estado "Esperando exec.", aguardando ação do participante executor. Caso contrário a atividade ficará suspensa com o estado corrente "Habilitado a exéc" e é avaliada periodicamente pela máquina de workflow até que a expressão seja satisfeita e então possa iniciar execução.

Durante a especificação da atividade do tipo item de trabalho, são fornecidas as suas propriedades, tais como: nome da atividade, descrição da atividade, pré-condição, situações (estados) que a atividade pode assumir, número de instanciações que podem ser feitas, papéis executores (exceto para a atividade subprocesso), tempo previsto de execução, identificação do subprocesso caso seja uma atividade subprocesso, ações (exceto para subprocesso) e descrição da ação. A précondição e a descrição da ação são especificadas por uma linguagem com esse fim. As atividades desse tipo podem ser especificadas utilizando-se as propriedades de atividades já existentes. 


\subsubsection{Conexōes entre atividades}

Conexões descrevem interações entre atividades e determinam a seqüência de execução entre elas. Há duas formas de conexão entre atividades: conexão direta e conexão executada por atividade de roteamento.

\subsection{Conexão díreta}

É utilizada para ligar duas atividades e é representada graficamente por uma flecha (aresta) conectando-as. Duas atividades que são ligadas por uma aresta têm um significado intuitivo, isto é, de acordo com a figura 3.6, tão logo a atividade A1 finalize, a atividade A2 está pronta para executar. É caracterizada por um fluxo simples entre atividades. Um exemplo de uso pode ser visto na figura 3.13, com a conexão entre as atividades A4 e A5.

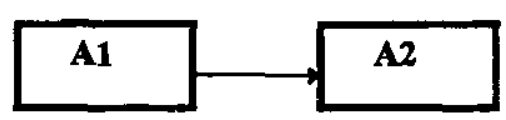

Figura 3.6 Exemplo de representação gráfica de uma conexão direta

\subsection{Conexão por Atividade de roteamento}

Conecta mais de duas atividades e é composta pelas seguintes formas: and-split, and-join, orsplit e or-join. É representada graficamente por um pequeno círculo com arestas ligando as atividades envolvidas. Uma regra de navegação (condição de transição) pode ser definida, a qual é avaliada pela máquina de workflow em tempo de execução, para decidir a seqüência de execução do processo.

Durante a especificação desse tipo de atividade são fornecidas algumas propriedades, tais como: tipo de roteamento e uma expressão (regra de navegação). 


\subsection{And-split}

Um ponto dentro do workflow no qual um fluxo simples de controle se divide em dois ou mais, levando a atividades que serão executadas em paralelo (representada pela atividade RI na figura 3.7).

A semântica da figura 3.7 mostra que após o término da atividade $\mathrm{A} 1$, as atividades $\mathrm{A} 2, \mathrm{~A} 3 \mathrm{e}$ A4 estarão prontas para iniciar a execução em paralelo.

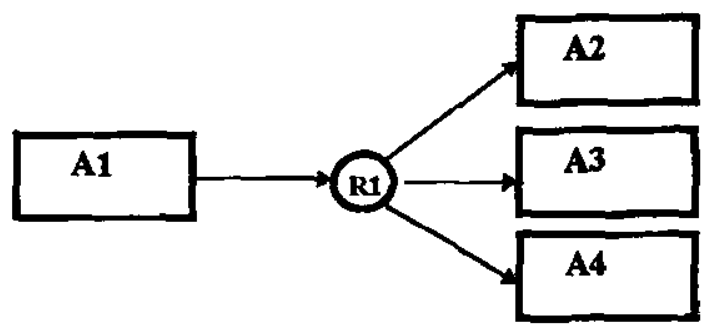

Figura 3.7 Exemplo de representação gráfica de um and-split.

Neste tipo de roteamento a atividade $\mathrm{R} 1$ não tem nenhuma expressão (regra de navegação) a ser avaliada pela máquina de workflow, a qual identifica e habilita para execução as atividades sucessoras, utilizando a classe "Conector" [Bru97a].

\subsection{And-join}

Um ponto no workflow onde duas ou mais atividades que executam em paralelo convergem para um fluxo de controle simples (representada pela atividade R1 na figura 3.8).

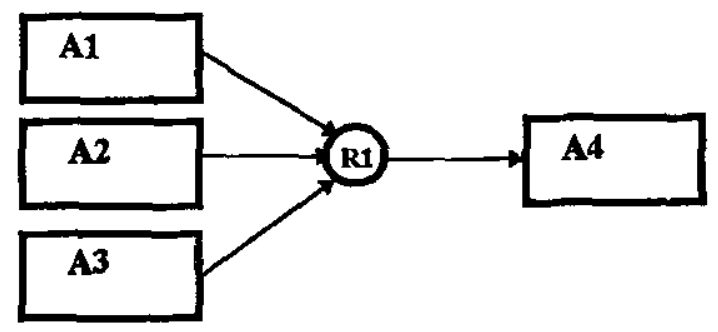

Figura 3.8 Exemplo de representação gráfica de um and-join 
A semântica da figura 3.8 mostra que a atividade A4 estará pronta para iniciar execução somente após o término das atividades A1, A2 e A3. A atividade de roteamento $R 1$, nesta estrutura, não possui regra de navegação a ser avaliada pela máquina de workflow. O controle da atividade de roteamento quanto a esperar o término de suas atividades predecessoras para habilitar a execução de sua atividade sucessora, é feito pela máquina de workflow a partir da classe "Conector" [Bru97a], que contém registros das suas atividades predecessoras. Quando todas as atividades predecessoras terminarem, então a máquina de workflow habilita a execução da atividade sucessora.

\subsection{Or-split}

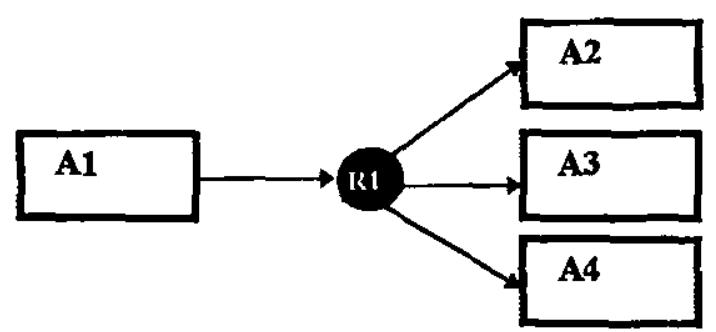

Figura 3.9 Exemplo de representação gráfica de um or-split

Um ponto no workflow onde um fluxo simples de controle toma uma decisão de qual ramo seguir quando encontra múltiplos ramos alternativos de workflow (representada pela atividade R1 da figura 3.9).

A semântica da figura 3.9 indica que após o término da atividade Al a condição de transição da atividade R1 será avaliada para decidir qual das atividades (A2 ou A3 ou A4) será habilitada para execução. A atividade de roteamento $\mathrm{R} 1$ contém uma expressão que possui a regra de navegação que é avaliada pela máquina de workflow e que indica qual das atividades sucessoras é habilitada para execução. No exemplo da figura 3.9, a atividade R1 contém uma expressão com a possibilidade mutuamente exclusiva de execução das atividades A2, A3 e A4. Um exemplo de sua aplicação é a atividade R3 da figura 3.13. 


\subsection{Or-join}

Um ponto no workflow onde dois ou mais ramos alternativos de atividades de workflow convergem para uma atividade comum como próximo passo (representada pela atividade R1 da figura 3.10).

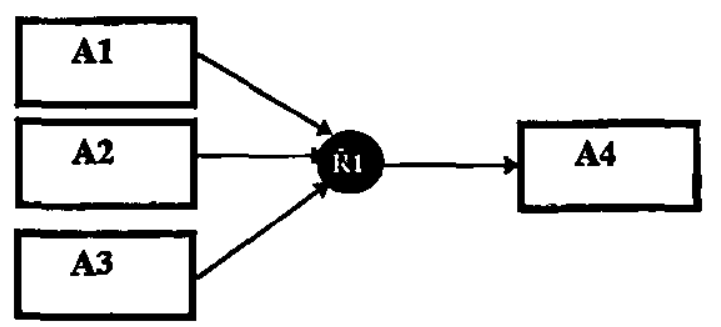

Figura 3.10 Exemplo de representação gráfica de um or-join

A semântica da figura 3.10 mostra que quando uma das atividades $\mathrm{Al}$ ou $\mathrm{A} 2$ ou $\mathrm{A} 3$ finalizar, a atividade A4 iniciará sua execução.

Nesse tipo de estrutura o especificador do processo pode ter duas alternativas:

- Não especificar expressão para a atividade R1.

Neste caso a máquina de workflow controla a evolução da seqüência das atividades, através da classe "conector" [Bru97a], que contêm o registro das atividades predecessoras e sucessoras de R1. Quando uma das atividades predecessoras de R1 finalizar, a máquina de workflow habilitará para execụ̣ão a sua atividade sucessora.

- Controle da atividade RI feito pelo participante especificador.

Nesta situação a atividade de roteamento R1 contém uma expressão a ser avaliada pela máquina de workflow e que indica quais ou quantas atividades predecessoras devem aguardar finalização, para habilitar a execução da atividade sucessora (A4). No exemplo da figura 3.10, uma variável pode ser incrementada de um no término de cada atividade predecessora da atividade RI e na expressão desta, a variável incrementada pelas atividades predecessoras é testada por igualdade de dois (variável $=2$ ), indicando a necessidade de término de duas atividades predecessoras, para habilitar a execução de sua sucessora (A4). 
Um exemplo de uso de or-join pode ser visto na figura 3.13, na atividade $\mathrm{R} 2$ do subprocesso "cálculo de deduções".

\subsubsection{Iteração}

Um ciclo de atividade de workflow envolvendo a execução repetitiva de uma atividade até que uma condição seja satisfeita. Representada graficamente por um retângulo com um arco saindo e retornando a si mesmo no lado superior.

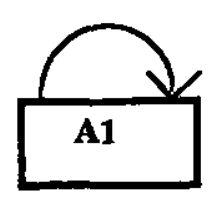

Figura 3.11 Exemplo de representação gráfica de uma iteração

A iteração da figura 3.11 é controlada pela última ação da atividade, do tipo automática, inserida de forma automática, pelo editor de workflow, mas que solicita ao participante a condição a ser inserida e satisfeita nessa ação. Quando a atividade de iteração for instanciada pela máquina de workflow e esta executar a última ação (ação de controle) e o resultado for verdadeiro, a atividade é finalizada e a maquina habilita para iniciar execução sua atividade sucessora. Caso o resultado seja falso, a máquina de workflow finaliza essa instância da atividade de forma normal e automaticamente cria uma nova instância da atividade, habilitando-a para execução.

\subsubsection{Terminadores}

Símbolo gráfico (dois traços em paralelo) que indica o ponto inicial/final da representação do workflow. Estes terminadores indicarão ao sistema quais atividades devem ser especificadas como iniciais ou finais. Não têm outra função semântica no workflow, isto é, não são executados. 


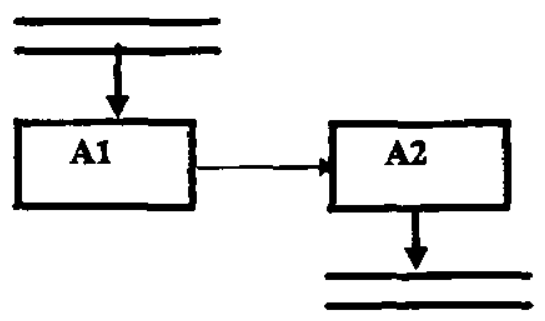

Figura 3.12 Exemplo de uma representação gráfica com terminadores

Conforme a figura 3.12, a atividade A1 é a atividade inicial e a atividade A2 é a atividade final. No exemplo da figura 3.13 as atividades Rl (do processo e do seu subprocesso) são atividades iniciais e as atividades $\mathrm{A6}, \mathrm{A} 7 \mathrm{e} \mathrm{A} 3$ são atividades finais.

\subsubsection{Padronização (WFMC)}

O Glossário de terminologias de Workflow [Wfm96b] desenvolvido pela WfMC apresenta símbolos para representação gráfica de um workflow com suas respectivas definições. Embora se tenha procurado adotar essa simbologia, foram promovidas algumas alterações necessárias do ponto de vista deste trabalho, para simplificação, para se tornar mais intuitiva e para tratamento de abstrações não definidas no glossário WfMC, as quais são citadas a seguir:

- a inclusão de um circulo cheio na representação gráfica do Or-split e Or-join, porque identifica melhor visualmente a existência de uma atividade de roteamento, da mesma forma que existe no And-split e And-join, diferenciando-os pelo circulo cheio (Or) ou vazio (And).

- a representação gráfica da iteração de atividade foi alterada por questão de simplificação e a semântica foi restringida a uma atividade.

- a representação gráfica de terminadores (duas barras paralelas) não é tratada pela WFMC.

- a decomposição da atividade item de trabalho como um subprocesso também não é sugerida pela WFMC.

\subsubsection{Exemplo de aplicação da linguagem}


A figura 3.13 representa graficamente um workflow de um exemplo simplificado de cálculo de imposto de renda.

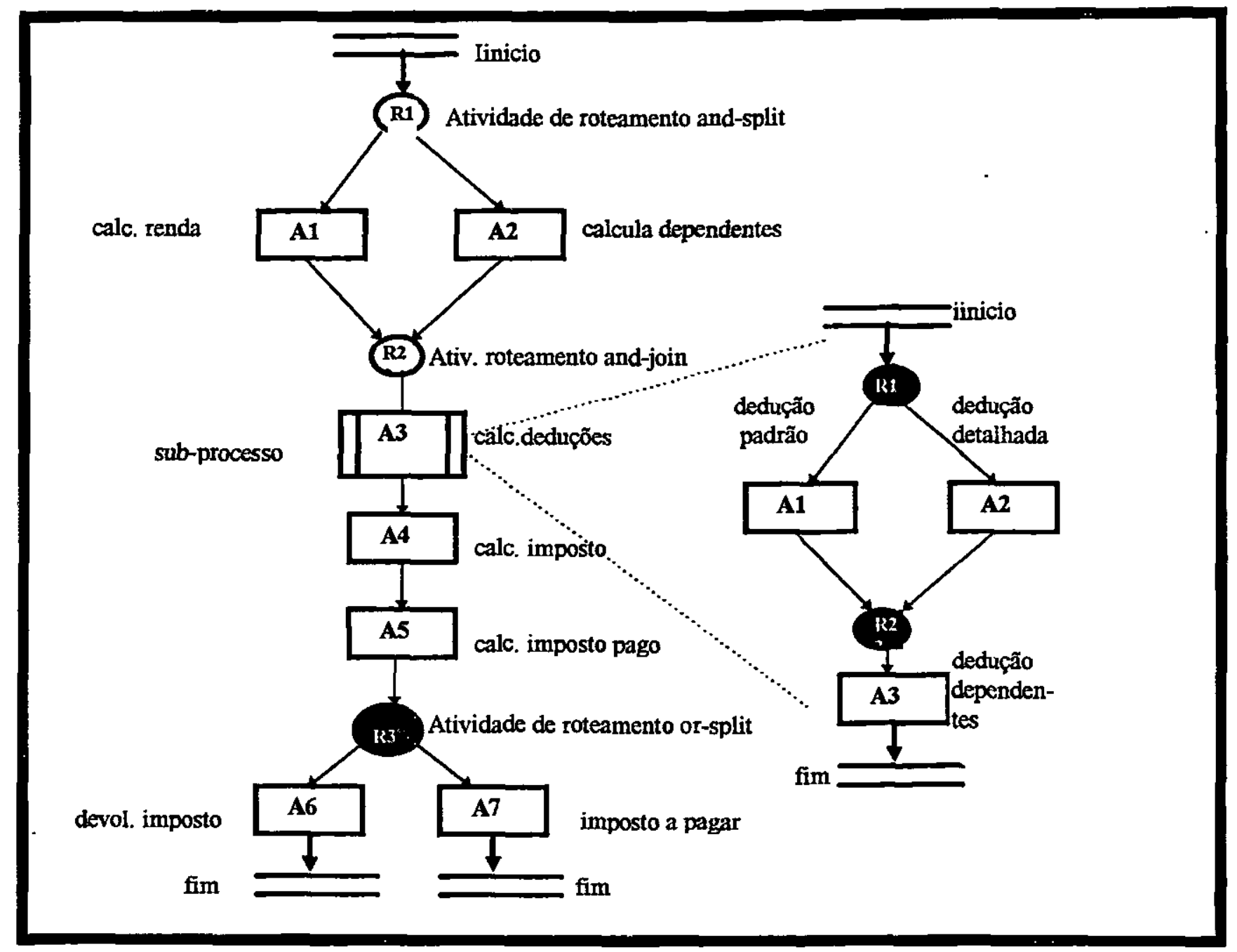

Figura 3.13 Representação gráfica de um exemplo simplificado do workflow de cálculo de imposto de renda

\subsubsection{Linguagem de Definição de Ação (LIDA)}

Esta linguagem define uma gramática que é uma extensão do SQL (Structured Query Language), para especificação de ações e expressões de pré-condições das atividades itens de trabalho, bem como as expressões de transições das atividades de roteamento [Bru97d]. 
O subconjunto de comandos SQL da linguagem é: CREATE TABLE, DECLARE, DROP TABLE, GOTO, IF...ELSE, PRINT, SELECT, UPDATE, XP_SENDMAIL, WHILE, /*..*/, e @. A sintaxe desses comandos é apresentada de forma simplificada no apêndice " $A$ " e um maior detalhamento pode ser obtido no manual Transact-SQL Reference [Mic93].

Os comandos não pertencentes ao SQL os quais são: "GET", "EXECUTAR", WINDOW e "\#”, têm um tratamento específico pelo editor e interpretador e sua sintaxe também é apresentada no apêndice " $\mathrm{A}$ ". O comando "GET", quando interpretado e executado, abre uma janela com a mensagem solicitando a informação desejada, a qual é armazenada em uma tabela temporária. 0 comando "EXECUTAR", na sua interpretação e execução, instancia a atividade cuja identificação é o conteúdo do seu identificador. O comando "WINDOW", quando interpretado e executado abre uma janela mostrando o resultado da execução do comando embutido. O comando “\#” indica na sua interpretação que a ação é do tipo manual e, portanto, executada fora do controle do sistema.

Em tempo de especificação do workflow, os comandos são consistidos e os erros apresentados para correção. A linguagem permite definir variáveis temporárias usadas para passar dados entre atividades e como controle em expressōes de atividades de roteamento, pré-condição e ação, em atividade de item de trabalho.

\subsection{Funcionalidades do sistema}

Abaixo são listadas as funcionalidades oferecidas pelo sistema classificadas por interface, conforme o modelo de referência proposto pela WfMC e apresentado na figura 3.14 [Wfm95].

\section{INTERFACE um (manutenção de processo - Editor Gráfico)}

1 - Consultar a lista de definições de processo e seus detalhes.

2 - Criar um processo

3 - Alterar/criar versão de um processo

4 - Excluir um processo 
5 - Consolidar um processo

6 - Exportar a definição de processo em WPDL.

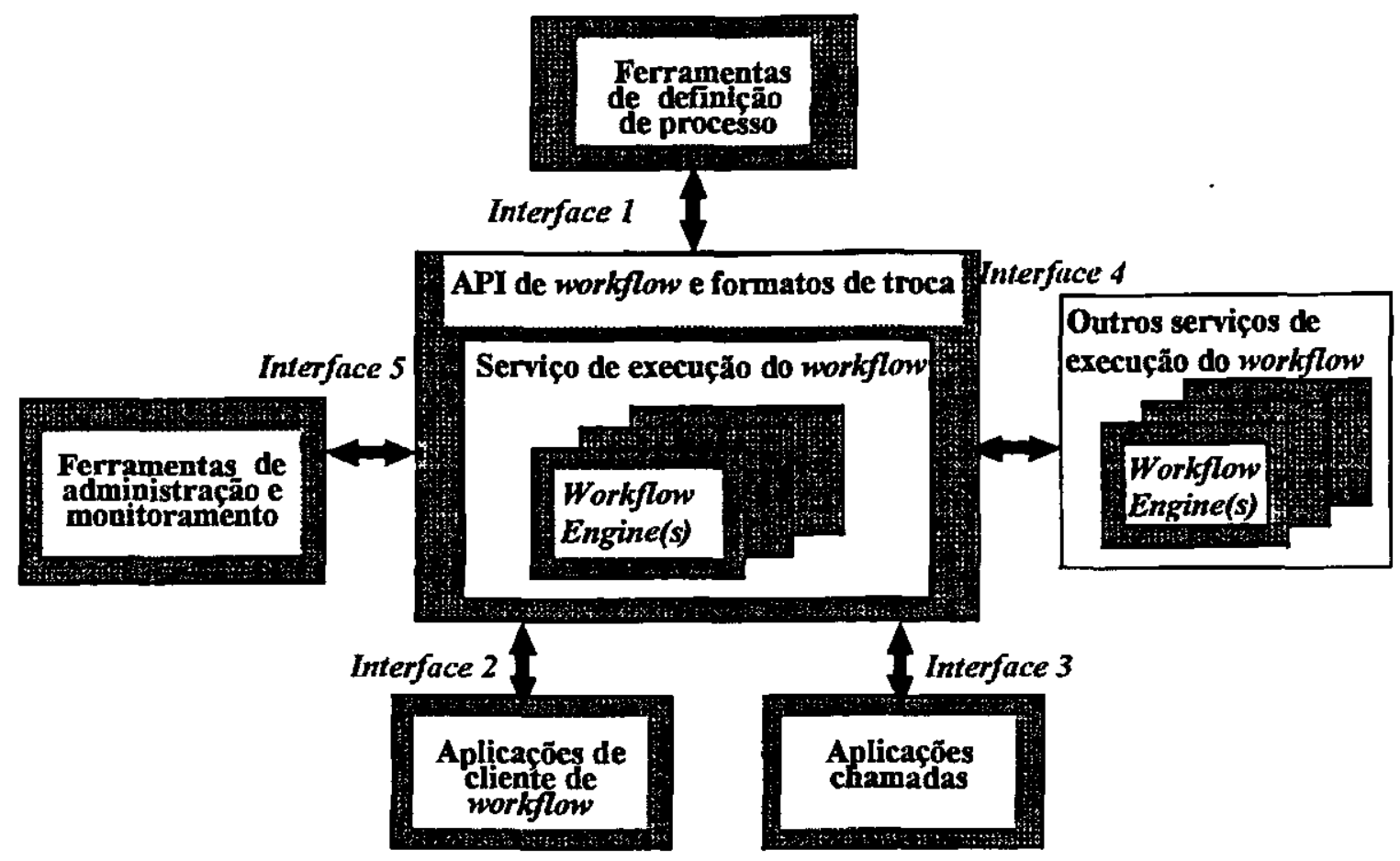

Figura 3.14 Modelo de referência da WfMC

\section{INTERFACE 2 (cliente)}

1 - Conectar no sistema de workflow

2 - Desconetar do sistema de workflow

3 - Consultar a lista de trabalho/item de trabalho

4 - Consultar a definição de processo/atividade

5 - Alocar um item de trabalho sem participante executor

6 - Executar um item de trabalho/ação

7 - Finalizar uma ação. 
8 - Instanciar um processo (execução do workflow)

9 - Forçar a mudança de estado da instância de atividade/ação

10 - Alterar/especificar papel/participante na execução do workflow

\section{INTERFACE 5 (administrador)}

1 - Consultar a definição de processo/atividade

2 - Consultar as instâncias de processos /atividades.

3 - Atribuir prioridade a processo/atividade

4 - Mudar o estado de instância de processo/atividade/ação (por ex.: suspender ou cancelar)

5 - Consultar a lista de trabalho global pendente (de instâncias de atividades sem participantes-executores)

6 - Consultar a lista de trabalho de cada participante

7 - Realocar o participante-executor de um item de trabalho

8 - Especificar participantes-executores para as atividades pendentes na lista global

9 - Consultar a carga de trabalho

10 - Estatísticas

11 - Dar manutenção nas tabelas básicas do sistema (Administração).

12 - Dar manutenção no histórico dos processos/atividades executados

13 - Habilitar ou desabilitar definição de processo.

14 - Exportar definição de processo (WPDL)

O primeiro bloco refere-se às funcionalidades de manutenção de processos oferecidas pelo editor gráfico. O segundo bloco refere-se às funcionalidades oferecidas ao módulo cliente para instanciação e acompanhamento de workflows. $\mathrm{O}$ último bloco refere-se às funcionalidades oferecidas a um cliente especial, o administrador, por meio das quais ele pode avaliar o 
comportamento do sistema e de seus participantes e tomar as medidas necessárias para manter o bom desempenho do sistema.

\subsection{Exemplos de workflow}

Conforme tabela 3.1 há a necessidade de se especificar workflows para a manipulação das categorias de documentos, a qual define níveis de workflow. O primeiro nível é exemplificado pelo desenvolvimento do processo para manipulação de tipos de documentos, na seção 3.7.1. A execução desse processo permite criar um tipo de documento e consequentemente surge a necessidade de gerar um outro nível de workflow, o de uso desse tipo de documento gerado, na seção 3.7.2, cuja execução cria um documento preenchido por algum usuário. Nesses exemplos, a tabela "Tabw" é uma tabela temporária criada em tempo de execução do workflow, utilizada para passar dados entre ações de atividades e que é eliminada no final da execução do workflow. Explicações sobre as tabelas e atributos envolvidos podem ser obtidas no apêndice B.

\subsubsection{Workflow para criar tipo de documento}

Este workflow cria um tipo de documento, como por exemplo, um formulário para abertura de conta no sistema [Bru97e]. A sua representação gráfica é mostrada na figura 3.15. As atividades especificadas graficamente na figura 3.15 são descritas a seguir:

- Atividade 1 - "Iniciar formulário": permite que o participante executor defina as características do formulário que deseja criar.

- Atividade 2 - "Propor formulário": o participante executor, de acordo com as características descritas do formulário na atividade 1, gera seu leiaute.

- Atividade 3 - "Conferir": o participante executor verifica se o leiaute do formulário proposto pela atividade anterior obedece aos padrões pré-estabelecidos pela organização e indica o resultado de sua conferência. 


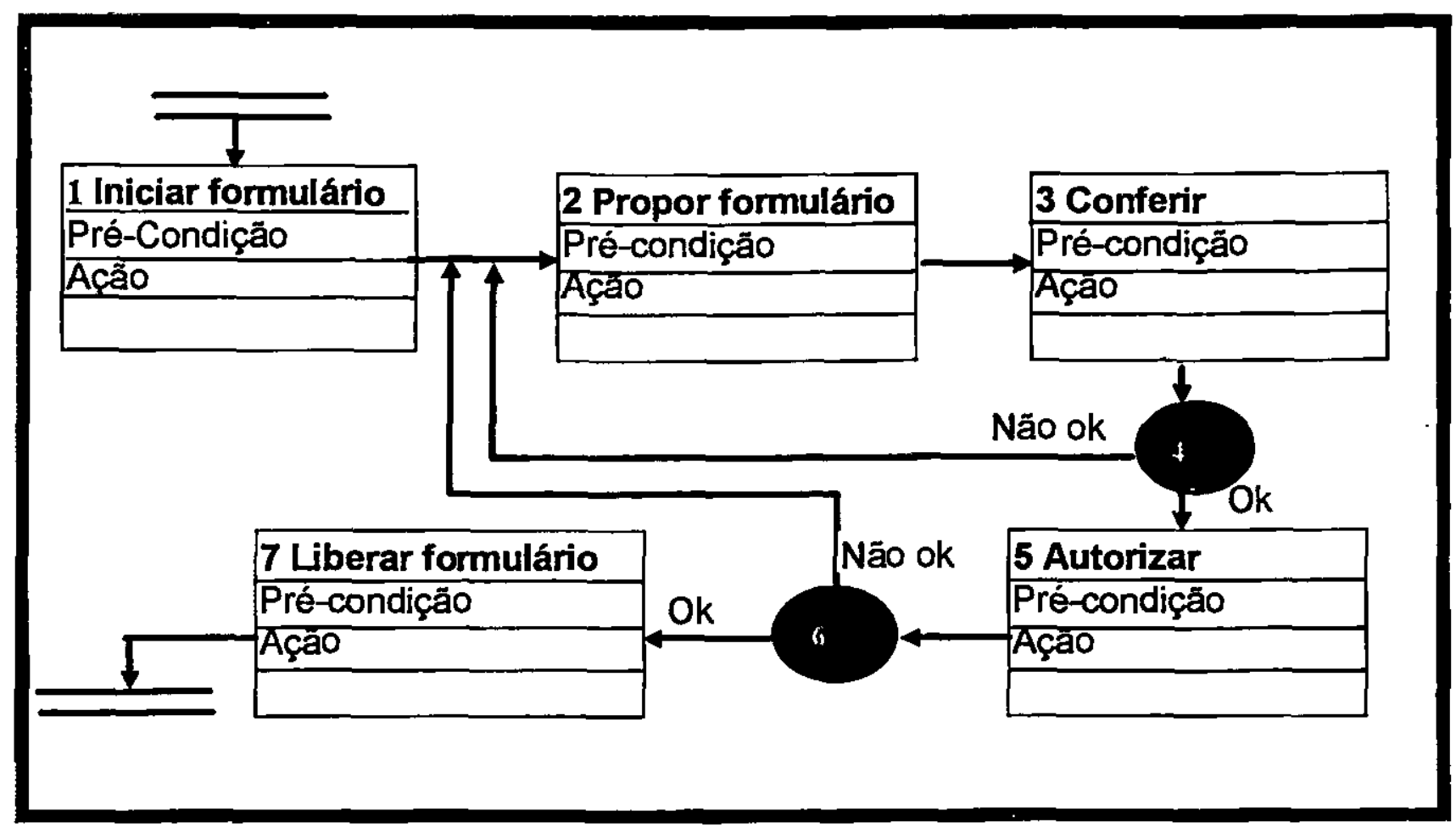

Figura 3.15 Representação gráfica de workflow para criação de tipo de documento

- Atividade 4 - "roteamento 1": avalia o resultado da conferência da atividade 3. Se o resultado = ok então instancia a atividade 5 ("Autorizar") senão instancia a atividade 2 ("Propor") para correção do formulário.

- Atividade 5 - "Autorizar": um participante executor com competência na organização para autorizar o uso do formulário, avalia-o e decide se está pronto para uso ou não.

- Atividade 6 - "roteamento 2": verifica o resultado de autorização da atividade 5. Se o resultado = ok então instancia a atividade 7 ("Liberar formulário") senão instancia a atividade 2 ("Propor formulário") para que sejam feitas as devidas correções.

A seguir são mostradas como exemplo algumas propriedades da atividade 1 ('Tniciar formulário"), cujas ações foram especificadas com a LIDA:

Atividade 1: (IT 1 - item de trabalho) - Iniciar formulário 
Finalidade: Iniciar o processo de criação, descrevendo a aplicação do formulário e algumas características.

\section{Ação:}

1 - /* Ação que permite ao usuário entrar com as características, áreas envolvidas e 2 aplicação do documento, a qual será armazenada no atributo observação da tabela

3 instância de atividade */

4 - GET "Observação: (Entrar com características/áreas envolvidas/aplicação do docto, 5 para executores do processo)", observação;

$6 \quad U P D A T E$ Instância_de_atividade

7 SET observação $=($ SELECT observação FROM Tabw $)$

8 WHERE id_instância_atividade = (SELECT id_inst_ativ FROM Tabw);

$9-I^{*}$ atualiza a flag seq_ativ com a seqüência da atividade em execução no processo */

$10-U P D A T E$ Tabw1

$11 \quad S E T$ seq ativ $=1$;

Os comandos $\mathrm{LiDa}$ utilizados na especificação da atividade 1 descrita acima, possuem o seguinte significado:

- linha 1-3 $-/^{* *} /$ : comentários sobre os comandos seguintes.

- linha 4 - GET: comando que na sua execução abre uma janela mostrando a mensagem entre aspas e permitindo a digitação de um dado, que nesse caso é a observação, a qual é armazenada temporariamente.

- linha 6 - UPDATE: transfere o conteúdo do atributo "observação" armazenado temporariamente, para um armazenamento permanente na Instância da atividade.

- linha 10 - UPDATE: seta para 1 o conteúdo do atributo "seq_ativ", o qual é uma condição que indica a sequiência de execução das atividades. 


\subsubsection{Workflow de uso para o tipo de documento de abertura de conta no sistema}

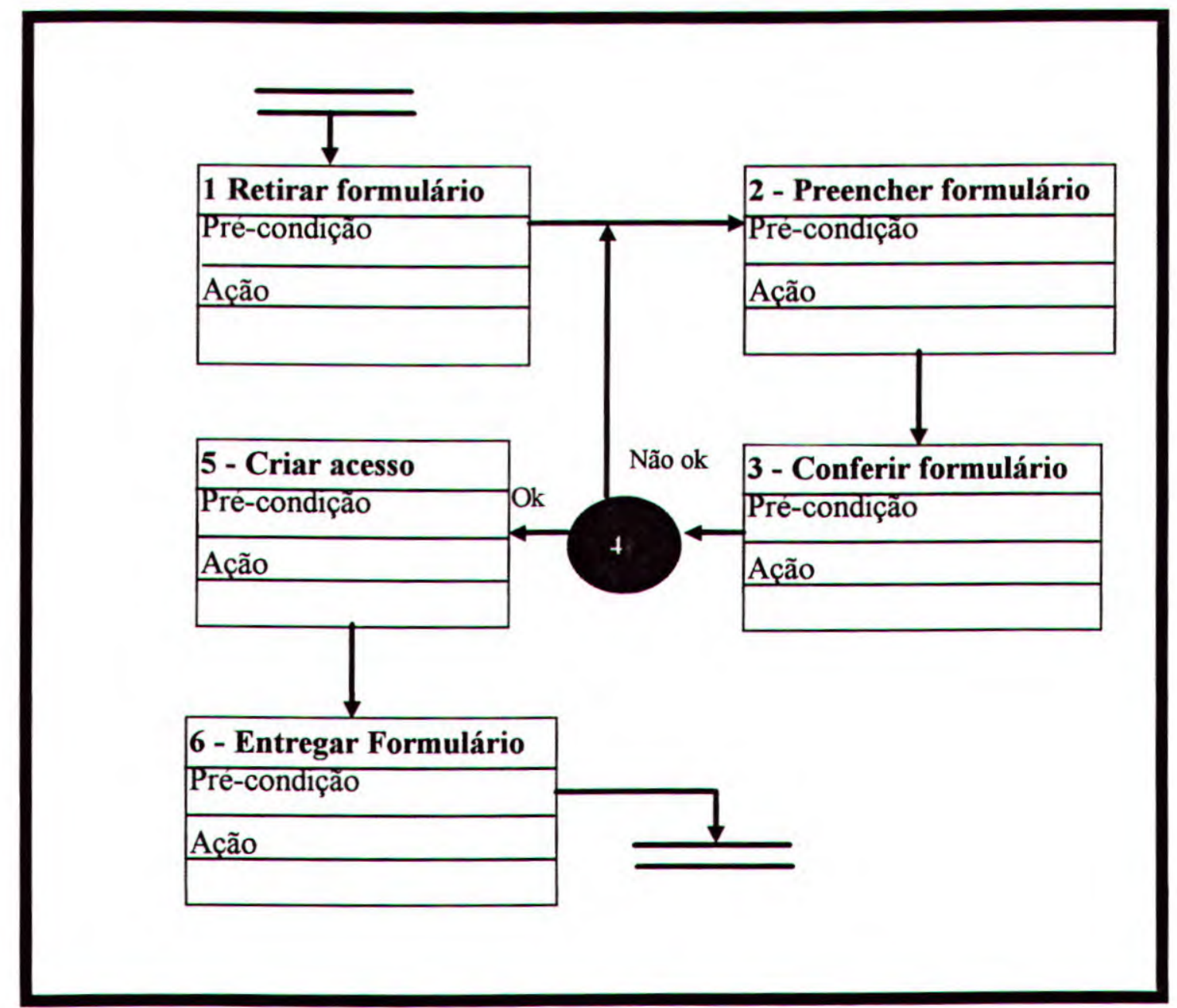

Figura 3.16 Representação gráfica do workflow de uso do tipo de documento de solicitação de abertura de conta

Este exemplo é a representação gráfica de um workflow para uso do formulário de abertura de conta em um sistema computacional, supostamente criado pela execução do workflow representado no item 3.7.1 (veja figura 3.16) [Bru97e]. A sua execução gera um documento de solicitação de abertura de conta no sistema, preenchido, que é encaminhado às pessoas competentes dentro da organização para gerar o username e senha inicial para o solicitante. As atividades especificadas graficamente na figura 3.16 , são descritas a seguir: 
- Atividade 1 - "Retirar formulário": o formulário de abertura de conta no sistema é mostrado ao participante executor para seu preenchimento.

- Atividade 2 - "Preencher formulário": o formulário preenchido é armazenado na base de dados.

- Atividade 3 - "Conferir formulário": o formulário preenchido é conferido por um participante, o qual indica o seu resultado.

- Atividade 4 - "roteamento 1": avalia o resultado da conferência da atividade 3 . Se o resultado = ok então instancia a atividade 5 ("Criar acesso") senão instancia a atividade 2 ("Preencher formulário") para correção do formulário.

Atividade 5 - "Criar acesso": participante executor abre conta para o solicitante, no sistema.

- Atividade 6 - "Entregar formulário": o formulário com o login name e a senha inicial gerado pela atividade 5 é entregue para o solicitante de abertura de conta.

A seguir são mostradas como exemplo algumas propriedades de uma das atividades do workflow especificado, a atividade 1 "Retirar formulário", utilizando a linguagem LiDA na especificação de suas ações.

Atividade 1(8): (IT 6 - item de trabalho) - Retirar formulário

Finalidade: Retirar formulário para preenchimento.

Ação:

1 - \# verificar instruções de retirada de formulário;

2 - \# executar comandos de retirada de formulário;

3

4 - /* Bloco de comandos para obter do executor a sua observação e 5 armazená-la na instância da atividade corrente */

$6-$ - $*$ observação */

7 GET “observação”, observação; 
8

9

10
UPDATE Instância_de_atividade

SET observação $=(S E L E C T$ observação FROM Tabw $)$

WHERE id_instância_atividade $=(S E L E C T$ id_inst_ativ FROM Tabw $)$;

Os comandos LiDa utilizados na especificação da atividade 1 descrita acima, possuem o seguinte significado:

- linha 1 - \#. significa que a ação é executada manualmente, ou seja, fora do controle do sistema.

- linha 2: comandos dado fora do controle do sistema para retirar o formulário.

- linha $4-/ * * /$ : comentários a respeito do bloco de comando seguinte.

- linha 6,7,8,9 e 10: comandos que permitem ao participante executor fornecer via teclado sua observação, a qual é armazenada na instância da atividade.

\subsection{Considerações finais}

Neste capítulo pode-se verificar as principais características e requisitos do sistema, o seu modelo conceitual, as linguagens utilizadas na especificação de um workflow, as suas funcionalidades e exemplos de especificação informal de workflows e que são a base para a implementação descrita no capítulo 4. 


\section{Capítulo 4}

\section{Protótipo do Sistema de Workflow}

\subsection{Consideraçōes iniciais}

Este capitulo introduz a implementação do sistema de workflow para gestão de documentos. $\mathrm{O}$ resultado da implementação é um protótipo do sistema, o qual apresenta a interface homem-máquina com as funcionalidades oferecidas em páginas HTML (Hypertext Markup Language), manipuladas por intermédio de qualquer web browser da internet e composto pelos módulos de administração, especificação e execução.

Inicialmente este capítulo apresenta na seção 4.2 as decisões de projeto em relação à arquitetura do sistema, à linguagem de programação adotada e à arquitetura interna do sistema. Em seguida na seção 4.3 trata da implementação do sistema, cujo resultado é um protótipo apresentado na seção 4.4 e que mostra as suas funcionalidades na interface com o usuário. Finalmente, na seção 4.5 demonstra exemplos de utilização do protótipo desde a especificação de um workflow até a sua execução.

\subsection{Decisões de projeto}

\subsubsection{Arquitetura do sistema}

A arquitetura escolhida para a execução do Sistema de Gerenciamento de Workflow para Gestão de Documentos foi a Cliente-Servidor, por apresentar beneficios tais como: independência 
de plataforma, permitir o uso de processadores de custo baixo, rightsizing (dimensionamento conforme necessidade de hardware), flexibilidade e escalabilidade e incentivar aplicações centradas no usuário [Ave97]. O ambiente operacional escolhido foi o Windows 95 para o cliente e o Windows NT para o servidor.

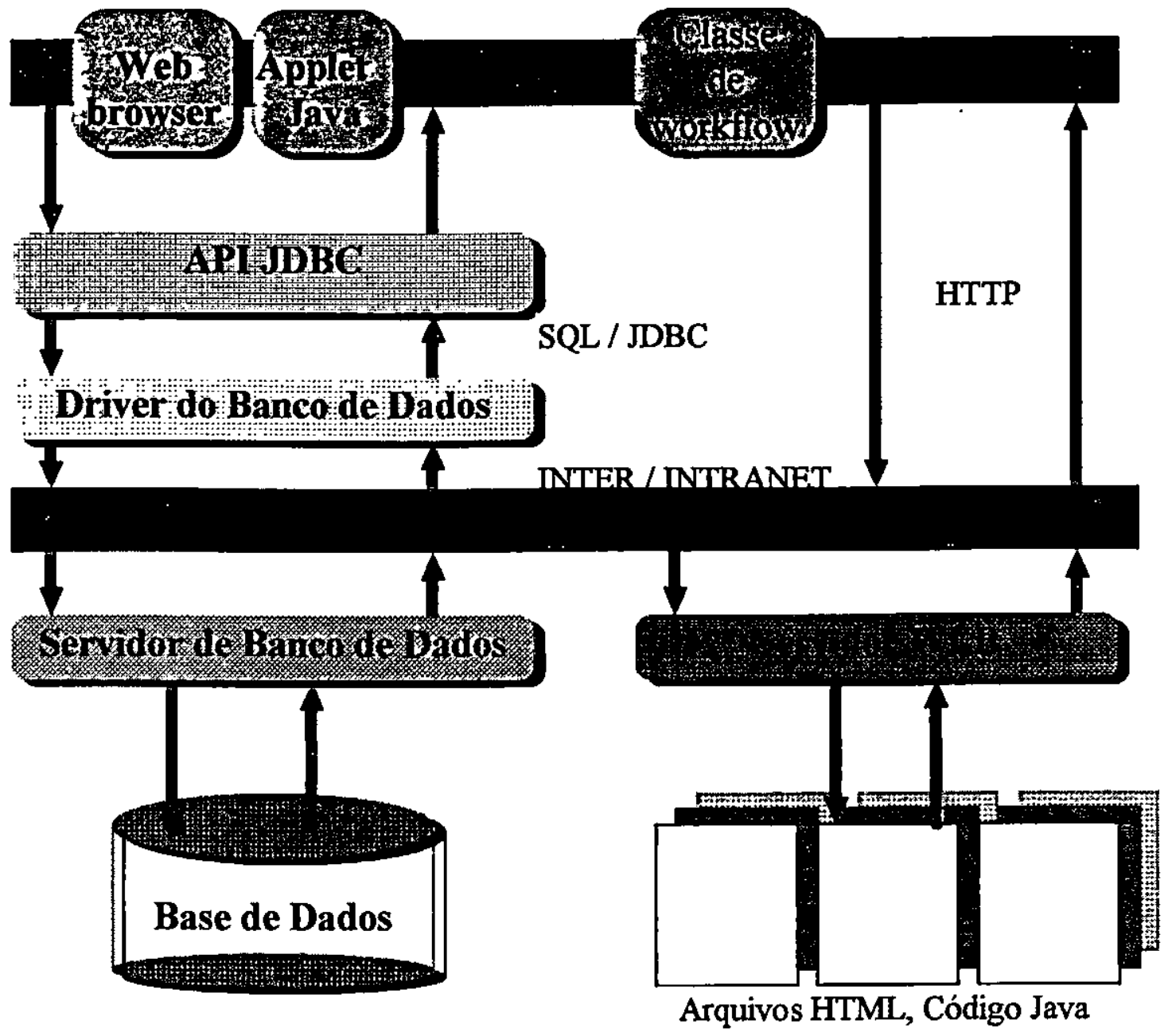

Figura 4.1 Arquitetura do sistema

A arquitetura do sistema (veja figura 4.1) é distribuida, podendo ser executado em ambiente Internet ou Intranet. Nessa arquitetura, um browser de HTML estendido por programas escritos em linguagem Java constituem a camada de software do lado cliente. No lado servidor é encontrado um servidor WWW que armazena as páginas HTML e o código Java e um servidor de banco de dados armazenando as classes do modelo de objetos apresentado na figura 3.1, mapeadas para o modelo relacional, cujos atributos podem ser vistos no apêndice " $\mathrm{C}$ ". $\mathrm{O}$ banco de dados utilizado na construção da base de dados é o sistema Microsoft SQL server 4.21. 
Utilizando um browser, um usuário especifica uma operação (por exemplo, uma especificação ou execução de workflow) para ser executada. O browser envia uma solicitação ao servidor WWW, obtendo o código Java que corresponde à operação a ser executada. $\mathrm{O}$ código Java é então executado no lado cliente e se comunica com o servidor de banco de dados a fim de enviar ou receber os dados manipulados pelo sistema. O protocolo usado na comunicação com o servidor da base de dados é o protocolo JDBC (Java Database Conectivity) [Pat96], o qual é um protocolo aberto que permite a conexão de clientes Java com servidores de banco de dados usando drivers de banco de dados específicos. O driver JDBC utilizado é o FastForward, da empresa Conect Software [Con97].

\subsubsection{Linguagem de programação}

A linguagem de programação escolhida para o desenvolvimento do protótipo do sistema de gerenciamento de workflow para gestão de documentos foi Java - Visual JH [Ste96] [Dei97]. Ela oferece as seguintes características: acessar recursos distribuídos na Internet; portabilidade e não requer instalações adicionais na camada cliente, pois os programas que compõem o sistema de workflow localizam-se no servidor web da aplicação, os quais são carregados para o lado cliente quando sua utilização é solicitada; acessar a banco de dados relacionais; uma interface padronizada para acesso a banco de dados, tornando o sistema independente da plataforma de sistema de banco de dados; e finalmente, permite ter uma interface padrão e independente de plataforma. Também é orientada a objetos, disponibiliza bibliotecas de classes para utilização no desenvolvimento de applets e aplicações, a partir das quais pode-se criar outras bibliotecas que desempenham funções mais específicas do sistema.

\subsubsection{Arquitetura interna do sistema}

A arquitetura interna do sistema, representada graficamente pela figura 4.2 , possui dois componentes: um de especificação e um de execução [Bru98f]. O componente de especificação, representado pelo editor gráfico permite a um participante modelar visualmente um processo e especificar suas propriedades, gerando uma definição de processo, a qual é armazenada em um 
banco de dados relacional, sendo que a representação gráfica e especificação de suas propriedades exigem a utilização das linguagens LIRA e LIDA, descritas anteriormente. Esse componente pode gerar também uma definição de processo em WPDL (Workflow Process Definition Language - WfMC) [Wfm96c], a qual pode ser interpretada e executada por máquinas de workflow de produtos de empresas diferentes. O componente de execução propicia o ambiente run-time do sistema representado pela máquina de workflow, por intermédio da qual uma definição de processo é interpretada, além de ser responsável por criar e controlar a instância desse processo, coordenando a evolução da execução de suas atividades, bem como as disponibilizando aos participantes especificados na sua definição, para execução. Os participantes podem utilizar aplicações e ferramentas da tecnologia de informação (TI), em ações de atividades externas ao sistema [Bar97], cujo progresso de execução não é monitorado pelo sistema.

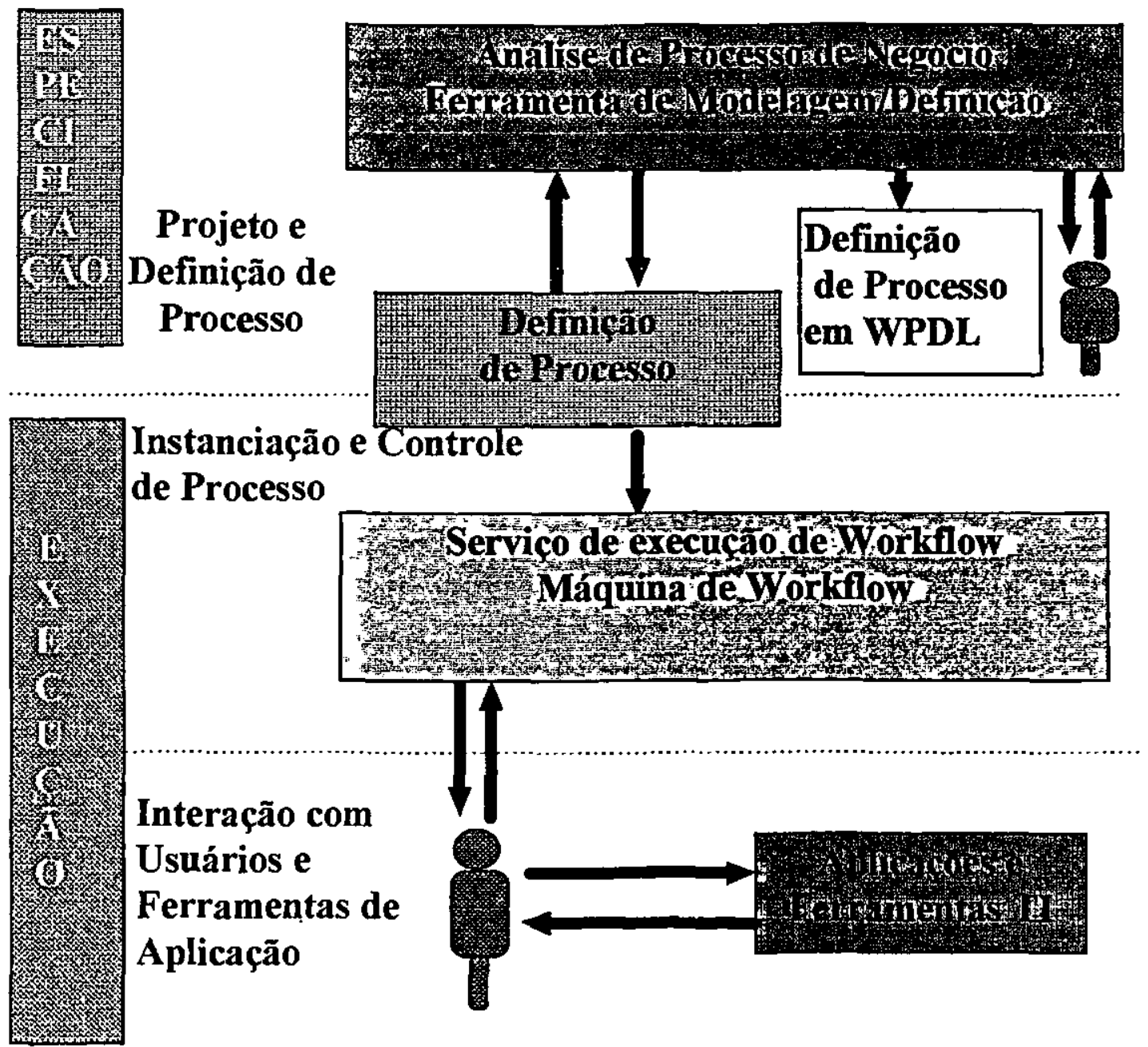

Figura 4.2 Arquitetura interna do sistema 


\subsection{Implementação do sistema}

A implementação do sistema de gerenciamento de workflow para gestão de documentos tem como resultado um protótipo. O sistema possui um módulo de instalação, o qual é responsável pela geração das tabelas permanentes do sistema no servidor de banco de dados e pela solicitação do nome de um participante para cadastramento com o papel de administrador do sistema. $\mathrm{O}$ administrador possui alguns privilégios especiais no sistema, tais como: manutenção das suas tabelas básicas e de funcionalidades que permitem acompanhar e tomar decisões sobre o desempenho do sistema. Com a instalação do sistema algumas informações são cadastradas automaticamente, tais como: situação "Ativo", tipo de participante "ser humano", etc.

\subsection{Prototipo do sistema}

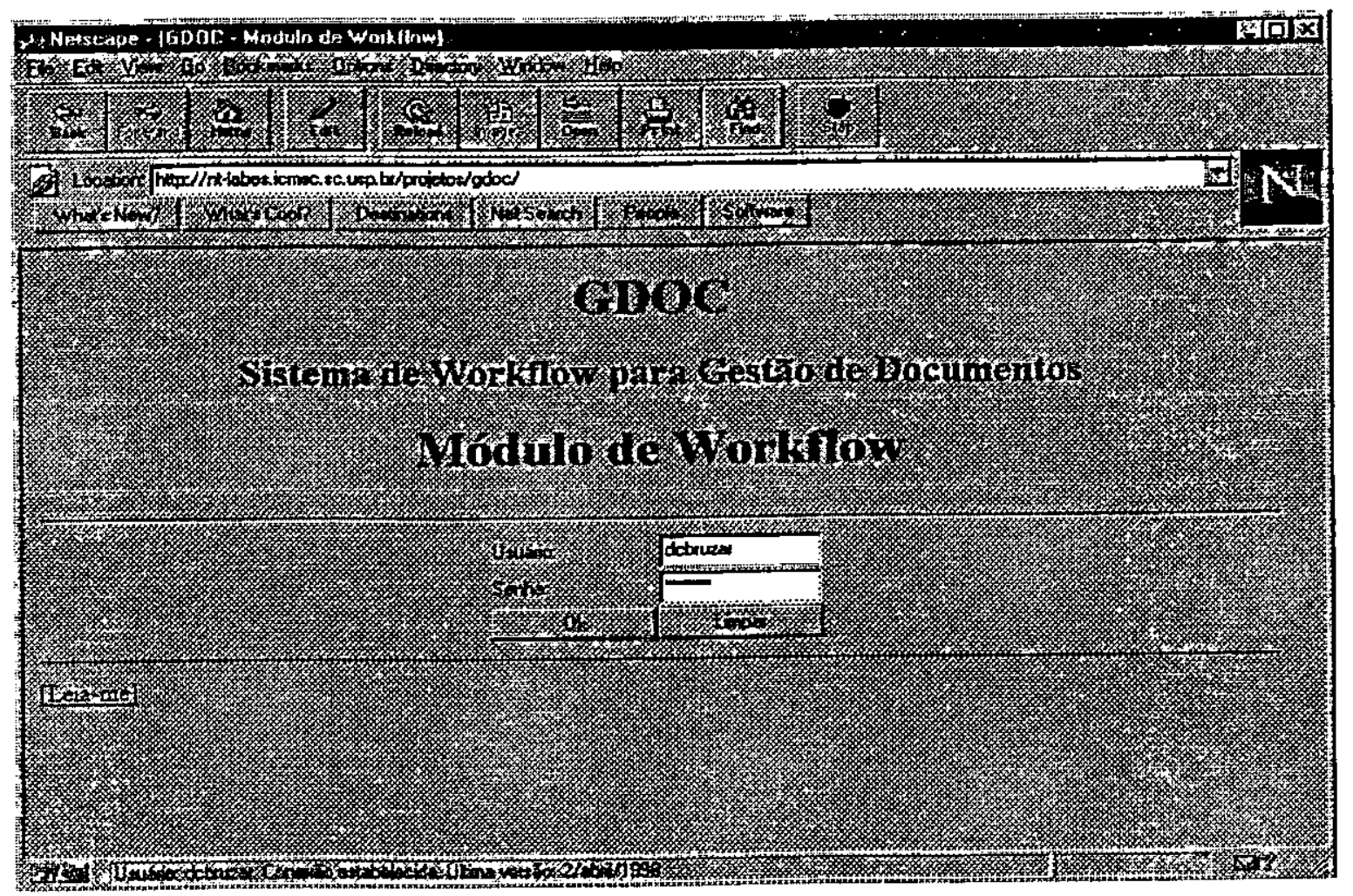

Figura 4.3 Tela de identificação

O protótipo serve como base para a implementação de um sistema mais completo e com mais funcionalidades. 
A interface do sistema, a qual foi projetada seguindo-se recomendações técnicas [Min94], é disponibilizada por intermédio de um web browser, digitando-se o URL (Uniform Resource Locator):

\section{“http://nt-labes.icmsc.sc.usp.br/projetos/gdoc"}

Em seguida, é apresentada ao usuário uma página HTML contendo uma tela de identificação do usuário, conforme figura 4.3.

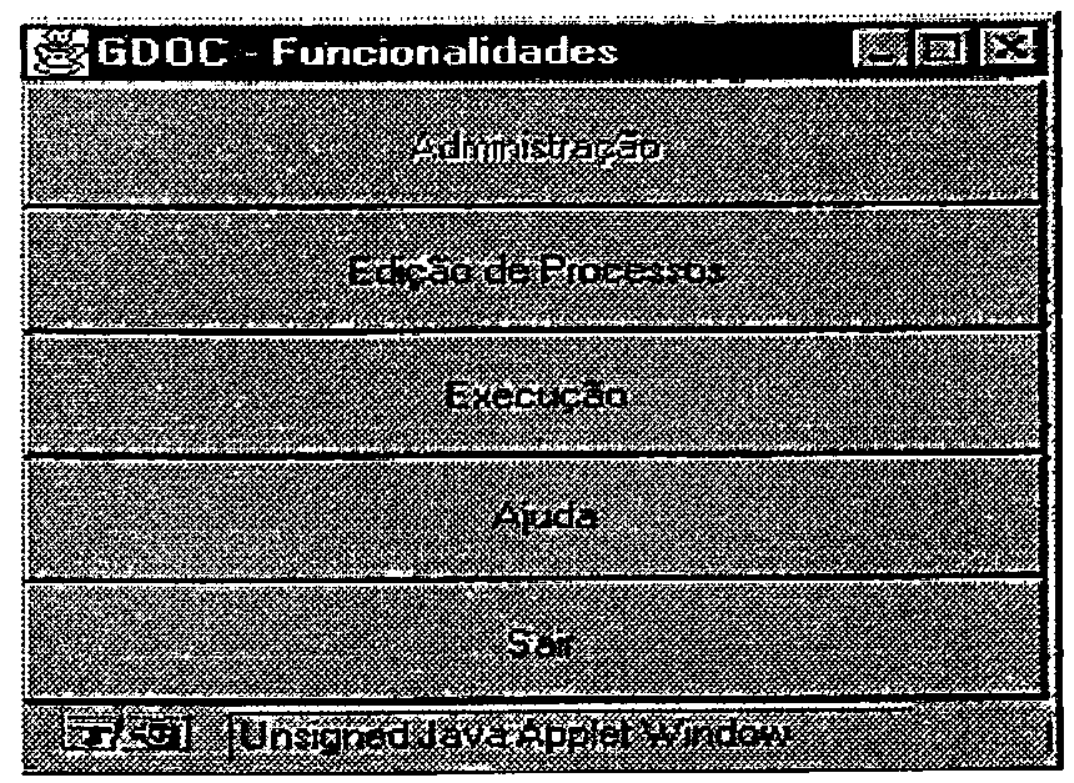

Figura 4.4 Menu de funcionalidades gerais

Após o usuário digitar seu user name e sua password, o sistema faz a sua validação e caso estejam corretos mostra as funcionalidades gerais do sistema conforme figura 4.4. As opções nas telas são customizadas (habilitadas ou desabilitadas), conforme privilégios atribuídos ao papel que o usuário exerce dentro da organização. Maiores detalhes sobre papel e privilégio são fornecidos no tratamento das funcionalidades de administração.

O menu da figura 4.4 apresenta as seguintes funcionalidades:

- Administração: permite dar manutenção nas tabelas básicas do sistema para que este se torne operacional.

- Edição de processos: corresponde ao editor gráfico, utilizado na manutenção de processos (workflows). 
- Execução: ativa a máquina de workflow por meio da qual, por exemplo, se executa um workflow, participantes interagem para executar atividades que lhe são alocadas e se monitora o sistema.

- Opções: apresenta a possibilidade de emissão de estatísticas sobre o sistema

- Ajuda: oferece texto explicativo a respeito das funcionalidades dessa tela.

- Sair: fecha a tela de funcionalidades, mostrando uma página HTML de saída do sistema.

\subsubsection{Administração}

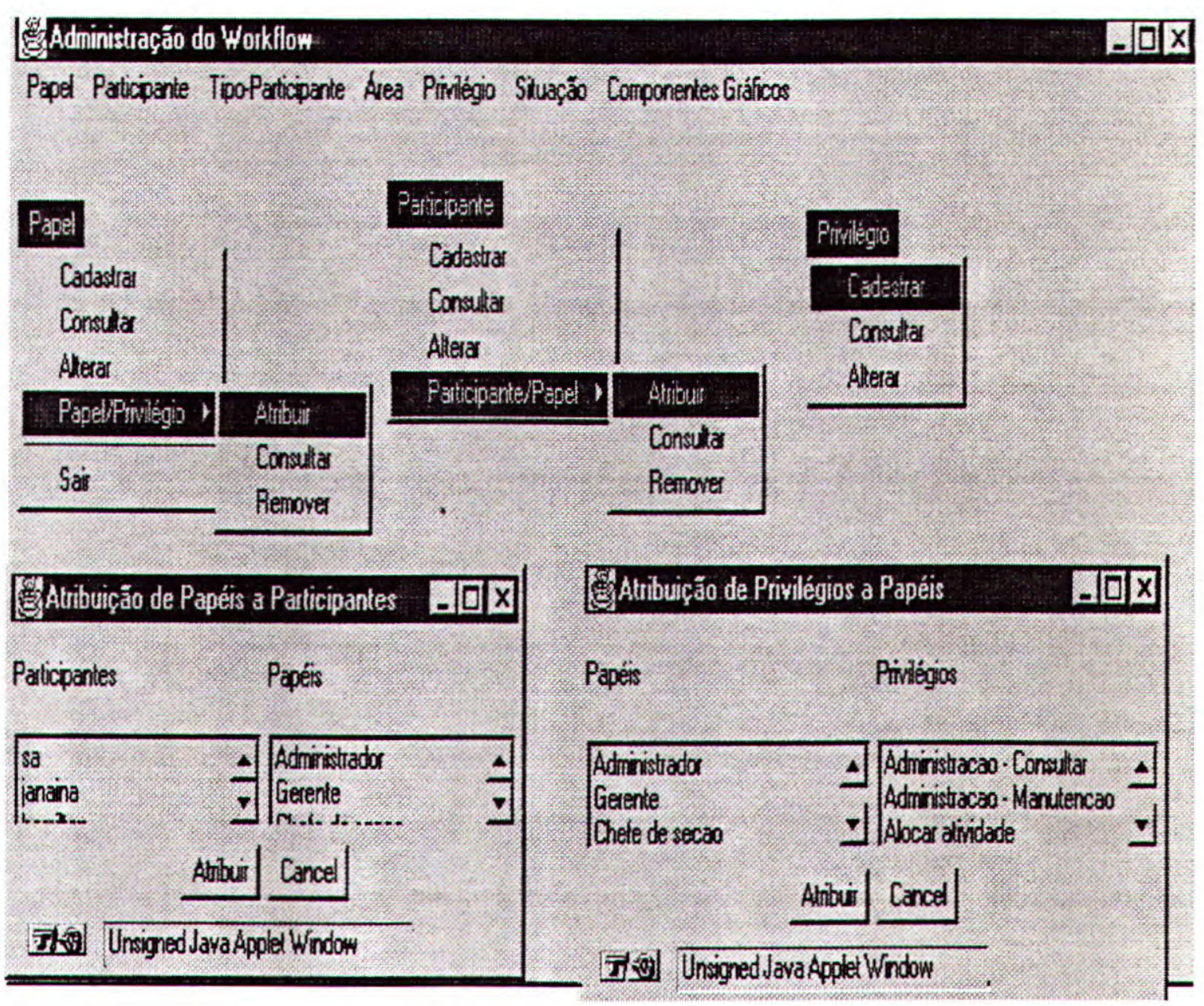

Figura 4.5 Administração

A opção "Administração", como já foi dito anteriormente dá acesso à funcionalidade que permite manter as tabelas básicas do sistema para que ele se torne operacional. A figura 4.5 mostra as opções que se pode executar nessa modalidade. 
A tela da figura 4.5 mostra na sua parte superior uma barra de menus pulldown com o seguinte significado:

- Papel: permite cadastrar, consultar e alterar papéis, bem como lhes atribuir privilégios, alem de oferecer consulta e exclusão de atribuições realizadas. Exemplos de papéis: gerente, chefe de departamento, auxiliar administrativo, etc.

- Participante: cadastra, consulta e altera participantes, bem como atribui, consulta e remove um papel de um participante. Exemplos de participantes: João, Maria, etc.

- Tipo-Participante: cadastra, consulta e altera tipos de participantes. Exemplos de tipos de participantes: ser humano, recurso, etc.

- Área: cadastra, consulta e altera áreas organizacionais. Exemplos de áreas organizacionais: administrativa, financeira, comercial, etc.

- Privilégio: cadastra, consulta e altera privilégios. Exemplos de privilégios: editar workflow e executar workflow.

- Situação: cadastra, consulta e altera situações. Exemplos de situações: ativo, inativo, executando, suspenso, etc.

- Componentes gráficos: cadastra, consulta e altera os componentes gráficos utilizados pelo editor. Exemplos de componentes gráficos: atividade item de trabalho, atividade de roteamento, terminador, etc.

As tabelas mantidas pela opção "Administração", permitem apenas exclusões lógicas, por meio da alteração da sua situação para "inativo".

\subsubsection{Edição de processos}

Essa opção possibilita a manutenção das especificações de workflows. Inicialmente apresenta a tela da figura 4.6, a qual possui uma barra de ícones vertical, na sua lateral esquerda, uma barra de menus pulldown na sua parte superior e uma área de desenho. Os ícones possuem opções correspondentes nos menus pulldown e têm o seguinte significado, iniciando de cima para baixo: 
- para especificar um workflow "novo": abre uma janela para especificação de propriedades do workflow, tais como: nome e descrição do processo e tempo de execução. Após o fornecimento desses dados o participante pode iniciar a especificação gráfica do workflow desejado.

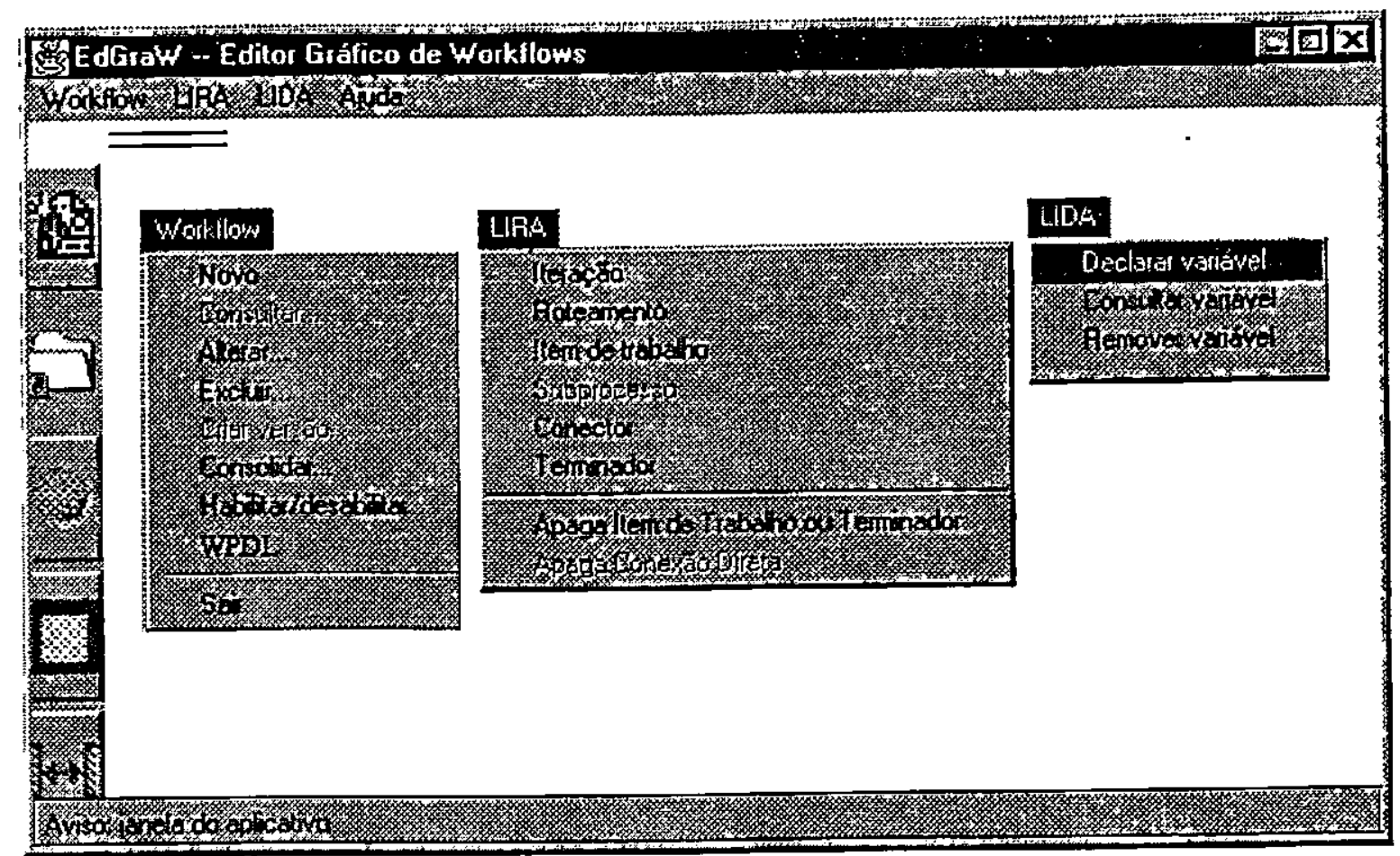

Figura 4.6 Edição de workflows

- mostra uma lista de workflows não consolidados, disponibilizando-os para alteração.

- atividade do tipo roteamento: quando esse ícone é selecionado, o ponteiro do mouse deve ser posicionado no local da área de desenho em que se deseja representar graficamente a atividade e então se pressiona duplamente o botão esquerdo do mouse, o que acarreta a abertura de uma janela solicitando a informação das suas propriedades, tais como: descrição, tipo do roteamento e expressão de roteamento, se houver. Logo após, o componente gráfico é incluído na área de desenho na posição indicada.

- atividade do tipo item de trabalho: após a sua seleção, o ponteiro do mouse deve ser posicionado no local da área de desenho em que se deseja representar graficamente a atividade e então pressionar duplamente o botão esquerdo do mouse, o que provoca a abertura de uma janela para informação das suas propriedades, tais como: pré-condição, descrição, papéis executores e ações. $\mathrm{Na}$ informação das propriedades pré-condição e ação, a especificação é 
feita utilizando-se a linguagem LIDA. Deve ser especificada pelo menos uma ação. Em seguida, o componente gráfico é incluído na área de desenho.

- Conector: com a sua seleção pode-se ligar os componentes gráficos estabelecendo-se a seqüência do workflow. Posicionar o ponteiro do mouse em um dos componentes gráficos, pressionar a tecla esquerda do mouse mantendo-a assim e então mover o ponteiro do mouse até o outro componente gráfico que se quer ligar. Solta-se a tecla do mouse mantida pressionada, o que gera uma aresta entre os componentes gráficos apontados.

A barra de menus pulldown, da parte superior da figura 4.6, apresenta os seguintes itens e seus significados:

$\Rightarrow$ Workflow: este menu oferece as seguintes opçōes quando selecionado:

- Novo: possui a mesma funcionalidade do primeiro ícone

- Consultar: abre uma lista de workflows especificados e após a seleção de um deles é mostrada a sua representação gráfica, podendo-se ver as suas propriedades.

- Alterar: abre uma lista de workflows especificados e não consolidados e quando um deles é escolhido mostra a sua representação gráfica, permitindo visualizar as suas propriedades, bem como alterá-las. Pode-se com isso, acrescentar e excluir atividades/ações.

- Excluir: mostra uma lista de workflows não consolidados para seleção daquele que se deseja excluir.

- Criar versão: quando um workflow está consolidado não se permite mais alteração, possibilitando-se apenas a criaçã̀o de versão, caso se deseje alterá-lo. Esta opção é semelhante à de alteração, exceto que é criada uma versão do workflow alterado, mantendo inalterada a versão original.

- Consolidar: no momento em que um workflow especificado esteja conferido e correto, ele deve ser consolidado, ou seja, disponibilizado para execução, não se permitindo mais a sua alteração ou exclusão. Nesse momento é feita uma consistência geral do workflow, verificando-se, por exemplo, a existência de atividades sem conexão e que se 
partindo do componente inicial (terminador) exista um caminho para se chegar a qualquer atividade especificada.

- Habilitar/desabilitar: um workflow consolidado pode ser desabilitado, isto é, seu estado ser passado para "Inativo", o que impede sua execução, ou pode ser habilitado, quando foi desabilitado e se deseja permitir novamente a sua execução, isto é, seu estado é restaurado como "Ativo".

- WPDL (Linguagem de Definição de Processo de Workflow): gera uma definição de processo no formato WPDL de um workflow indicado a partir de uma lista de workflows consolidados.

- Sair: quando selecionado, fecha a janela de edição, retornando o controle para a janela de funcionalidades gerais (figura 4.4).

$\Rightarrow$ LIRA (Linguagem de Roteamento de Atividades): na sua escolha, mostra as seguintes opções:

- Iteração: após sua seleção permite especificar uma atividade do tipo iteração na posição do ponteiro do mouse, na área de desenho, após pressionar duplamente a tecla esquerda do mouse. Em seguida é aberta uma janela para informação de suas propriedades, sendo que a última ação deve ser uma expressão booleana a ser avaliada pela máquina e que indica se a atividade deve ser novamente instanciada ou finalizada. Após isso, o componente gráfico correspondente é acrescentado na área de desenho.

- Roteamento: idem ao ícone de atividade do tipo roteamento.

- Item de trabalho: idem ao ícone de atividade do tipo item de trabalho

- Subprocesso: sua escolha especifica uma atividade que é um subprocesso, isto é, um outro processo já definido. Abre uma janela para ser informada as suas propriedades, tais como: descrição, identificação do processo que é o subprocesso, etc. A representação é efetuada na posição do ponteiro do mouse, da área de desenho, após ter a tecla esquerda do mouse pressionada duplamente.

- Conector: idem ao ícone conector.

- Terminador: Indica o inicio e o fim do workflow. O terminador inicial é gerado automaticamente quando a especificação de workflow é iniciada. O terminador final é representado após a seleção dessa op̧̧ão e ter-se posicionado o ponteiro do mouse na 
posição desejada da área de desenho, pressionando-se duplamente a tecla esquerda do mouse.

- Apagar: opção que permite apagar um componente gráfico da área de desenho. Após a sua seleção, posicionar o ponteiro do mouse sobre o componente gráfico que se deseja apagar, pressionar a tecla esquerda do mouse e então o componente é excluído da área de desenho.

$\Rightarrow$ LDA (Linguagem de Definição de Ação): ao ser selecionada, apresenta as seguintes alternativas:

- Declarar variável: durante a especificação de um workflow pode haver a necessidade de se criar uma variável para passar um dado entre atividades ou usá-la como controle em expressão de pré-condição ou ação da atividade item de trabalho e da atividade de roteamento. Ao ser selecionada, abre-se uma janela onde se define o nome da variável, se indica seu tipo por meio de uma lista de tipos, bem como seu tamanho, para os tipos char e varchar. Essas variáveis são geradas como atributos de uma tabela temporária em tempo de execução do workflow. A tabela temporária é excluída no fim da execução do workflow.

- Consultar variável: esta opção permite consultar as variáveis definidas, abrindo uma janela com o nome, tipo e o tamanho delas.

- Remover variável: exclui uma variável definida.

\subsubsection{Execução}

A seleção da opção "Execução" do menu de Funcionalidades da figura 4.4 abre uma janela (veja figura 4.7) com uma barra de menus pulldown na sua parte superior, os quais possuem as seguintes opções:

$\Rightarrow$ Lista de trabalho: mostra as atividades alocadas ao participante e as atividades não alocadas, mas atribuídas ao seu papel. Possui as seguintes alternativas: 


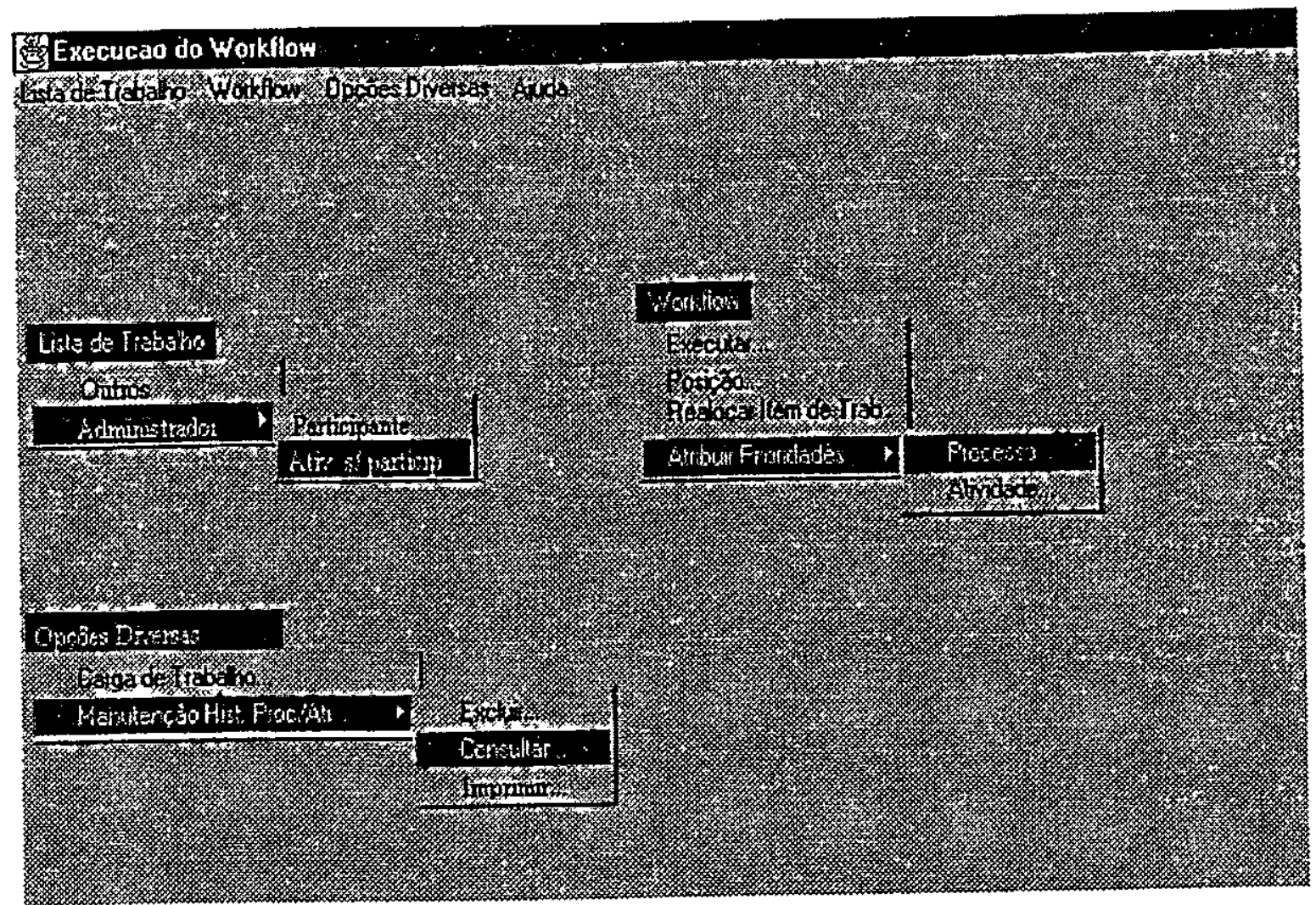

Figura 4.7 Execução de workflow

- Outros: é aberta a lista de trabalho, do participante corrente autorizado a usar o sistema, contendo na área "Atividades alocadas", as atividades que the foram alocadas ou selecionadas por ele e na área "Atividades não alocadas" as atividades disponíveis para sua alocação, atribuídas ao seu papel.

- Administrador: esta opção fica habilitada somente para participantes com papel de administrador $e$ oferece as seguintes alternativas:

* Participante: apresenta uma lista de participantes e após a indicação de um deles abre uma janela com as suas atividades alocadas e as disponíveis para alocação, conforme seu papel.

* Ativ. s/ particip.: abre uma janela com todas as atividades de workflows em execução esperando alocação de um participante. Apresenta data e hora da habilitação de execução e data e hora de disponibilização para alocação (quando a pré-condição, se houver, tiver sido satisfeita). O administrador pode 
a partir dessas informações decidir alocar essas atividades aos participantes que the convier.

Ao ser aberta a janela contendo a lista de trabalho (opcão "Outros" e "Administrador Participante", é disponibilizada uma série de botões contendo as seguintes opções:

- Alocar: quando uma atividade da área "Atividades não alocadas" é marcada e esse botão pressionado, significa que se está alocando tal atividade para sua execução, fazendo com que essa atividade saia dessa área e seja inchúda na área "Atividades alocadas". Esta operação é ignorada para as atividades da área "Atividades alocadas".

- Executar: marcando uma atividade da área "Atividades alocadas" e pressionando-se esse botão, faz com que se inicie sua execução, abrindo-se uma janela com suas ações e seus respectivos estados. Esta operação não tem validade para as atividades da área "Atividades não alocadas". As ações podem sofrer as seguintes operações:

Executar: marcando uma ação e pressionando este botão significa que a ação está iniciando execução, ou no caso de uma ação suspensa, a restauração de seu estado "Executando". Sua situação é alterada para "Executando" e se o tipo da ação for automática, ela é interpretada e executada pela máquina de workflow, sendo que no final da execução tem sua situação alterada para "Executada", automaticamente. Se a ação for manual significa que sua execução é feita fora do controle do sistema.

- Suspender: esta opção é válida para ações do tipo manual e para as de tipo automático que estejam no estado "Ativo", isto é, não iniciou execução. Marcando uma ação e pressionando este botão, seu estado é alterado para "Suspenso(a)", significando que a sua execução foi temporariamente interrompida.

○ Cancelar: Marcando uma ação e pressionando esse botão, seu estado é alterado para "Cancelado(a)". Significa que a ação é interrompida, não sendo completada, no caso de estar em execução (válida somente para ação do tipo manual) ou suspensa. Ou que não será executada nos casos de açð̃es com estado "Ativo". 
Finalizar: esta opção é válida somente para ações do tipo manual. Marcando uma ação e pressionando esse botão, seu estado é alterado para "Executado(a)", significando que a ação foi completada.

Fim: fecha a janela de ações, retornando o controle para a janela de lista de trabalho

- Suspender: marcando uma atividade da área "Atividades alocadas". e pressionando este botão, significa que a atividade está sendo suspensa, interrompendo temporariamente sua execução (não válida para as atividades da área "Atividades não alocadas').

- Consultar: marcando uma atividade da área "Atividades alocadas" e pressionando este botão, abre uma janela com as ações dessa atividade, disponibilizando as operações com ações descritas no botão "Executar". Marcando uma atividade da área “Atividades não alocadas" e pressionado esse botão, é mostrada a janela com as ações dessa atividade, mas com as suas operações desabilitadas.

- Cancelar: marcando uma atividade da área "Atividades alocadas" e pressionando esse botão, significa que a sua execução é interrompida definitivamente. Esta operação é ignorada para as atividades da área "Atividades não alocadas".

- Fim: a janela "lista de trabalho" é fechada e o controle é passado para a tela de menus "Execução do workflow", da figura 4.7.

$\Rightarrow$ Workflow: oferece como alternativa as seguintes opções:

- Executar: esta opção é selecionada quando se deseja instanciar um workflow, neste caso, abre-se uma janela contendo uma lista de workflows consolidados para escolha de um deles. Após indicar um deles, o participante pode escolher um dos botões:

* ok: a máquina de workflow faz a interpretação da definição de processo do workflow indicado, instanciando a sua primeira atividade, que após a avaliação da sua pré-condição, se houver, fica aguardando a alocação por algum participante componente de papéis que lhe foram especificados, isto é, passa a compor a lista de atividades não alocadas, da lista de trabalho de participantes 
cujos papéis foram especificados para essa atividade. A janela é fechada e o controle retorna para a janela da figura 4.7.

* selecionar: com esta op§ão, se o participante for autorizado, ele pode nesse momento alterar os papéis atribuidos para as atividades do tipo item de trabalho, na definição do workflow, bem como especificar participantes para execução dessas atividades. Para isso é aberta uma janela contendo todas as atividades do tipo item de trabalho com seus respectivos papéis e apresentando os botões:

- escolher papel: selecionando uma atividade e pressionando-se esse botão, mostra-se uma lista de papéis para seleção e após isto ser feito, abre-se uma nova janela indicando as atividades com os novos papéis.

- escolher participante: selecionando uma atividade e pressionando-se esse botão, mostra-se uma lista de participantes componentes dos papéis especificados a essa atividade. Selecionando-se um deles, a atividade é alocada a ele, passando a compor as atividades alocadas de sua lista de trabalho.

- fím: quando pressionado, essa janela é fechada e é executado o procedimento do botão "ok", exceto que o controle retorna para a janela que permite selecionar a execução de um outro workflow.

- Posição: esta opção permite visualizar em uma janela a posição dos workflows em execução, apresentando informações tais como: identificação de workflow, participante que iniciou execução, data e hora de inicio de execução e seu estado. A partir da janela contendo as informações citadas seleciona-se um workflow e então se pode executar as opçōes abaixo:

* Consultar: mostra mais informações do workflow.

* Suspender: altera o estado do workflow para "Suspenso", não permitindo a execução de suas atividades. Ë mantido na tabela "Instancia_de_processo" o registro do último participante que o suspendeu. 
* Cancelar: altera o estado do workflow para "Cancelado", interrompendo definifitivamente a sua execução. É armazenada na tabela "Historia_processo" a identificação do participante que cancelou sua execução.

* Executar: restaura o estado de um workflow "suspenso" para "Executando", permitindo continuar a sua execução.

* Fim: fecha a janela, retomando o controle para a janela da figura 4.7.

- Realocar item de trabalho: altera o participante executor de uma atividade. Sua escolha abre uma lista de workflows em execução para indicação de um deles. Após a indicação, é aberta uma janela com suas atividades e respectivos participantesexecutores. Marcando-se uma atividade e pressionando-se o botão "novo executor", mostra-se uma lista de participantes componentes de papéis especificados para a atividade. Selecionando-se um deles, substitui o participante-executor da atividade.

Atribuir prioridades: altera a prioridade especificada para processos e atividades

* Processo: abre uma janela contendo os workflows em execução com suas respectivas prioridades. Ao marcar um workflow e pressionar o botão "nova prioridade", abre-se uma lista de prioridades de 1 a 9 e a seleção de um deles substitui a prioridade do workflow indicado.

* Atividade: abre uma lista de workflows em execução para escolha de um deles. Após a escolha é aberta uma janela com suas atividades e respectivas prioridades. Marcando-se uma atividade e pressionando-se o botão de "nova prioridade", abre-se uma lista de prioridades de 1 a 9 para a seleção de uma delas e ela substitui a prioridade da atividade indicada.

$\Rightarrow$ Opções diversas: aqui são agrupadas as opções de finalidade geral

- Carga de trabalho: esta op̧ão apresenta a carga de trabalho dos participantes. Para isso, a máquina de workflow calcula o volume de trabalho de cada participante baseando-se nas atividades que lhe foram alocadas e no tempo previsto de execução de cada atividade. No primeiro nivel de informação, mostra a carga de trabalho por papel e participante, sendo que no seu detalhamento apresenta informações tais como: 
participante-executor, identificação de workflow, identificação de atividade e tempo previsto de execução.

- Manutenção Hist.Proc/ati (Histórico de Processo/Atividade): permite as seguintes opções:

* excluir: solicita o período de exclusão e após isso, exclui as linhas das tabelas "História_processo" e "História_atividade" cuja data e hora de finalização de workflow se enquadram no periodo informado.

* consultar: solicita o periodo de consulta e então mostra as informações da história de processos e história de atividades do período informado.

* imprimir: solicita o periodo de impressão e então imprime as informações da história de processos e história de atividades do período informado.

\subsubsection{Ajuda}

A opção "Ajuda" permite obter texto explicativo a respeito das funcionalidades apresentadas na figura 4.5 .

\subsubsection{Sair}

Esta opção faz com que o sistema finalize as operações do participante.

\subsection{Exemplo de uso}

Nesta seção é dado um exemplo de especificação e execução de workflow feito com o sistema de gerenciamento de workflow para gestão de documentos. Inicialmente deve-se a partir de um web browser, digitar a URL (veja seção 4.4), a qual abre a página inicial do sistema (veja figura 4.4), contendo os campos para validação do usuário. Sendo um usuário válido, é aberta uma janela com as funcionalidades gerais do sistema, conforme visualizado na figura 4.4. 


\subsubsection{Especificação de workflow}

A especificação a seguir é do exemplo do item 3.7.1, do capítulo 3, o qual se refere a um workflow para criar tipo de documento. Utiliza o editor gráfico de workflow do sistema (EdGraW), gerando uma definição de processo.

No menu de funcionalidades (figura 4.4), um participante seleciona o botão "Edição de Processos", o qual abre a janela inicial do editor, conforme mostrado na figura 4.6. Então, seleciona o primeiro ícone da barra de ícones vertical ou abre o menu "Workflow" e escolhe a opção "Novo". Isto provoca a abertura de uma janela para informação dos dados do processo, preenchidos conforme figura 4.8 .

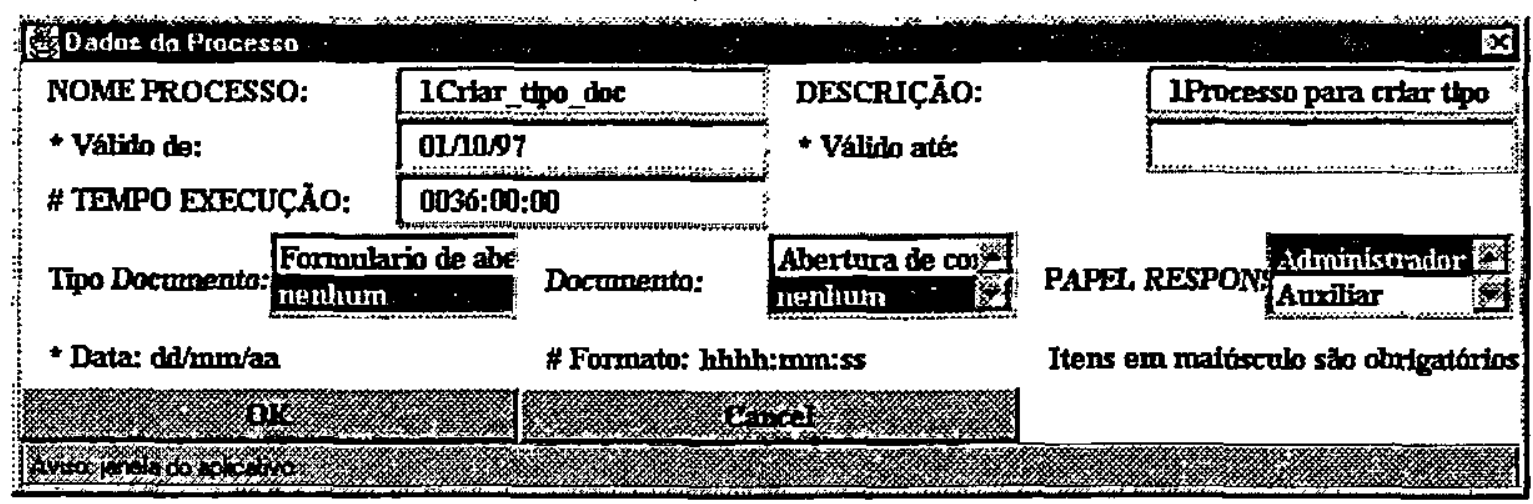

Figura 4.8 Exemplo de preechimento dos dados do processo

Após o preenchimento dos atributos obrigatórios, distinguidos pelo rótulo com letras maiúsculas, da figura 4.8, pressionado o botão "OK" e o conteúdo dos campos terem sido validados, a janela é fechada e pode-se iniciar a especificação da primeira atividade do workflow na área de desenho da figura 4.6. O terminador inicial é colocado automaticamente na área de desenho.

A primeira atividade desse workflow é do tipo item de trabalho ("Iniciar formulário"), cujo objetivo é permitir que seu participante executor descreva a aplicação e as características do formulário a ser criado. Então, seleciona-se o quarto ícone ou abre-se o menu "LIRA" e escolhese a opção item de trabalho (figura 4.9). Posiciona-se o ponteiro do mouse na posição que ser quer representar o componente gráfico correspondente e pressiona-se duplamente o seu botão 
esquerdo, o qual abre uma janela para informação de dados referente às propriedades da atividade, os quais podem ser vistos preenchidos na figura 4.10.

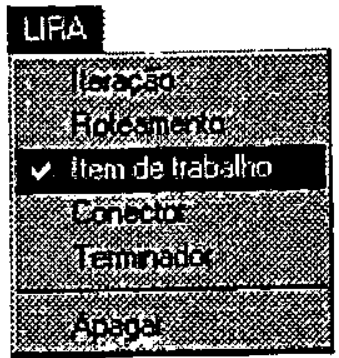

Figura 4.9 Seleção para representar um item de trabalho

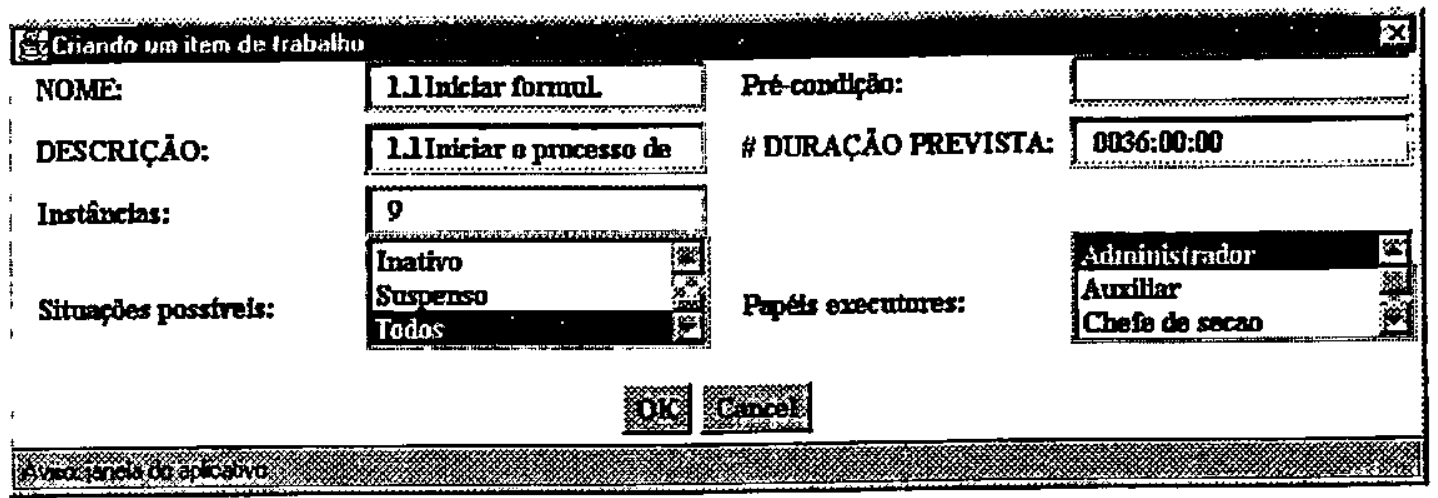

Figura 4.10 Exemplo de janela com informação de dados do item de trabalho "Iniciar formulário"

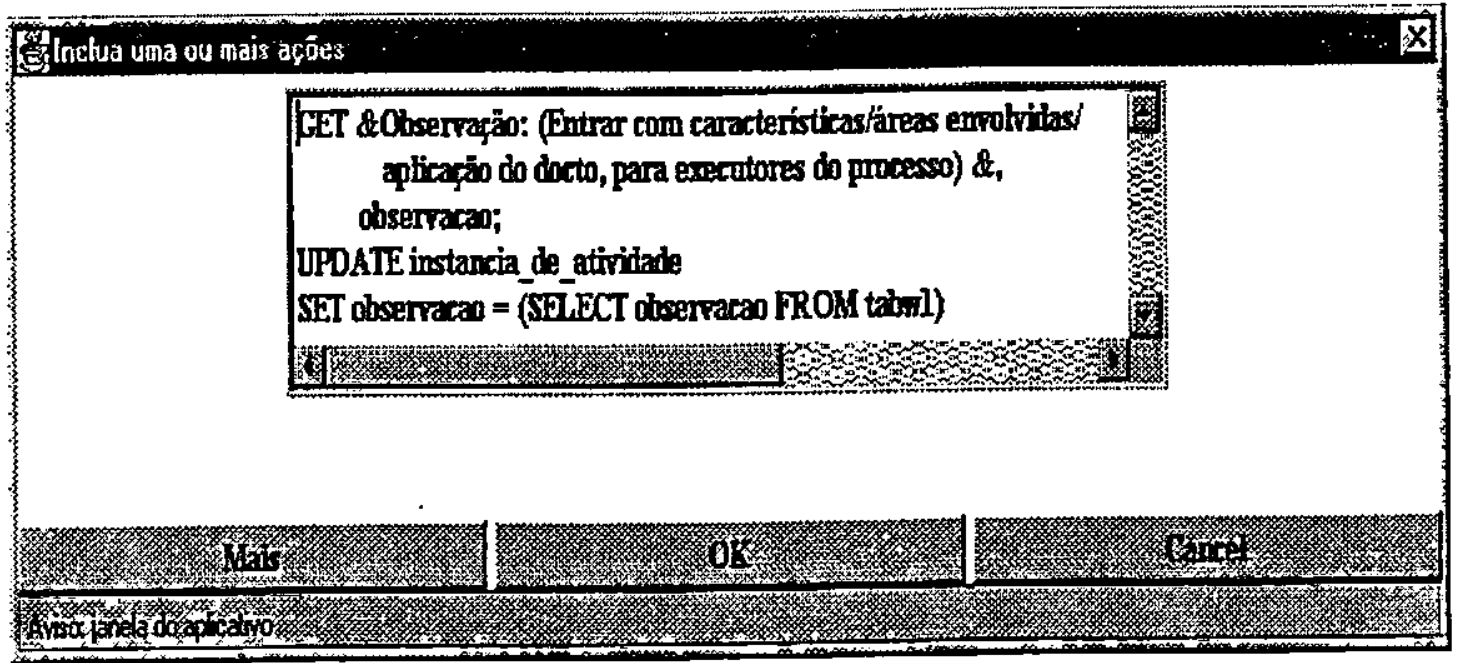

Figura 4.11 Especificação da primeira ação da atividade 1.1 - "Iniciar formulário" 
Após ter preenchido os atributos obrigatórios (rótulo com letras maiúsculas), pressionado o botão "Ok" e os atributos terem sido validados, a janela é fechada e é aberta uma outra para especificar as ações. A ação é especificada utilizando a linguagem LIDA (figura 4.11). A primeira ação dessa atividade inclui comandos que na sua execução abrem uma janela solicitando a descrição da aplicação e características do formulário a ser criado. Esse dado é armazenado na tabela Instancia de Atividade (ver apêndices "B" e "C").

Na especificação da ação há necessidadè de definir a variável "observação". Então, o usuário ativa a janela da figura 4.6, a qual está aberta e seleciona o seu menu "LIDA", escolhendo a opção "Declarar variável", conforme figura 4.12. Abre-se uma nova janela para a declaração da variável, a qual pode ser vista na figura 4.13.

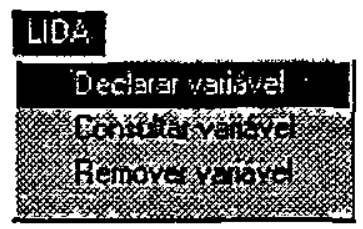

Figura 4.12 Menu de manutenção de variável

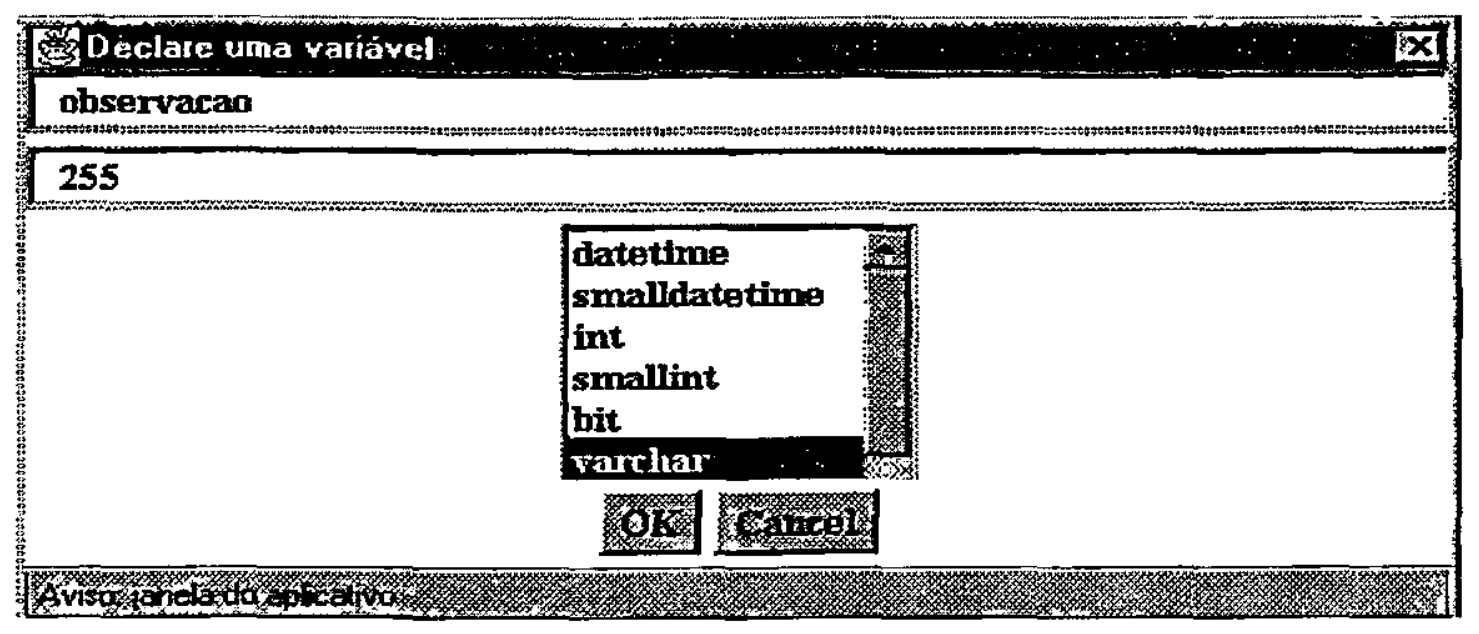

Figura 4.13 Declaração da variável "observação"

Ao ser pressionado o botão "Ok", da figura 4.13, essa janela é fechada. No término da digitação dessa ação, pressiona-se o botão "mais", para habilitar a digitação da próxima ação. 
Após a digitação da última ação, o botão "Ok" deve ser pressionado, fechando a janela de inclusão de ações (figura 4.11) e então o componente gráfico da atividade é desenhado na posição indicada, da área de desenho. Uma conexão deve ser estabelecida entre o terminador inicial e o componente gráfico desenhado, o qual é feito selecionando-se o quinto ícone ou abrindo-se o menu "LIRA" e escolhendo a opção "Conector". Então, posiciona-se o ponteiro do mouse sobre o componente gráfico do terminador inicial, pressiona-se e mantém-se pressionado o botão esquerdo do mouse. Arrasta-se o ponteiro do mouse até o componente gráfico da atividade item de trabalho e então se solta a tecla mantida pressionada do mouse. Uma aresta é desenhada ligando os dois componentes citados.

As atividades: 1.2 ("Propor formulário"), 1.3 ("Conferir"), 1.5 ("Autorizar") e 1.7 ("Liberar formulário") que compõem o exemplo são do tipo item de trabalho e, portanto, é executado o mesmo procedimento da atividade 1.1 ("Iniciar formulário") para a especificação de cada uma delas. $\mathrm{O}$ conteúdo dos dados informados para essas atividades pode ser visto no apêndice "C".

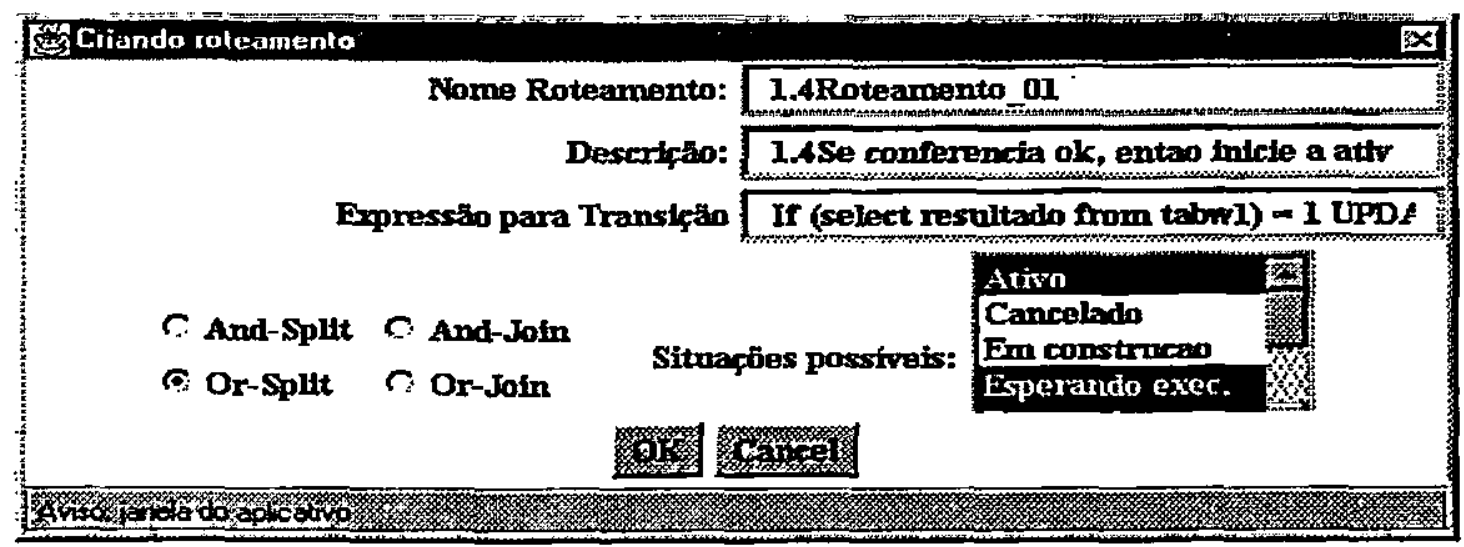

Figura 4.14 Propriedades da atividade 1.4 (roteamento 1)

$\mathrm{Na}$ especificação da atividade 4 (atividade de roteamento), seleciona-se o terceiro ícone ou abre-se o menu "LIRA", escolhendo a opção "Roteamento". Posiciona-se o ponteiro do mouse na posição que se quer representar o componente gráfico correspondente e pressiona-se duplamente o seu botão esquerdo, o qual abre uma janela para informação de dados referentes às propriedades da atividade, os quais podem ser vistos preenchidos na figura 4.14. A atividade de roteamento é do tipo "Or-Split", possuindo uma expressão especificada utilizando a linguagem 
LIDA, a qual é validada pelo editor no momento em que é pressionado o botão "ok" e, caso haja algum erro, este é informado ao usuário para correção. Não existindo erro, a janela é fechada e o componente gráfico correspondente a essa atividade é desenhado na área indicada. Após a representação gráfica das atividades que devem ser ligadas a esse roteamento, faz-se a conexão entre elas, selecionando o quinto ícone ou abrindo o menu "LIRA" e escolhendo a opção "Conector". Entāo, posiciona-se o ponteiro do mouse no componente gráfico predecessor da atividade de roteamento (atividade 1.3), pressiona-se o botão esquerdo do mouse e, mantendo-o pressionado, arrasta-se o ponteiro do mouse ao componente gráfico da atividade de roteamento e solta-se o botão do mouse pressionado, ocorrendo então uma ligação. Em seguida, liga-se o componente gráfico de roteamento aos componentes gráficos das atividades 1.2 e 1.5, seguindose essa ordem e o procedimento descrito para conexão.

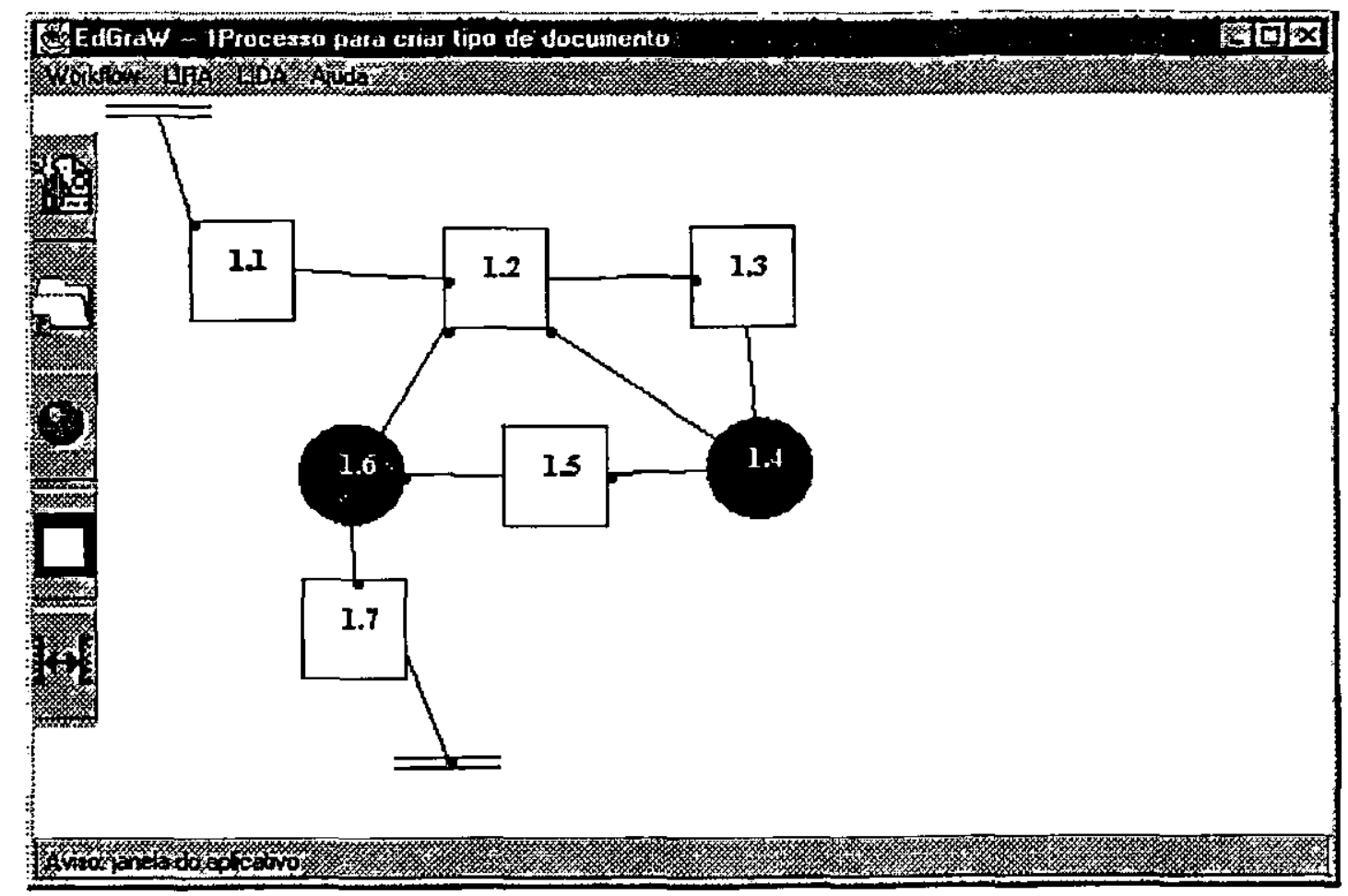

Figura 4.15 Representação gráfica do workflow para criar um tipo de documento

A especificação da atividade 1.6 (roteamento 2) é feita obedecendo ao mesmo procedimento descrito para a atividade de roteamento 1.4. A figura 4.15 , mostra a representação gráfica completa desse workflow e o conteúdo das suas propriedades pode ser visto no apêndice 'D". 
A seqüuência de figuras $4.16,4.17,4.18,4.19,4.20,4.21,4.22,4.23,4.24,4.25,4.26$, 4.27 e 4.28 mostram as telas com a especificação do exemplo da seção 3.7 .2 (Workflow de uso para o tipo de documento de abertura de conta no sistema).

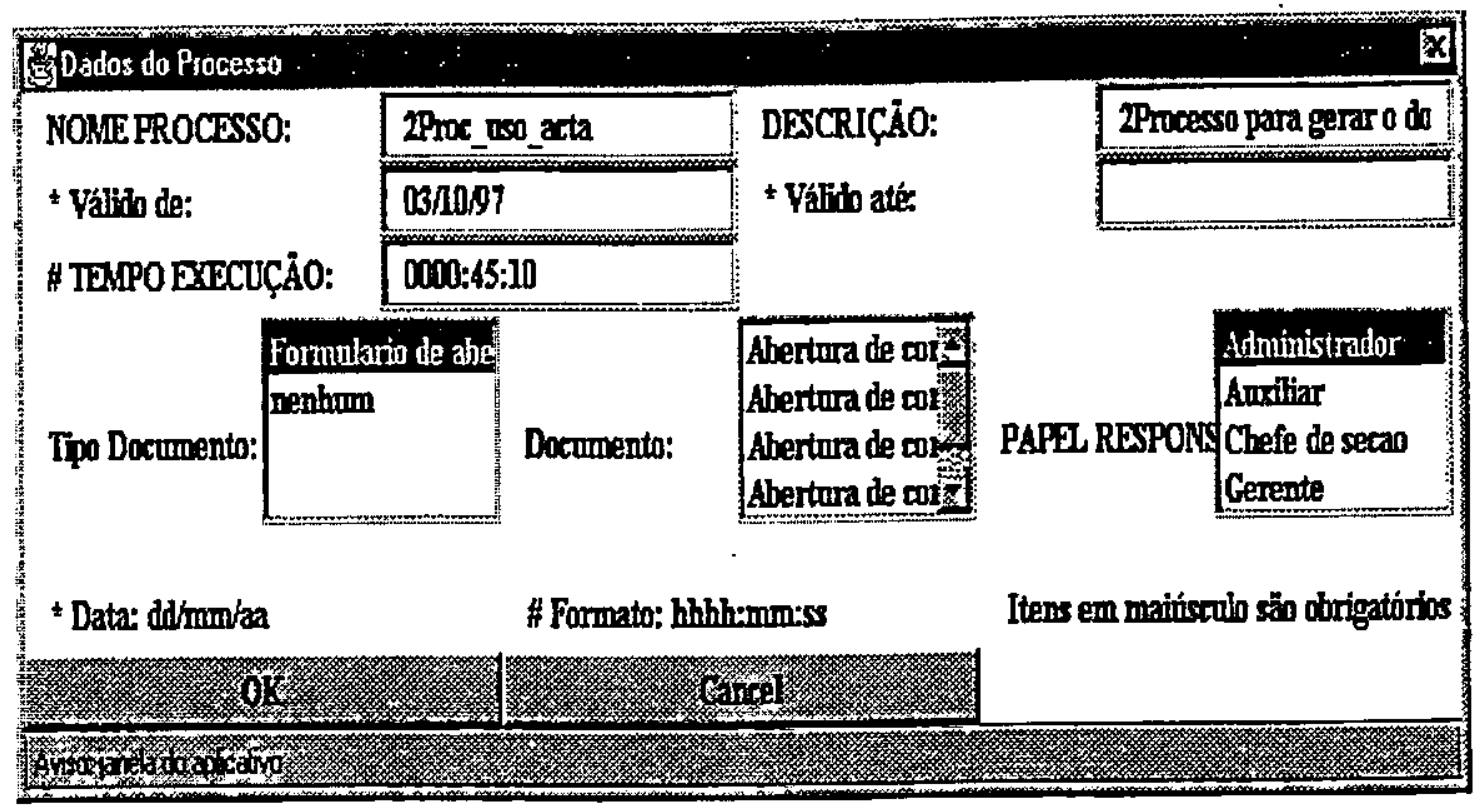

Figura 4.16 Janela com as propriedades do processo

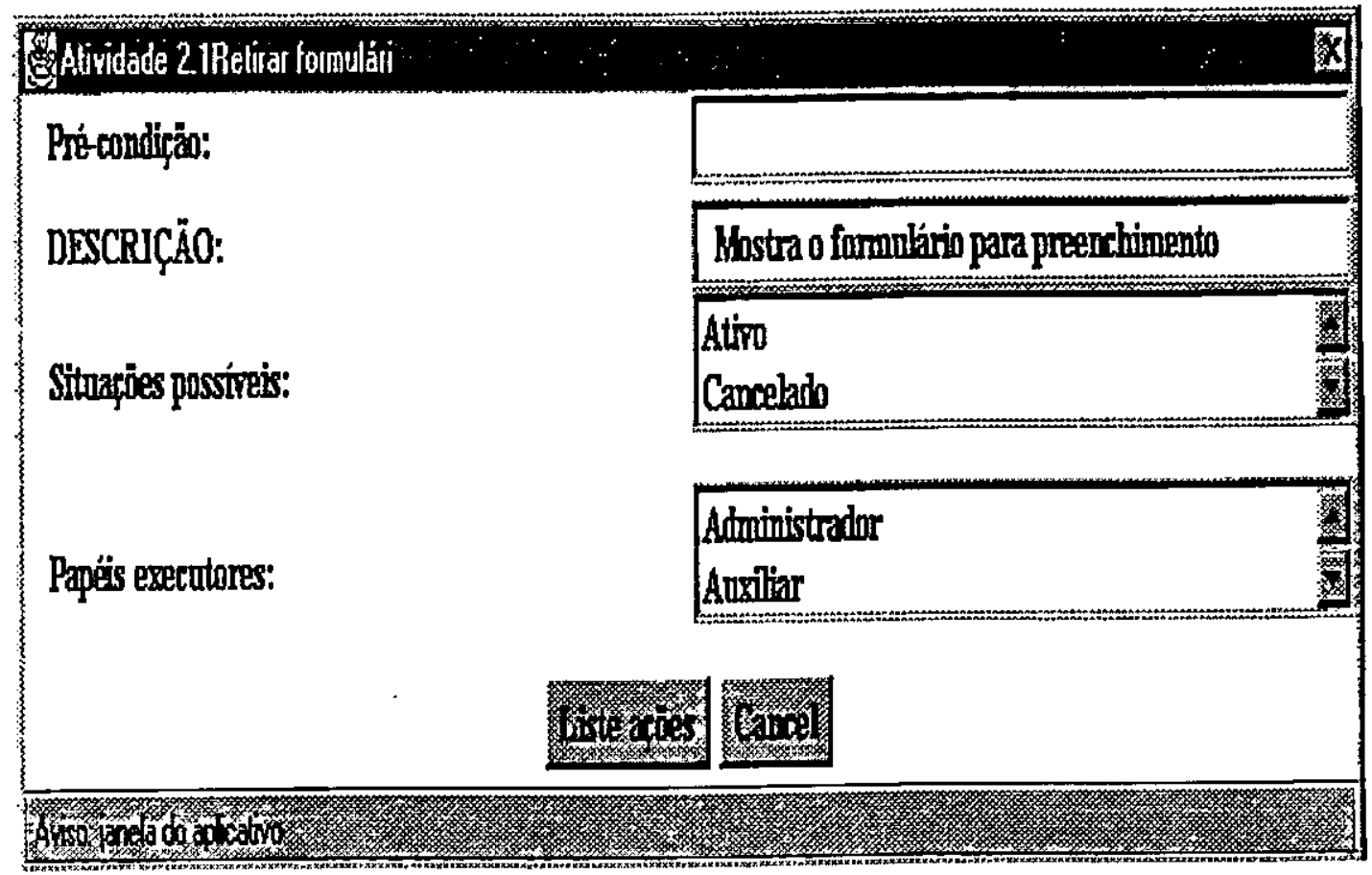

Figura 4.17 Janela com as propriedades da atividade 2.1 


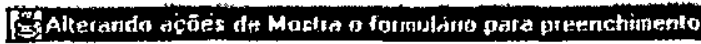

\# vertficar fostruçoes de retirata io formothing

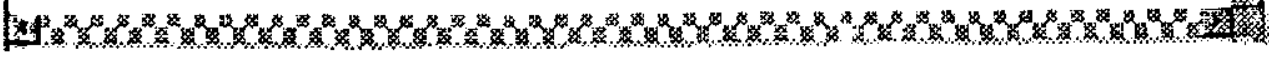

\# dar comandos de rethata io formulato

i* Observiçän *I

GET \&Otuenragan \&, observacon;

UPDATE instanein_de_attividade

SET observacao - (SEI,FCT abservacao from tabw)

WHERE id_instancta_attridade - (SELECT id_fnst_athr FROM tabw)

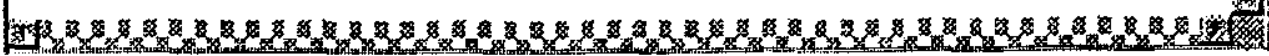

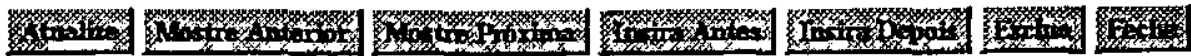

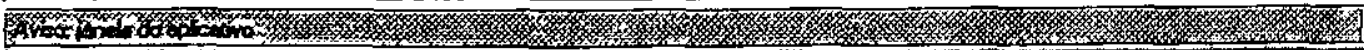

Figura 4.18 Janela com as ações da atividade 2.1

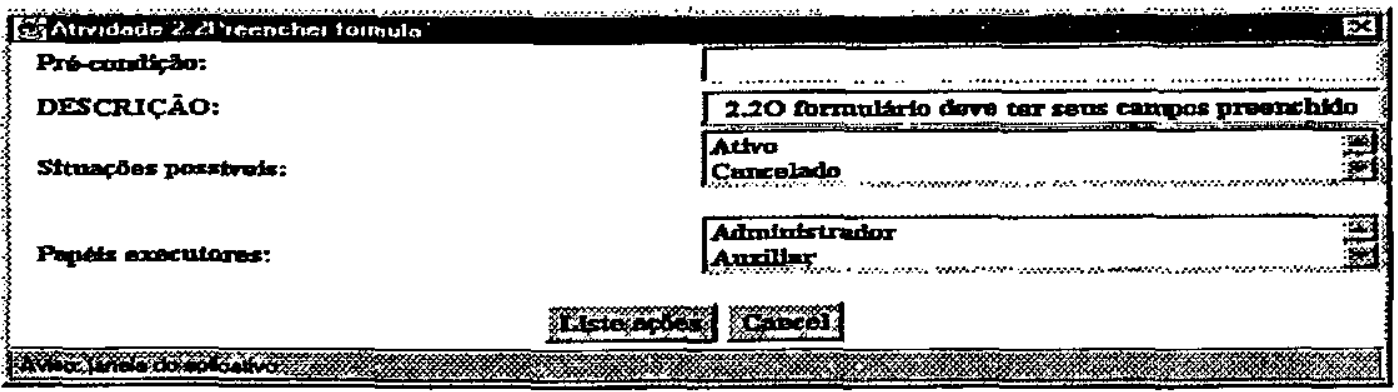

Figura 4.19 Janela com as propriedades da atividade 2.2

\begin{tabular}{|c|}
\hline 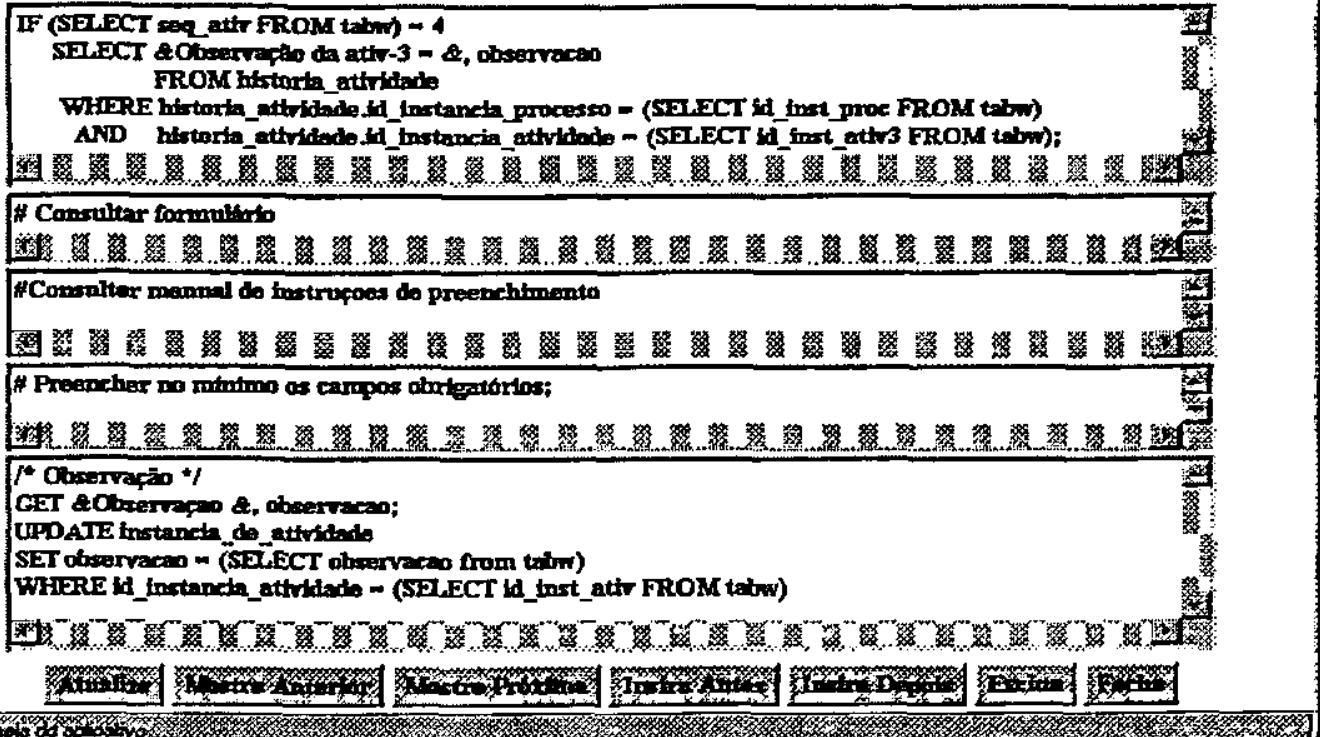 \\
\hline
\end{tabular}

Figura 4.20 Janela com as ações da atividade 2.2 


\begin{tabular}{|c|c|c|c|}
\hline Atividade 2.3Confenit formulat & & & $x$ \\
\hline \multicolumn{4}{|l|}{ Pré-condiçäo: } \\
\hline \multicolumn{2}{|l|}{ DESCRIÇÃO: } & \multicolumn{2}{|c|}{ 2.3Conferir se os campos do formulario foram pre } \\
\hline \multicolumn{2}{|l|}{ Situaçōes possiveis: } & $\begin{array}{l}\text { Ativo } \\
\text { Cancelado }\end{array}$ & 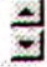 \\
\hline \multirow[t]{2}{*}{ Papéis excecutores: } & & $\begin{array}{l}\text { Administrarlor } \\
\text { Awciliar }\end{array}$ & $\frac{\Delta}{2}$ \\
\hline & Liste agies & Cancel & \\
\hline Aviso. janela do aplicativo & 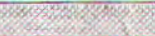 & 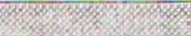 & \\
\hline
\end{tabular}

Figura 4.21 Janela com as propriedades da atividade 2.3

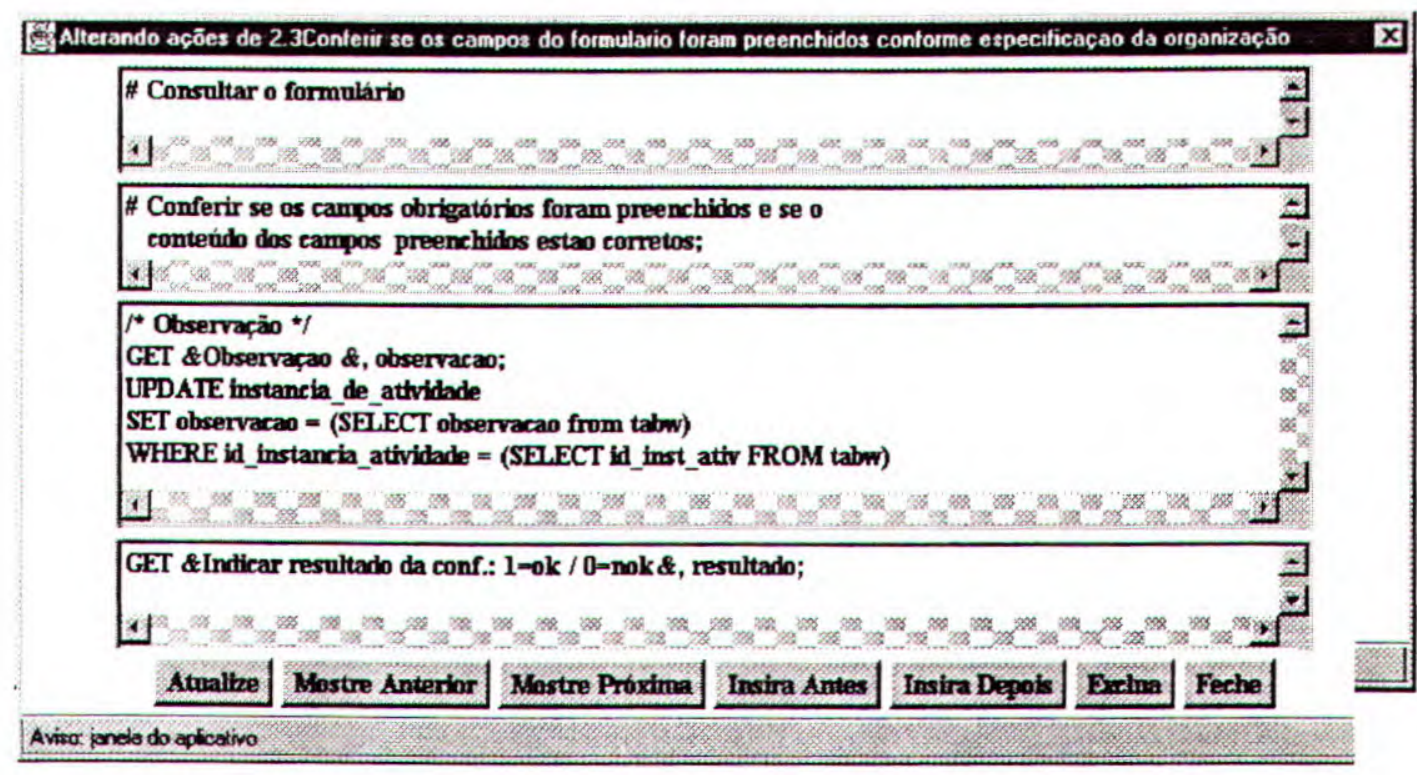

Figura 4.22 Janela com as ações da atividade 2.3

Expressão para Transição Preencher formulario \&); EXECUTAR idativ_aux;

\begin{tabular}{cc|l|} 
Expcutando \\
Habilitado(a) a exe \\
Inatiso
\end{tabular}

Ok Cancel

Avisec janela do aplicativo

Figura 4.23 Janela com as propriedades da atividade 2.4 


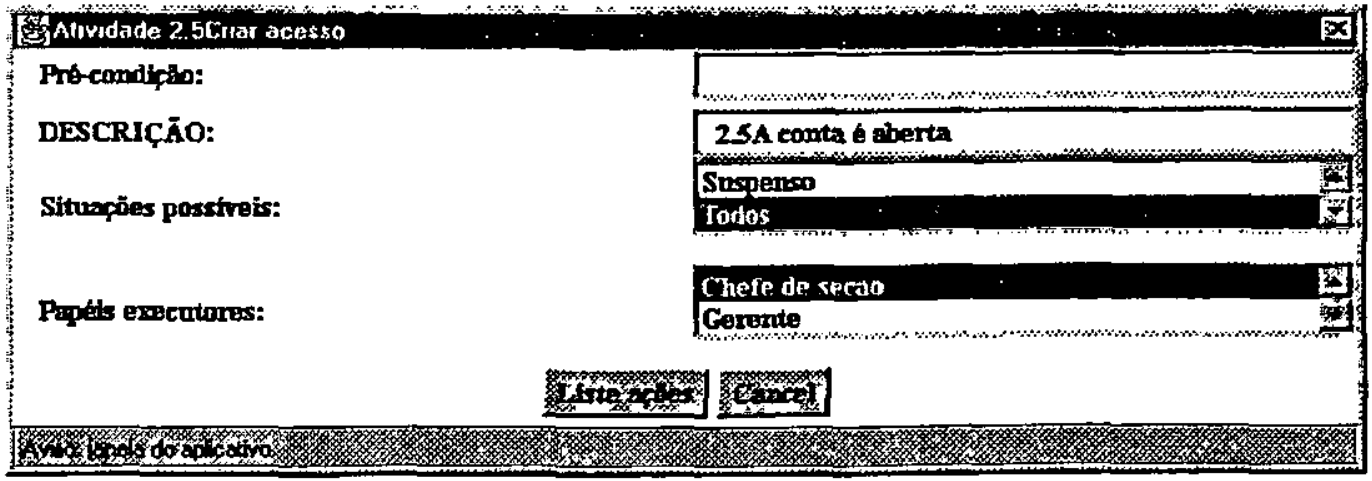

Figura 4.24 Janela com as propriedades da atividade 2.5

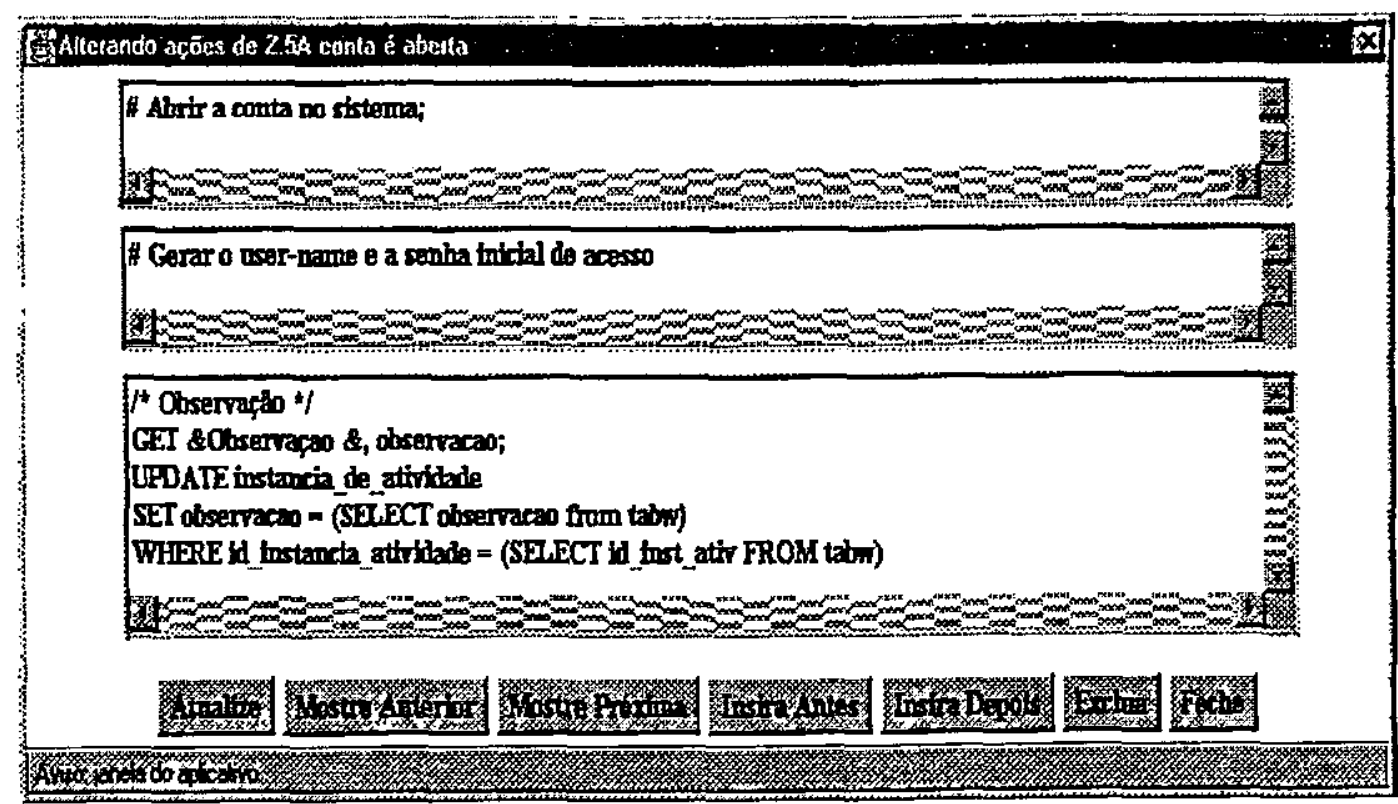

Figura 4.25 Janela com as ações da atividade 2.5

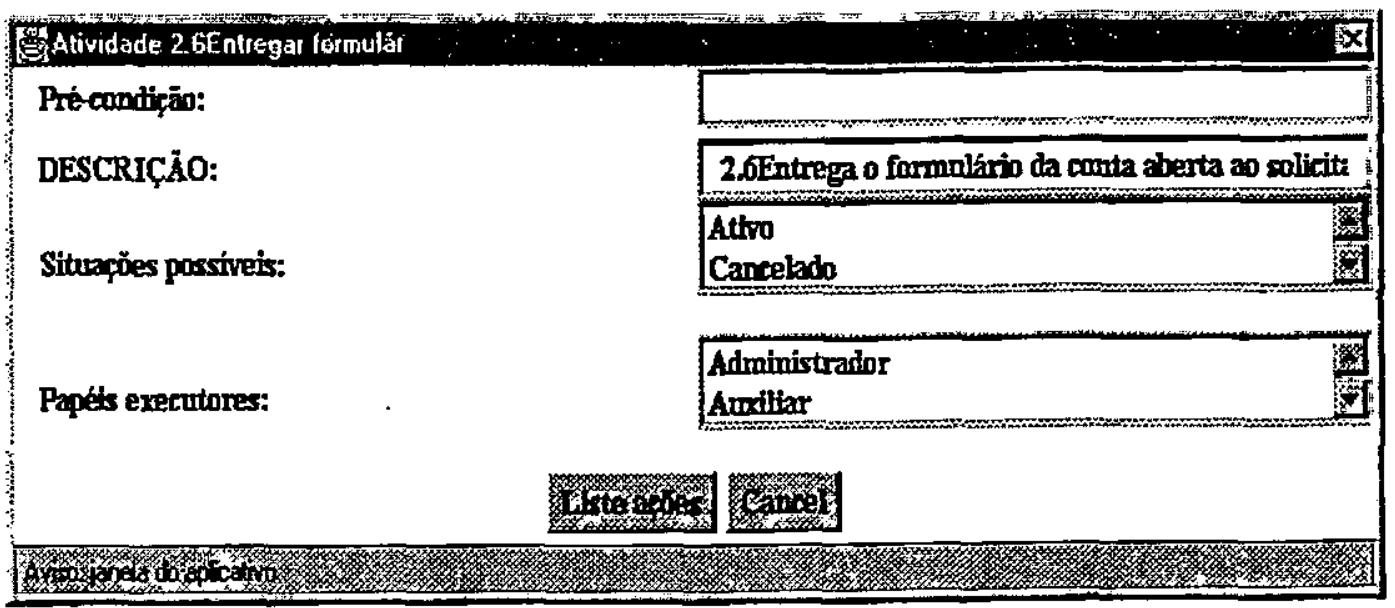

Figura 4.26 Janela com a propriedade da atividade 2.6 


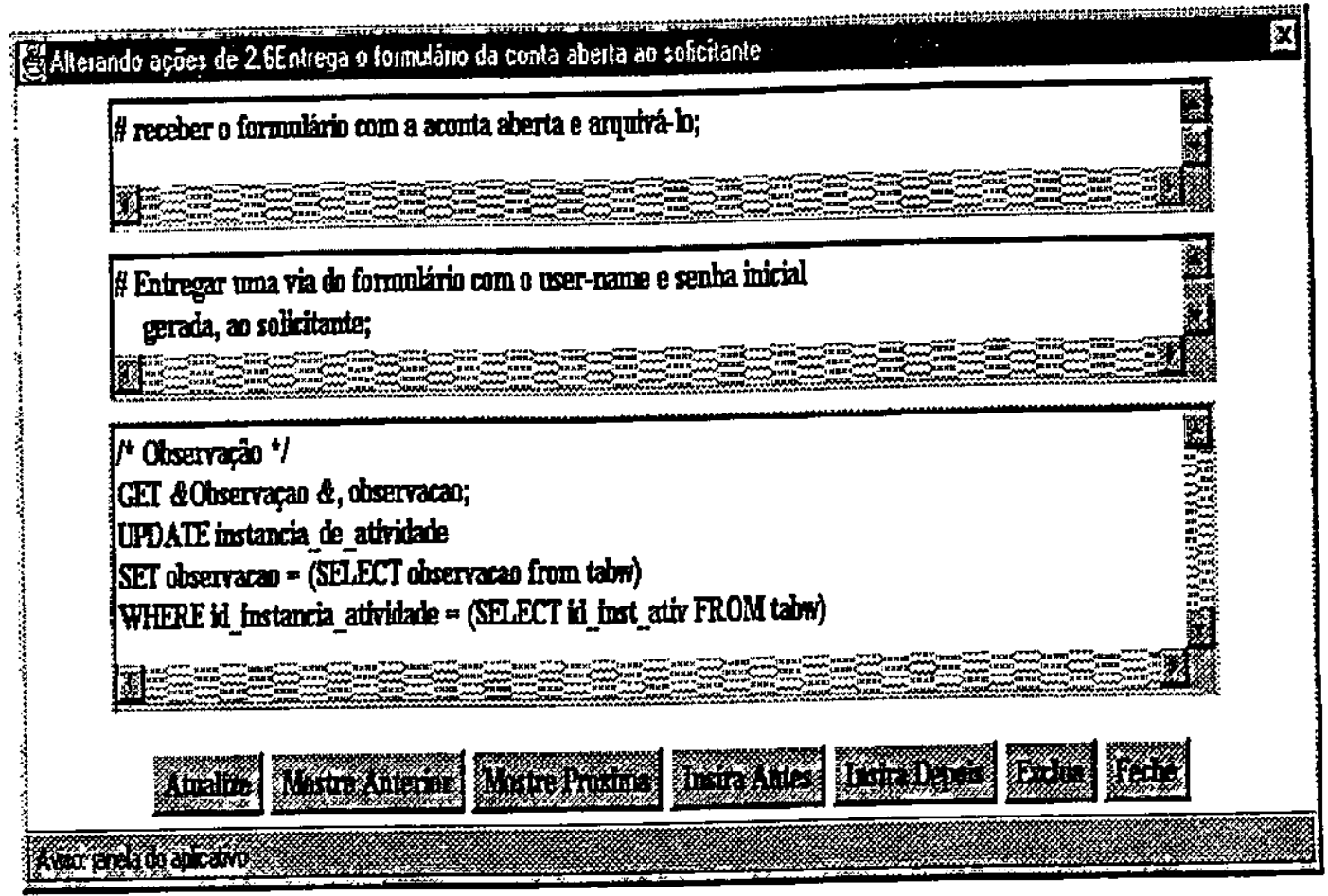

Figura 4.27 Janela com as ações da atividade 2.6

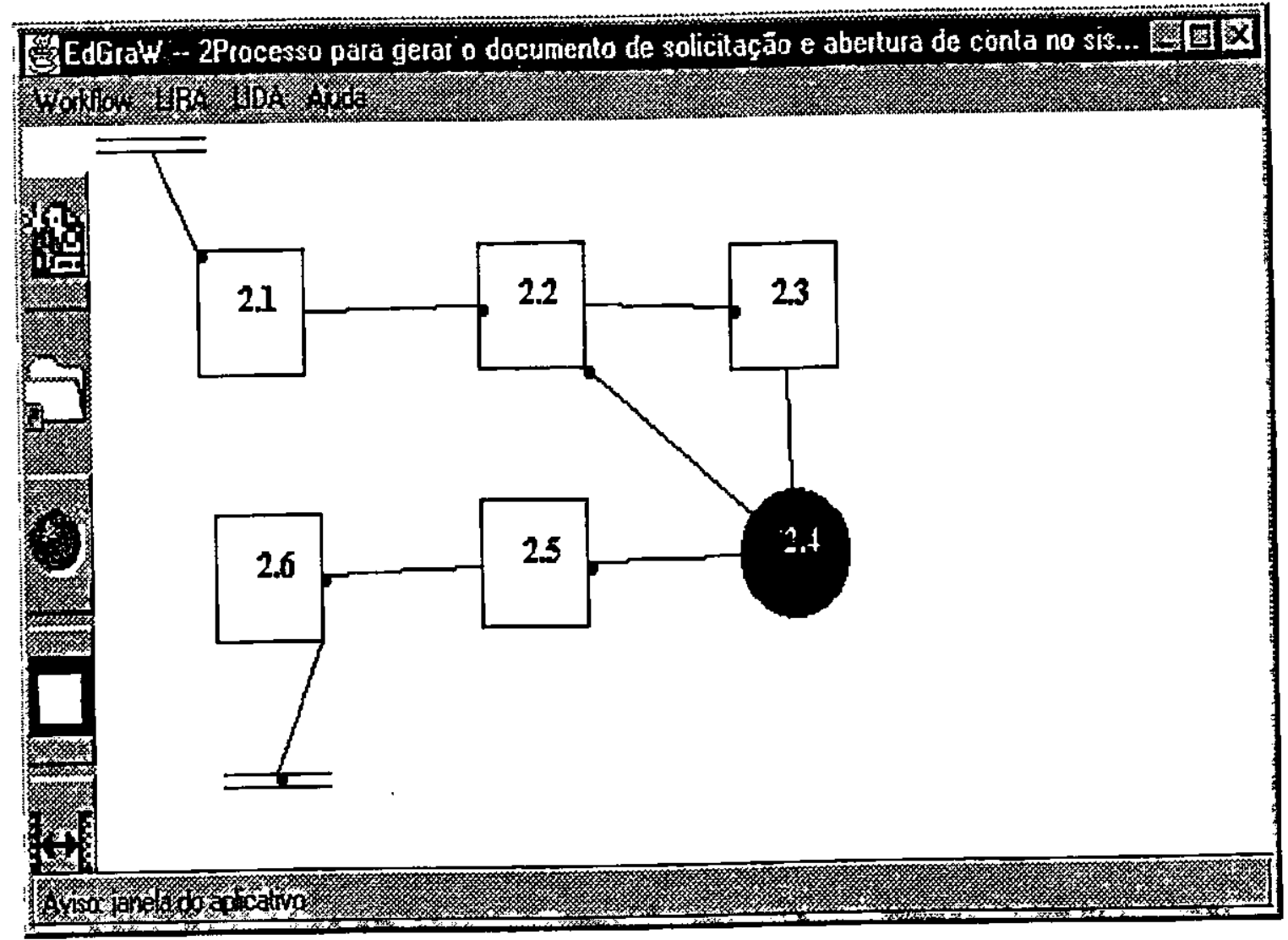

Figura 4.28 - Janela com a representação gráfica do exemplo 


\subsubsection{Execução de workflow}

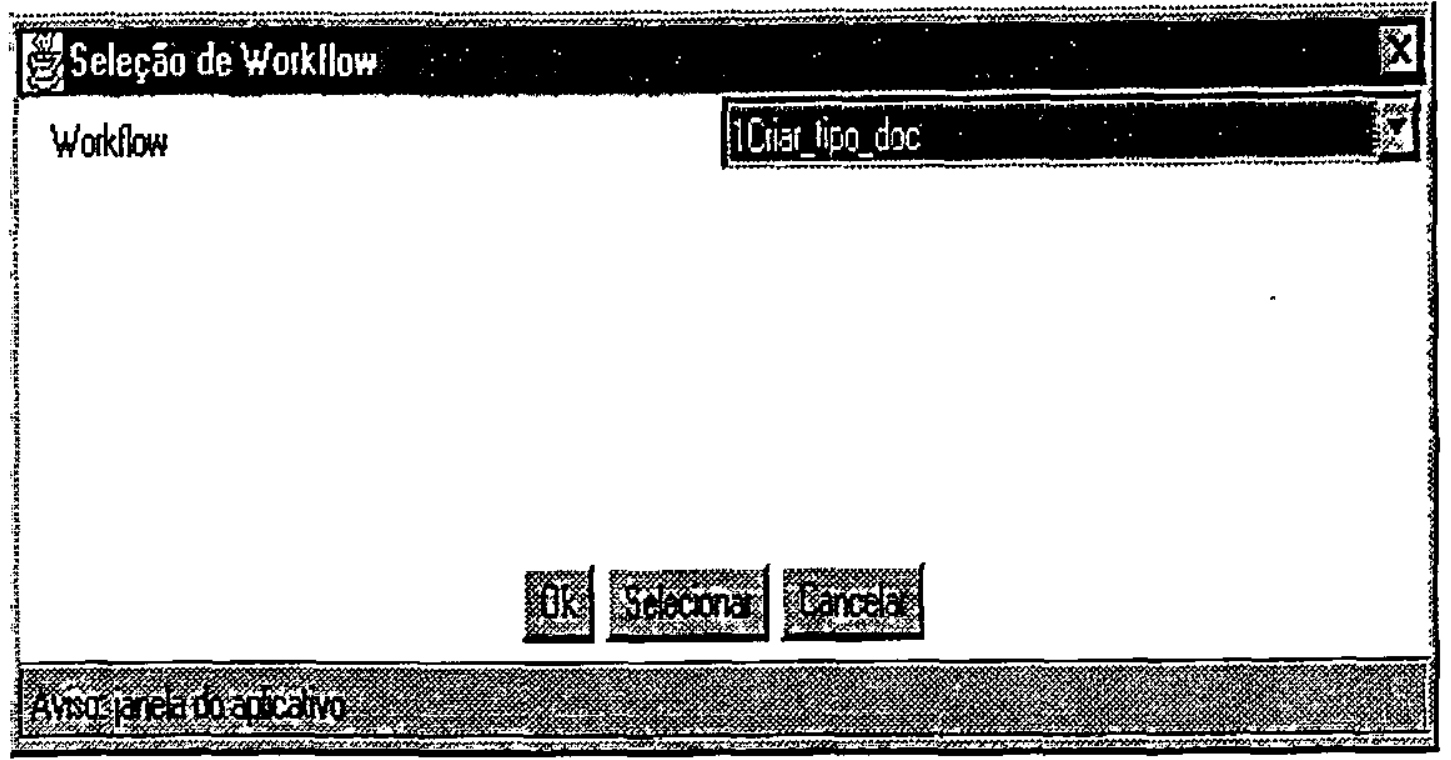

Figura 4.29 Lista de workflows para execução

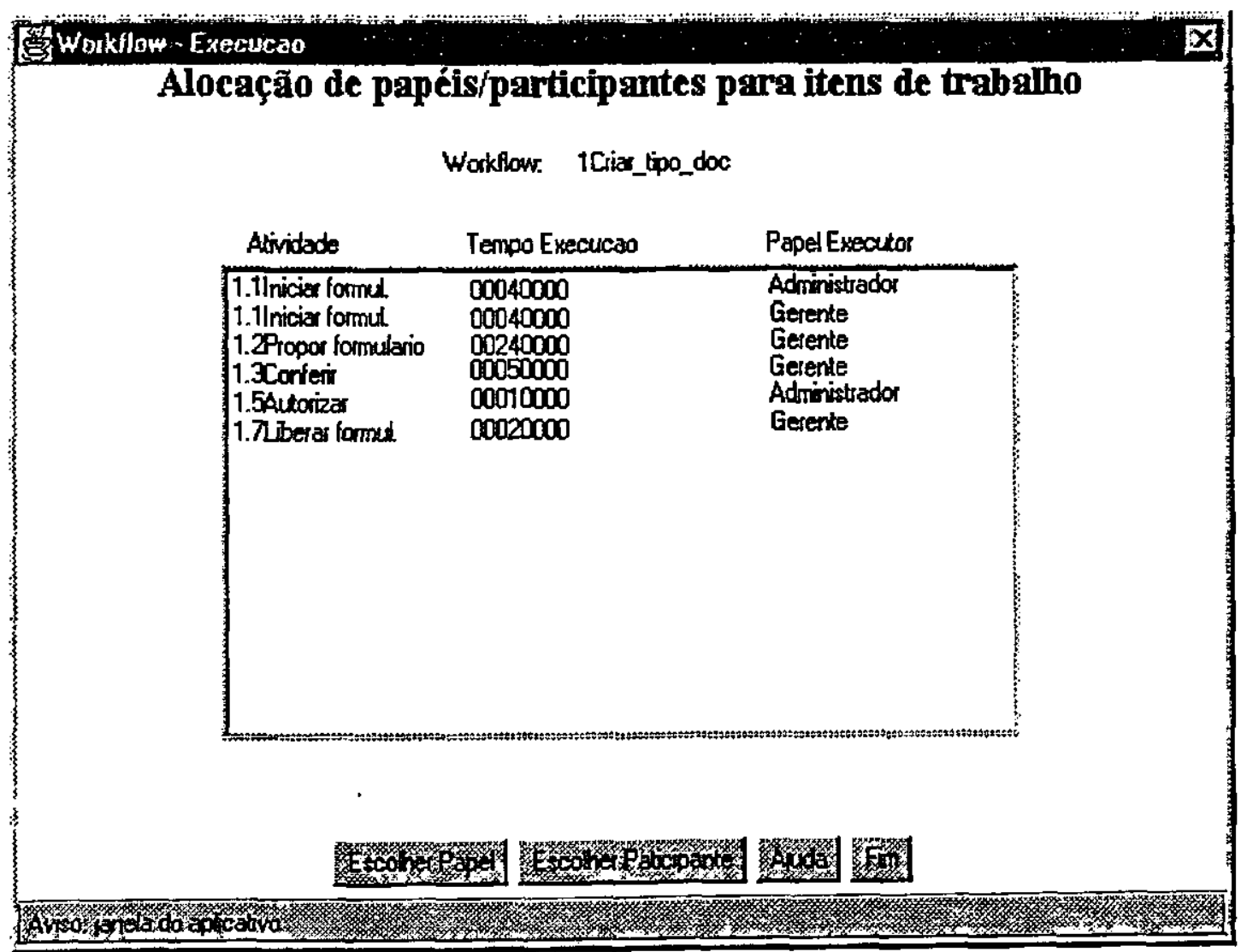

Figura 4.30 - Alocação de papéis/participantes para as atividades 


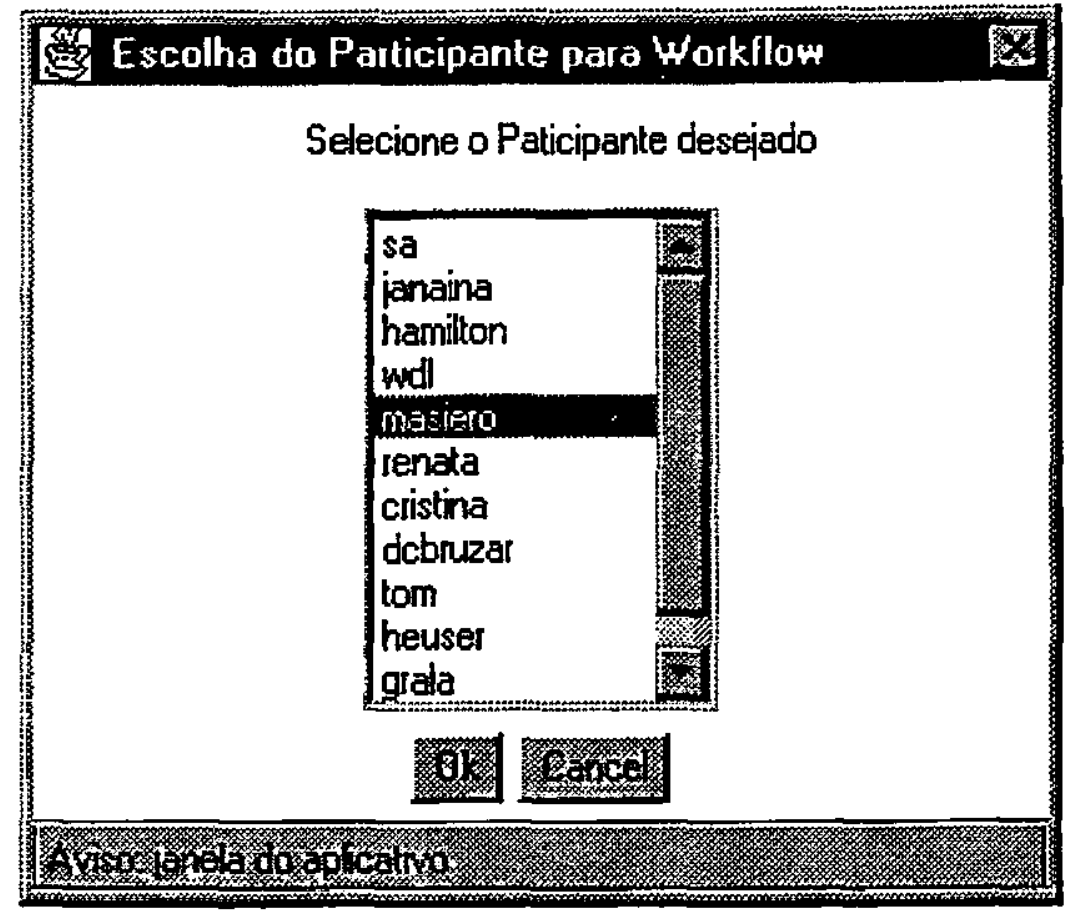

Figura 4.31 Indicação de um participante para um item de trabalho

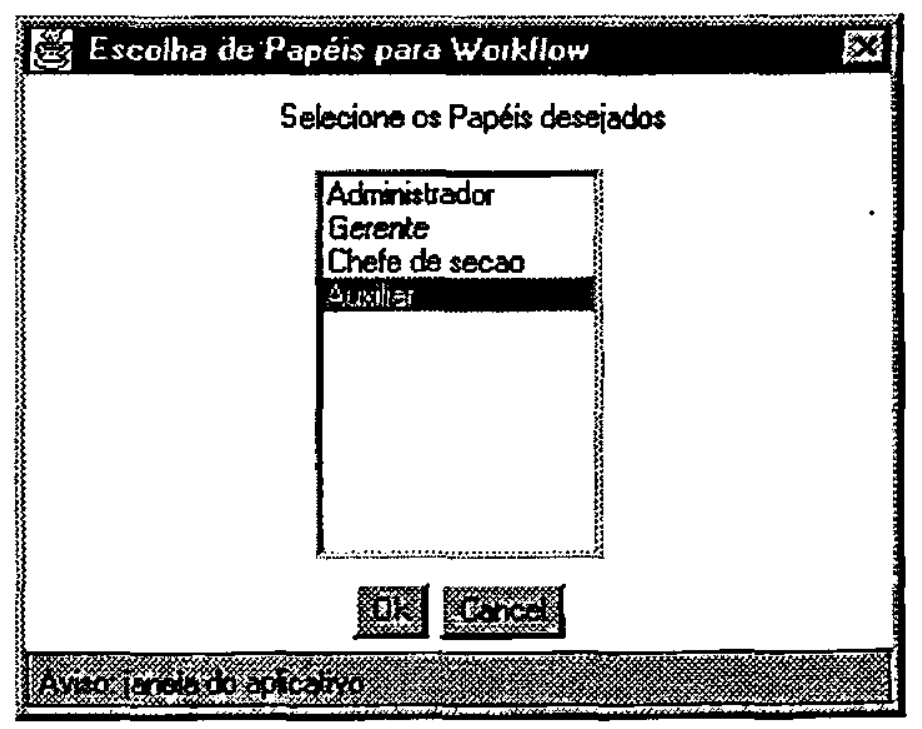

Figura 4.32 - Indicação de um papel para um item de trabalho

A execução a seguir refere-se ao workflow especificado na seção 4.5.1, cujo resultado é a geração de um tipo de documento, que neste caso é um formulário de abertura de conta no sistema computacional do ICMC. Inicialmente, seleciona-se a opção "Execução" do menu de funcionalidades (figura 4.4) e é aberta uma janela com menus de execução (figura 4.7). Escolha a 
opção "Executar" e abre-se uma janela contendo uma lista de workflows consolidados para execução. É marcado o workflow "1Criar_tipo_doc" (veja figura 4.29). Nesse momento desejase redefinir papéis e especificar participante para as atividades do processo. Para isso, pressionase o botão "selecionar", o qual abre uma nova janela (figura 4.30), mostrando todas as atividades do tipo item de trabalho do workflow. Marca-se a atividade para a qual deseja-se especificar um participante-executor, no caso, a atividade 1.5 - "autorizar" e pressiona-se o botão "Escolher participante", o qual abre uma lista de participantes para indicação de um deles. Indica-se o participante "masiero" conforme mostra a figura 4.31 e logo após pressiona-se o botão "Ok", o qual fecha essa janela e retorna o controle para a janela da figura 4.30 para novas seleções.

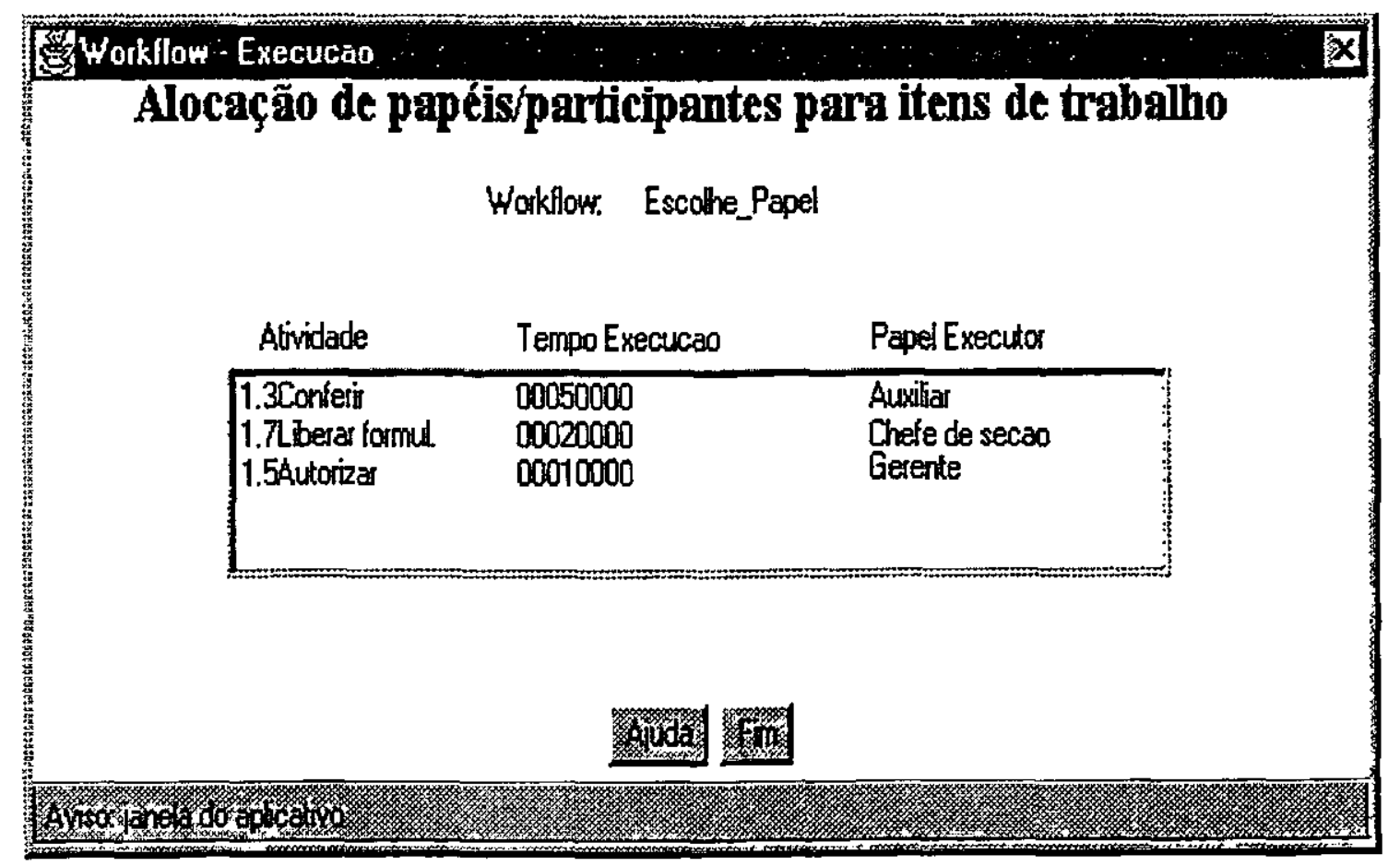

Figura 4.33 Atividades com redefinição de papéis e especificação de participante

Agora se deseja redefinir papéis para as atividades 1.3 - "Conferir" e 1.7 - "Liberar formul.". Para isso, marca-se primeiramente a atividade 1.3 - "Conferir" e então se pressiona o botão "Escolher papel", o qual abre uma lista de papéis mostrados na figura 4.32, onde se indica o papel "Auxiliar". Pressiona-se o botão "Ok" e a janela é fechada, abrindo-se uma nova janela mostrando as atividades com seus novos papéis. Após a verificação, essa última janela aberta é fechada, pressionando-se o botão "Fim". Esse procedimento é repetido para redefinir o papel da 
atividade 1.7 - "Liberar formul.", atribuindo-lhe o papel "Gerente". A janela aberta mostrando as atividades que sofreram alteração de papel/participante é vista na figura 4.33.

Após a alocação de papéis/participantes para as atividades desejadas, pressiona-se o botão "Fim", o qual indica para a máquina de workflow iniciar a interpretação do processo, instanciando a sua primeira atividade (atividade 1.1 - "Iniciar formulário". Essa atividade passa a compor a lista de trabalho, na área "Atividades não alocadas" (veja figura 4.34), dos participantes cujo papel é administrador ou gerente, aguardando sua alocação por um desses participantes. No caso da atividade 1.5 - "Autorizar", quando for instanciada passará a compor a lista de trabalho, na área de atividades alocadas, do participante "masiero".

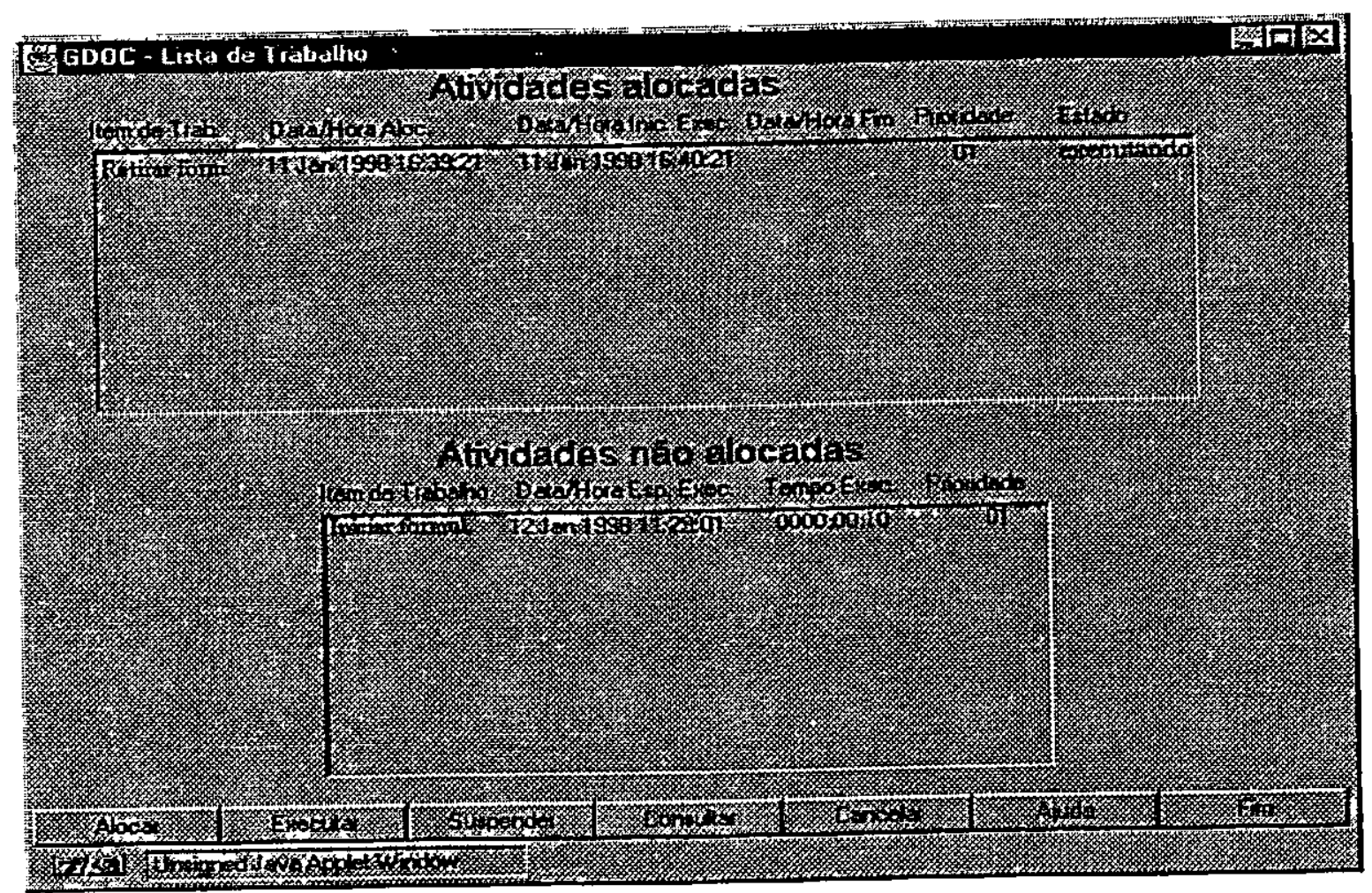

Figura 4.34 Lista de trabalho de um participante "gerente" - fase 1

A lista de trabalho mostrada na figura 4.34, de um participante "gerente", possui uma atividade alocada a ele em execução e uma atividade "Iniciar formul.", do workflow que foi iniciado sua execução, disponibilizada para sua alocação. Se esse participante alocá-la para si, marcando-a e pressionando o botão "alocar", essa atividade passa a incorporar a sua lista de atividades alocadas, desaparecendo da sua área "Atividades não alocadas" e de todos os 
participantes que possuírem o papel de gerente ou administrador, conforme mostrado na figura 4.35.

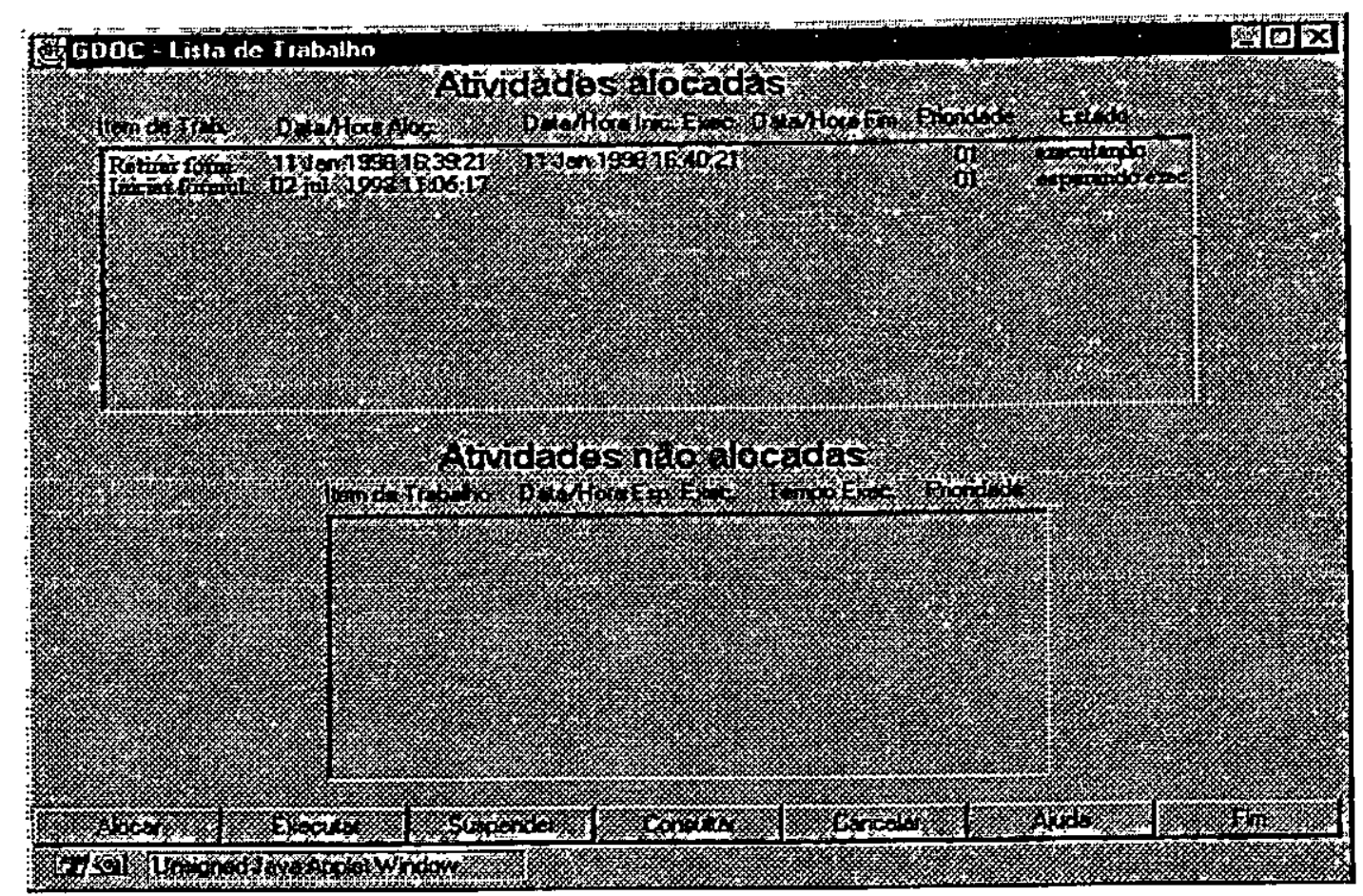

Figura 4.35 Lista de trabalho de um participante "gerente" - fase 2

\subsection{Avaliaçáo}

No capítulo 3, na seção 3.7 foram desenvolvidos manualmente exemplos reais de workflows, simulando as respectivas especificações e seguindo o modelo conceitual proposto na figura 3.1 e cujos dados resultantes são apresentados no apêndice "C". Essa simulação teve como objetivo fazer a validação do sistema.

Após os principais componentes do sistema terem sido implementados, os exemplos da seção 3.7 foram especificados e executados, utilizando-se o sistema e seus resultados foram comparados com os resultados da simulação manual o que permitiu fazer o teste de integração do sistema com uma situação real, já que um dos exemplos se refere a um processo existente no ICMC. Esse teste revelou a eficiência do sistema no atendimento de requisitos e mostrou um bom desempenho em relação a tempo de resposta quando utilizado em ambiente intranet. Em relação ao seu uso em ambiente internet, o desempenho em relação ao tempo de resposta é baixo 
em função da lentidão da rede e pelo menor desempenho da linguagem Java em relação a outras linguagens tais como, as linguagens " $\mathrm{C}$ " ou " $\mathrm{C}++$ ", mas que também depende dos recursos envolvidos, tais como: capacidade da estação, modem, qualidade da linha de comunicação, etc.

Embora sejam poucos os casos de testes aplicados, pôde-se verificar a potencialidade oferecida pelo sistema no atendimento dos requisitos do sistema apresentados no capitulo 3 e, portanto o protótipo cumpre a sua finalidade de ser uma ferramenta de apoio às organizações.

\subsection{Considerações finais}

Neste capítulo, pôde-se ver os beneficios da arquitetura do sistema, pela manipulação de suas funcionalidades por intermédio de um browser da web, o que lhe dá uma independência geográfica e em relação a restrição de horários de trabalho, dentre outros. $\mathrm{O}$ armazenamento dos dados do sistema em um banco da dados que é um meio bastante popular e sem se prender a um sistema gerenciador de banco de dados (pelo uso da API JDBC) e pela portabilidade com o uso da linguagem Java. Pôde-se também visualizar os principais pontos da interface do sistema com o usuário e obter uma descrição detalhada de como e quando as funcionalidades são oferecidas. Finalmente, mostrou-se a simplicidade e a capacidade dos recursos do sistema pela especificação e execução de exemplo de workflows. 


\section{Conclusão}

\subsection{Considerações gerais}

O poder computacional e seus recursos afins têm-se desenvolvido significativamente, mas apesar de todo esse potencial estar disponibilizado para os ambientes organizacionais a produtividade nesses ambientes não tem evoluído no mesmo nível. Isso se deve a vários fatores, tais como: a falta de integração entre produtos, a não orientação de sistemas de informação ao negócio, a gargalos existentes no fluxo de trabalho, do desconhecimento em detalhe dos processos do negócio por parte dos executivos e do volume de documentos envolvido no fluxo de trabalho e a falta de controle do seu ciclo de vida.

A ISO (International Standardization Organization), órgão internacional de padronização, estabelece processos que garantem a qualidade na produção de bens e serviços e cuja certificação é fundamental para a sobrevivência de qualquer organização.

As modernas abordagens de desenvolvimento de sistemas e aplicativos seguem uma visão centrada no processo (negócio) ou trabalho. Esta abordagem integra funções, dados, programas, pessoas e estruturas organizacionais.

Embora a tecnologia de workflow esteja longe de se tomar madura, foi mostrada neste trabalho a sua potencialidade no auxilio às organizações na solução dos problemas citados e na obtenção e manutenção da certificação ISO-9000. Essa tecnologia é centrada no processo e seu esquema resultante, compreensível e completo é uma excelente base para se promover revisão e racionalização dos processos, permitindo uma melhor minimização de custos e otimização da empresa globalmente. 
A WfMC define niveis de conformidade com seus padrões estabelecidos; os quais se diferenciam pela implementação de API's que permitam a manipulação da definição de processo e de atributos definidos no seu meta-modelo de entidades. De acordo com sua classificação, o sistema desenvolvido se enquadra no nível C, o qual se caracteriza pela implementação da maioria das entidades e atributos definidos no seu meta-modelo de entidades e de formato padrão, permitindo facilidade de entendimento e execução por outros produtos de workflow.

Todo o conhecimento adquirido e os resultados obtidos com o desenvolvimento deste protótipo serão repassados ao parceiro industrial (empresa Polo de Software, de Curitiba), os quais serão utilizados na construção de um produto comercial.

\subsection{Contribuições}

Este trabalho apresenta como contribuição o desenvolvimento de um modelo conceitual do módulo de workflow que permite especificar e instanciar workflows genéricos e de controle de ciclos de vida de documentos. Uma definição de arqquitetura distribuída para sistema de gerenciamento de workflow para documentos, que é baseada em uma plataforma intranet/internet e cuja interface de execução do sistema é auxiliada por web browsers. Isto propicia uma visão homogênea e execução uniforme das funcionalidades do sistema, além da independência geográfica e de horários. Uma linguagem de definição de ação, utilizada para especificação de ações executadas automaticamente e na especificação de atividades padrão que possam ser reutilizadas incrementando a produtividade do especificador e aumentando o grau de usabilidade do sistema pela execução de atividades conhecidas. E a implementação do protótipo do sistema de gerenciamento de workflow para gestão de documentos que permite controlar o ciclo de vida de documentos, fornecendo suporte às empresas na obtenção e manutenção do certificado ISO 9000.

\subsection{Trabalhos futuros}

Como trabalhos futuros, sugerimos a utilização do protótipo em vários casos de testes reais, especificando processos e atividades padrões para o ciclo de vida de documentos de uma empresa, avaliando os recursos oferecidos pelo sistema e sugerindo/implementando soluções para 
possíveis problemas encontrados. A implementação de extensões ao protótipo em relação a possibilitar interoperabilidade nos pontos definidos pelo modelo de referência da WfMC, a possibilidade de alteração dinâmica, isto é, permitir que a modelagem do processo seja completada durante a execução, tolerância à falhas, integração com o módulo de documentos via API's e a construção de um simulador de execução de workflow, permitindo testes logo após a especificação. 


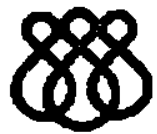

ICMC - USP

\section{BIBLIOGRAFIA}

[Act96] ACTION TECHNOLOGIES, INC. Process Builder: Analyst Edition. Disponivel em http://www.actiontech.com/analyst/demo/index.html.

[Als94] ALSOP, R. Workflow Automation Integration Requires A Large Technology and A Structured Approach. Computer Technology Review, 1994.

[Ave97] AVELLINO, K. Course notes: Introduction to client/server computing. Learning Tree International, 1997.

[Bar97] BARROS, R.M. Alocação de Atividade em um Sistema de Gerência de Workflow. Porto Alegre, 1997. 103p. Dissertação (Mestrado). Instituto de Informática, Universidade Federal do Rio Grande do Sul.

[Bru97a] BRUZAROSCO, D.C.; MASIERO, P.C. GDOC-Relatório Técnico $\mathbf{n}^{\circ} \quad$ : Especificação do Módulo de Workflow. ICMC - USP. 1997.

[Bru97b] BRUZAROSCO, D.C.; MASIERO, P.C. GDOC-Relatório Técnico $\mathrm{n}^{\circ}$ 02: Workflow de Documentos: Proposta de Modelo Conceitual para o GDOC. ICMC - USP. 1997.

[Bru97c] BRUZAROSCO, D.C.; MASIERO, P.C. GDOC-Relatório Técnico $\mathbf{n}^{\circ}$ 03: Linguagem de Roteamento de Atividades. ICMC - USP. 1997.

[Bru97d] BRUZAROSCO, D.C.; MASIERO, P.C. GDOC-Relatório Técnico $\mathrm{n}^{\circ} \quad$ 4: Linguagem de Descrição de Ações. ICMC - USP. 1998.

[Bru97e] BRUZAROSCO, D.C.; MASIEBO, P.C. GDOC-Relatório técnico número 5: Módulo de Workflow: Exemplos de uso. ICMC - USP. 1997. 
[Bru98f] BRUZAROSCO, D.C.; MASIERO, P.C. Um Sistema para Workflow de Documentos para Apoio às Normas da série ISO-9000. In: IX Conferência Internacional de Tecnologia de Software: Qualidade de Software, Curitiba-Pr. Junho, 1998. Anais. 169-180.

[Cas95] CASATI, F. et al. Deriving Active Rules for Workflow Enactment. Dipartimento di Eletronica e Informazione Politecnico di Milano. Milano. P. 1-22, 1995. (casati@elet.polimi.it).

[Co194] COLEMAN, D. et al. Object Oriented Development: The Fusion Method. Prentice hall object oriented series, 1994.

[Con97] CONNECTSOFTWARE. The FastForward JDBC Driver API. Disponivel em http://www.connectsw.com/ffl .

[Dei97] DEITEL, H.M; DEITEL, P.J. Java How to Program with an Introduction to Visual JH. Prentice Hall (http//www.prenhall.com/deitel), 1997.

[Fry94] FRYE, C. Move to Workflow Provokes Business Process Scrutiny. Software Magazine, 1994.

[El193\} ELLIS, C.A; NUTT, G.J. Modeling and Enactment of Workflow Systems. Department of Computer Science. Colorado. P. 1-16, 1993. (nutt@cs.colorado.edu).

[Ge095] GEORGAKOPOULOS, D.; HORNICK, M. An Overview of Workflow Management: From Process Modeling to Workflow Automation Infrastructure. Distributed and Parallel Databases, v. 3, p. 119-153, 1995.

[Gra97] GRALA, A.S.; HEUSER, C.A. GDOC: A System for Storage and Authoring of Documents through WEB Browsers. In: Proceedings of the XVII International Conference of the Chilean Compute Science Society. Valparaiso, Chile. Novembro, 1997. 115-124.

[Gra98] GRALA, Anderson Santos. GDOC: Um sistema para armazenamento e autoria de documentos através de web browsers. Porto alegre, 1998. 94p. Dissertação (Mestrado) - Instituto de Informática, Universidade Federal do Rio Grande do Sul. 
[Har87] HAREL, D. On the formal semantics of statecharts. In: Proceedings of the $2^{\text {ad }}$ IEEE Symposium on Logic in Computer Science. Ithaca, New York, p.4-64. 1987.

[Jab96] JABLONSKI, S.; BUSSLER, C. Workflow Management: Modeling Concepts, Architecture and Implementation. International Thomson Computer Press, 1996.

[Jac97] JACKSON, M.; TWADDLE, G. Business Process Implementation: Building Workflow Systems. Addison-Wesley, 1997.

[Law97] LAWRENCE, P. WfMC: Workflow Hand Book. Wiley, 1997.

[Jo095] JOOSTEN, S.M.M. A method for analysing workflows. In: ECSCW conference, Estocolmo, 1995. P. 1-30. (tutorial).

[Mic93] MICROSOFT, C. Microsoft SQL Server for Windows NT: Transact-SQL Reference, 1993.

[Min94] MINASI, M. Segredos de Projeto de Interface Gráfica com o usuário. Livraria e Editora Infobook S. A, 1994.

[Pol97] POLO DE SOFTWARE. Doc-Control - Guia do usuário. Curitiba. 1997.

[Por96] PORTFOLIO TECHNOLOGIES INC. Office.Iq Business Solutions. Disponível em http://www.officeiq.com/lit/default.htm.

[Pat96] PATEL, P.; MOSS, K. Java Database: Programming with JDBC. Coriolis Group Books, 1996.

[Rei96] REINWALD, B., MOHAN, C. Structured Workflow Management with Lotus Notes Release 4. In: Proc. 41th IEEEE Computer Society Int'1 Conference (CompCon). Santa Clara. $\quad$ Fevereiro 1996. (http://www.almaden.ibm.com/cs/exotica/exotica_wf_notes0296.ps).

[Rus94] RUSINKIEWICZ, M.; SHETH, A. Specification and Execution of Transactional Workflows. University of Houston. Houston. P. 1-20. (marek@cs.uh.edu).

[Sch96] SCHAL, T. Workflow Management Systems for Process Organisations. Springer, 1996.

[Ste96] STHEPHEN R. D. Learn Java Now. Microsoft Press, 1996.

[Wfm95] WORKFLOW MANAGEMENT COALITION. The Workflow Reference Model. Disponivel em http://www.aiai.ed.uk/WFMC/. 
[Wfm96a] WORKFLOW MANAGEMENT COALITION. - Coalition Overview. Disponivel em http://www.aiai.ed.ac.uk/WFMC/.

[Wfm96b] WORKFLOW MANAGEMENT COALITION. Terminology \& Glossary. Disponível em http://www.aiai.ed.uk/WFMC/.

[Wfm96c] WORKFLOW MANAGEMENT COALITION. Interface1: Process Definition Interchange. Disponivel em http://www.aiai.ed.uk/WFMC/. 


\section{Especificação da gramática da Linguagem de Definição de Ação (LIDA)}

O objetivo deste documento é definir a gramática de uma linguagem para especificação de ações e expressões de pré-condições das atividades itens de trabalho, bem como as expressões de transições das atividades de roteamento.

Os comandos da linguagem seguem sempre que possível a estrutura dos comandos SQL apresentados no manual Transact-SQL Reference [Mic93]. Esta linguagem será utilizada pelo editor gráfico EdGraW (Editor Gráfico de Workflow), durante o desenvolvimento de um workflow, na especificação das propriedades das atividades.

Os comandos SQL fornecidos na especificação de workflow são compilados pelo editor incluindo-se o comando SET com a clausula NOEXEC e permitindo-se assim ao especificador eliminar erros de sintaxe. Os comandos não pertencentes ao SQL os quais são: "GET" (veja item 1.5), "EXECUTAR" (veja item 1.4), "WINDOW" (veja item 1.13) e "\#" (veja item 1.14), tem um tratamento específico pelo editor, interpretador e pela máquina de workflow. Em tempo de execução do workflow, os comandos da LIDA, são interpretados e executados pela máquina de workflow.

Na especificação com a LIDA, os comandos que utilizam literal não numérico e/ou usam os caracteres aspas e apóstrofes como delimitadores tiveram tais caracteres substituídos pelo caractere \& (e comercial) para evitar conflitos na execução de comandos JDBC. Esses comandos possuem tratamento especial pelo interpretador/executor da LIDA.

\section{Gramática da LIDA}


A seguir são apresentadas a sintaxe e as regras de uso dos componentes da linguagem.

\subsection{CREATE TABLE}

Cria uma tabela nova. Este comado é de uso restrito da máquina de workflow.

\section{Sintaxe}

CREATE TABLE [[database] table_name

(column_name datatype [NOT NULL | NULL]

[,column_name datatype [NOT NULL | NULL]]...)

\section{Onde}

table_name: é o nome da tabela nova. Deve seguir as regras para identificadores e deve ser único dentro da base de dados.

column_name: especifica uma coluna (atributo) da tabela. Deve estar conforme as regras para identificadores e deve ser único na tabela.

datatype: especifica o tipo de dados da coluna (exs.:int, smallint, tinyint, float, real,money, smallmoney, $\operatorname{char}(\mathrm{n}), \quad \operatorname{varchar}(\mathrm{n}), \quad$ text, $\operatorname{binary}(\mathrm{n})$, varbinary(n), image, datetime, smalldatetime, bit, timestamp, sysname)

NOT NULL: indica que quando não há valor default para esta coluna, uma mensagem de erro é produzida se nenhuma entrada for feita no momento de inserção.

NULL: indica que caso o usuário não faça uma entrada em tempo de inserção e não haja valor default, esta coluna será preenchida com NULL

\section{Exemplo}

\section{CREATE TABLE Titles 1}

(title_id tid, title varchar(80), type char(12), 
pub_id char(4),

price money null,

advance money null,

royalty float null,

ytd_sales money null,

notes varchar(200),

pubdate datetime

\subsection{DECLARE}

Declara o nome e tipo de variáveis locais para um batch ou procedure.

Sintaxe

DECLARE@variable_name datatype [, @variable_name datatype...]

Onde

@variable_name: é o nome de uma variavel

datatype: tipo de dados

\subsection{DROP TABLE}

Remove uma definição e todos os dados, índices, etc. Este comando é de uso restrito da máquina de workflow.

Sintoxe

DROP TABLE [database.] table_name

Onde

table_name: especifica a tabela a ser removida

Exemplo

DROP TABLE Titles1 


\subsection{EXECUTAR}

Executa uma atividade (cria uma instância de execução)

SINTAXE

EXECUTAR identificador

ONDE

identificador: id da atividade que se deseja executar. O nome do identicador segue as regras do SQL.

OBSERVAÇÃO:

Esse comando é interpretado pela máquina de workflow, a qual instancia a atividade do conteúdo do identificador.

EXEMPLO

Update Tabw

SET idativ_aux $=($ SELECT id_atividade FROM Atividade WHERE nome_atividade = \&autorizar\&);

EXECUTAR idativ_aux;

\subsection{GET}

Comando para se obter dado do usuário (participante/ator).

\section{Sintoxe}

GET \&mensagem\&, identificador

Onde

mensagem: informação ao usuário sobre o dado a fornecer

identificador: variável definida usada para armazenar o dado fornecido pelo usuário.

Observação: 
Este comando em tempo de execução é interpretado pela máquina de workflow, a qual passa a mensagem e o identificador do comando como parâmetro para uma APPLET padrão, a qual executa a função do comando.

\section{Exemplo}

GET \&Informar observação\&, observação

\subsection{GOTO}

Faz um desvio incondicional para um label definido pelo usuário

Sintaxe

label:

GOTO label

Onde

label: deve seguir as regras para identificadores.

Exemplo

Inicio:

GOTO Inicio

\subsection{IF...ELSE}

Impõe condições na execução de uma declaração da linguagem. A declaração logo após a palavra chave "IF" somente é executada se a condição for satisfeita, caso contrario é executada a declaração (se houver) logo após a cláusula ELSE (quando a condição não for satisfeita).

Sintaxe

IF

Boolean_expression

sql_statement

[ELSE 
[Boolean_expression]

sql_statement]

Onde

Boolean_expression: é uma expressão (um nome de coluna, uma constante, qualquer combinação de nomes de colunas e constantes, conectadas por operadores aritméticos ou uma subquery) que retorna falos ou verdadeiro. Se a expressão boolenana contêm uma declaração SELECT, esta deve estar entre parênteses.

Exemplo

IF (SELECT seq ${ }^{\text {ativ FROM Tabw) }}=4$

SELECT \& Observação da Ativ-3 = \&, observação FROM

Instancia_de_atividade

WHERE id_instância_atividade $=($ SELECT id_inst_ativ3 FROM Tabw $)$

ELSE

IF (SELECT seq $\_$ativ FROM Tabw1) $=6$

SELECT \& Observação da Ativ-5 = \&, observação FROM

Instancia_de_atividade

WHERE id_instância_atividade $=($ SELECT id_inst_ativ5 FROM

Tabw)

\subsection{Print}

Mostra uma mensagem e/ou o conteúdo de uma variável local ou global, a um usuário.

Sintaxe

PRINT \& qualquer texto ASCI \& | @local_variable | @@global_variable Comentários 
A variavel local ou global deve ser do tipo char ou varchar e deve ser declarada dentro do batch ou procechre em que é usada.

Exemplo

DECLARE@msg char(50)

SELECT @msg = \&workflow finalizado\&

PRINT@msg

\subsection{SELECT}

Recupera linhas da base de dados

\section{Sintaxe}

SELECT [ALL | DISTINCT] select_list

[INTO[[database.]owner.]table_name]

[FROM [[ database.]owner.]\{table_name $\mid$ view_name $\}$ [HOLDLOCK]

[,[[database.]owner.]\{table_name |view_name $\}$ [HOLDLOCK]]...]

[WHERE search_conditions]

[GROUP BY [ALL] aggregate_free_expression

[,aggregate_free_expression]...]

[HAVING search_conditions]

[ORDER BY \{[[[database.]owner.]\{table_name. | view_name. $\}]$

column_name | select_list_number | expression\} [ASC | DESC]

[,\{[I[database.]owner.] table_name $\mid$ view_name. $\}]$

column_name | select_list_number | expression\} [ASC | DESC]]...]

[COMPUTE row_aggregate(column_name)

[,row_aggregate(column_name)...]

[BY column_name [,column_name]...]]

As palavras chaves da declaração SELECT devem ser usadas na ordem mostrada 
Onde

ALL: inclui todas linhas no resultado (default)

DISTINCT: inclui somente as linhas únicas no resultado select_list:

- asterisco $\left({ }^{*}\right)$, representa todas as colunas

- uma lista de nomes de colunas

- uma coluna cabeçalho para substituir o cabeçalho default da coluna

INTO: cria uma nova tabela baseada nas colunas especificadas na selec_list e linhas selecionadas pela cláusula WHERE.

FROM: indica as tabelas e visões usadas na declaração select.

Table_name /view_name: especifica os nomes de tabelas e visões usadas na declaração select

HOLDLOCK: não permite o compartilhamento de uma tabela ou visão especificada, durante a execução de uma transação.

search_conditions: especifica as condições para as linhas que são recuperadas. Pode incluir nomes de colunas; expressões; operadores aritméticos; operadores de comparação; as palavras chaves NOT, LIKE, IS NULL, AND, OR, BETWEEN, IN, EXISTS, ANY, or ALL; subqueries; ou qualquer combinação desses itens.

GROUP BY: usado para totalizar por grupo especificado ou ser usado com aggregate_functions (SUM, AVG, COUNT MAX, MIN) que produz um valor único por grupo.

HAVING: especifica condições para a cláusula GROUP BY (similar a cláusula WHERE).

ORDER BY: classifica os resultados por colunas. 
ASC: indica que os resultados serão classificados em ordem ascendente.

DESC: indica que os resultados serão classificados em ordem descendente.

COMPUTE: usada com linha de funções agregadas (SUM, AVG, MIN, MAX, e COUNT) para gerar totais nas quebras de controles (imprime uma linha de total adicional nas quebras). A cláusula BY estabelece subtotais.

\section{Exemplo}

1 - SELECT * FROM publisher

2 - SELECT pub_id, pub_name, city, state FROM publisher

3 - SELECT pub_id, total = sum (ytd_sales) FROM titles

WHERE advance $<\$ 10000$

AND ytd_sales IS not null

GROUP BY pub_id

HAVING count(*) $>1$

4 - SELECT type, price, advance FROM titles

ORDER BY type DESC

COMPUTE AVG(price), SUM(advance) BY type

COMPUTE SUM(price), SUM(advance)

\section{$1.10 \times p \_s e n d m a i l$}

O procedimento estendido armazenado xp_sendmail envia uma mensagem, e/ou um resultado de uma consulta, e/ou recipientes especificados como attachment.

SINTAXE

master.dbo.xp_sendmail @recipientes, [@message] [, @query] [, @attachments] [, @copy_recipients] [, @blind_copy_recipientes] [, @subject] [, @type] [, @attach_results] [, @no_output] [, @ no_header] [, @width] 
$O N D E$

@recipients: é um parâmetro requerido para especificar nomes de pessoas de destino da mensagem. Se for especificado mais que um nome, eles devem ser separados por ponto e vírgula.

@message: é um parâmetro opcional que especifica a mensagem a ser enviada. 0 xp_sendmail deve ter especificado um @message, @query ou @attachments.

@query: é um parâmetro opcional que especifica uma $S Q L$ Server query válida e o resultado da sua execução será enviado na mensagem. Voce deve especificar@query,@message ou@attachments.

@attachments: é um parâmetro opcional que especifica um arquivo a ser atachado à mensagem. Voce deve especificar @attachments, @query ou @message.

@copy_recipients: é um parâmetro opcional que identifica outros recipientes de destino para a mensagem ser enviada.

@blind_copy_recipients: é um parâmetro opcional que identifica outros recipientes para quem você está enviando um blind copy da mensagem.

@subject: é um parâmetro opcionalque especifica o assunto da mensagem. Se não for especificado um assunto, "SQL Server Message" é usado como o assunto.

@type: é um parâmetro opcional que coloca um tipo de mensagem padrão na mensagem. Mensagem do tipo padrão é da seguinte forma:

$\mathbb{P}<$ mic $>$.VendorName.subclass

Uma mensagem começando com IPM (mensagem interpessoal) será ,mostrada no recipiente "Inbox"; uma mensagem começando com IPC não aparecerá no inbox e deve ser lida por uma aplicação MAPI padrão. $O$ tipo default é o Microsoft Mail's IPM 
@attach_results: é um parâmetro opcional que especifica um conjunto de resultados de uma query a ser enviado com uma mensagem como um arquivo texto atachado. (.TXT) ao invés de ser inserido na mensagem. A associação default para um arquivo .TXT é com o aplicativo Notepad, ma uma associação diferente pode ser feita usando o gerenciador de arquivo. $O$ conteúdo default para este parâmetro é false, que significa que o conjunto de resultado é inserido na mensagem.

@no_output: é um parâmetro opcional que envia a mensagem, mas não retorna qualquer saída ao cliente da sessão SQL Server que enviou a mensagem. O valor default para esse parâmetro é false, o que significa que o cliente da sessão SQL Server recebe um retorno como saída.

@no_header: é um parâmetro opcional que envia o resultado de uma query em uma mensagem, mas não envia a informação de cabeçalho das colunas desse resultado. O valor default para esse parâmetro é false, o que significa que as informações de cabeçalhos das colunas do resultado são enviadas.

@width: ë um parâmetro opcional que coloca o comprimento da linha do texto de saida para uma mensagem utilizando o parâmetro "@query”. Este parâmetro é indêntico ao parâmetro "/W" do ISQL. Para consultas que produzem linhas longas de saída, deve-se usar @width junto com @attach_results para enviar a saida sem quebrar linhas no meio. $\mathbf{O}$ comprimento default é 80 caracteres.

EXEMPLO

1. master.dbo.xp_sendmail \&usuário1\&, \&A base de dados mestre está cheia.\&.

2. master.dbo.xp_sendmail @recipients= \&usuário1; usuário2\&, @message = \&A base de dados mestre está cheia.\&, @copy_recipients = \&usuário3; usuário4\&,@subject \&Posição da base de dados mestre\& 
3. master.dbo.xp_sendmail \&usuário1\&, @query = \&sp_configure\&

4. master.dbo.xp_sendmail @recipients=\&usuário1\&, @query = \&select * from sysobjects\&, @subject = \&SQL Server Report\&, @message = \&O conteúdo de sysobject:\&, @attach_results=\&True\&,@width=250

\subsection{UPDATE}

Atualiza atributo de linha de tabela.

\section{Sintoxe}

UPDATE [[datatbase.]owner.]\{table_name | view_name $\}$

SET [[[database.]owner.] table_name. | view_name. $\}]$

column_name $1=\{$ expressionl $\mid$ NULL $\mid$ (select_statement $)\}$

$[$,column_name $2=\{$ expression $2 \mid$ NULL $\mid$ (select_statement $)\} \ldots]$

[FROM [[database.]owner.] table_name $\mid$ view_name

[,[[database.]owner.] $\{$ table_name $\mid$ view_name $\}] \ldots]$

[WHERE search_conditions]

\section{Onde}

SET: especifica o valor para uma coluna. $O$ valor pode ser uma expressão ou um valor null.

FROM: puxa dados de outras tabelas ou visões para modificar linhas nas tabelas ou visões especificadas na cláusula UPDATE.

WHERE: idem da declaração SELECT.

\section{Exemplo}

UPDATE titles

SET ytd_sales $=$ ytd_sales + qty

FROM titles, sales 
WHERE titles.title_id $=$ sales.title_id

AND sales.date IN (SELECT max(sales.date) FROM sales)

\subsection{WHILE}

Executa repetidamente uma ou um bloco de declarações até que a condição seja verdadeira.

Sintoxe

WHIIE

Boolean_expression

sql_stement

Onde

Boolean_expression: é um nome de coluna, uma constante, quaisquer combinações de nomes de colunas e constantes conectados por operadores aritméticos e lógicos, ou uma subquery, que retorna falso ou verdadeiro.

\section{Exemplo}

WHIIE (SELECT AVG(price) FROM titles) $<\$ 30$

BEGIN

UPDATE titles

SET price $=$ price $* \$ 2$

END

\subsection{WINDOW}

Abre uma janela mostrando o resultado de um comando "PRINT ou SELECT". Somente pode ser utilizado na especificação de uma ação de uma atividade do tipo item de trabalho e um por ação. 
SINTAXE

WINDOW \& PRINT ou SELECT\&

$O N D E$

\&PRINT ou SELECT\& : somente um dos comandos PRINT ou SELECT pode estar entre \&. A sintaxe dos comandos PRINT e SELECT pode ser vista nos itens 2.1 .8 e 2.1 .9 respectivamente.

EXEMPLO

WINDOW \&Print \&Execute o workflow de revisão\&\&

WINDOW \&SELECT observação from Tabw\&

\subsection{4 \#}

Símbolo usado para identificar ações manuais.

sintaxe

$$
\text { \# ação }
$$

Onde

ação: descrição em linguagem natural da ação a ser executada.

Exemplo

\# gerar um layout do documento

\section{$1.15 /{ }^{*} \ldots{ }^{*}$}

Símbolo usado para se fazer comentarios

Sintaxe

/* comentários */

Onde

comentários: descrição em linguagem natural

Exemplo 
/* Bloco de comandos que recebe e armazena a observação da atividade* $/$

\section{$1.16 @$}

Símbolo usado para identificar variáveis locais de procedures.

Sintoxe

$$
\text { @variável }
$$

\section{Onde}

variável: deve seguir as regras para identificadores e ser componente de um comando DECLARE na procedure que a utiliza.

Exemplo

@observação 


\section{Dicionário de Dados}

Este dicionário de dados contém uma descrição dos componentes do modelo de objetos (das figuras $3.1,3.3$ e 3.4) e dos atributos do modelo relacional.

\section{Classes}

\begin{tabular}{|c|c|}
\hline NOME & DESCRIÇÃO \\
\hline Ação & $\begin{array}{l}\text { Manifestação de uma força, uma energia, um agente. Ato ou efeito de atuar. } \\
\text { Comportamento da atividade [Fer86]. }\end{array}$ \\
\hline Área & $\begin{array}{l}\text { Identifica uma unidade organizacional, tal como: gerência administrativa, } \\
\text { gerência industrial, gerência comercial, etc. }\end{array}$ \\
\hline Atividade & $\begin{array}{l}\text { É uma descrição de uma parte de trabalho que forma um passo lógico dentro } \\
\text { de um processo. Pode ser manual ou automática. Uma atividade de } \\
\text { workflow requer recursos humanos ou de máquina na execução de um } \\
\text { processo; quando um recurso humano é requerido, a atividade é alocada } \\
\text { para um participante do workflow [Wfm96]. É sinônimo de tarefa } \\
\text { [Cas95]. }\end{array}$ \\
\hline $\begin{array}{l}\text { Atividade_ } \\
\text { situação }\end{array}$ & $\begin{array}{l}\text { Resultante do relacionamento "pode assumir", que indica as situações } \\
\text { (estados) que uma atividade pode assumir. }\end{array}$ \\
\hline
\end{tabular}




\begin{tabular}{|c|c|}
\hline $\begin{array}{l}\text { Componente_ } \\
\text { gráfico }\end{array}$ & $\begin{array}{l}\text { Tipos de componentes gráficos utilizados para representar visualmente um } \\
\text { worflow pelo editor gráfico. }\end{array}$ \\
\hline Conector & $\begin{array}{l}\text { Coordenadas de um conector na representação gráfica de um processo pelo } \\
\text { editor gráfico. }\end{array}$ \\
\hline Documento & $\begin{array}{l}\text { Texto escrito utilizável para consulta, estudo, prova, etc [Fer86]. Pode } \\
\text { conter texto, figura, imagem, etc. É manipulado pelas atividades de um } \\
\text { workflow: criado, consultado, distribuído, etc. }\end{array}$ \\
\hline $\begin{array}{l}\text { História_ } \\
\text { atividade }\end{array}$ & $\begin{array}{l}\text { Registro histórico da execução de uma instância de atividade, desde o seu } \\
\text { inicio até o seu fim. }\end{array}$ \\
\hline $\begin{array}{l}\text { História_- } \\
\text { processo }\end{array}$ & $\begin{array}{l}\text { Registro histórico da execução de uma instância de processo desde o seu } \\
\text { inicio até o seu fim. }\end{array}$ \\
\hline $\begin{array}{l}\text { Instância_ } \\
\text { ação }\end{array}$ & Execução particular de uma ação. \\
\hline $\begin{array}{l}\text { Instância_ } \\
\text { compon_graf }\end{array}$ & $\begin{array}{l}\text { Coordenadas de um componente gráfico (exceto conector), na representação } \\
\text { gráfica de um processo pelo editor gráfico. }\end{array}$ \\
\hline $\begin{array}{l}\text { Instância_de_ } \\
\text { atividade }\end{array}$ & $\begin{array}{l}\text { Execução particular de uma atividade, que pode ser uma instância de um } \\
\text { item de trabalho (instância_item_trabalho) ou uma instância de roteamento } \\
\text { (instância_roteamento). }\end{array}$ \\
\hline $\begin{array}{l}\text { Instância_de_ } \\
\text { processo }\end{array}$ & Execução particular de um processo. \\
\hline $\begin{array}{l}\text { Instância_item_t } \\
\text { rabalho }\end{array}$ & Veja instância_de_atividade. \\
\hline $\begin{array}{l}\text { Instância_itemtr } \\
\text { abalho_papel }\end{array}$ & $\begin{array}{l}\text { Resultante do relacionamento "para_executar" são papéis para execução de } \\
\text { um item de trabalho especificados em tempo de execução, substituindo a } \\
\text { especificação feita em tempo de definição do processo. Essa especificação é } \\
\text { válida somente para a execução em que foi efetuada. }\end{array}$ \\
\hline
\end{tabular}




\begin{tabular}{|c|c|}
\hline $\begin{array}{l}\text { Instância_- } \\
\text { roteamento }\end{array}$ & Veja instância_de_atividade. \\
\hline $\begin{array}{l}\text { Item_de_ } \\
\text { trabalho }\end{array}$ & $\begin{array}{l}\text { É um tipo de atividade e especifica o trabalho a ser executado (por um } \\
\text { participante do workflow) no contexto de uma atividade em uma } \\
\text { instância de um processo [Wfm96]. }\end{array}$ \\
\hline $\begin{array}{l}\text { Itemtrabalho_ } \\
\text { executor }\end{array}$ & $\begin{array}{l}\text { Resultante do relacionamento "e_executor_de" especifica um participante } \\
\text { executor para um item de trabalho. É realizada no inicio de execução de } \\
\text { um workflow. }\end{array}$ \\
\hline $\begin{array}{l}\text { Itemtrabalho_ } \\
\text { papel }\end{array}$ & $\begin{array}{l}\text { Resultante do relacionamento "é_atribuído_a", que indica os papéis } \\
\text { atribuídos a um item de trabalho para sua execução. São considerados os } \\
\text { papéis default para a execução do processo, podendo ser substituidos para } \\
\text { uma execução de processo específica. }\end{array}$ \\
\hline Papel & $\begin{array}{l}\text { Um grupo de participantes compartilhando um conjunto específico de } \\
\text { atributos, qualificações e/ou habilidades [Wfm96]. }\end{array}$ \\
\hline $\begin{array}{l}\text { Papel_ } \\
\text { participante }\end{array}$ & $\begin{array}{l}\text { Resultante do relacionamento "E_desempenhado_por", que indica os } \\
\text { participantes de um papel. }\end{array}$ \\
\hline $\begin{array}{l}\text { Papel_ } \\
\text { privilégio }\end{array}$ & $\begin{array}{l}\text { Resultante do relacionamento "é_concedido_a", que indica os privilégios } \\
\text { concedidos a papéis. }\end{array}$ \\
\hline Participante & $\begin{array}{l}\text { Um recurso que executa o trabalho representado por uma instância de } \\
\text { atividade de um workflow [Wfm96]. Pode ser um ser humano, uma } \\
\text { máquina, uma unidade organizacional ou um papel. }\end{array}$ \\
\hline Privilégio & $\begin{array}{l}\text { Operações do sistema, as quais poderão ser atribuídas a papéis e/ou } \\
\text { participantes. Tais operações são as caracterizadas pelas funcionalidades } \\
\text { do sistema. Por exemplo, criar processo, disparar processo, consultar } \\
\text { atividades pendentes, etc. }\end{array}$ \\
\hline Processo & $\begin{array}{l}\text { Uma visão formalizada de um processo de negócio, representada como um } \\
\text { conjunto ordenado de atividades (paralelas e/ou seriais), que são conectadas }\end{array}$ \\
\hline
\end{tabular}




\begin{tabular}{|l|l|}
\hline & $\begin{array}{l}\text { de forma a atingirem uma meta comum [Wfm96]. É um conjunto de uma ou } \\
\text { mais atividades, as quais coletivamente realizam as metas das políticas ou } \\
\text { objetivos do negócio [Wfm96]. É sinônimo de procedimento [El193] }\end{array}$ \\
\hline Roteamento & $\begin{array}{l}\text { É um tipo de atividade que contém uma expressão lógica que é avaliada } \\
\text { durante a execução de um workflow para decidir a seqüência de execução } \\
\text { das atividades em um processo [Wfm96]. }\end{array}$ \\
\hline Situação & $\begin{array}{l}\text { É um estado que pode ser assumido por instância de processo, instância } \\
\text { de atividade e tupla de tabela, tais como: ativo, inativo, executando, } \\
\text { suspenso, cancelado, executado. }\end{array}$ \\
\hline Tocumento & $\begin{array}{l}\text { É uma classificação dos documentos em categorias. Identifica a natureza do } \\
\text { documento. }\end{array}$ \\
\hline Tipo_partici & Contêm os participantes que poderão executar uma atividade, tais como: \\
unidade organizacional, papel, recurso, ser humano.
\end{tabular}

\section{Relacionamentos}

\begin{tabular}{|l|l|l|}
\hline \multicolumn{1}{|c|}{ NOME } & \multicolumn{1}{|c|}{ CLASSES } & \multicolumn{1}{c|}{ DESCRIÇÃo } \\
\hline Classifica & Tipo_ & \\
& documento: & $\begin{array}{l}\text { Indica quais documentos seguem um esquema pré- } \\
\text { definido de estrutura lógica e de apresentação (tipo } \\
\text { de documento) na sua geração. }\end{array}$ \\
\hline Contém & Item_de_- & Indica quais ações são de um item de trabalho e \\
vice-versa.
\end{tabular}




\begin{tabular}{|c|c|c|}
\hline & ação & ação e quais instâncias de ação são de uma ação. \\
\hline É_atribuído_a & $\begin{array}{l}\text { Papel: } \\
\text { Atividade }\end{array}$ & $\begin{array}{l}\text { Indica os papéis que poderão executar uma } \\
\text { atividade e que atividades um papel pode executar. }\end{array}$ \\
\hline É_composta_de & $\begin{array}{l}\text { Instância_de } \\
\text { atividade: } \\
\text { Instância_ação }\end{array}$ & $\begin{array}{l}\text { Indica quais instâncias de ação pertencem a uma } \\
\text { instância de atividade e a qual instância de } \\
\text { atividade uma instância de ação pertence. }\end{array}$ \\
\hline É_concedido_a & $\begin{array}{l}\text { Privilégio: } \\
\text { Papel }\end{array}$ & $\begin{array}{l}\text { Indica os privilégios que são concedidos a um papel } \\
\text { e a quais papéis um privilégio é concedido. }\end{array}$ \\
\hline $\begin{array}{l}\text { É_composto_ } \\
\text { por }\end{array}$ & $\begin{array}{l}\text { Processo: } \\
\text { Conector }\end{array}$ & $\begin{array}{l}\text { Indica por quais conectores um processo é composto } \\
\text { e de qual processo um conector faz parte. Indica } \\
\text { também a seqüência de execução das atividades para } \\
\text { a máquina de workflow e de quais atividades um } \\
\text { processo é composto, bem como de que processo } \\
\text { uma atividade faz parte. }\end{array}$ \\
\hline $\begin{array}{l}\text { É_conectado_ } \\
\text { por }\end{array}$ & $\begin{array}{l}\text { Instância_compon } \\
\text { gráfico: } \\
\text { Conector }\end{array}$ & $\begin{array}{l}\text { Indica quais instâncias de componentes gráficos são } \\
\text { conectadas por um conector e por quais conectores } \\
\text { uma instância de componente gráfico é conectada. }\end{array}$ \\
\hline $\begin{array}{l}\text { É_constituída_ } \\
\text { de }\end{array}$ & $\begin{array}{l}\text { História_ } \\
\text { processo: } \\
\text { História_ } \\
\text { atividade }\end{array}$ & $\begin{array}{l}\text { Indica a qual processo já terminado pertence uma } \\
\text { atividade encerrada e quais atividades já terminadas } \\
\text { pertencem a um processo encerrado. }\end{array}$ \\
\hline É_definido_por & $\begin{array}{l}\text { Processo: } \\
\text { Participante }\end{array}$ & $\begin{array}{l}\text { Indica o participante autor da definição de um } \\
\text { processo e de quais processos um participante é } \\
\text { autor. }\end{array}$ \\
\hline $\begin{array}{l}\text { É_desempenha } \\
\text { do_por }\end{array}$ & $\begin{array}{l}\text { Papel: } \\
\text { Participante }\end{array}$ & $\begin{array}{l}\text { Indica quais participantes desempenham um papel e } \\
\text { quais papéis um participante desempenha. }\end{array}$ \\
\hline
\end{tabular}




\begin{tabular}{|c|c|c|}
\hline É_executor_de & $\begin{array}{l}\text { Pariticipante: } \\
\text { Item_de_trabalho }\end{array}$ & $\begin{array}{l}\text { Indica o participante executor para um item de } \\
\text { trabalho, especificado em tempo de execução. }\end{array}$ \\
\hline $\begin{array}{l}\text { É_instanciada_ } \\
\text { em }\end{array}$ & $\begin{array}{l}\text { Atividade: } \\
\text { Instância_de_ } \\
\text { atividade }\end{array}$ & $\begin{array}{l}\text { Indica num dado momento quais as instâncias em } \\
\text { execução de uma atividade e de quais atividades } \\
\text { são as instâncias em execução. }\end{array}$ \\
\hline $\begin{array}{l}\text { É_instanciado_ } \\
\text { em }\end{array}$ & $\begin{array}{l}\text { Processo: } \\
\text { Instância_de_ } \\
\text { processo }\end{array}$ & $\begin{array}{l}\text { Indica num dado momento quais as instâncias em } \\
\text { execução de um processo e de quais processos são as } \\
\text { instâncias em execução. }\end{array}$ \\
\hline $\begin{array}{l}\text { É_manipulado_ } \\
\text { por }\end{array}$ & $\begin{array}{l}\text { Documento: } \\
\text { Processo }\end{array}$ & $\begin{array}{l}\text { Indica quais documentos são manipulados por um } \\
\text { processo e por quais processos um documento é } \\
\text { manipulado. }\end{array}$ \\
\hline $\begin{array}{l}\text { É_referenciado_p } \\
\text { or }\end{array}$ & $\begin{array}{l}\text { Tipo_documento: } \\
\text { Processo }\end{array}$ & $\begin{array}{l}\text { Indica quais tipos de documentos são referenciados } \\
\text { por um processo e por quais processos um tipo de } \\
\text { documento é referenciado. }\end{array}$ \\
\hline $\begin{array}{l}\text { É_registrada_ } \\
\text { por }\end{array}$ & $\begin{array}{l}\text { Instância_de_ } \\
\text { atividade: } \\
\text { História_ } \\
\text { atividade }\end{array}$ & $\begin{array}{l}\text { Indica que as instâncias_de_atividades são } \\
\text { registradas em história_atividade e quais } \\
\text { história_atividade são das instâncias _de } \\
\text { atividade em execução num dado momento. }\end{array}$ \\
\hline É_um & $\begin{array}{l}\text { Processo: } \\
\text { Item_de_ } \\
\text { trabalho }\end{array}$ & $\begin{array}{l}\text { Indica quais atividades são um subprocesso e quais } \\
\text { processos são subprocessos e de quais atividades. } \\
\text { Subprocesso é um processo que é executado ou } \\
\text { chamado de um outro processo (ou subprocesso), } \\
\text { isto é, é parte de um processo geral [Wfm96]. } \\
\text { Permite definir um workflow com multiplos niveis de } \\
\text { abstração. }\end{array}$ \\
\hline Executa & Participante: & $\begin{array}{l}\text { Indica num dado momento quais instâncias de } \\
\text { atividades estão sendo executadas por um }\end{array}$ \\
\hline
\end{tabular}




\begin{tabular}{|c|c|c|}
\hline & $\begin{array}{l}\text { Instância_de_- } \\
\text { atividade }\end{array}$ & $\begin{array}{l}\text { participante e quem são os participantes que estão } \\
\text { executando as instâncias de atividades. }\end{array}$ \\
\hline Para_executar & $\begin{array}{l}\text { Papel: } \\
\text { Item_de_trabalho }\end{array}$ & $\begin{array}{l}\text { Indica os papéis especificados para execução de um } \\
\text { item de trabalho, em tempo de execução. }\end{array}$ \\
\hline Pertence_ao & $\begin{array}{l}\text { Instância_ } \\
\text { compon_gráfico: } \\
\text { Processo }\end{array}$ & $\begin{array}{l}\text { Indica quais os componentes gráficos (exceto } \\
\text { conector) que pertencem a um processo e a qual } \\
\text { processo pertence um componente gráfico (exceto } \\
\text { conector). }\end{array}$ \\
\hline Pode_assumir & $\begin{array}{l}\text { Situação: } \\
\text { Atividade }\end{array}$ & $\begin{array}{l}\text { Indica quais situaçōes (estados) uma atividade pode } \\
\text { assumir. Por exemplo, se uma atividade não pode } \\
\text { ser suspensa ou cancelada, estes estados não devem } \\
\text { constar neste relacionamento. }\end{array}$ \\
\hline possui & $\begin{array}{l}\text { Instância_de_ } \\
\text { processo: } \\
\text { Instância_de_- } \\
\text { atividade }\end{array}$ & $\begin{array}{l}\text { Indica num dado momento quais instâncias de } \\
\text { atividades pertencem a uma instância de processo e } \\
\text { quais instâncias de processos possuem instâncias } \\
\text { de atividades. }\end{array}$ \\
\hline registra & $\begin{array}{l}\text { História } \\
\text { processo: } \\
\text { Instância de } \\
\text { processo }\end{array}$ & $\begin{array}{l}\text { Indica que a história_processo registra as instâncias } \\
\text { de processos e quais história_processo } \\
\text { correspondem às instâncias de processo em } \\
\text { execuçāo num dado momento. }\end{array}$ \\
\hline Tem & $\begin{array}{l}\text { Instância_- } \\
\text { compon_gráfico: } \\
\text { Atividade }\end{array}$ & $\begin{array}{l}\text { Indica se uma instância de componente gráfico possui } \\
\text { uma atividade e qual. Também indica qual a instância } \\
\text { de componente gráfico que uma atividade tem. }\end{array}$ \\
\hline $\begin{array}{l}\text { tem_reponsável } \\
\text { _em }\end{array}$ & $\begin{array}{l}\text { Processo: } \\
\text { Papel }\end{array}$ & $\begin{array}{l}\text { Indica o papel responsável por um processo e por } \\
\text { quais processos um papel é responsável. }\end{array}$ \\
\hline
\end{tabular}




\section{Atributos}

\begin{tabular}{|c|c|c|}
\hline Nome & Classe(s) & Descrição \\
\hline Autor & Processo & $\begin{array}{l}\text { Identificação do participante que especificou o processo } \\
\text { (Participante.id_participante). } \\
\text { Tipo: datetime - Tamanho: } 8 \text { bytes } \\
\text { Valor: (data-hora-minuto-seg-cent-milésimo). }\end{array}$ \\
\hline Coord_horiz & $\begin{array}{l}\text { Instância_ } \\
\text { compon_graf }\end{array}$ & $\begin{array}{l}\text { Coordenada horizontal inicial para os componentes } \\
\text { gráficos de item de trabalho, roteamento, subprocesso e } \\
\text { iteração. Coordenada horizontal inicial da primeira barra } \\
\text { para o componente gráfico terminador. } \\
\text { Tipo: smallint - tamanho: } 2 \text { bytes } \\
\text { Valor: }(1 \mid \ldots 32.767)\end{array}$ \\
\hline $\begin{array}{l}\text { Coord_horiz_ } \\
\text { final }\end{array}$ & Conector & $\begin{array}{l}\text { Coordenada horizontal final. } \\
\text { Tipo: smallint - tamanho: } 2 \text { bytes } \\
\text { Valor: }(1 \mid \ldots 32.767)\end{array}$ \\
\hline $\begin{array}{l}\text { Coord_horiz_ } \\
\text { inicial }\end{array}$ & Conector & $\begin{array}{l}\text { Coordenada horizontal inicial. } \\
\text { Tipo: smallint - tamanho: } 2 \text { bytes } \\
\text { Valor: }(1 \mid \ldots 32.767)\end{array}$ \\
\hline Coord_vertical & $\begin{array}{l}\text { Instância_ } \\
\text { compon_graf }\end{array}$ & $\begin{array}{l}\text { Coordenada vertical inicial para os componentes gráficos } \\
\text { de item de trabalho, roteamento, subprocesso e iteração. } \\
\text { Coordenada vertical inicial da primeira barra para o } \\
\text { componente gráfico terminador. } \\
\text { Tipo: smallint - tamanho: } 2 \text { bytes } \\
\text { Valor: }(1 \mid \ldots 32.767)\end{array}$ \\
\hline Coord_verti & Conector & Coordenada vertical inicial. \\
\hline
\end{tabular}




\begin{tabular}{|c|c|c|}
\hline inicial & & $\begin{array}{l}\text { Tipo: smallint - tamanho: } 2 \text { bytes } \\
\text { Valor: }(1 \mid \ldots 32.767)\end{array}$ \\
\hline $\begin{array}{l}\text { Coord_verti } \\
\text { final }\end{array}$ & Conector & $\begin{array}{l}\text { Coordenada vertical final. } \\
\text { Tipo: smallint - tamanho: } 2 \text { bytes } \\
\text { Valor: }(1 \mid \ldots 32.767)\end{array}$ \\
\hline Cria_tab_work & Processo & $\begin{array}{l}\text { Contém declaração SQL para criar uma tabela de } \\
\text { trabalho com as variáveis declaradas no editor gráfico. } \\
\text { Essa declaração é executada no inicio da execução do } \\
\text { processo. } \\
\text { Tipo: text - Tamanho: mínimo de } 2 \mathrm{k} \\
\text { Valor: declaração SQL }\end{array}$ \\
\hline $\begin{array}{l}\text { data_hora_ } \\
\text { aloc_ati }\end{array}$ & $\begin{array}{l}\text { Instância_de_ } \\
\text { atividade }\end{array}$ & $\begin{array}{l}\text { Data e hora inicial em que a atividade é alocada ao } \\
\text { participante executor. } \\
\text { Tipo: datetime - Tamanho: } 8 \text { bytes } \\
\text { Valor: (Apr } 151988 \text { 10:23AM) }\end{array}$ \\
\hline $\begin{array}{l}\text { Data_hora_ } \\
\text { aloc_ha }\end{array}$ & $\begin{array}{l}\text { História } \\
\text { atividade }\end{array}$ & $\begin{array}{l}\text { Data e hora inicial em que a atividade é alocada ao } \\
\text { participante executor. } \\
\text { Tipo: datetime - Tamanho: } 8 \text { bytes } \\
\text { Valor: (Apr } 15 \text { 1988 10:23AM) }\end{array}$ \\
\hline $\begin{array}{l}\text { Data_hora_ } \\
\text { esp_ex_ati }\end{array}$ & $\begin{array}{l}\text { Instância_de_ } \\
\text { atividade }\end{array}$ & $\begin{array}{l}\text { Data e hora inicial do estado esperando execução da } \\
\text { instância de atividade. } \\
\text { Tipo: datetime - Tamanho: } 8 \text { bytes } \\
\text { Valor: (Apr } 15 \text { 1988 10:23AM) }\end{array}$ \\
\hline $\begin{array}{l}\text { Data_hora_ } \\
\text { esp_ex_ha }\end{array}$ & $\begin{array}{l}\text { História_ } \\
\text { atividade }\end{array}$ & $\begin{array}{l}\text { Data e hora inicial do estado esperando execução da } \\
\text { instância de atividade, na História de atividade. } \\
\text { Tipo: datetime - Tamanho: } 8 \text { bytes }\end{array}$ \\
\hline
\end{tabular}




\begin{tabular}{|c|c|c|}
\hline & & Valor: (Apr 151988 10:23AM) \\
\hline $\begin{array}{l}\text { Data_hora_ } \\
\text { execut_ati }\end{array}$ & $\begin{array}{l}\text { Instância_de_ } \\
\text { atividade }\end{array}$ & $\begin{array}{l}\text { Data e hora inicial do estado executando da instância de } \\
\text { atividade. } \\
\text { Tipo: datetime - Tamanho: } 8 \text { bytes } \\
\text { Valor: (Apr } 15 \text { 1988 10:23AM) }\end{array}$ \\
\hline $\begin{array}{l}\text { Data_hora_ } \\
\text { execut_ha }\end{array}$ & $\begin{array}{l}\text { História_ } \\
\text { atividade }\end{array}$ & $\begin{array}{l}\text { Data e hora inicial do estado executando da instância de } \\
\text { atividade, na História de atividade. } \\
\text { Tipo: datetime - Tamanho: } 8 \text { bytes } \\
\text { Valor: (Apr } 15 \text { 1988 10:23AM) }\end{array}$ \\
\hline $\begin{array}{l}\text { Data_hora_fim_ } \\
\text { ação }\end{array}$ & Instância_ação & $\begin{array}{l}\text { Data e hora final de execução da instância de ação. } \\
\text { Tipo: datetime - Tamanho: } 8 \text { bytes } \\
\text { Valor: (Apr } 15 \text { 1988 10:23AM) }\end{array}$ \\
\hline $\begin{array}{l}\text { Data_hora_fim_ } \\
\text { há }\end{array}$ & $\begin{array}{l}\text { História_ } \\
\text { atividade }\end{array}$ & $\begin{array}{l}\text { Data e hora final de execução da instância de atividade } \\
\text { na história de atividade. } \\
\text { Tipo: datetime - Tamanho: } 8 \text { bytes } \\
\text { Valor: (Apr } 15 \text { 1988 10:23AM) }\end{array}$ \\
\hline $\begin{array}{l}\text { Data_hora_fim_ } \\
\text { hp }\end{array}$ & $\begin{array}{l}\text { História_ } \\
\text { processo }\end{array}$ & $\begin{array}{l}\text { Data e hora final da execução da instância do processo } \\
\text { registrada pela história do processo. } \\
\text { Tipo: datetime - Tamanho: } 8 \text { bytes } \\
\text { Valor: (Apr } 15 \text { 1988 10:23AM) }\end{array}$ \\
\hline $\begin{array}{l}\text { Data_final } \\
\text { validade }\end{array}$ & Processo & $\begin{array}{l}\text { Data final de validade do processo. } \\
\text { Tipo: smalldatetime - Tamanho: } 4 \text { bytes } \\
\text { Valor: (January 1, } 1900 \text { | June 6, 2079) }\end{array}$ \\
\hline $\begin{array}{l}\text { Data_inicial_ } \\
\text { validade }\end{array}$ & Processo & $\begin{array}{l}\text { Data inicial de validade do processo. } \\
\text { Tipo: smalldatetime - Tamanho: } 4 \text { bytes }\end{array}$ \\
\hline
\end{tabular}




\begin{tabular}{|c|c|c|}
\hline & & Valor: (January 1, $1900 \mid$ June 6, 2079) \\
\hline $\begin{array}{l}\text { Data_hora_ } \\
\text { habil_ati }\end{array}$ & $\begin{array}{c}\text { Instância_de_ } \\
\text { atividade }\end{array}$ & $\begin{array}{l}\text { Data e hora inicial de habilitação para execução da } \\
\text { instância da atividade. } \\
\text { Tipo: datetime - Tamanho: } 8 \text { bytes } \\
\text { Valor: (Apr } 151988 \text { 10:23AM) }\end{array}$ \\
\hline $\begin{array}{l}\text { Data_hora_ } \\
\text { habil_ha }\end{array}$ & $\begin{array}{l}\text { História_ } \\
\text { atividade }\end{array}$ & $\begin{array}{l}\text { Data e hora inicial de habilitação para execução da } \\
\text { instância de atividade na história de atividade. } \\
\text { Tipo: datetime - Tamanho: } 8 \text { bytes } \\
\text { Valor: (Apr } 15 \text { 1988 10:23AM) }\end{array}$ \\
\hline $\begin{array}{l}\text { Data_hora_ } \\
\text { inicio }\end{array}$ & $\begin{array}{c}\text { Instância_de } \\
\text { processo }\end{array}$ & $\begin{array}{l}\text { Data e hora em que a instância de processo foi iniciada. } \\
\text { Tipo: datetime - Tamanho: } 8 \text { bytes } \\
\text { Valor: (Apr } 151988 \text { 10:23AM) }\end{array}$ \\
\hline $\begin{array}{l}\text { Data_hora_ } \\
\text { inicio_ação }\end{array}$ & $\begin{array}{l}\text { Instância_de_ } \\
\text { ação }\end{array}$ & $\begin{array}{l}\text { Data e hora em que a instância de ação foi iniciada. } \\
\text { Tipo: datetime - Tamanho: } 8 \text { bytes } \\
\text { Valor: (Apr } 15 \text { 1988 10:23AM) }\end{array}$ \\
\hline $\begin{array}{l}\text { Data_hora_- } \\
\text { inicio_hp }\end{array}$ & $\begin{array}{l}\text { História_ } \\
\text { processo }\end{array}$ & $\begin{array}{l}\text { Data e hora inicial de execução da instância do processo } \\
\text { registrada pela história do processo. } \\
\text { Tipo: datetime - Tamanho: } 8 \text { bytes } \\
\text { Valor: (Apr } 151988 \text { 10:23AM) }\end{array}$ \\
\hline Descrição & Processo & $\begin{array}{l}\text { Descrição resumida do processo. } \\
\text { Tipo: varchar - Tamanho: } 256 \text { caracteres } \\
\text { Valor: texto explicativo sobre o processo }\end{array}$ \\
\hline $\begin{array}{l}\text { Descrição_ } \\
\text { ação }\end{array}$ & Ação & $\begin{array}{l}\text { Operação a ser executada pelo participante ou uma } \\
\text { chamada a um produto de software. } \\
\text { Tipo: text - Tamanho: mínimo de } 2 k\end{array}$ \\
\hline
\end{tabular}




\begin{tabular}{|c|c|c|}
\hline & & $\begin{array}{l}\text { Valor: (texto indicando a operação a ser efetuada } \\
\text { linguagem de definição de ação (ver relatório técnico } n^{\circ} 4 \\
\text { [Bru97d)). }\end{array}$ \\
\hline $\begin{array}{l}\text { Descrição_ } \\
\text { área }\end{array}$ & Área & $\begin{array}{l}\text { Descrição da área. } \\
\text { Tipo: varchar - Tamanho: } 50 \text { caracteres } \\
\text { Valor: (ex: Gerência Administrativa-financeira | } \\
\text { Gerência Comercial | Departamento contábil | } \\
\text { Departamento financeiro | Departamento de } \\
\text { informática | Setor fiscal | Setor patrimonial | } \\
\text { etc.). }\end{array}$ \\
\hline $\begin{array}{l}\text { Descrição_ } \\
\text { atividade }\end{array}$ & Atividade & $\begin{array}{l}\text { Descrição resumida da atividade. } \\
\text { Tipo: varchar - Tamanho: } 256 \text { caracteres } \\
\text { Valor: texto explicativo sobre a atividade. }\end{array}$ \\
\hline $\begin{array}{l}\text { Descrição_ } \\
\text { componente }\end{array}$ & $\begin{array}{l}\text { Componente } \\
\text { gráfico }\end{array}$ & $\begin{array}{l}\text { Descrição do componente gráfico. Para mais detalhes } \\
\text { consulte o Relatório Técnico } \mathrm{n}^{\circ} 3 \text { [Bru97c]. } \\
\text { Tipo: varchar - Tamanho: } 256 \text { caracteres } \\
\text { Valor: (ex.: terminador: componente gráfico que indica o } \\
\text { ponto inicial ou final de um workflow). }\end{array}$ \\
\hline Descrição_pa & Papel & $\begin{array}{l}\text { Descrição resumida do papel. } \\
\text { Tipo: varchar - Tamanho: } 256 \text { caracteres } \\
\text { Valor: texto explicativo sobre o papel organizacional. }\end{array}$ \\
\hline Descrição_priv & Privilégio & $\begin{array}{l}\text { Descrição do privilégio. } \\
\text { Tipo: varchar - Tamanho: } 256 \text { caracteres } \\
\text { Valor: texto explicativo sobre o privilégio. }\end{array}$ \\
\hline $\begin{array}{l}\text { Descrição_ } \\
\text { situação }\end{array}$ & Situação & $\begin{array}{l}\text { Descrição da situação (estado de: instância de } \\
\text { processo, instância de atividade ou tupla de tabela) }\end{array}$ \\
\hline
\end{tabular}


Tipo: varchar - Tamanho: 256 caracteres

Valor:

- Ativo(a): significa que o processo/atividade ou linha da tabela está disponível para uso.

- Inativo(a): significa que o processo/atividade ou linha da tabela não está disponível para uso.

- Habilitado(a) a exec.: significa que foi criada uma instância de uma atividade, de um workflow, para execução.

- Esperando exec. : significa que a instância de atividade para iniciar execução, teve a expressão de pré-condição avaliada e satisfeita, estando aguardando ação do participante executor, alocada para a mesma.

- Suspenso(a): significa que a instância do processo/atividade/ação está com a execução momentaneamente interrompida.

- Executando: significa que a instância do processo/atividade/ação está sendo executada

- Cancelado(a): significa que a instância do processo/atividade/ação foi interrompida definitivamente.

- Executado(a): significa que a instância do processo/atividade/ação foi executado normalmente.

- Em construção: significa que o workflow está sendo especificado e não está disponível para execução. 


\begin{tabular}{|c|c|c|}
\hline Descrição_tpa & $\begin{array}{l}\text { Tipo_partici } \\
\text { pante }\end{array}$ & $\begin{array}{l}\text { Descrição do tipo de participante. } \\
\text { Tipo: varchar - Tamanho: } 30 \text { caracteres } \\
\text { Valor: (unidade organizacional | papel | recurso | ser } \\
\quad \text { humano). }\end{array}$ \\
\hline Expressão & Roteamento & $\begin{array}{l}\text { Expressão que deverá ser satisfeita para que a atividade } \\
\text { de roteamento efetue a transição. } \\
\text { Tipo: text - Tamanho: mínimo de } 2 k \\
\text { Valor: }((A>B \text { and } C=3) \text { or }(X \diamond 1)) \text {. }\end{array}$ \\
\hline Id_ação & $\begin{array}{l}\text { Ação } \\
\text { Instância_ação }\end{array}$ & $\begin{array}{l}\text { Identificação da ação (do item de trabalho). } \\
\text { Tipo: datetime - Tamanho: } 8 \text { bytes } \\
\text { Valor: (data-hora-minuto-seg-cent-milésimo) }\end{array}$ \\
\hline Id_área & $\begin{array}{l}\text { Área } \\
\text { Paricipante }\end{array}$ & $\begin{array}{l}\text { Identificação da área organizacional. } \\
\text { Tipo: datetime - Tamanho: } 8 \text { bytes } \\
\text { Valor: (data-hora-minuto-seg-cent-milésimo) }\end{array}$ \\
\hline Id_atividade & $\begin{array}{l}\text { Atividade } \\
\text { Atividade_ } \\
\text { situação } \\
\text { História_ } \\
\text { atividade } \\
\text { Instância_de_ } \\
\text { atividade } \\
\text { Instância_. } \\
\text { compon_graf }\end{array}$ & $\begin{array}{l}\text { Identificação de atividade. } \\
\text { Tipo: datetime - Tamanho: } 8 \text { bytes } \\
\text { Valor: (data-hora-minuto-seg-cent-milésimo) }\end{array}$ \\
\hline $\begin{array}{l}\text { Id_atividade_ } \\
\text { final }\end{array}$ & Conector & $\begin{array}{l}\text { Identificação da atividade final do conector } \\
\text { (Atividade.id_atividade). }\end{array}$ \\
\hline
\end{tabular}




\begin{tabular}{|c|c|c|}
\hline & & $\begin{array}{l}\text { Tipo: datetime - Tamanho: } 8 \text { bytes } \\
\text { Valor: (data-hora-minuto-seg-cent-milésimo) }\end{array}$ \\
\hline $\begin{array}{l}\text { Id_atividade } \\
\text { inicial }\end{array}$ & Conector & $\begin{array}{l}\text { Identificação da atividade inicial do } \\
\text { (Atividade.id_atividade). } \\
\text { Tipo: datetime - Tamanho: } 8 \text { bytes } \\
\text { Valor: (data-hora-minuto-seg-cent-milésimo) }\end{array}$ \\
\hline $\begin{array}{l}\text { Id_atividade_ } \\
\text { roteamento }\end{array}$ & Roteamento & $\begin{array}{l}\text { Identificação da atividade de roteamento. } \\
\text { Tipo: datetime - Tamanho: } 8 \text { bytes } \\
\text { Valor: (data-hora-minuto-seg-cent-milésimo) }\end{array}$ \\
\hline $\begin{array}{l}\text { Id } \\
\text { componente }\end{array}$ & $\begin{array}{l}\text { Componente_ } \\
\text { gráfico } \\
\text { Instância_- } \\
\text { compon_graf }\end{array}$ & $\begin{array}{l}\text { Identificação do componente gráfico. } \\
\text { Tipo: datetime - Tamanho: } 8 \text { bytes } \\
\text { Valor: (data-hora-minuto-seg-cent-milésimo). }\end{array}$ \\
\hline $\begin{array}{l}\text { Id_- } \\
\text { componente_ } \\
\text { final }\end{array}$ & Conector & $\begin{array}{l}\text { Identificação do componente final do conector } \\
\text { (Componente_gráfico.id_componente). } \\
\text { Tipo: datetime - Tamanho: } 8 \text { bytes } \\
\text { Valor: (data-hora-minuto-seg-cent-milésimo). }\end{array}$ \\
\hline $\begin{array}{l}\text { Id_ } \\
\text { componente_ } \\
\text { inicial }\end{array}$ & Conector & $\begin{array}{l}\text { Identificação do componente inicial do conector } \\
\text { (Componente_gráfico.id_componente). } \\
\text { Tipo: datetime - Tamanho: } 8 \text { bytes } \\
\text { Valor: (data-hora-minuto-seg-cent-milésimo). }\end{array}$ \\
\hline $\begin{array}{l}\text { Id_compon_ } \\
\text { graf_atividade }\end{array}$ & $\begin{array}{l}\text { Instância_ } \\
\text { compon_graf }\end{array}$ & $\begin{array}{l}\text { Identificação da instância do componente grafico } \\
\text { utilizado em um processo. } \\
\text { Tipo: datetime - Tamanho: } 8 \text { bytes } \\
\text { Valor: (data-hora-minuto-seg-cent-milésimo). }\end{array}$ \\
\hline
\end{tabular}




\begin{tabular}{|c|c|c|}
\hline Id_conector & Conector & $\begin{array}{l}\text { Identificação do conector. } \\
\text { Tipo: datetime - Tamanho: } 8 \text { bytes } \\
\text { Valor: (data-hora-minuto-seg-cent-milésimo). }\end{array}$ \\
\hline Id_documento & Processo & $\begin{array}{l}\text { Identificação do documento que o processo manipula. } \\
\text { Tipo: datetime - Tamanho: } 8 \text { bytes } \\
\text { Valor: (data-hora-minuto-seg-cent-milésimo). }\end{array}$ \\
\hline $\begin{array}{l}\text { Id_instância_ } \\
\text { ação }\end{array}$ & $\begin{array}{l}\text { Instância_ } \\
\text { ação }\end{array}$ & $\begin{array}{l}\text { Identificação da instância da ação. } \\
\text { Tipo: datetime - Tamanho: } 8 \text { bytes } \\
\text { Valor: (data-hora-minuto-seg-cent-milésimo). }\end{array}$ \\
\hline $\begin{array}{l}\text { Id_instância_ } \\
\text { atividade }\end{array}$ & $\begin{array}{l}\text { História_ } \\
\text { atividade } \\
\text { Instância_ação } \\
\text { Instância_de_ } \\
\text { atividade }\end{array}$ & $\begin{array}{l}\text { Identificação da instância da atividade. } \\
\text { Tipo: datetime - Tamanho: } 8 \text { bytes } \\
\text { Valor: (data-hora-minuto-seg-cent-milésimo). }\end{array}$ \\
\hline $\begin{array}{l}\text { Id_inst__ } \\
\text { compon_graf }\end{array}$ & $\begin{array}{l}\text { Instância_ } \\
\text { compon_graf } \\
\text { Instância_de_ } \\
\text { atividade }\end{array}$ & $\begin{array}{l}\text { Identificação da instância do componente gráfico. } \\
\text { Tipo: datetime - Tamanho: } 8 \text { bytes } \\
\text { Valor: (data-hora-minuto-seg-cent-milésimo). }\end{array}$ \\
\hline $\begin{array}{l}\text { Id_inst_compon } \\
\text { graf_final }\end{array}$ & Conector & $\begin{array}{l}\text { Identificação da instância de um componente gráfico final } \\
\text { de um conector. } \\
\text { Tipo: datetime - Tamanho: } 8 \text { bytes } \\
\text { Valor: (data-hora-minuto-seg-cent-milésimo). }\end{array}$ \\
\hline $\begin{array}{l}\text { Id_inst_compon } \\
\text { graf_inicial }\end{array}$ & Conector & $\begin{array}{l}\text { Identificação da instância de um componente gráfico } \\
\text { inicial de um conector. } \\
\text { Tipo: datetime - Tamanho: } 8 \text { bytes }\end{array}$ \\
\hline
\end{tabular}




\begin{tabular}{|c|c|c|}
\hline & & Valor: (data-hora-minuto-seg-cent-milésimo). \\
\hline $\begin{array}{l}\text { Id_instância_ } \\
\text { processo }\end{array}$ & $\begin{array}{l}\text { História_ } \\
\text { atividade } \\
\text { História_ } \\
\text { processo } \\
\text { Instância_de_ } \\
\text { atividade } \\
\text { Instância_de_ } \\
\text { processo } \\
\text { Instância_item } \\
\text { trabalho_papel } \\
\text { Itemtrabalho__ } \\
\text { executor }\end{array}$ & $\begin{array}{l}\text { Identificação da instância do processo. } \\
\text { Tipo: datetime - Tamanho: } 8 \text { bytes } \\
\text { Valor: (data-hora-minuto-seg-cent-milésimo). }\end{array}$ \\
\hline $\begin{array}{l}\text { Id_item_ } \\
\text { trabalho }\end{array}$ & $\begin{array}{l}\text { Ação } \\
\text { Instância_item } \\
\text { trabalho_papel } \\
\text { Item_de_ } \\
\text { trabalho } \\
\text { Itemtrabalho_ } \\
\text { executor } \\
\text { Itemtrabalho_ } \\
\text { papel }\end{array}$ & $\begin{array}{l}\text { Identificação da atividade de tipo item de trabalho. } \\
\text { Tipo: datetime - Tamanho: } 8 \text { bytes } \\
\text { Valor: (data-hora-minuto-seg-cent-milésimo). }\end{array}$ \\
\hline Id_papel & $\begin{array}{l}\text { Instância_item } \\
\text { trabalho_papel }\end{array}$ & $\begin{array}{l}\text { Identificação do papel. } \\
\text { Tipo: datetime - Tamanho: } 8 \text { bytes }\end{array}$ \\
\hline
\end{tabular}




\begin{tabular}{|c|c|c|}
\hline & $\begin{array}{l}\text { Itemtrabalho_ } \\
\text { papel } \\
\text { Papel } \\
\text { Papel__ } \\
\text { participante } \\
\text { Papel_ } \\
\text { privilégio }\end{array}$ & Valor: (data-hora-minuto-seg-cent-milésimo). \\
\hline $\begin{array}{l}\text { Id_papel_ } \\
\text { responsável }\end{array}$ & Processo & $\begin{array}{l}\text { Identificação do papel responsável pela execução do } \\
\text { processo (Participante.id_participante). } \\
\text { Tipo: datetime - Tamanho: } 8 \text { bytes } \\
\text { Valor: (data-hora-minuto-seg-cent-milésimo). }\end{array}$ \\
\hline Id_participante & $\begin{array}{l}\text { Itemtrabalho_ } \\
\text { executor } \\
\text { Papel_ } \\
\text { participante } \\
\text { Participante_ } \\
\text { privilégio } \\
\text { Participante }\end{array}$ & $\begin{array}{l}\text { Identificação do participante. } \\
\text { Tipo: datetime - Tamanho: } 8 \text { bytes } \\
\text { Valor: (data-hora-minuto-seg-cent-milésimo). }\end{array}$ \\
\hline Id_partic_canc & $\begin{array}{l}\text { Instância_de_ } \\
\text { ação } \\
\text { Instância_de_ } \\
\text { atividade }\end{array}$ & $\begin{array}{l}\text { Identificação do participante } \\
\text { (Participante.id_participante) que cancelou a instância } \\
\text { de atividade/ação. } \\
\text { Tipo: datetime - Tamanho: } 8 \text { bytes } \\
\text { Valor: (data-hora-minuto-seg-cent-milésimo). }\end{array}$ \\
\hline $\begin{array}{l}\text { Id_partic_canc_ } \\
\text { hp }\end{array}$ & $\begin{array}{l}\text { História_ } \\
\text { processo }\end{array}$ & $\begin{array}{l}\text { Identificação do } \\
\text { (Participante.id_participante) que cancelou a instância } \\
\text { de processo, na história da atividade. }\end{array}$ \\
\hline
\end{tabular}




\begin{tabular}{|c|c|c|}
\hline & & $\begin{array}{l}\text { Tipo: datetime - Tamanho: } 8 \text { bytes } \\
\text { Valor: (data-hora-minuto-seg-cent-milésimo) }\end{array}$ \\
\hline $\begin{array}{l}\text { Id_partic_canc_ } \\
\text { ip }\end{array}$ & $\begin{array}{l}\text { Instância_de_ } \\
\text { processo }\end{array}$ & $\begin{array}{l}\text { Identificação do participante } \\
\text { (Participante.id_participante) que cancelou a instância } \\
\text { de processo. } \\
\text { Tipo: datetime - Tamanho: } 8 \text { bytes } \\
\text { Valor: (data-hora-minuto-seg-cent-milésimo) }\end{array}$ \\
\hline $\begin{array}{l}\text { Id_partic_ } \\
\text { situação_ha }\end{array}$ & $\begin{array}{l}\text { História_ } \\
\text { atividade }\end{array}$ & $\begin{array}{l}\text { Identificação do participante } \\
\text { (Paticipante.id_participante) que provocou o término da } \\
\text { instância de atividade. } \\
\text { Tipo: datetime - Tamanho: } 8 \text { bytes } \\
\text { Valor: (data-hora-minuto-seg-cent-milésimo). }\end{array}$ \\
\hline Id_partic_susp & $\begin{array}{l}\text { Instância_de_ } \\
\text { ação } \\
\text { Instância_de_ } \\
\text { atividade }\end{array}$ & $\begin{array}{l}\text { Identificação_ do participante } \\
\text { (Participante.id_participante) que suspendeu a instância } \\
\text { de atividade/ação. } \\
\text { Tipo: datetime - Tamanho: } 8 \text { bytes } \\
\text { Valor: (data-hora-minuto-seg-cent-milésimo). }\end{array}$ \\
\hline $\begin{array}{l}\text { Id_partic_susp_ } \\
\mathrm{hp}\end{array}$ & $\begin{array}{l}\text { História_ } \\
\text { processo }\end{array}$ & $\begin{array}{l}\text { Identificação do participante } \\
\text { (Participante.id_participante) que suspendeu a instância } \\
\text { de processo, na História de processo. } \\
\text { Tipo: datetime - Tamanho: } 8 \text { bytes } \\
\text { Valor: (data-hora-minuto-seg-cent-milésimo). }\end{array}$ \\
\hline $\begin{array}{l}\text { Id_partic_susp_ } \\
\text { ip }\end{array}$ & $\begin{array}{l}\text { Instância_de_ } \\
\text { processo }\end{array}$ & $\begin{array}{l}\text { Identificação do participante } \\
\text { (Participante.id_participante) que suspendeu a instância } \\
\text { de processo. } \\
\text { Tipo: datetime - Tamanho: } 8 \text { bytes } \\
\text { Valor: (data-hora-minuto-seg-cent-milésimo). }\end{array}$ \\
\hline
\end{tabular}




\begin{tabular}{|c|c|c|}
\hline Id_privilégio & $\begin{array}{l}\text { Papel_ } \\
\text { privilégio } \\
\text { Participante_ } \\
\text { privilégio } \\
\text { Privilégio }\end{array}$ & $\begin{array}{l}\text { Identificação do privilégio. } \\
\text { Tipo: datetime - Tamanho: } 8 \text { bytes } \\
\text { Valor: (data-hora-minuto-seg-cent-milésimo). }\end{array}$ \\
\hline Id_processo & $\begin{array}{l}\text { Conector } \\
\text { História_ } \\
\text { processo } \\
\text { Instância_ } \\
\text { compon_graf } \\
\text { Instância_de_ } \\
\text { processo } \\
\text { Processo }\end{array}$ & $\begin{array}{l}\text { Identificação do processo. Contém a data de criação do } \\
\text { processo. } \\
\text { Tipo: datetime - Tamanho: } 8 \text { bytes } \\
\text { Valor: (data-hora-minuto-seg-cent-milésimo). }\end{array}$ \\
\hline Id_situação & $\begin{array}{l}\text { Ação } \\
\text { Área } \\
\text { Atividade_ } \\
\text { situação } \\
\text { Componente_ } \\
\text { gráfico } \\
\text { História_ } \\
\text { atividade } \\
\text { História_. } \\
\text { processo } \\
\text { Instância_ação } \\
\text { Instância_de_ }\end{array}$ & $\begin{array}{l}\text { Identificação da situação (indica o estado conforme } \\
\text { tabela de situações). } \\
\text { Tipo: datetime - Tamanho: } 8 \text { bytes } \\
\text { Valor: (data-hora-minuto-seg-cent-milésimo). }\end{array}$ \\
\hline
\end{tabular}




\begin{tabular}{|c|c|c|}
\hline & $\begin{array}{l}\text { atividade } \\
\text { Instância_de__ } \\
\text { processo Papel } \\
\text { Participante } \\
\text { Processo } \\
\text { Situação } \\
\text { Tipo_ } \\
\text { participante }\end{array}$ & \\
\hline $\begin{array}{l}\text { Id_situação_ } \\
\text { sit }\end{array}$ & Situação & $\begin{array}{l}\text { Identificação da situação (indica o estado conforme } \\
\text { tabela de situações) da tabela de situação. } \\
\text { Tipo: datetime - Tamanho: } 8 \text { bytes } \\
\text { Valor: (data-hora-minuto-seg-cent-milésimo). }\end{array}$ \\
\hline $\begin{array}{l}\text { Id_tipo } \\
\text { documento }\end{array}$ & Processo & $\begin{array}{l}\text { Identificacão do tipo de documento a que o processo se } \\
\text { refere. } \\
\text { Tipo: datetime - Tamanho: } 8 \text { bytes } \\
\text { Valor: (data-hora-minuto-seg-cent-milésimo). }\end{array}$ \\
\hline $\begin{array}{l}\text { Id_tipo } \\
\text { participante }\end{array}$ & $\begin{array}{l}\text { Tipo_ } \\
\text { participante }\end{array}$ & $\begin{array}{l}\text { Identificação do tipo de participante. } \\
\text { Tipo: datetime - Tamanho: } 8 \text { bytes } \\
\text { Valor: (data-hora-minuto-seg-cent-milésimo). }\end{array}$ \\
\hline Nome & Participante & $\begin{array}{l}\text { Nome do participante. } \\
\text { Tipo: varchar - Tamanho: } 40 \text { caracteres } \\
\text { Valor: cadeia de caracteres que identificam um } \\
\text { participante. }\end{array}$ \\
\hline $\begin{array}{l}\text { Nome_ } \\
\text { atividade }\end{array}$ & Atividade & $\begin{array}{l}\text { Nome da atividade. } \\
\text { Tipo: varchar - Tamanho: } 20 \text { caracteres } \\
\text { Valor: cadeia de caracteres que identificam uma }\end{array}$ \\
\hline
\end{tabular}




\begin{tabular}{|c|c|c|}
\hline & & atividade (T1). \\
\hline $\begin{array}{l}\text { Nome_ } \\
\text { componente }\end{array}$ & $\begin{array}{l}\text { Componente_ } \\
\text { gráfico }\end{array}$ & $\begin{array}{l}\text { Nome do componente gráfico. } \\
\text { Tipo: varchar - Tamanho: } 25 \text { caracteres } \\
\text { Valor: (ex.: terminador | item de trabalho | roteamento } \\
\qquad \mid \text { subprocesso | iteração | conector) }\end{array}$ \\
\hline Nome_pa & Papel & $\begin{array}{l}\text { Nome do papel (nome da função organizacional, por ex., } \\
\text { gerente). } \\
\text { Tipo: varchar - Tamanho: } 30 \text { caracteres } \\
\text { Valor: cadeia de caracteres que identificam um papel } \\
\text { (gerente administrativo | chefe do setor fiscal } \mid \\
\quad \text { faturista } \mid \text { etc...). }\end{array}$ \\
\hline Nome_priv & Privilégio & $\begin{array}{l}\text { Nome do privilégio (operações do sistema, tais como: } \\
\text { definir processo, criar instância de processo ou executar } \\
\text { um processo definido). } \\
\text { Tipo: varchar - Tamanho: } 20 \text { caracteres } \\
\text { Valor: cadeia de caracteres que identificam um privilégio } \\
\text { (cria_proc | exec_proc_P1 | cons_proc | etc...). }\end{array}$ \\
\hline Nome_proc & Processo & $\begin{array}{l}\text { Nome do processo (uma identificação textual para os } \\
\text { processos definidos). } \\
\text { Tipo: varchar - Tamanho: } 20 \text { caracteres } \\
\text { Valor: cadeia de caracteres que identificam um processo } \\
\text { (cria_proc (permite criar processos) } \\
\text { exec_proc_P1 (permite executar um processo } \\
\text { definido) | etc...). }\end{array}$ \\
\hline Nome_situação & Situação & $\begin{array}{l}\text { Nome da situação (estado de: instância de processo, } \\
\text { instância de atividade ou tupla de tabela). } \\
\text { Tipo: varchar - Tamanho: } 20 \text { caracteres }\end{array}$ \\
\hline
\end{tabular}




\begin{tabular}{|c|c|c|}
\hline & & $\begin{array}{l}\text { Valor: (Ativo - Inativo - Habilitado - Esperando exec. - } \\
\text { Suspenso - Executando - Cancelado - Executado). }\end{array}$ \\
\hline $\begin{array}{l}\text { Número_ } \\
\text { instâncias }\end{array}$ & $\begin{array}{l}\text { Item_de_ } \\
\text { trabalho }\end{array}$ & $\begin{array}{l}\text { Indica se o item de trabalho pode ser instanciado mais } \\
\text { de uma vez. } \\
\text { Tipo: tinyint - Tamanho: } 1 \text { byte } \\
\text { Valor: (1(uma vez) } \mid 9 \text { (mais de uma vez)). }\end{array}$ \\
\hline Observação & $\begin{array}{l}\text { História_ } \\
\text { atividade } \\
\text { Instância_de_ } \\
\text { atividade }\end{array}$ & $\begin{array}{l}\text { Registro de ocorrência. } \\
\text { Tipo: varchar - Tamanho: } 256 \text { caracteres } \\
\text { Valor: (descrição em linguagem natural). }\end{array}$ \\
\hline $\begin{array}{l}\text { Participante } \\
\text { executor }\end{array}$ & $\begin{array}{l}\text { História_ } \\
\text { atividade } \\
\text { Instância_de } \\
\text { atividade }\end{array}$ & $\begin{array}{l}\text { Identificação do participante } \\
\text { (Participante.id_participante) executor da instância da } \\
\text { atividade. } \\
\text { Tipo: datetime - Tamanho:'8 bytes } \\
\text { Valor: (data-hora-minuto-seg-cent-milésimo). }\end{array}$ \\
\hline Pré_condição & $\begin{array}{l}\text { Item_de_ } \\
\text { trabalho }\end{array}$ & $\begin{array}{l}\text { Expressão que indica as condições necessárias para que } \\
\text { um tipo de atividade item de trabalho possa iniciar } \\
\text { execução. } \\
\text { Tipo: text - Tamanho: mínimo de } 2 \mathrm{k} \\
\left.\text { Valor: expressão }\left(\left(\mathrm{K}=\mathrm{y}^{*} 10\right) \text { or } \mathrm{J}<=\mathrm{I}\right)\right)\end{array}$ \\
\hline Prioridade & $\begin{array}{l}\text { História_ } \\
\text { atividade } \\
\text { História_ } \\
\text { processo } \\
\text { Instância_de } \\
\text { atividade }\end{array}$ & $\begin{array}{l}\text { Prioridade de execução. } \\
\text { Tipo: tinyint - Tamanho: } 1 \text { byte } \\
\text { Valor: (1 } \mid \ldots 9),(9 \text { = prioridade maior). }\end{array}$ \\
\hline
\end{tabular}




\begin{tabular}{|c|c|c|}
\hline & $\begin{array}{l}\text { Instância_de_ } \\
\text { processo }\end{array}$ & \\
\hline $\begin{array}{l}\text { Produto_ } \\
\text { criador }\end{array}$ & Processo & $\begin{array}{l}\text { Identificação do produto gerador do processo. (identifica } \\
\text { a ferramenta). } \\
\text { Tipo: varchar - Tamanho: } 20 \text { caracteres } \\
\text { Valor: cadeia de caracteres que identificam a ferramenta } \\
\quad \text { (EdGraW } \mid . . . \text { D de outra ferramenta geradora de } \\
\quad \text { definição de processo). }\end{array}$ \\
\hline Seq_ação & Ação & $\begin{array}{l}\text { Indica a sequência lógica das ações de uma atividade do } \\
\text { tipo item de trabalho. } \\
\text { Tipo: datetime - Tamanho: } 8 \text { bytes } \\
\text { Valor: (data-hora-minuto-seg-cent-milésimo). }\end{array}$ \\
\hline $\begin{array}{l}\text { Seq_ação_ } \\
\text { inicial }\end{array}$ & $\begin{array}{l}\text { Item_de } \\
\text { Trabalho }\end{array}$ & $\begin{array}{l}\text { Indica a primeira ação, da sequência lógica de ações } \\
\text { armazenada na tabela "Ação", de um item de trabalho. } \\
\text { Tipo: datetime - Tamanho: } 8 \text { bytes } \\
\text { Valor: (data-hora-minuto-seg-cent-milésimo). }\end{array}$ \\
\hline Sub_processo & $\begin{array}{l}\text { Item_de } \\
\text { trabalho }\end{array}$ & $\begin{array}{l}\text { Indica se é uma atividade atômica ou um subprocesso } \\
\text { (Se zeros = atômica, senão é a identificação do processo } \\
\text { (Processo.id_processo)). } \\
\text { Tipo: datetime - Tamanho: } 8 \text { bytes } \\
\text { Valor: (data-hora-minuto-seg-cent-milésimo). }\end{array}$ \\
\hline $\begin{array}{l}\text { Tempo_ } \\
\text { duração_it }\end{array}$ & $\begin{array}{l}\text { Item_de } \\
\text { trabalho }\end{array}$ & $\begin{array}{l}\text { Tempo estimado de execução do item de trabalho. } \\
\text { Tipo: char - Tamanho: } 7 \text { caracteres } \\
\text { Valor: (hhh,mm,ss). }\end{array}$ \\
\hline $\begin{array}{l}\text { Tempo_ } \\
\text { execução }\end{array}$ & Processo & $\begin{array}{l}\text { Tempo estimado pelo autor do processo, para sua } \\
\text { execução. }\end{array}$ \\
\hline
\end{tabular}




\begin{tabular}{|c|c|c|}
\hline & & $\begin{array}{l}\text { Tipo: char - Tamanho: } 8 \text { caracteres } \\
\text { Valor: (hhhh,mm,ss). }\end{array}$ \\
\hline Tipo & Roteamento & $\begin{array}{l}\text { Indica o tipo da atividade de roteamento. } \\
\text { Tipo: char - Tamanho: } 2 \text { caracteres } \\
\text { Valor: cadeia de caracteres que identificam a atividade de } \\
\text { roteamento (AS (and-split) | AJ (and-join) | OS } \\
\text { (or-split) | OJ (or-join)). }\end{array}$ \\
\hline Tipo_ação & Ação & $\begin{array}{l}\text { Indica o tipo da ação, manual ou automática. Se uma } \\
\text { ação é indicada como automática, no término de sua } \\
\text { predecessora, esta inicia automaticamente sem } \\
\text { intervenção do usuário. Se uma ação é indicada como } \\
\text { manual e sua predecessora finaliza, há a necessidade da } \\
\text { intervenção do usuário, executando a funcionalidade de } \\
\text { execução de ação oferecida na interface do sistema com o } \\
\text { usuário, para que esta inicie execução. } \\
\text { Tipo: char - tamanho: } 1 \text { caracter } \\
\text { Valor: (A (automática) |M (manual)). }\end{array}$ \\
\hline Tipo_atividade & Atividade & $\begin{array}{l}\text { Indica o tipo da atividade. } \\
\text { Tipo: char - tamanho: } 2 \text { caracteres } \\
\text { Valor: (IT (item de trabalho) | RO (roteamento)). }\end{array}$ \\
\hline Tipo_pa & Participante & $\begin{array}{l}\text { Identificação do tipo de participante } \\
\text { (Tipo_participante.id_tipoparticipante). } \\
\text { Tipo: datetime - Tamanho: } 8 \text { bytes } \\
\text { Valor: (data-hora-minuto-seg-cent-milésimo). }\end{array}$ \\
\hline Versão & $\begin{array}{l}\text { História_ } \\
\text { processo } \\
\text { Instância_de_ } \\
\text { processo } \\
\text { Processo }\end{array}$ & $\begin{array}{l}\text { Identificação da versão do processo (seqüência). } \\
\text { Tipo: tinyint- Tamanho: } 1 \text { byte } \\
\text { Valor: }(1 \mid \ldots \text { 255). }\end{array}$ \\
\hline
\end{tabular}




\section{Apêndice C}

ICMC - USP

\section{Implementação Relacional do}

\section{Modelo de Objetos}

Este apêndice lista as tabelas com seus atributos, resultante do mapeamento do modelo de objetos da figura 3.1, do capítulo 3. O modelo de objetos não contém todas as tabelas aqui descritas por questão de legibilidade, constando apenas as mais importantes. Esclarecimento a respeito das tabelas (classes) e seus atributos pode ser obtido no dicionário de dados (Apêndice "B")

$$
\begin{aligned}
& \text { LEGENDA: } \quad \text { identificador }=\text { chave primária } \\
& <\text { identificador }>=\text { chave secundária } \\
& *_{\text {identificador }} * \text { chave estrangeira }
\end{aligned}
$$

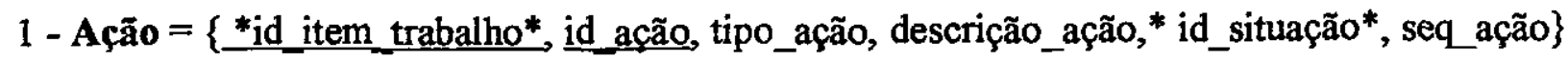

2 - Área $=\{$ id_área, $<$ descrição_área $>$, *id_situação* $\}$

$3-$ Atividade $=\{\underline{\text { id_atividade }},<$ nome_atividade $>$, descrição_atividade, tipo_atividade $\}$

4 - Atividade_situação $=\left\{*_{\text {id_atividade }}^{*}, *_{\text {id_situação }}^{*}\right\}$ 
5 - Componente_gráfico $=\{$ id_componente, nome_componente, descrição_componente, *id_situação*

$6-$ Conector $=\left\{{ }^{*}<\right.$ id_processo $>*$, id_conector, ${ }^{*}<$ id_inst_compon_graf_inicial $>$, $*<$ id_inst_compon_graf_final $>*$ coord_horiz_inicial, coord_verti_inicial, coord_horiz_final, coord_verti_final \}

7 - História_atividade $=\{$ id_instância_processo, id_instância_atividade, id_atividade, data_hora_habil_ha, data_hora_aloc_ha, data_hora_esp_ex_ha, data_hora_execut_ha, data_hora_fim_ha, "participante_executor*, prioridade, observação, *id_partic_situação_ha*, * id_situação*\}

8 - História_processo $=\left\{\right.$ id_instância_processo, ${ }^{*}$ id_processo*, versão, prioridade, data_hora_inicio_hp, data_hora_fim_hp, *id_partic_susp_hp*, *id_partic_canc_hp*, *id_situação*\}

9 - Instância_ação $=\{$ *id_instância_atividade* id_instância_ação, *id_ação*, data_hora_inicio_ação, data_hora_fim_ação, *id_partic_susp*, *id_partic_canc*, *id_situação*

10 - Instância_compon_graf $=\left\{{ }^{*}\right.$ id_processo* ${ }^{*}$, id_inst_compon_graf, ${ }^{*}$ id_componente ${ }^{*}$, *id_atividade*, coord_horiz, coord_vertical\}

11 - Instância_de_atividade $=\left\{\right.$ *id_instância_processo* ${ }^{*}$ id_instância_atividade, data_hora_habil_ati, data_hora_esp_ex_ati, data_hora_aloc_ati data_hora_execut_ati, prioridade, *<participante_executor $>$, *id_partic_susp*, *id_partic_canc*, observação, *id_inst_compon_graf*, *id_situação* 
12 - Instância_de_processo $=\{$ id instância_processo, $*$ id_processo*, versão, prioridade, data_hora_inicio, *id_partic_susp_ip*, *id_partic_canc_ip*, *id_situação*

13 - Instância_itemtrabalho_papel $=\{$ id_instância_processo, id_item_trabalho, id_papel $\}$

14 - Item_de_trabalho $=\{\underline{\text { id item_trabalho }}$ pré-condição, tempo_duração_it, número_instâncias, *sub_processo*, seq_ação_inicial \}

15 - Itemtrabalho_executor $=\left\{\right.$ id instância processo*, *id item trabalho* ${ }^{*}$ *id participante* \}

16 - Itemtrabalho_papel $=\left\{*_{\text {id item_trabalho*, } * \text { id papel }}^{*}\right\}$

$17-$ Papel $=\{$ id_papel,$<$ nome_pa $>$, descricao_pa, *id_situação* $\}$

18 - Papel_participante $=\left\{\right.$ *id_papel $*$ *id participante $\left.{ }^{*}\right\}$

19 - Papel_privilégio $=\{$ * $\underline{\text { id_papel } * \text { *id_privilégio* }}\}$

20 - Participante $=\{\underline{\text { id participante }},<$ nome $>, *$ tipo_pa*, *id_área*, *id_situação* $\}$

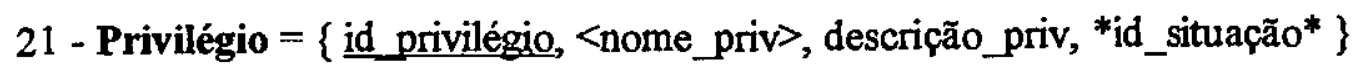

$22-$ Processo $=\{\underline{\text { id_processo }},<$ nome-proc $>$, *id_tipodocumento*, *id_documento*, descrição, *id_papel_responsável*, versão, produto_criador, *autor*, 
data_inicial_validade, data_final_validade, tempo_execução, cria_tab_work, *id_situação*

$23-$ Roteamento $=\{$ id atividade_roteamento, tipo, expressão $\}$

$24-$ Situação $=\{$ id situação, nome_situação, descrição_situação, id_situação_sit $\}$

25 - Tipo_participante $=\{\underline{\text { id tipoparticipante }}$, descrição_tpa, *id_situação* $\}$

Tabelas com alguns atributos, do módulo de documento (não constam no dicionário por não fazerem parte do módulo de workflow):

- Tipo_docto $=\{\underline{\text { id_tipodocumento }}$, descrição $\}$

- Docto $=\{$ id documento , descrição, id_tipodocumento, participante_emissor, área, local_armaz, mídia, projeto, data_criação, data_ultima_revisão 
ICMC - USP

\section{Situação final das tabelas após simulação do sistema}

Este apêndice representa o conteúdo final das tabelas após a simulação de especificação dos exemplos de workflows mostrados nas seções 3.7.1 e 3.7.2. Explicações sobre as tabelas e seus atributos podem ser obtidas no dicionário de dados apresentado no apêndice " $\mathrm{B}$ ".

Tipo docto

\begin{tabular}{|l|l|l|}
\hline \multicolumn{1}{|c|}{ id_tipo_docto } & \multicolumn{1}{c|}{ descrição } & dados \\
\hline 01 & Formulário de abertura de conta & \\
\hline
\end{tabular}

\section{Processo}

\begin{tabular}{|c|c|c|c|c|c|c|c|}
\hline $\begin{array}{l}\text { id pro } \\
\text { cesso }\end{array}$ & $\begin{array}{l}\text { nome } \\
\text { proc }\end{array}$ & $\begin{array}{l}\text { id_ } \\
\text { tipo } \\
\text { docu- } \\
\text { mento }\end{array}$ & $\begin{array}{l}\text { id_docu } \\
\text { mento }\end{array}$ & descriç̄o & $\begin{array}{l}\text { id_papel } \\
- \\
\text { responsa } \\
\text { vel }\end{array}$ & $\begin{array}{l}\text { ver- } \\
\text { são }\end{array}$ & $\begin{array}{l}\text { produto } \\
\text { criador } \\
\text { s }\end{array}$ \\
\hline 1 & $\begin{array}{l}\text { criar_tipo_ } \\
\text { doc }\end{array}$ & & & $\begin{array}{l}\text { Processo para criar } \\
\text { tipo de documento }\end{array}$ & 1 & & EHGraW \\
\hline 2 & $\begin{array}{l}\text { proc_uso_a } \\
\text { cta }\end{array}$ & 01 & & $\begin{array}{l}\text { Processo para gerar } \\
0 \text { documento de }\end{array}$ & 1 & & EHGraW \\
\hline
\end{tabular}




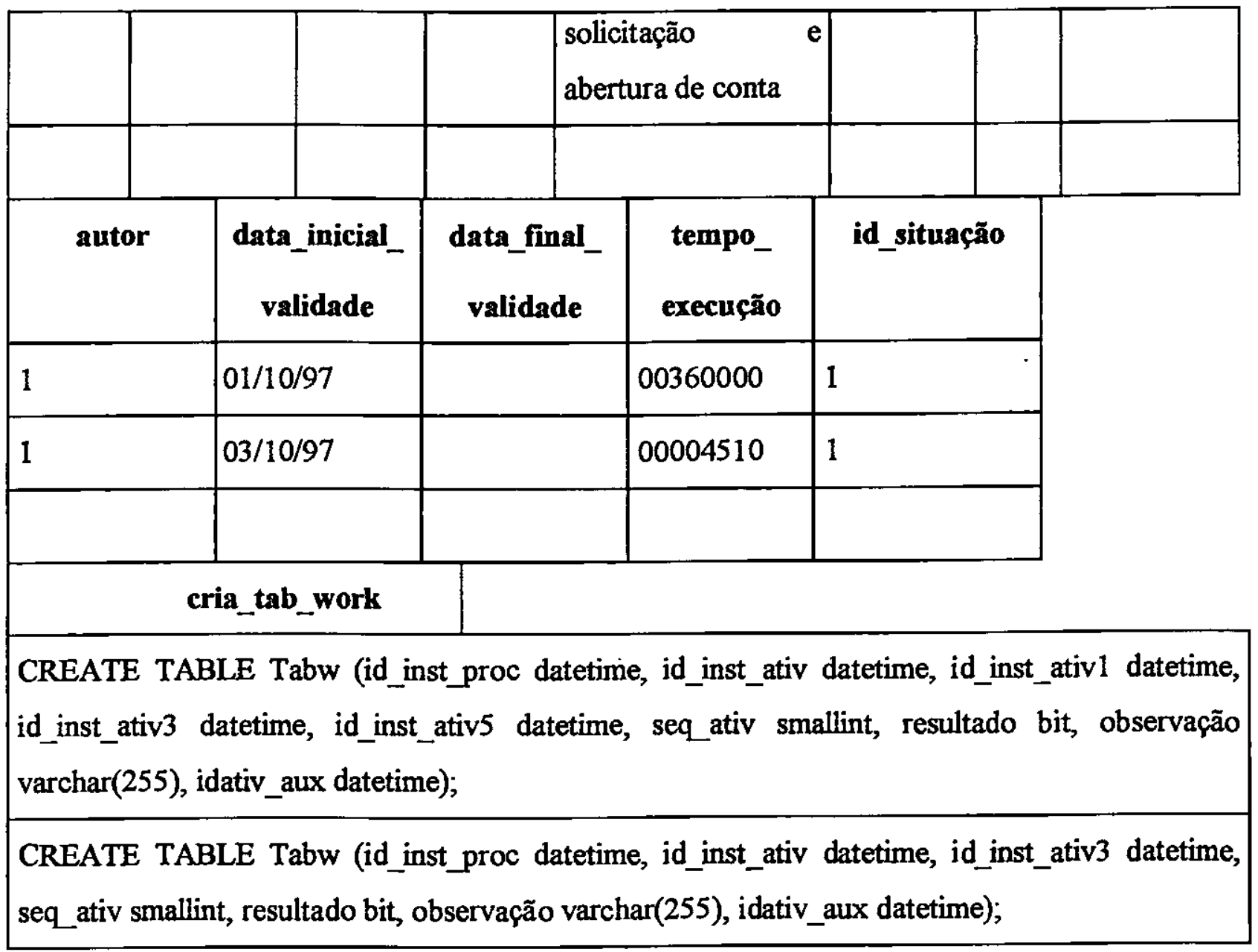

\section{Instância compon graf}

\begin{tabular}{|l|l|l|l|l|l|}
\hline id_processo & $\begin{array}{l}\text { id_inst_ } \\
\text { compon_graf }\end{array}$ & $\begin{array}{l}\text { id_compo- } \\
\text { nente }\end{array}$ & id_atividade & coord_horiz & $\begin{array}{l}\text { coord_ } \\
\text { vertical }\end{array}$ \\
\hline 1 & 1 & 6 & & 35 & 5 \\
\hline 1 & 2 & 1 & 1 & 76 & 63 \\
\hline 1 & 3 & 1 & 2 & 199 & 67 \\
\hline 1 & 4 & 1 & 3 & 319 & 66 \\
\hline 1 & 5 & 2 & 4 & 327 & 162 \\
\hline 1 & 6 & 1 & 5 & 228 & 166 \\
\hline 1 & 7 & 2 & 6 & 129 & 165 \\
\hline
\end{tabular}




\begin{tabular}{|l|l|l|l|l|l|}
\hline 1 & 8 & 1 & 7 & 130 & 243 \\
\hline 1 & 9 & 6 & & 175 & 333 \\
\hline 2 & 10 & 6 & & 35 & 5 \\
\hline 2 & 11 & 1 & 8 & 81 & 50 \\
\hline 2 & 12 & 1 & 9 & 214 & 48 \\
\hline 2 & 13 & 1 & 10 & 333 & 50 \\
\hline 2 & 14 & 2 & 11 & 337 & 148 \\
\hline 2 & 15 & 1 & 12 & 214 & 150 \\
\hline 2 & 16 & 1 & 13 & 88 & 155 \\
\hline 2 & 17 & 6 & & 91 & 258 \\
\hline
\end{tabular}

Conector

\begin{tabular}{|c|c|c|c|c|c|c|c|}
\hline $\begin{array}{l}\text { id_pro- } \\
\text { cesso }\end{array}$ & $\begin{array}{l}\text { id_co- } \\
\text { nector }\end{array}$ & $\begin{array}{l}\text { id_inst__ } \\
\text { compon_ } \\
\text { graf_ } \\
\text { inicial }\end{array}$ & $\begin{array}{l}\text { id_inst__ } \\
\text { compon_- } \\
\text { graf_ } \\
\text { final }\end{array}$ & $\begin{array}{l}\text { coord_ } \\
\text { horiz_- } \\
\text { inicial }\end{array}$ & $\begin{array}{l}\text { coord_ } \\
\text { verti_ } \\
\text { inicial }\end{array}$ & $\begin{array}{l}\text { coord_ } \\
\text { horiz_ } \\
\text { fingl }\end{array}$ & $\begin{array}{l}\text { coord_ } \\
\text { verti_ } \\
\text { final }\end{array}$ \\
\hline 1 & 1 & 1 & 2 & 60 & 10 & 76 & 10 \\
\hline 1 & 2 & 2 & 3 & 126 & 88 & 199 & 88 \\
\hline 1 & 3 & 3 & 4 & 249 & 92 & 319 & 92 \\
\hline 1 & 4 & 4 & 5 & 346 & 116 & 350 & 116 \\
\hline 1 & 5 & 5 & 3 & 328 & 182 & 278 & 188 \\
\hline 1 & 6 & 5 & 6 & 228 & 191 & 178 & 191 \\
\hline 1 & 7 & 6 & 7 & 168 & 170 & 199 & 170 \\
\hline 1 & 8 & 7 & 3 & 332 & 173 & 249 & 173 \\
\hline
\end{tabular}




\begin{tabular}{|l|l|l|l|l|l|l|l|}
\hline 1 & 9 & 7 & 8 & 154 & 214 & 155 & 214 \\
\hline 1 & 10 & 8 & 9 & 180 & 280 & 200 & 280 \\
\hline 2 & 11 & 10 & 11 & 60 & 10 & 81 & 10 \\
\hline 2 & 12 & 11 & 12 & 131 & 75 & 214 & 75 \\
\hline 2 & 13 & 12 & 13 & 264 & 73 & 333 & 73 \\
\hline 2 & 14 & 13 & 14 & 359 & 100 & 361 & 100 \\
\hline 2 & 15 & 14 & 12 & 343 & 158 & 264 & 158 \\
\hline 2 & 16 & 14 & 15 & 338 & 173 & 264 & 173 \\
\hline 2 & 17 & 15 & 16 & 214 & 176 & 138 & 176 \\
\hline 2 & 18 & 16 & 17 & 138 & 205 & 116 & 205 \\
\hline
\end{tabular}

\section{Atividade}

\begin{tabular}{|c|c|c|c|c|}
\hline $\begin{array}{l}\text { id__ } \\
\text { ativi } \\
\text { dade }\end{array}$ & nome_atividade & $\begin{array}{l}\text { descrição_ } \\
\text { atividade }\end{array}$ & $\begin{array}{l}\text { tipo_- } \\
\text { ativi } \\
\text { dade }\end{array}$ & $\begin{array}{l}\text { id_atv_ } \\
\text { itemtraba } \\
\text { lho_rot }\end{array}$ \\
\hline 1 & Iniciar formulário & $\begin{array}{l}\text { Iniciar o processo de criação } \\
\text { descrevendo a aplicação do } \\
\text { formulário e algumas características }\end{array}$ & IT & 1 \\
\hline 2 & $\begin{array}{l}\text { Propor } \\
\text { formulário }\end{array}$ & Fazer uma proposta do formulário & IT & 2 \\
\hline 3 & Conferir & $\begin{array}{l}\text { Verificar se o formulário criado está } \\
\text { de acordo com os padrões pré- } \\
\text { estabelecidos }\end{array}$ & IT & 3 \\
\hline 4 & Roteamento01 & $\begin{array}{l}\text { Se conferência dos padrões estiverem } \\
\text { ok, então inicie a atividade } 5 \text {, senão } \\
\text { retorne a atividade } 2\end{array}$ & RO & 1 \\
\hline
\end{tabular}




\begin{tabular}{|c|c|c|c|c|}
\hline 5 & Autorizar & $\begin{array}{l}\text { Verifica se o formulário criado atende } \\
\text { os requisitos especificados }\end{array}$ & IT & 4 \\
\hline 6 & Roteamento02 & $\begin{array}{l}\text { Se os requisitos foram atendidos, } \\
\text { inicie a atividade } 7 \text {, senão retorne a } \\
\text { atividade } 2 \text {. }\end{array}$ & RO & 2 \\
\hline 7 & $\begin{array}{l}\text { Liberar } \\
\text { formulário }\end{array}$ & disponibilizar o formulário para uso & IT & 5 \\
\hline 8 & $\begin{array}{l}\text { Retirar } \\
\text { formulário }\end{array}$ & mostra formulário para preenchimento & IT & 6 \\
\hline 9 & $\begin{array}{l}\text { Preencher } \\
\text { formulário }\end{array}$ & $\begin{array}{l}\text { O formulário deverá ter seus campos } \\
\text { preenchidos }\end{array}$ & IT & 7 \\
\hline 10 & $\begin{array}{l}\text { Conferir } \\
\text { formulário }\end{array}$ & $\begin{array}{l}\text { conferir se os campos foram } \\
\text { preenchido conforme especificação }\end{array}$ & IT & 8 \\
\hline 11 & Roteamento03 & $\begin{array}{l}\text { Se os campos tiverem sido } \\
\text { preenchidos ok, então inicie atividade } \\
12 \text {, senão retorne a atividade } 9\end{array}$ & RO & 3 \\
\hline 12 & Criar acesso & A conta é aberta & IT & 9 \\
\hline 13 & $\begin{array}{l}\text { Entregar } \\
\text { formulário }\end{array}$ & $\begin{array}{l}\text { Entregar o formulário da conta aberta } \\
\text { ao solicitante }\end{array}$ & IT & 10 \\
\hline & & & & \\
\hline
\end{tabular}

Atividade situacão

\begin{tabular}{|l|l|}
\hline \multicolumn{1}{|c|}{ id_atividade } & \multicolumn{1}{c|}{ id_situação } \\
\hline 1 & 7 \\
\hline 2 & 1 \\
\hline 2 & 3 \\
\hline
\end{tabular}




\begin{tabular}{|l|l|}
\hline 2 & 6 \\
\hline 3 & 7 \\
\hline 4 & 1 \\
\hline 4 & 3 \\
\hline 4 & 5 \\
\hline 4 & 6 \\
\hline 5 & 7 \\
\hline 6 & 1 \\
\hline 6 & 3 \\
\hline 6 & 5 \\
\hline 10 & 6 \\
\hline 13 & 7 \\
\hline
\end{tabular}

Item de trabalho

\begin{tabular}{|c|c|c|c|c|}
\hline \multicolumn{1}{|c|}{$\begin{array}{c}\text { id_item_ } \\
\text { trabalho }\end{array}$} & $\begin{array}{c}\text { pré_ } \\
\text { condição }\end{array}$ & $\begin{array}{c}\text { número_ } \\
\text { instâncias }\end{array}$ & $\begin{array}{c}\text { tempo_duração } \\
\text { it }\end{array}$ & $\begin{array}{c}\text { sub_proces } \\
\text { so }\end{array}$ \\
\hline 1 & & 9 & 0040000 & \\
\hline
\end{tabular}




\begin{tabular}{|l|l|l|l|l|}
\hline 2 & & 9 & 0240000 & \\
\hline 3 & & 9 & 0050000 & \\
\hline 4 & 9 & 9 & 0010000 & \\
\hline 5 & & 9 & 0020000 & \\
\hline 6 & & 9 & 0000010 & \\
\hline 7 & & 9 & 0000500 & \\
\hline 8 & & 9 & 0003000 & \\
\hline 9 & & 9 & 0000500 & \\
\hline 10 & & & 0000500 & \\
\hline & & 9 & & \\
\hline
\end{tabular}

\section{Acão}

\begin{tabular}{|l|l|l|l|r|}
\hline $\begin{array}{l}\text { id_item_ } \\
\text { trabalho }\end{array}$ & id_ação & $\begin{array}{l}\text { tipo_ } \\
\text { ação }\end{array}$ & \multicolumn{1}{|c|}{ descrição_ação } & $\begin{array}{c}\text { id_ } \\
\text { situa } \\
\text { cão }\end{array}$ \\
\hline 1 & 1 & A & $\begin{array}{l}\text { GET \&Observação: (Entrar com } \\
\text { características/áreas envolvidas / aplicação do } \\
\text { docto, para executores do processo)\&, } \\
\text { observação; } \\
\text { UPDATE Instância_de_atividade } \\
\text { SET observação =(SELECT observação } \\
\text { FROM Tabw1) } \\
\text { WHERE id_instância_atividade= (SELECT } \\
\text { id_inst_ativ FROM Tabw); }\end{array}$ & 1 \\
\hline 2 & A & $\begin{array}{l}\text { UPDATE Tabw } \\
1\end{array}$ & 1 \\
\hline
\end{tabular}




\begin{tabular}{|c|c|c|c|}
\hline & & SET seq_ativ $=1$ & \\
\hline & A & $\begin{array}{l}\text { UPDATE Instância_de_atividade } \\
\text { SET id_situação = (SELECT id_situação } \\
\text { FROM Situação } \\
\text { WHERE descrição_situação = } \\
\text { \&executado(a)\&) } \\
\text { WHERE id_instância_atividade = (SELECT } \\
\text { id_inst_ativ FROM Tabw); }\end{array}$ & 1 \\
\hline 2 & 1 & $\begin{array}{l}\text { IF (SELECT seq_ativ FROM Tabw) }=4 \\
\text { SELECT \&Observação da Ativ-3 = \&, } \\
\text { observação } \\
\text { FROM História Atividade } \\
\text { WHERE } \\
\text { História_atividade.id_instância_processo = } \\
\text { (SELECT id_inst_proc FROM Tabw1) } \\
\text { AND } \\
\text { História_atividade.id_instância_atividade = } \\
\text { (SELECT id_inst_ativ3 FROM Tabw) } \\
\text { ELSE } \\
\text { IF (SELECT seq_ativ FROM } \\
\text { Tabw) = 6 } \\
\text { SELECT \&Observação da Ativ-5 = \& } \\
\text { FROM Tabw } \\
\text { Observação FROM História_atividade } \\
\text { WHERE História_atividade.id_instância } \\
\text { AND }\end{array}$ & 1 \\
\hline
\end{tabular}




\begin{tabular}{|c|c|c|c|}
\hline & & $\begin{array}{l}\text { História_atividade.id_instância_atividad } \\
\text { e = (SELECT id_inst_ativ5 FROM } \\
\text { Tabw) } \\
\text { ELSE } \\
\text { SELECT \&observação: } \\
\text { características/áreas } \\
\text { envolvidas/aplicação do docto Ativ-1 } \\
=\text { \&, observação FROM } \\
\text { História_atividade } \\
\quad \text { WHERE } \\
\text { História_atividade.id_instância_proce } \\
\text { sso = (SELECT id_inst_proc FROM } \\
\text { Tabw } \\
\text { História_atividade.id_instância_ativid } \\
\text { ade = (SELECT id_inst_ativ1 FROM } \\
\text { Tabw); }\end{array}$ & \\
\hline 2 & $\mathbf{M}$ & \begin{tabular}{|l} 
\# gerar um layout do formulário e armazená-lo \\
no módulo de documentos: \\
- definir título do formulário \\
- identificar campos necessários \\
fazendo uma descrição destes, com \\
seus tipos e tamanhos \\
- identificar campos opcionais e \\
obrigatórios \\
- definir a estrutura lógica do \\
documento \\
- definir a estrutura de apresentação;
\end{tabular} & 1 \\
\hline
\end{tabular}




\begin{tabular}{|c|c|c|c|c|}
\hline & 3 & M & \# fazer mamual de uso; & 1 \\
\hline & 4 & $M$ & \# informar data de revisão; & 1 \\
\hline & 5 & $\mathbf{M}$ & \# determinar papéis para a revisão; & 1 \\
\hline & 6 & $\mathbf{M}$ & \# definir ou confirmar as áreas envolvidas; & 1 \\
\hline & 7 & $\mathbf{M}$ & $\begin{array}{l}\text { \# definir período de arquivamento do uso do } \\
\text { formulário; }\end{array}$ & 1 \\
\hline & 8 & A & $\begin{array}{l}\text { /* observação */ } \\
\text { GET \&observação\&, observação; } \\
\text { UPDATE Instância_de_atividade } \\
\text { SET observação = (SELECT observação } \\
\text { FROM Tabw) } \\
\text { WHERE id_instância_atividade = (SELECT } \\
\text { id_inst_ativ FROM Tabw); }\end{array}$ & 1 \\
\hline & 9 & M & \# armazenar tipo de documento; & 1 \\
\hline 3 & 1 & $\mathbf{M}$ & \# consultar documento proposto: & 1 \\
\hline & 2 & M & $\begin{array}{l}\text { \# conferir padrões: } \\
\text { - a disposição dos campos } \\
\text { - fonte das letras } \\
\text { - tamanho da fonte das letras } \\
\text { - espaço para preenchimento dos campos } \\
\text { - o manual de preenchimento do } \\
\text { formulário } \\
\text { - o tamanho do layout } \\
\text { - se estão definidos: } \\
\text { - papéis executores }\end{array}$ & 1 \\
\hline
\end{tabular}




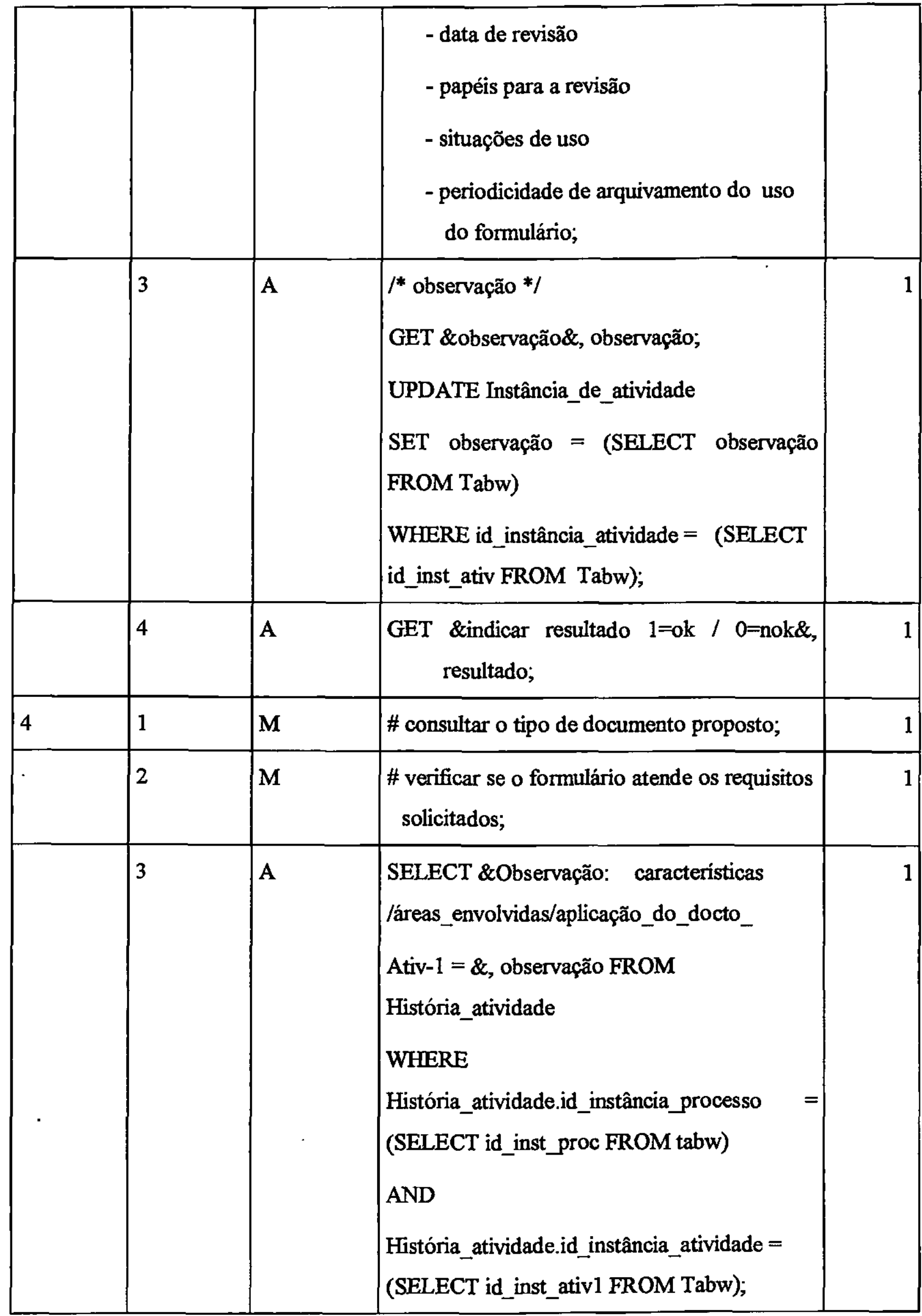




\begin{tabular}{|c|c|c|c|c|}
\hline & 4 & A & $\begin{array}{l}\text { GET "indicar resultado } 1=\mathrm{ok} / 0=\text { nok", } \\
\text { resultado; }\end{array}$ & 1 \\
\hline & 5 & A & $\begin{array}{l}\text { /* observação */ } \\
\text { GET \&observação\&, observação; } \\
\text { UPDATE Instância_de_atividade } \\
\text { SET observação = (SELECT observação } \\
\text { FROM Tabw) } \\
\text { WHERE id_instância_atividade = (SELECT } \\
\text { id_inst_ativ FROM Tabw); }\end{array}$ & 1 \\
\hline \multirow[t]{3}{*}{5} & 1 & M & $\begin{array}{l}\text { \# adicionar o formulário na base de dados de } \\
\text { produção; }\end{array}$ & 1 \\
\hline & 2 & M & $\begin{array}{l}\text { \# adicionar programas envolvidos na biblioteca } \\
\text { de programas de produção; }\end{array}$ & 1 \\
\hline & 3 & M & \# comunicar os interessados; & 1 \\
\hline \multirow[t]{3}{*}{6} & 1 & M & $\begin{array}{l}\text { \# verificar instruções de retirada de } \\
\text { formulário; }\end{array}$ & 1 \\
\hline & 2 & M & \# dar comandos de retirada de formulário; & 1 \\
\hline & 3 & A & $\begin{array}{l}\text { /* observação */ } \\
\text { GET \&observação\&, observação; } \\
\text { UPDATE Instância_de_atividade } \\
\text { SET observação = (SELECT observação } \\
\text { FROM Tabw) } \\
\text { WHERE id_instância_atividade = (SELECT } \\
\text { id_inst_ativ FROM Tabw); }\end{array}$ & 1 \\
\hline 7 & 1 & A & $\begin{array}{l}\text { IF (SELECT seq_ativ FROM Tabw) }=4 \\
\text { SELECT \&Observação da ativ-3 }=\&,\end{array}$ & 1 \\
\hline
\end{tabular}




\begin{tabular}{|c|c|c|c|c|}
\hline & & & $\begin{array}{l}\text { observação FROM História_atividade } \\
\text { WHERE } \\
\text { História_atividade.id_instância_processo = } \\
\text { (SELECT id_inst_proc FROM Tabw) } \\
\text { AND } \\
\text { História_atividade.id_instância_atividade = } \\
\text { (SELECT id_inst_ativ3 FROM Tabw); }\end{array}$ & \\
\hline & 2 & $\mathbf{M}$ & \# consultar formulário; & 1 \\
\hline & 3 & $\mathbf{M}$ & $\begin{array}{l}\text { \# consultar manual de instruções de } \\
\text { preenchimento }\end{array}$ & 1 \\
\hline & 4 & $\mathbf{M}$ & $\begin{array}{l}\text { \# preencher no mínimo os campos } \\
\text { obrigatórios; }\end{array}$ & 1 \\
\hline . & 5 & A & $\begin{array}{l}\text { /* observação */ } \\
\text { GET \&observação\&, observação; } \\
\text { UPDATE instância_de_atividade } \\
\text { SET observação = (SELECT observação } \\
\text { FROM Tabw) } \\
\text { WHERE id_instância_atividade = (SELECT } \\
\text { id_inst_ativ FROM Tabw); }\end{array}$ & 1 \\
\hline \multirow[t]{3}{*}{8} & 1 & $\mathbf{M}$ & \# consultar formulário; & 1 \\
\hline & 2 & $\mathbf{M}$ & $\begin{array}{l}\text { \# conferir campos obrigatórios preenchidos } \\
\text { corretamente; }\end{array}$ & 1 \\
\hline & 3 & A & $\begin{array}{l}\text { /* observação */ } \\
\text { GET \&observação\&, observação; } \\
\text { UPDATE instância_de_atividade } \\
\text { SET observação = (SELECT observação } \\
\text { FROM Tabw2) }\end{array}$ & 1 \\
\hline
\end{tabular}




\begin{tabular}{|c|c|c|c|c|}
\hline & & & $\begin{array}{l}\text { WHERE id_instância_atividade }=\text { (SELECT } \\
\text { id_inst_ativ FROM Tabw); }\end{array}$ & \\
\hline & 4 & A & $\begin{array}{l}\text { GET "indicar resultado } 1=0 \mathrm{k} / 0=\text { nok", } \\
\text { resultado; }\end{array}$ & 1 \\
\hline \multirow[t]{3}{*}{9} & 1 & $\mathbf{M}$ & \# abrir a conta no sistema; & 1 \\
\hline & 2 & $\mathbf{M}$ & \# gerar senha inicial de acesso; & 1 \\
\hline & 3 & A & $\begin{array}{l}\text { /* observação*/ } \\
\text { GET \&observação\&, observação; } \\
\text { UPDATE instância_de_atividade } \\
\text { SET observação = (SELECT observação } \\
\text { FROM Tabw) } \\
\text { WHERE id_instância_atividade = (SELECT } \\
\text { id_inst_ativ FROM Tabw); }\end{array}$ & 1 \\
\hline 10 & 1 & $\mathbf{M}$ & $\begin{array}{l}\text { \# receber o formulário com a conta aberta e } \\
\text { arquivá-lo; }\end{array}$ & 1 \\
\hline \multirow[t]{2}{*}{. } & 2 & $\mathbf{M}$ & $\begin{array}{l}\text { \# entregar uma via do formulário com a conta } \\
\text { e a senha gerada ao solicitante; }\end{array}$ & 1 \\
\hline & 3 & A & $\begin{array}{l}\text { /* observação */ } \\
\text { GET \&observação\&, observação; } \\
\text { UPDATE instância_de_atividade } \\
\text { SET observação = (SELECT observação } \\
\text { FROM Tabw) } \\
\text { WHERE id_instância_atividade = (SELECT } \\
\text { id_inst_ativ FROM Tabw); }\end{array}$ & 1 \\
\hline
\end{tabular}




\begin{tabular}{|l|l|}
\hline \multicolumn{1}{|c|}{ id_item_trabalho } & id_papel \\
\hline 1 & 1 \\
\hline 1 & 2 \\
\hline 2 & 2 \\
\hline 3 & 2 \\
\hline 4 & 1 \\
\hline 5 & 2 \\
\hline 6 & 4 \\
\hline 7 & 4 \\
\hline 8 & 3 \\
\hline 9 & 3 \\
\hline 10 & 4 \\
\hline & \\
\hline
\end{tabular}

Roteamento

\begin{tabular}{|c|c|c|}
\hline $\begin{array}{l}\text { id_atividade } \\
\text { _roteamento }\end{array}$ & tipo & expressão \\
\hline 1 & OS & $\begin{array}{l}\text { IF (SELECT resultado FROM Tabw) }=1 \\
\text { UPDATE Tabw } \\
\text { SET idativ_aux }=(\text { SELECT id_atividade FROM } \\
\text { Atividade } \\
\text { WHERE nome_atividade }=\text { \&autorizar } \&) \\
\text { ELSE } \\
\text { UPDATE Tabw }\end{array}$ \\
\hline
\end{tabular}




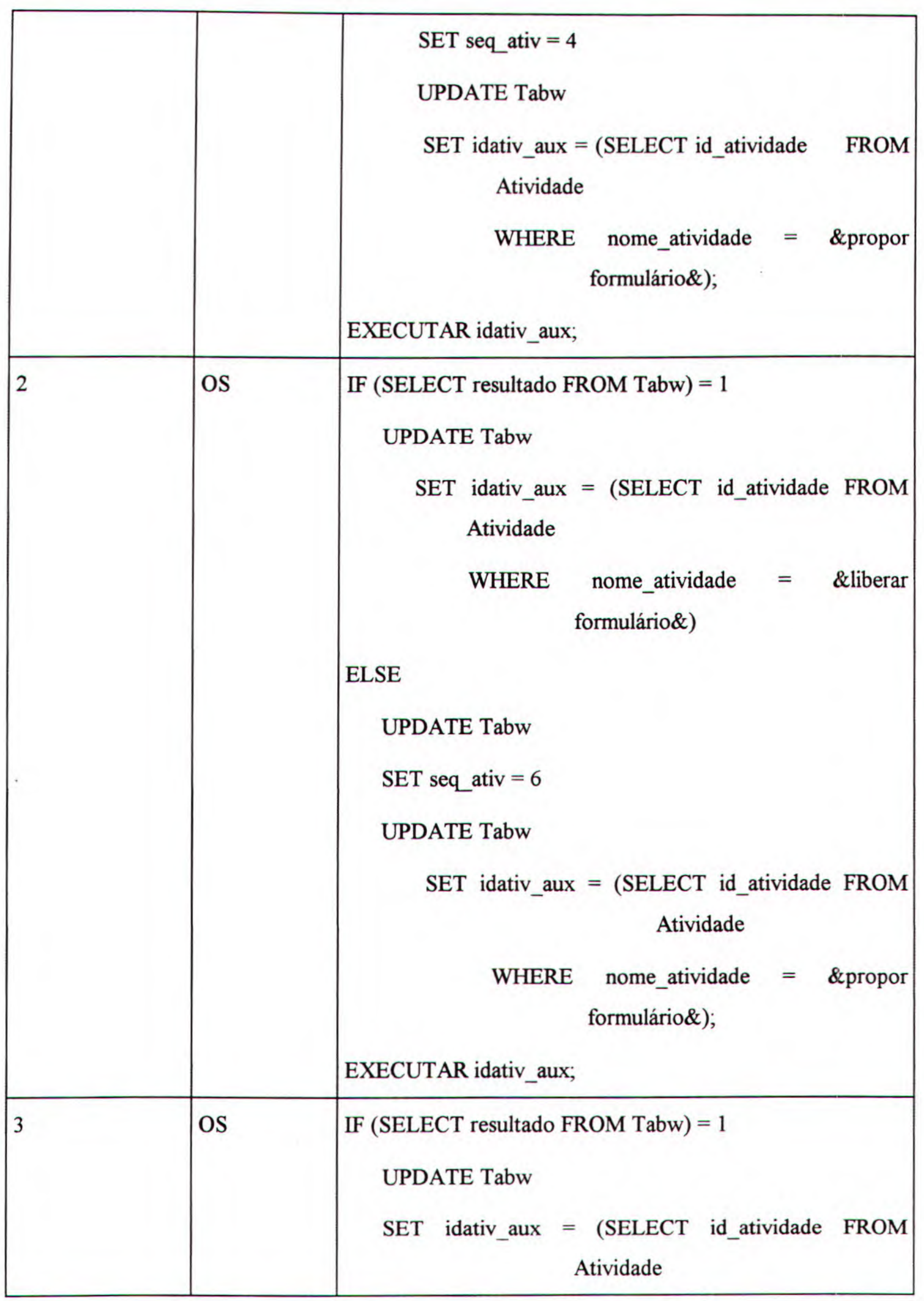




\begin{tabular}{|l|l|}
\hline WHERE nome_atividade = \&criar acesso\&) \\
ELSE \\
UPDATE Tabw \\
SET seq_ativ $=4$ \\
UPDATE Tabw \\
SET idativ_aux = (SELECT id_atividade FROM \\
WHERE nome_atividade = \&preencher formulário\&); \\
EXECUTAR idativ_aux;
\end{tabular}

Privilégio

\begin{tabular}{|l|l|l|c|}
\hline id_privilégio & nome_priv & descrição_priv & id_situação \\
\hline 1 & administração & manutenção das tabelas básicas do sistema & 1 \\
\hline 2 & criar_meta_proc & Cria processo para criar tipo de documento & 1 \\
\hline 3 & criar_tipo_doc & Processo para criar tipo de documento & 1 \\
\hline 4 & proc_uso_acta & $\begin{array}{l}\text { Processo para gerar o documento de } \\
\text { solicitação e abertura de conta }\end{array}$ & 1 \\
\hline
\end{tabular}

